ESCOLA POLITÉCNICA DA UNIVERSIDADE DE SÃO PAULO

CAIO CESAR MENDES BORDALLO

\title{
ESTUDO DO COMPORTAMENTO DE TRANSISTORES DE TUNELAMENTO INDUZIDO POR EFEITO DE CAMPO (TFET) OPERANDO EM DIFERENTES TEMPERATURAS
}


CAIO CESAR MENDES BORDALLO

\section{ESTUDO DO COMPORTAMENTO DE TRANSISTORES DE TUNELAMENTO INDUZIDO POR EFEITO DE CAMPO (TFET) OPERANDO EM DIFERENTES TEMPERATURAS}

Tese apresentada à Escola Politécnica da Universidade de São Paulo para a obtenção do título de Doutor em Ciências. 
CAIO CESAR MENDES BORDALLO

\section{ESTUDO DO COMPORTAMENTO DE TRANSISTORES DE TUNELAMENTO INDUZIDO POR EFEITO DE CAMPO (TFET) OPERANDO EM DIFERENTES TEMPERATURAS}

Tese apresentada à Escola Politécnica da Universidade de São Paulo para a obtenção do título de Doutor em Ciências.

Área de Concentração:

Engenharia Elétrica / Microeletrônica.

Orientadora: Prof. Dra. Paula Ghedini Der Agopian Co-orientador: Prof. Dr. João Antonio Martino

São Paulo

2017 
Este exemplar foi revisado e alterado em relação à versão original, sob responsabilidade única do autor e com a anuência de seu orientador.

São Paulo, 29 de novembro de 2017

Assinatura do autor

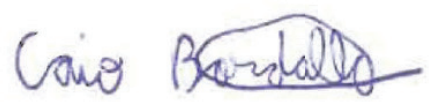

Assinatura do orientador

\section{Catalogação-na-publicação}

Bordallo, Caio

ESTUDO DO COMPORTAMENTO DE TRANSISTORES DE

TUNELAMENTO INDUZIDO POR EFEITO DE CAMPO (TFET) OPERANDO

EM DIFERENTES TEMPERATURAS / C. Bordallo -- versão corr. -- São Paulo, 2017.

$150 \mathrm{p}$.

Tese (Doutorado) - Escola Politécnica da Universidade de São Paulo. Departamento de Engenharia de Sistemas Eletrônicos.

1.TFET 2.nanofio 3.tunelamento de banda para banda 4.influência da temperatura 5.parâmetros analógicos I.Universidade de São Paulo. Escola Politécnica. Departamento de Engenharia de Sistemas Eletrônicos II.t. 
Dedico este trabalho aos meus pais pelo exemplo e educação que me deram, à minha esposa pelo amor e dedicação, que me motivaram durante 0 desenvolvimento deste trabalho 


\section{AGRADECIMENTOS}

A realização deste trabalho foi possível graças à confiança e dedicação da minha orientadora e amiga Profa. Dra. Paula Ghedini Der Agopian, que me inspirou, motivou e ajudou a concluir este projeto.

Ao Prof. Dr. João Antonio Martino, pelo conhecimento e experiência compartilhados e o grande incentivo.

Sou muito grato ao amor e grande incentivo da minha mãe, e de todo o aprendizado que meu pai sempre me deu para enfrentar a vida. À minha família, meus primos e tios, minha querida avó, minha irmã, minha sogrinha e todos os meus grandes amigos, que sempre acreditaram no meu potencial, tiveram fé e me apoiaram muito para que se pudesse tornar realidade o desafio de concluir o doutorado. Agradeço muito aos meus filhotes queridos Amora e Brandon pelo amor, carinho e muitas lambidas. Agradeço principalmente ao amor e compreensão da minha esposa, Amanda.

A FAPESP, pelo apoio financeiro indispensável para a realização deste trabalho.

Aos amigos do grupo SOI-CMOS do LSI/EPUSP que muito me ajudaram e inspiraram, e também pelo companheirismo, compartilhamento de experiências profissionais e pessoais e mútua torcida.

A todos os colegas do IMEC que me ajudaram em meu trabalho e me fizeram evoluir profissionalmente e pessoalmente.

As tantas outras pessoas, que de alguma forma colaboraram para a realização deste trabalho. 
Não importa o quanto você bate, mas sim o quanto aguenta apanhar e continuar. $O$ quanto pode suportar e seguir em frente, é assim que se ganha. Nada pode bater mais forte em você do que a vida. Rocky Balboa 


\section{RESUMO}

Neste trabalho iniciou-se os estudos com transistores de tunelamento por efeito de campo (TFET) de silício (Si) em estruturas de nanofios (NW-TFET), analisando o efeito da redução do diâmetro dos nanofios, de $167 \mathrm{~nm}$ até $15 \mathrm{~nm}$, através de analises baseadas em medidas experimentais e simulações numéricas. Para diâmetros maiores que $30 \mathrm{~nm}$, os dispositivos são pouco influenciados pela redução do diâmetro. Para diâmetros menores que $30 \mathrm{~nm}$, ao diminui-los, o tunelamento entre bandas (BTBT) passa a ser o mecanismo dominante, aumentando a corrente de dreno normalizada. Reduzindo o diâmetro em baixa condução, a maior parte da junção passa a ser dominada por BTBT, aumentando a eficiência devido ao melhor acoplamento eletrostático, reduzindo a inclinação de sublimiar (SS). A análise em diferentes temperaturas (de $10 \mathrm{~K}$ a $423 \mathrm{~K}$ ) destes TFETs de estruturas de nanofios mostrou que o aumento da temperatura aumentou tanto a corrente de estado ligado (IoN) quanto a de estado desligado (IofF), sendo que o aumento de loff é responsável pela degradação da eficiência em baixa condução. Para melhorar o desempenho dos dispositivos TFET de $\mathrm{Si}$, que possuem baixa corrente, foram utilizados dispositivos experimentais com fontes de Germânio $(\mathrm{Ge})$ e de uma liga de $\mathrm{Si}$ e $\mathrm{Ge}\left(\mathrm{Si}_{0,73} \mathrm{Ge}_{0,27}\right)$. O aumento da concentração de Ge na fonte reduz a largura da banda proibida $\left(E_{G}\right)$, resultando em um aumento da corrente de BTBT nos dispositivos. Esse aumento da corrente de BTBT também aumenta a transcondutância (gm) e o ganho intrínseco de tensão (Av). Para melhorar ainda mais o desempenho dos TFETs, foram estudados novos dispositivos fabricado com Arseneto de Indio-Galio (InxGa1-XAs), com leiaute em anel, com comprimento de canal de $5 \mu \mathrm{m}$ e largura de canal de $400 \mu \mathrm{m}$, utilizando dispositivos experimentais e simulados. $O$ uso desse material gera um grande aumento de lon devido ao aumento considerável de BTBT, alcançando valores de SS próximos a $60 \mathrm{mV} / \mathrm{dec}$, valor muito menor que $200 \mathrm{mV} / \mathrm{dec}$ obtido nos dispositivos de $\mathrm{Si}$. Os dispositivos com InxGa1-XAs apresentaram alto $\mathrm{A} \vee(\sim 50 \mathrm{~dB})$ mesmo em baixas polarizações, sendo promissores em aplicações de baixa tensão e baixa potência. Aumento da concentração de In ( $\left.\ln _{0,7} \mathrm{Ga}_{0,3} \mathrm{As}\right)$ reduz $\mathrm{E}_{\mathrm{G}}$, aumentando BTBT. O aumento de BTBT aumenta gm, porém, aumenta também a condutância de saída (gD), aumentando $A \vee$ para alto $V_{G S}$ e reduzindo para baixos $V_{G S}$. A redução da espessura de $\mathrm{HfO}_{2}$, de $3 \mathrm{~nm}$ para $2 \mathrm{~nm}$, resultou em melhoria em todos os dispositivos devido ao melhor acoplamento eletrostático, onde o dispositivo de Ino,53Ga0,47As apresentou um 
SS de $56 \mathrm{mV} /$ dec. A temperatura influencia mais gD que gm, aumentando Av em baixas temperaturas. O uso de fonte gasosa na difusão de Zinco (Zn), no lugar de fonte sólida, resultou em uma junção mais abrupta, aumentando loN e melhorando SS. Pode-se obter um dispositivo otimizado utilizando Ino,7 $\mathrm{Ga}_{0,3} \mathrm{As}$ utilizando difusão de $\mathrm{Zn}$ na fonte por fase gasosa, para dispositivos que vão atuar em aplicações digitais, ou utilizando difusão de Zn na fonte por fonte sólida, para dispositivos que vão atuar em aplicações analógicas, ambos à $520^{\circ} \mathrm{C}$ por 1 minuto, utilizando $2 \mathrm{~nm}$ de $\mathrm{HfO}_{2}$ na porta.

Palavras chaves: TFET, nanofio, tunelamento de banda para banda, diferentes materiais, influência da temperatura, parâmetros analógicos 


\section{ABSTRACT}

In this work, initially it was studied Silicon (Si) n type tunnel field effects transistors (TFET) in nanowire structures (NW-TFET), analyzing the diameter reduction effect of the nanowires, from $167 \mathrm{~nm}$ to $15 \mathrm{~nm}$, using experimental measurements and numerical simulations. For diameters higher than $30 \mathrm{~nm}$, the devices are less influenced by the diameter reduction. For diameters lower than $30 \mathrm{~nm}$, decreasing the diameter, band-to-band tunneling (BTBT) start to become the dominant mechanism, increasing the normalized drain current. Reducing the diameter, in low conduction, the most of the junction becomes dominated by BTBT, increasing the transistor efficiency due to the better electrostatic coupling, reducing the subthreshold swing (SS). The analysis of this nTFETs at different temperatures (from $10 \mathrm{~K}$ to $423 \mathrm{~K}$ ) showed that at high temperatures both the on and the off state current (IoN and loFF) of these NW-TFETs have raised, degrading SS, and consequently the efficiency at low conduction. In order to improve lon, which is very low in pure Si nTFETs, experimental devices using source made by $\mathrm{Ge}$ and $\mathrm{Si}_{0.73 \mathrm{Ge}} \mathrm{G}_{27}$ was studied. The increase of the Ge concentration in the source reduces the bandgap results in higher BTBT current. This high BTBT current also lead the transconductance $(\mathrm{gm})$ and the intrinsic voltage gain $(A v)$ to increase. To further improve the TFETs performance, new devices made of InGaAs with ring layout, with channel length of $5 \mu \mathrm{m}$ and channel width of $400 \mu \mathrm{m}$ was studied, using experimental and simulated data. The use of InGaAs generates a large increase of lon due to its low bandgap, enabling to reach values of SS near $60 \mathrm{mV} / \mathrm{dec}$, much steeper than the $200 \mathrm{mV} / \mathrm{dec}$ obtained on Si nTFETs. These InGaAs nTFETs have presented high $A v(\sim 50 \mathrm{~dB})$, even at low bias, being promising devices in low power low voltage applications. When increasing the In concentration in the InxGa1-XAs TFET the bandgap is reduced, improving the BTBT current. The BTBT raise leads both gm and the output conductance $\left(g_{D}\right)$ to increase, improving $A v$ for high $V_{G s}$ bias and degrading it at low $\mathrm{VGS}_{\mathrm{GS}}$ bias. The reduction of the $\mathrm{HfO}_{2}$ thickness, from $3 \mathrm{~nm}$ to $2 \mathrm{~nm}$, have resulted in improvement all devices due to the better electrostatic coupling, where the $\operatorname{In} 0.53 \mathrm{Ga} 0.47 \mathrm{As}$ device have presented $S S$ of $56 \mathrm{mV} / \mathrm{dec}$. As the temperature have more influence in $\mathrm{g}_{\mathrm{D}}$ than $\mathrm{gm}, \mathrm{Av}_{\mathrm{v}}$ is improved at low temperatures. The use of gas phase $\mathrm{Zn}$ diffusion at the source doping, instead of solid source $\mathrm{Zn}$ diffusion, have increased lon and improved SS. The possibly reason to this behavior is the higher abruptness of the source/channel junction when using gas phase $\mathrm{Zn}$ 
diffusion. An optimized device can be obtained using a device with $\ln _{0,7} \mathrm{Ga}_{0,3} \mathrm{As}_{\mathrm{s}}$ with the source diffusion made by gas phase, for devices to be used in digital applications, or with the source diffusion made by solid source, for devices to be used in analog applications. Both diffusion process made at $520^{\circ} \mathrm{C}$, using $2 \mathrm{~nm}$ of $\mathrm{HfO}_{2}$ in the gate stack.

Keywords: TFET, nanowire, band to band tunneling, different materials, temperature influence, analog parameters. 


\section{LISTA DE FIGURAS}

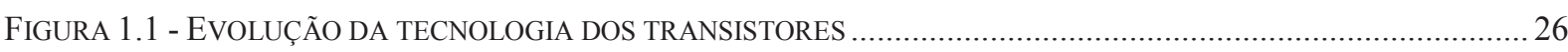

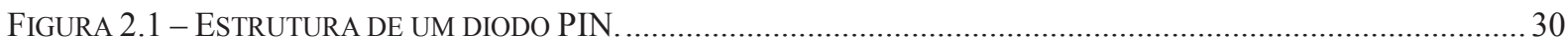

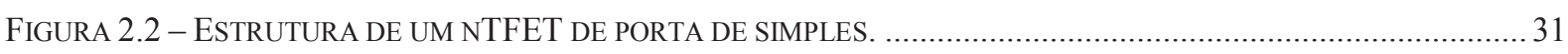

FigURA 2.3 - TUNELAMENTO ENTRE BANDAS EM UMA JUNÇÃO DE UM TFET COM ALTA POLARIZAÇÃO DE PORTA.

Figura 2.4 - Diagrama de FAIXAS DE ENERGia PARA UM NTFET POLARIZADO COM VGS PRÓXIMO DE 0 (A), $V_{\text {GS }}$

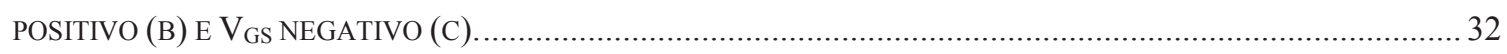

FIGURA 2.5 - BARREIRA DE POTENCIAL E FUNÇÃO DE ONDA DE UM ELÉTRON. ..................................................... 35

FIGURA 2.6 - REPRESENTAÇ̃̃O ESQUEMÁTICA DO TUNELAMENTO ASSISTIDO POR ARMADILHAS. ............................. 36

FIGURA 2.7 - REPRESENTAÇ̃̃O DO EFEITO DA TEMPERATURA EM TFETS.............................................................. 38

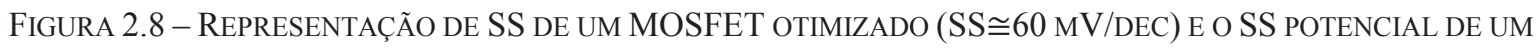
TFET

FIGURA 2.9 - REPRESENTAÇ̃̃O DA TRANSCONDUTÂNCIA EM UM MOSFET E EM UM TFET..................................... 43

FIGURA 2.10 - REPRESENTAÇ̃̃o DA EFICIÊNCIA DE TRANSISTORES TFET E MOSFET EM FUNÇÃO DE IDS............. 44

FIGURA 2.11 - REPRESENTAÇÃO DA EXTRAÇÃO DE VEA EM UMA CURVA IDS EM FUNÇÃO DE VDS............................ 45

FIGURA 2.12 - REPRESENTAÇÃO DE IDS VARIANDO COM A TEMPERATURA EM UM MOSFET, COM O APARECIMENTO DO ZTC, E EM UM TFET, SEM A PRESENÇA DE ZTC.

FIGURA 2.13 - DiAGRAMA DE FAIXAS DE ENERGIA PARA UM NTFET SEM (A) E COM (B) UNDERLAP DE PORTA NA JUNÇ̃̃O CANAL/DRENO POLARIZADO COM V VS NEGATIVO E SUAS RESPECTIVAS CURVAS IDVG.

FIGURA 2.14 - DIAGRAMA DE FAIXAS DE ENERGIA PARA UM NTFET COM FONTE DE GERMÂNIO POLARIZADO COM $\mathrm{V}_{\mathrm{GS}}$ NEGATIVO. 49

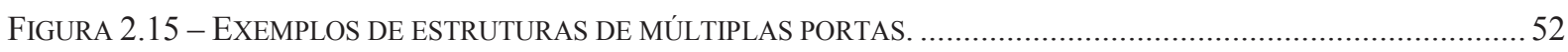

FIGURA 3.1 - REPRESENTAÇÃO ESTRUTURAL DE UM NW-TFET INDICANDO SUAS DIMENSÕES. 53

FigurA 3.2 - REPRESENTAÇÃO ESTRUTURAL DO TFET DE IN $\mathrm{I}_{0,53} \mathrm{GA}_{0,47} \mathrm{AS}$ (A) E DE IN $\mathrm{IN}_{0,7} \mathrm{GA}_{0,3} \mathrm{AS}$ (B) E SUAS DIMENSÕES.

FigURA 3.3 - REPRESENTAÇÃO do LEIAUTE DO TFET DE INGAAs (A) E FOTO VISTA DE CIMA DO DiSPOSITIVO (B).

FIGURA 4.1 - CORRENTE DE DRENO EXPERIMENTAL EM FUNÇ̃̃O DA TENSÃO NA PORTA DO NTFET NANOFIO PARA

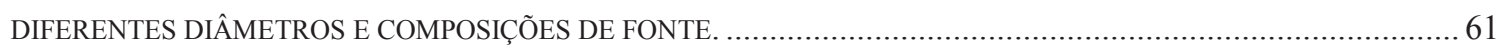

FIGURA 4.2 - ENERGIA DE ATIVAÇÃO PARA MATERIAIS COM DIFERENTES COMPOSIÇÕES DE FONTE. 62

FIGURA 4.3 - TRANSCONDUTÂNCIA EXPERIMENTAL EM FUNÇÃO DO DIÂMETRO EFETIVO DO NTFET NANOFIO PARA DIFERENTES COMPOSIÇÕES DE FONTE.

FIGURA 4.4 - CONDUTÂNCIA DE SAÍDA EXPERIMENTAL EM FUNÇÃO DO DIÂMETRO EFETIVO DO NTFET NANOFIO PARA DIFERENTES COMPOSIÇÕES DE FONTE.

FIGURA 4.5 - GANHO INTRÍNSECO DE TENSÃO EXPERIMENTAL EM FUNÇÃO DO DIÂMETRO EFETIVO DO NTFET NANOFIO PARA DIFERENTES COMPOSIÇÕES DE FONTE..

FIGURA 4.6 - CORRENTE DE DRENO NORMALIZADA EM RELAÇÃO À LARGURA EM FUNÇÃO DA TENSÃO DE PORTA PARA UM DISPOSITIVO NTFET NANOFIO COM FONTE DE SI PURO SIMULADO PARA DIFERENTES DIÂMETROS. 
FIGURA 4.7 - COMPONENTES DA CORRENTE DE DRENO EM FUNÇÃO DA TENSÃO DE PORTA PARA UM DISPOSITIVO NTFET NANOFIO COM FONTE DE SI PURO SIMULADO PARA DIFERENTES DIÂMETROS.

FIGURA 4.8 - REPRESENTAÇÃO ESQUEMÁTICA DA SECÇÃO TRANSVERSAL DE UM TFET VERTICAL EM ESTRUTURA DE NANOFIOS COM DIÂMETROS GRANDES (A), MÉDIOS (B) E PEQUENOS (C).

FIGURA 4.9 - TAXA DE GERAÇÃO E RECOMBINAÇÃO EM FUNÇÃO DA PROFUNDIDADE PARA UM DISPOSITIVO NTFET NANOFIO COM FONTE DE SI PURO SIMULADO PARA DIÂMETROS EFETIVOS DE 30NM E 110 NM.

FIGURA 4.10 - ENERGIA DE ATIVAÇÃO EM FUNÇÃO DA TENSÃO DE PORTA PARA UM NTFET NANOFIO COM FONTE DE Si PURO SIMULADO PARA DIFERENTES DIÂMETROS E V ON EM FUNÇÃO DO DIÂMETRO NO GRÁFICO INSERIDO.

FIGURA 4.11 - EFICIÊNCIA DO TRANSISTOR EM FUNÇÃO DA CORRENTE DE DRENO NORMALIZADA DOS DISPOSITIVOS NTFET NANOFIO PARA DIFERENTES DIÂMETROS E COMPOSIÇÕES DE FONTE. 71

FIGURA 4.12 - EFICIÊNCIA EM FUNÇÃO DA CORRENTE DE DRENO NORMALIZADA EM RELAÇÃO À LARGURA PARA UM DISPOSITIVO NTFET NANOFIO COM FONTE DE SI PURO SIMULADO PARA DIFERENTES DIÂMETROS. .... 72

FIGURA 4.13 - TAXA DE GERAÇÃO E RECOMBINAÇÃO EM FUNÇÃO DA PROFUNDIDADE PARA UM DISPOSITIVO NTFET NANOFIO COM FONTE DE SI PURO SIMULADO PARA CONDUÇÃO FRACA (A) E FORTE (B) DE CORRENTE.

FIGURA 4.14 - TRANSCONDUTÂNCIA E CONDUTÂNCIA DE SAÍDA EM FUNÇÃO DO DIÂMETRO EM CONDUÇÃO FORTE E FRACA DE CORRENTE PARA UM DISPOSITIVO NTFET NANOFIO COM FONTE DE SI PURO SIMULADO. 74

FIGURA 4.15 - GANHO INTRÍNSECO DE TENSÃO EM FUNÇÃO DO DIÂMETRO EM CONDUÇÃO FORTE E FRACA DE CORRENTE PARA UM DISPOSITIVO NTFET NANOFIO COM FONTE DE SI PURO SIMULADO.

FIGURA 4.16 - CURVA EXPERIMENTAL DA CORRENTE DE DRENO EM FUNÇÃO DA TENSÃO NA PORTA EM NTFETS DE NANOFIOS COM FONTE DE SI PURO PARA DIFERENTES TEMPERATURAS. 77

FIGURA 4.17 - TRANSCONDUTÂNCIA EXPERIMENTAL EM FUNÇÃO DA TEMPERATURA DO NTFET NANOFIO PARA DIFERENTES COMPOSIÇÕES DE FONTE. .78

FIGURA 4.18 - CONDUTÂNCIA DE SAÍDA EXPERIMENTAL EM FUNÇÃO DA TEMPERATURA DO NTFET NANOFIO PARA DIFERENTES COMPOSIÇÕES DE FONTE.

FIGURA 4.19 - CURVA EXPERIMENTAL DA EFICIÊNCIA EM FUNÇÃO DA CORRENTE DE DRENO PARA UM DISPOSITIVO NTFET NANOFIO COM FONTE DE SI PURO PARA DIFERENTES TEMPERATURAS.

FIGURA 4.20 - TENSÃO EARLY EXPERIMENTAL EM FUNÇÃO DA TEMPERATURA DO NTFET NANOFIO PARA DIFERENTES COMPOSIÇÕES DE FONTE.

FIGURA 4.21 - CORRENTE DE DRENO EXPERIMENTAL EM FUNÇÃO DA TENSÃO NA PORTA DO NTFET NANOFIO COM DIFERENTES COMPOSIÇÕES DE FONTE.

FIGURA 4.22 - ENERGIA DE ATIVAÇÃO EM FUNÇÃO DA TENSÃO NA PORTA DO NTFET NANOFIO COM DIFERENTES COMPOSIÇÕES DE FONTE.

FIGURA 4.23 - EFICIÊNCIA DO TRANSISTOR EM FUNÇÃO DA CORRENTE DE DRENO DE NTFET NANOFIOS COM DIFERENTES COMPOSIÇÕES DE FONTE.

FIGURA 4.24 - VALORES EXTRAÍDOS DA EFICIÊNCIA DO TRANSISTOR EM DIFERENTES CONDIÇÕES DE CONDUÇÃO DE CORRENTE PARA NTFET NANOFIOS COM DIFERENTES COMPOSIÇÕES DE FONTE.

FIGURA 4.25 - TENSÃO EARLY EM DIFERENTES CONDIÇÕES DE CONDUÇÃO DE CORRENTE PARA NTFET NANOFIOS COM DIFERENTES COMPOSIÇÕES DE FONTE. 
FIGURA 4.26 - ENERGIA DE ATIVAÇÃO EM DIFERENTES CONDIÇÕES DE CONDUÇ̃̃O DE CORRENTE PARA NTFET NANOFIOS COM DIFERENTES COMPOSIÇÕES DE FONTE.

FIGURA 4.27 - ENERGIA DE ATIVAÇÃO EM DIFERENTES CONDIÇÕES DE CONDUÇ̃̃O DE CORRENTE PARA NTFET NANOFIOS COM DIFERENTES COMPOSIÇÕES DE FONTE.

FIGURA 4.28 - GANHO INTRÍNSECO DE TENSÃO EM DIFERENTES CONDIÇÕES DE CONDUÇ̃̃O DE CORRENTE PARA NTFET NANOFIOS COM DIFERENTES COMPOSIÇÕES DE FONTE.

FIGURA 4.29 - CORRENTE DE DRENO EXPERIMENTAL EM FUNÇÃO DA TENSÃO NA PORTA PARA NTFET NANOFIO COM FONTE DE GE, COM DIFERENTES ESPESSURAS DE $\mathrm{HFO}_{2}$.

FIGURA 4.30 - EFICIÊNCIA DO TRANSISTOR EM FUNÇÃO DA TENSÃO NA PORTA PARA NTFET NANOFIO COM FONTE DE GE, COM DIFERENTES ESPESSURAS DE $\mathrm{HFO}_{2}$.

FIGURA 4.31 - CORRENTE DE DRENO EXPERIMENTAL NORMALIZADA EM FUNÇÃO DA TENSÃO NA PORTA DE TFET PLANARES DE IN $\mathrm{N}_{\mathrm{X}} \mathrm{GA}_{1-X}$ AS COM DIFERENTES PORCENTAGENS DE IN.

FIGURA 4.32 - ENERGIA DE ATIVAÇÃO EM FUNÇÃO DA TENSÃO NA PORTA DE TFET PLANARES DE IN $\mathrm{IN}_{\mathrm{X}} \mathrm{GA}_{1-\mathrm{X}} \mathrm{AS}$ COM DIFERENTES PORCENTAGENS DE IN.

FIGURA 4.33 - CORRENTE DE DRENO EXPERIMENTAL NORMALIZADA EM FUNÇÃO DA TENSÃO NA PORTA DE NTFETS DE SI EM ESTRUTURAS DE NANOFIOS VERTICAIS E NTFETS PLANARES DE IN $\mathrm{N}_{\mathrm{X}} \mathrm{GA}_{1-\mathrm{X}} \mathrm{AS}$. 97

FIGURA 4.34 - TRANSCONDUTÂNCIA PARA DIFERENTES TENSÕES DE PORTA E DE DRENO PARA NTFET PLANARES DE IN $\mathrm{GA}_{1-\mathrm{X}}$ AS COM DIFERENTES PORCENTAGENS DE IN.

FIGURA 4.35 - CONDUTÂNCIA DE SAÍDA PARA DIFERENTES TENSÕES DE PORTA E DE DRENO PARA NTFET PLANARES DE IN $\mathrm{N}_{\mathrm{X}} \mathrm{GA}_{1-\mathrm{X}}$ AS COM DIFERENTES PORCENTAGENS DE IN.

FIGURA 4.36 - DISPOSIÇÃO DA JANELA EFETIVA DE ENERGIA DE SOBREPOSIÇÃO NA JUNÇÃO ENTRE FONTE E CANAL PARA BAIXOS $\mathrm{V}_{\mathrm{GS}}$ (A) E ALTOS $\mathrm{V}_{\mathrm{GS}}$ (B) 99

FIGURA 4.37 - GANHO INTRÍNSECO DE TENSÃO PARA DIFERENTES TENSÕES DE PORTA E DE DRENO PARA NTFET PLANARES DE IN $\mathrm{NGA}_{\mathrm{1}-\mathrm{X}}$ AS COM DIFERENTES PORCENTAGENS DE IN. 100

FIGURA 4.38 - EFICIÊNCIA DO TRANSISTOR EM FUNÇÃO DA CORRENTE DE DRENO NORMALIZADA DE NTFETS PLANARES DE IN $\mathrm{N}_{\mathrm{X}} \mathrm{GA}_{1-\mathrm{X}}$ AS COM DIFERENTES PORCENTAGENS DE IN. 100

FIGURA 4.39 - CORRENTES DE DRENO E DE PORTA EXPERIMENTAIS NORMALIZADAS EM FUNÇÃO DA TENSÃO DE PORTA DE NTFETS PLANARES DE IN $\mathrm{K}_{\mathrm{X}} \mathrm{GA}_{1-\mathrm{X}}$ AS EM DIFERENTES TEMPERATURAS.

FIGURA 4.40 - ENERGIA DE ATIVAÇ̃̃O EM FUNÇÃO DA TENSÃO DE PORTA DE NTFETS PLANARES DE INXGA I $_{\text {-XAS. }}$

FIGURA 4.41 - TRANSCONDUTÂNCIA EXPERIMENTAL EM FUNÇ̃̃O DA TEMPERATURA PARA NTFETS PLANARES DE IN $\mathrm{IGA}_{1-\mathrm{X}} \mathrm{AS}$, COM TENSÕES DE DRENO DE 0,5 V (A) E 1,0 V (B). 104

FIGURA 4.42 - EFICIÊNCIA DO TRANSISTOR EXPERIMENTAL EM FUNÇÃO DA CORRENTE DE DRENO EM NTFETS PLANARES DE IN $\mathrm{X}_{\mathrm{X}} \mathrm{GA}_{1-\mathrm{X}}$ AS EM DIFERENTES TEMPERATURAS E INCLINAÇÃO DE SUBLIMIAR EM FUNÇ̃̃O DA TEMPERATURA NO GRÁFICO INSERIDO.

FIGURA 4.43 - CORRENTE DE DRENO EXPERIMENTAL EM FUNÇÃO DA TENSÃO DE DRENO EM NTFETS PLANARES DE IN $\mathrm{GA}_{1-\mathrm{X}} \mathrm{AS}$ EM DIFERENTES TEMPERATURAS 106

FIGURA 4.44 CONDUTÂNCIA DE SAÍDA EXPERIMENTAL EM FUNÇÃO DA TEMPERATURA PARA NTFETS PLANARES DE INXGA-XAS, COM TENSÕES DE DRENO DE 0,5 V (A) E 1,0 V (B). 
FIGURA 4.45 - CORRENTE DE DRENO EXPERIMENTAL E SIMULADA EM FUNÇÃO DA TENSÃO DE PORTA EM NTFETS PLANARES DE IN $\mathrm{I}_{0,53} \mathrm{GA}_{0,47} \mathrm{AS}$ E CORRENTE DE DRENO SIMULADA EM FUNÇÃO DA TENSÃO DE DRENO EM DIFERENTES TEMPERATURAS.

FIGURA 4.46 - CONDUTÂNCIA DE SAÍDA SIMULADA EM FUNÇÃO DA TEMPERATURA PARA NTFETS PLANARES DE $\mathrm{IN}_{0,53} \mathrm{GA}_{0,47} \mathrm{AS}$.

FIGURA 4.47 - ENERGIA DE CONDUÇÃO E VALÊNCIA SIMULADA EM FUNÇÃO DA DISTÂNCIA EM UMA SECÇÃO TRANSVERSAL INCLINADA (A), A QUAL ATRAVESSA OS VALORES MÁXIMOS DA TAXA DE GERAÇÃO DE BTBT DE ELÉTRONS (B) E LACUNAS (C). E A TAXA DE GERAÇÃO DE BTBT EM FUNÇÃO DA DISTÂNCIA NESTE CORTE, PARA TENSÃO DE DRENO DE 0,4 V E 0,6 V (D).

FIGURA 4.48 - GANHO INTRÍNSECO DE TENSÃO EXPERIMENTAL EM FUNÇÃO DA TEMPERATURA PARA NTFETS PLANARES DE IN $\mathrm{INA}_{1-\mathrm{X}} \mathrm{AS}$.

FIGURA 4.49 - CORRENTE DE DRENO EXPERIMENTAL NORMALIZADA EM FUNÇÃO DA TENSÃO NA PORTA DE NTFETS PLANARES DE IN $\mathrm{IAA}_{1-\mathrm{X}}$ AS COM DIFERENTES PORCENTAGENS DE IN E ESPESSURAS DE $\mathrm{HFO}_{2}, \mathrm{COM}$ TENSÃO DE DRENO ALTAS (A) E BAIXAS (B).

FIGURA 4.50 - TRANSCONDUTÂNCIA EM FUNÇÃO DA TENSÃO NA PORTA DE NTFETS PLANARES DE INXGA1-XAS COM DIFERENTES PORCENTAGENS DE IN E ESPESSURAS DE $\mathrm{HFO}_{2}$.

FIGURA 4.51 - CONDUTÂNCIA DE SAÍDA EM FUNÇÃO DA TENSÃO NA PORTA DE NTFETS PLANARES DE INXGA1-XAS COM DIFERENTES PORCENTAGENS DE IN E ESPESSURAS DE $\mathrm{HFO}_{2}$.

FIGURA 4.52 - EFICIÊNCIA DO TRANSISTOR EM FUNÇÃO DA CORRENTE DE DRENO DE NTFETS PLANARES DE IN $_{X} G_{1-X} A S$ COM DIFERENTES PORCENTAGENS DE IN E ESPESSURAS DE $\mathrm{HFO}_{2}$.

FIGURA 4.53 - INCLINAÇÃO DE SUBLIMIAR EM FUNÇÃO DA CORRENTE DE DRENO DE NTFETS PLANARES DE $\mathrm{IN}_{\mathrm{X}} \mathrm{GA}_{1-\mathrm{X}}$ AS COM DIFERENTES PORCENTAGENS DE IN E ESPESSURAS DE $\mathrm{HFO}_{2}$

FIGURA 4.54 - CORRENTE DE DRENO EXPERIMENTAL NORMALIZADA EM FUNÇÃO DA TENSÃO NO DRENO DE NTFETS PLANARES DE INXGA ${ }_{1} \mathrm{X} A S$ COM DIFERENTES PORCENTAGENS DE IN E ESPESSURAS DE $\mathrm{HFO}_{2}$.

FIGURA 4.55 - TENSÃO EARLY EM FUNÇÃO DA TENSÃO NA PORTA DE NTFETS PLANARES DE IN $\mathrm{X}_{1-\mathrm{X}} \mathrm{AS}$ COM DIFERENTES PORCENTAGENS DE IN E ESPESSURAS DE $\mathrm{HFO}_{2}$.

FIGURA 4.56 - CORRENTE DE DRENO EXPERIMENTAL NORMALIZADA EM FUNÇÃO DA TENSÃO NO DRENO DE

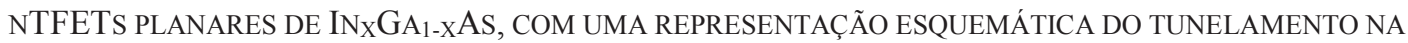
JUNÇÃO CANAL/DRENO EM UM DIAGRAMA DE BANDAS DE ENERGIA SIMPLIFICADO NO GRÁFICO INSERIDO.117 FIGURA 4.57 - GANHO INTRÍNSECO DE TENSÃO EM FUNÇÃO DA TENSÃO NA PORTA DE NTFETS PLANARES DE INX $_{X} \mathrm{GA}_{1-\mathrm{X}} \mathrm{AS}$ COM DIFERENTES PORCENTAGENS DE IN E ESPESSURAS DE $\mathrm{HFO}_{2}$.

FIGURA 4.58 - CONDUTÂNCIA DE SAÍDA E ENERGIA DE ATIVAÇÃO EM FUNÇÃO DA TENSÃO NA PORTA DE NTFETS PLANARES DE IN $\mathrm{XGA}_{1-\mathrm{X}}$ AS COM DIFERENTES PORCENTAGENS DE IN E ESPESSURAS DE $\mathrm{HFO}_{2}$ 118

FIGURA 4.59 - CORRENTE DE DRENO EXPERIMENTAL NORMALIZADA EM FUNÇÃO DA TENSÃO NA PORTA DE NTFETS PLANARES DE IN $\mathrm{I}_{0,53} \mathrm{GA}_{0,47}$ AS COM DIFERENTES ESPESSURAS DE $\mathrm{HFO}_{2}$, EM DIFERENTES TEMPERATURAS.

FIGURA 4.60 - ENERGIA DE ATIVAÇÃO EM FUNÇÃO DA TENSÃO NA PORTA DE NTFETS PLANARES DE IN $0,53 \mathrm{GA}_{0,47} \mathrm{AS}$ COM DIFERENTES ESPESSURAS DE $\mathrm{HFO}_{2}$.

FIGURA 4.61 - COMPOSIÇÃO DA CORRENTE DE DRENO EM FUNÇÃO DA TENSÃO NA PORTA DE NTFETS PLANARES DE $\mathrm{IN}_{0,53} \mathrm{GA}_{0,47} \mathrm{AS}$ SIMULADOS EM DIFERENTES TEMPERATURAS. 
FIGURA 4.62 - EFICIÊNCIA DO TRANSISTOR EM FUNÇÃO DA CORRENTE DE DRENO DE NTFETS PLANARES DE

$\mathrm{IN}_{0,53} \mathrm{GA}_{0,47}$ AS COM DIFERENTES ESPESSURAS DE $\mathrm{HFO}_{2}$, EM DIFERENTES TEMPERATURAS.

FIGURA 4.63 - INCLINAÇÃO DE SUBLIMIAR EM FUNÇÃO DA TEMPERATURA DE NTFETS PLANARES DE

$\mathrm{IN}_{0,53} \mathrm{GA}_{0,47}$ AS COM DIFERENTES ESPESSURAS DE $\mathrm{HFO}_{2}$

FIGURA 4.64 - TRANSCONDUTÂNCIA EM FUNÇÃO DA TEMPERATURA DE NTFETS PLANARES DE IN $\mathrm{IN}_{0,53} \mathrm{GA}_{0,47} \mathrm{AS}$ COM DIFERENTES ESPESSURAS DE $\mathrm{HFO}_{2}$.

FIGURA 4.65 - CONDUTÂNCIA DE SAÍDA DE SUBLIMIAR EM FUNÇão DA TEMPERATURA DE NTFETS PLANARES DE $\mathrm{IN}_{0,53} \mathrm{GA}_{0,47} \mathrm{AS}$ COM DIFERENTES ESPESSURAS DE $\mathrm{HFO}_{2}$.

FIGURA 4.66 - GANHO INTRÍNSECO DE TENSÃO EM FUNÇÃO DA TEMPERATURA DE NTFETS PLANARES DE $\mathrm{IN}_{0,53} \mathrm{GA}_{0,47} \mathrm{AS}$ COM DIFERENTES ESPESSURAS DE $\mathrm{HFO}_{2}$

FIGURA 4.67 - GANHO INTRÍNSECO DE TENSÃO EM FUNÇ̃̃O DA TENSÃO NA PORTA DE NTFETS PLANARES DE $\mathrm{IN}_{0,53} \mathrm{GA}_{0,47}$ AS COM $2 \mathrm{NM}$ (A) E 3 NM DE $\mathrm{HFO}_{2}$, EM DIFERENTES TEMPERATURAS 125

FIGURA 4.68 - CORRENTE DE DRENO EXPERIMENTAL NORMALIZADA EM FUNÇ̃̃O DA TENSÃO NA PORTA DE NTFETS PLANARES DE INX $\mathrm{GA}_{1-X}$ AS COM DIFERENTES PROCESSOS DE DIFUSÃO DE ZN E PORCENTAGENS DE IN.

FIGURA 4.69 - TRANSCONDUTÂNCIA EM FUNÇ̃̃O DA TENSÃO NA PORTA DE NTFETS PLANARES DE INx $G A_{1-x} A S$ COM DIFERENTES PROCESSOS DE DIFUSÃO DE ZN E PORCENTAGENS DE IN.

FIGURA 4.70 - CONDUTÂNCIA DE SAÍDA EM FUNÇ̃̃O DA TENSÃO NA PORTA DE NTFETS PLANARES DE IN $\mathrm{X}_{\mathrm{X}} \mathrm{GA}_{1-\mathrm{X}} \mathrm{AS}$ COM DIFERENTES PROCESSOS DE DIFUSÃO DE ZN E PORCENTAGENS DE IN.

FIGURA 4.71 - EFICIÊNCIA DO TRANSISTOR EM FUNÇÃO DA CORRENTE DE DRENO DE NTFETS PLANARES DE

IN $_{X} G_{1-X}$ AS COM DIFERENTES PROCESSOS DE DIFUSÃO DE ZN E PORCENTAGENS DE IN. 128

FIGURA 4.72 - GANHO INTRÍNSECO DE TENSÃO EM FUNÇÃO DA TENSÃO NA PORTA DE NTFETS PLANARES DE INXGA ${ }_{1-X}$ AS COM DIFERENTES PROCESSOS DE DIFUSÃO DE ZN E PORCENTAGENS DE IN.

FiguRA 4.73 - TRANSCONDUTÂNCIA (A) E CONDUTÂNCIA DE SAÍDA (B) EM FUNÇ̃̃o DA TEMPERATURA DE NTFETS PLANARES DE IN $\mathrm{N}_{\mathrm{X}} \mathrm{GA}_{1-\mathrm{X}}$ AS COM DIFERENTES PROCESSOS DE DIFUSÃO DE ZN E PORCENTAGENS DE IN.

FIGURA 4.74 - GANHO INTRÍNSECO DE TENSÃO EM FUNÇÃO DA TEMPERATURA DE NTFETS PLANARES DE INXGA xAS COM DIFERENTES PROCESSOS DE DIFUSÃO DE ZN E PORCENTAGENS DE IN. 130 


\section{LISTA DE TABELAS}

TABELA 4-1 - SUMARIZAÇÃO DA POLARIZAÇ̃̃o DE PORTA USADA PARA COMPARAÇ̃̃O ENTRE OS TRÊS MÉTODOS. 61

TABELA 4-2 - TABELA EXPERIMENTAL DA EFICIÊNCIA DO TRANSISTOR E DO GANHO INTRÍNSECO DE TENSÃO EM UM DISPOSITIVO NTFET NANOFIO COM DIFERENTES FONTES PARA DIFERENTES TEMPERATURAS.

TABELA 4-3 - TABELA DA EFICIÊNCIA, TENSÃO EARLY E GANHO INTRÍNSECO PARA NTFET NANOFIO COM FONTE DE GE, COM DIFERENTES ESPESSURAS DE $\mathrm{HFO}_{2}$

TABELA 4-4 - TABELA DA INFLUÊNCIA DA REDUÇ̃̃O DO DIÂMETRO, DO AUMENTO DA PORCENTAGEM DE GE E DO AUMENTO DA TEMPERATURA NOS PARÂMETROS ESTUDADOS

TABELA 4-5 - TABELA DA INFLUÊNCIA DA PORCENTAGEM DE IN EM DISPOSITIVOS IN INAA $_{1-X}$ AS NOS PRINCIPAIS PARÂMETROS ESTUDADOS.

TABELA 4-6 - TABELA DA INFLUÊNCIA DA TEMPERATURA DA DIFUSÃO DE ZN NA FONTE EM DISPOSITIVOS $\mathrm{IN}_{0,53} \mathrm{GA}_{0,47}$ AS NOS PRINCIPAIS PARÂMETROS ESTUDADOS.

TABELA 4-7 - TABELA DA INFLUÊNCIA DE DIFERENTES PROCESSOS DE DIFUSÃO DE ZN NA FONTE EM DISPOSITIVOS $\mathrm{IN}_{0,53} \mathrm{GA}_{0,47}$ AS NOS PRINCIPAIS PARÂMETROS ESTUDADOS.

TABELA 5-1 - TABELA COMPARATIVA ENTRE OS DISPOSITIVOS DE SI EM ESTRUTURAS DE NANOFIOS VERTICAIS E EM DISPOSITIVOS IN $\mathrm{N}_{0,53} \mathrm{GA}_{0,47}$ AS EM ESTRUTURAS PLANARES NOS PRINCIPAIS PARÂMETROS ESTUDADOS. . 135

TABELA 5-2 - TABELA DA INFLUÊNCIA DA REDUÇ̃̃O DA ESPESSURA DO DIELÉTRICO EM DISPOSITIVOS DE SI COM FONTE DE GE EM ESTRUTURAS DE NANOFIOS VERTICAIS E EM DISPOSITIVOS IN $\mathrm{N}_{0,53} \mathrm{GA}_{0,47}$ AS EM ESTRUTURAS PLANARES NOS PRINCIPAIS PARÂMETROS ESTUDADOS.

TABELA 5-3 - TABELA DOS PARÂMETROS PARA DISPOSITIVOS OTIMIZADOS, TENDO COMO REFERÊNCIA UM DISPOSITIVO COM IN $0,53 \mathrm{GA}_{0.47}$ AS COM DIFUSÃO DE ZN NA FONTE REALIZADA POR FONTE SÓLIDA À $500{ }^{\circ} \mathrm{C}$ E ESPESSURA DE $\mathrm{HFO}_{2}$ DE $3 \mathrm{NM}$ 


\section{LISTA DE SIGLAS E ABREVIATURAS}

BTBT Band to Band Tunneling (tunelamento de banda para banda).

BGN Bandgap Narrowing (Modelo de Estreitamento da Largura da Banda Proibida de Energia).

CTR Current and Transconductance Ratio (Razão entre corrente e transcondutância).

EOT Equivalent Oxide Thickness (espessura equivalente de óxido).

FET Field Effect Transistor (transistor de efeito de campo).

FLDMOB Parallel Electric Field Dependence (Modelo de Dependência do Campo Elétrico Paralelo).

Ge Germânio.

$\mathrm{HfO}_{2} \quad$ Óxido de Háfnio.

HR-SMU High Resolution Source Measurement Unit (Unidade de Fonte e Medida de Alta Resolução).

InxGa1-xAs Arseneto de liga Índio-Gálio, sendo x fração atômica de índio na liga.

InGaAs $\quad$ Arseneto de liga Índio-Gálio

LSI Laboratório de Sistemas Integrados.

MOS Metal-Oxide-Semiconductor (Metal-Óxido-Semicondutor).

MOSFET Metal-Oxide-Semiconductor Field-Effect Transistor (transistor de efeito de campo metal-óxido-semicondutor).

MuGFET Multiple Gates Field Effect Transistor (Transistor de efeito de campo de múltiplas portas).

nTFET TFET tipo $\mathrm{n}$.

NW Nanowire (nanofio).

NW-TFET Nanowire TFET (TFET em estrutura de nanofio)

pTFET TFET tipo p.

SHI Shirahata Mobility Model (Modelo de Mobilidade de Shirahata).

Si Silício.

SiGe $\quad$ Liga de Silício e Germânio 
$\mathrm{Si}_{1-\mathrm{x}} \mathrm{Ge}_{\mathrm{x}} \quad$ Liga de Silício e Germânio, sendo x fração atômica de germânio na liga.

$\mathrm{SiO}_{2} \quad$ Dióxido de Silício.

SOI Silicon-on-Insulator (silício-sobre-isolante).

SRH Schockley-Read-Hall Recombination (Modelo de Geração e Recombinação).

SS Subtreshold Swing (Inclinação de Sublimiar).

TAT Trap Assisted Tunneling (tunelamento assistido por armadilhas).

TFET Tunnel Field Effect Transistor (transistor de tunelamento por efeito de campo).

TiN Nitreto de Titânio.

ZTC Zero Temperature Coeficient (Ponto Invariante com a temperatura). a-Si Silício amorfo. 


\section{LISTA DE SIMBOLOS}

a

A

Av

b

B

C1F-N

$\mathrm{C} 2 \mathrm{~F}-\mathrm{N}$

$\mathrm{C}_{\text {BTBT }}$

Cox

CSRH

$\mathrm{C}_{\mathrm{TAT}}$

D Diâmetro do nanofio [nm].

Def Diâmetro efetivo do nanofio [nm].

E Energia de ativação $[\mathrm{eV}]$.

$\mathrm{E}_{\mathrm{C}}$

$E_{D}$

$\mathrm{E}_{\mathrm{g}}$ TFET. TFET. $[\mathrm{A} / \mu \mathrm{m}]$.

Largura da faixa proibida [eV].
Coeficiente determinado pela área da secção transversal de um

Parâmetro pré-exponencial da geração por BTBT.

Ganho de tensão de malha aberta em baixa frequência [dB].

Coeficiente determinado pelas propriedades do material de um

Parâmetro exponencial da geração por BTBT.

Constante pré-exponencial simplificada da densidade corrente devido ao mecanismo de tunelamento de Fowler-Nordheim $[\mathrm{A} / \mu \mathrm{m}]$.

Constante exponencial simplificada da densidade corrente devido ao mecanismo de tunelamento de Fowler-Nordheim $[\mathrm{A} / \mu \mathrm{m}]$.

Constante pré-exponencial simplificada da densidade corrente devido ao mecanismo de tunelamento de banda para banda $[\mathrm{A} / \mu \mathrm{m}]$.

Capacitância do óxido de porta [F/cm²].

Constante pré-exponencial simplificada da densidade corrente devido aos mecanismos de recombinação e geração $\mathrm{SRH}[\mathrm{A} / \mu \mathrm{m}]$.

Constante pré-exponencial simplificada da densidade corrente devido ao mecanismo de tunelamento assistido por armadilha

Nível de energia superior da faixa de condução [eV].

Nível de Energia da Armadilha [eV]. 


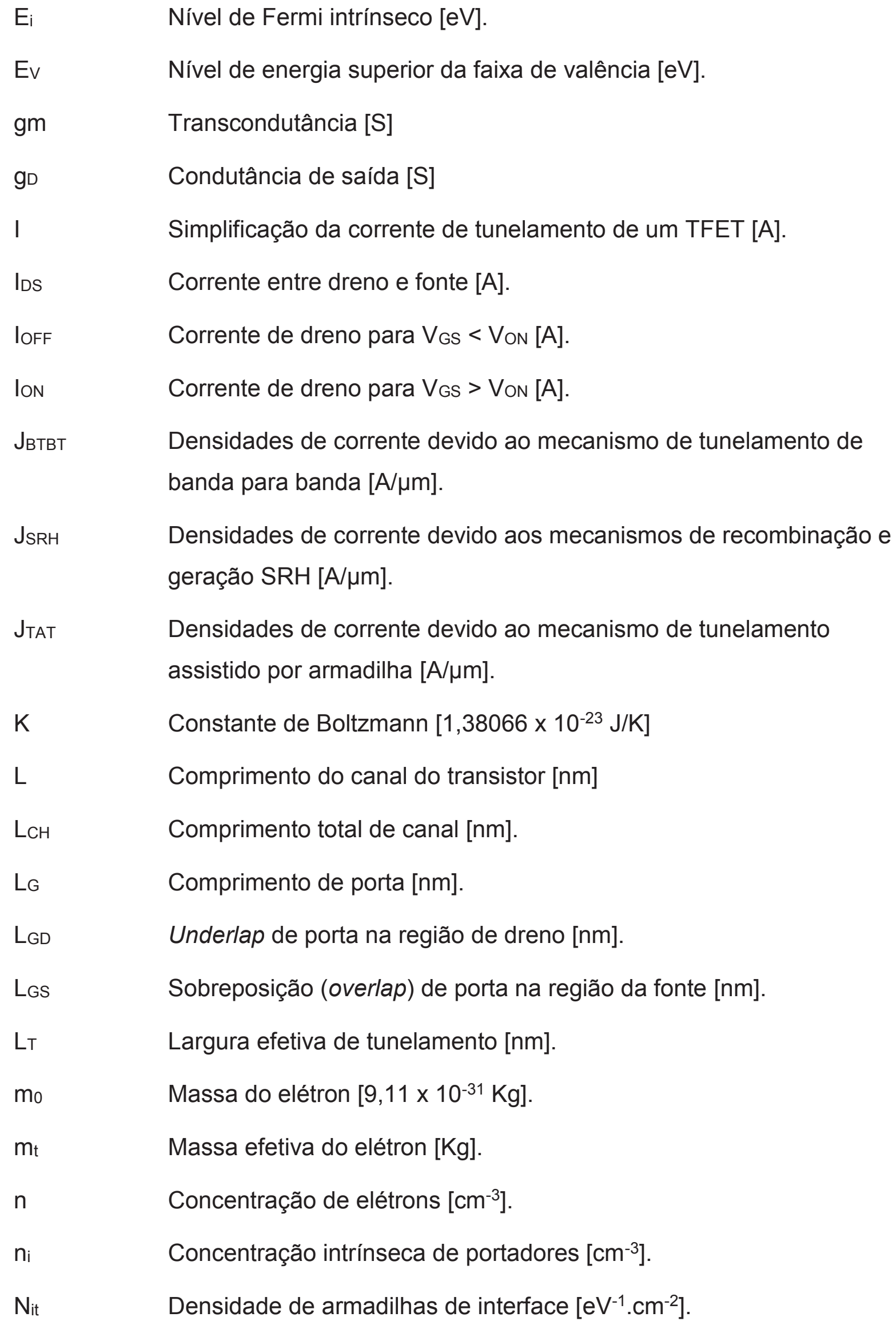




\begin{tabular}{|c|c|}
\hline Not & Densidade de armadilhas no óxido $\left[\mathrm{eV}^{-1} \mathrm{~cm}^{-3}\right]$. \\
\hline p & Concentração de lacunas $\left[\mathrm{cm}^{-3}\right]$. \\
\hline$P$ & Parâmetro de correção do campo elétrico na geração por BTBT. \\
\hline q & Carga do elétron $\left[1,6 \times 10^{-19} \mathrm{C}\right]$. \\
\hline $\mathrm{R}_{\text {BTBT }}$ & $\begin{array}{l}\text { Taxa de geração de portadores por tunelamento de banda para } \\
\text { banda }\left[\mathrm{cm}^{-3} \cdot \mathrm{s}^{-1}\right]\end{array}$ \\
\hline RsRH & Taxa de recombinação SRH $\left[\mathrm{cm}^{-3} \cdot \mathrm{s}^{-1}\right]$. \\
\hline RSRH+TAT & $\begin{array}{l}\text { Taxa de recombinação SRH considerando a geração por } \\
\text { TAT }\left[\mathrm{cm}^{-3} \cdot \mathrm{s}^{-1}\right] \text {. }\end{array}$ \\
\hline $\mathrm{T}$ & Temperatura $[\mathrm{K}]$. \\
\hline tox & Espessura do óxido de silício [nm]. \\
\hline$t_{s i}$ & Espessura do silício [nm]. \\
\hline$u$ & Variável de integração da função e efeito de campo. \\
\hline$V_{D S}$ & Tensão aplicada entre dreno e fonte [V]. \\
\hline$V_{E A}$ & Tensão Early [V]. \\
\hline$V_{\text {eff }}$ & Tensão reversa aplicada à porta de um TFET [V]. \\
\hline$V_{G S}$ & Tensão aplicada entre dreno e fonte [V]. \\
\hline Von & $\begin{array}{l}\text { Tensão aplicada à porta suficiente para ocorrer tunelamento entre } \\
\text { bandas [V]. }\end{array}$ \\
\hline $\mathrm{V}_{T}$ & Tensão de limiar de um transistor MOSFET [V]. \\
\hline W & Largura do canal do transistor $[\mathrm{nm}]$ \\
\hline$\Delta \mathrm{E}_{\mathrm{n}}$ & Faixa de Energia para Qual Ocorre o Tunelamento de Elétrons [eV]. \\
\hline$\Delta \mathrm{E}_{\mathrm{p}}$ & Faixa de Energia para Qual Ocorre o Tunelamento de Lacunas [eV] \\
\hline$\varepsilon_{0 x}$ & Constante dielétrica do óxido de silício [F/cm] \\
\hline$\varepsilon_{S i}$ & Constante dielétrica do silício $[\mathrm{F} / \mathrm{cm}]$ \\
\hline$\hbar$ & Constante de Plank reduzida $\left[6,626 \times 10^{-34} \mathrm{~J} . s\right]$. \\
\hline
\end{tabular}


$\tau_{n}$

$\tau_{p}$

$\Gamma_{p}^{T A T}$

$\xi$
Tempo de vida das lacunas [s].

Tempo de vida dos elétrons [s].

Função de efeito de campo.

Magnitude do Campo elétrico [V/m]. 


\section{SUMÁRIO}

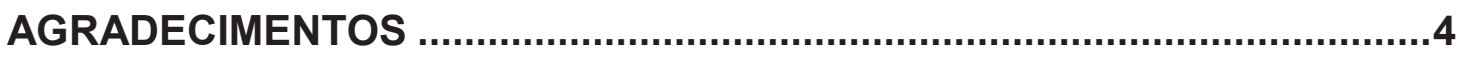

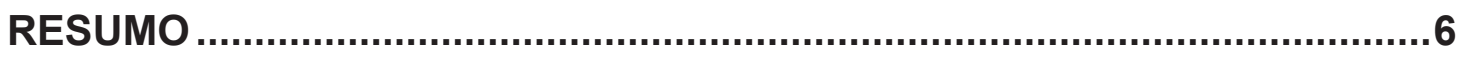

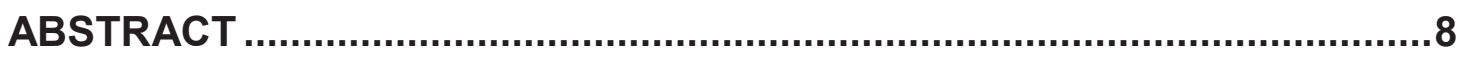

LISTA DE FIGURAS ......................................................................... 10

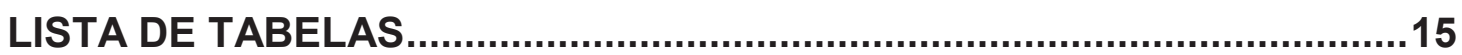

LISTA DE SIGLAS E ABREVIATURAS ..................................................16

LISTA DE SIMBOLOS .............................................................................. 18

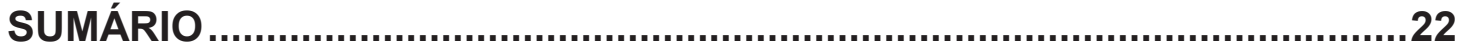

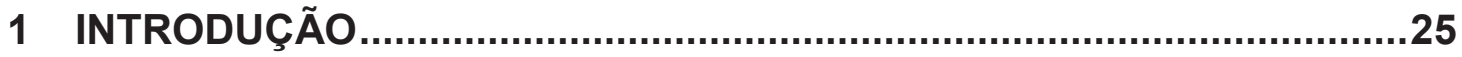

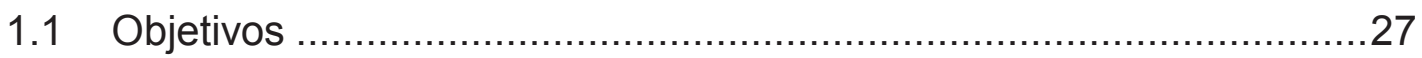

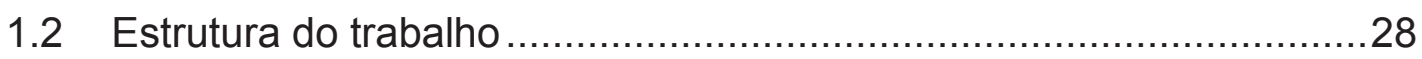

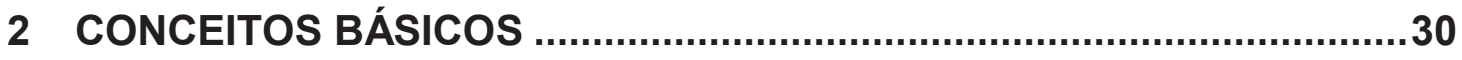

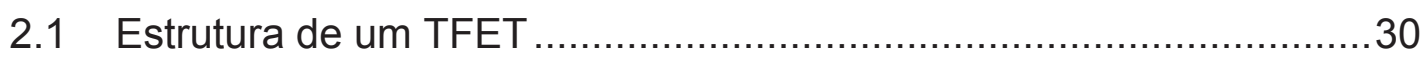

2.2 Mecanismos de condução do TFET .......................................... 33

2.2.1 Recombinação e geração Shockley-Read-Hall (SRH) ..................33

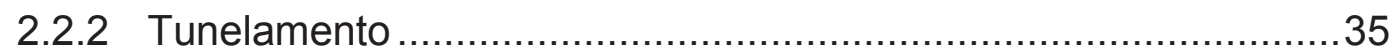

2.2.2.1 Tunelamento induzido por armadilhas (TAT) .........................36

2.2.2.2 Tunelamento entre bandas (BTBT) ............................... 37

2.3 Dependência com a temperatura ...........................................38

2.4 Parâmetros dos dispositivos TFET ........................................ 39

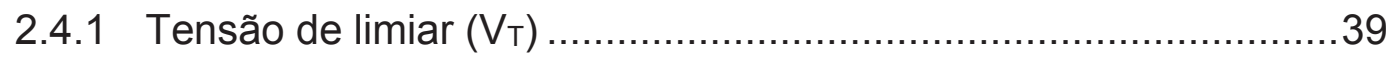

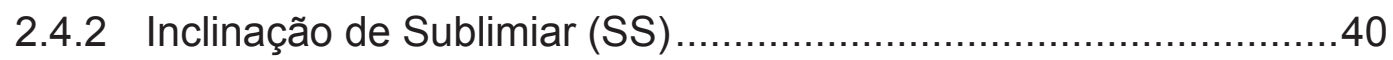

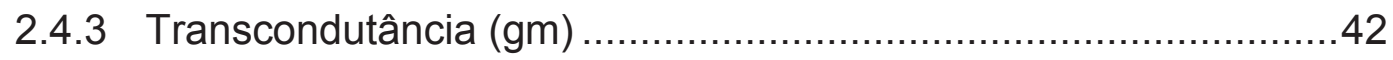

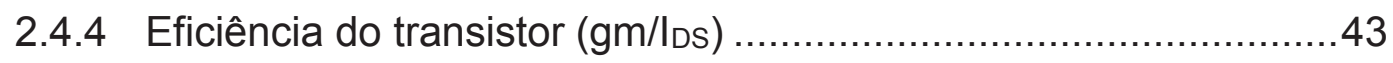

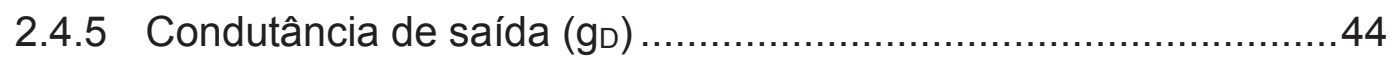

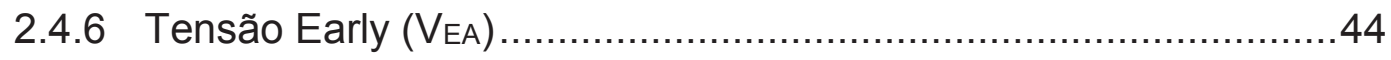




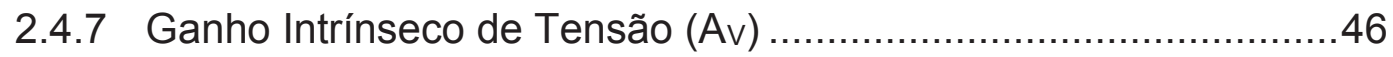

2.4.8 Ponto invariante com a temperatura (ZTC) .............................46

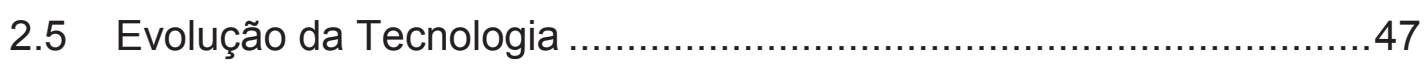

2.5.1 Underlap de porta na junção canal/dreno ...................................4

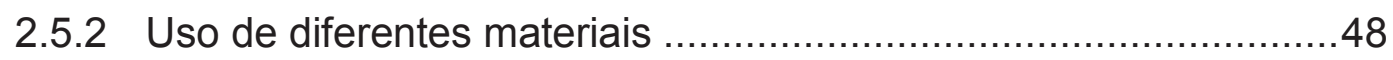

2.5.3 Materiais de alta constante dielétrica .......................................50

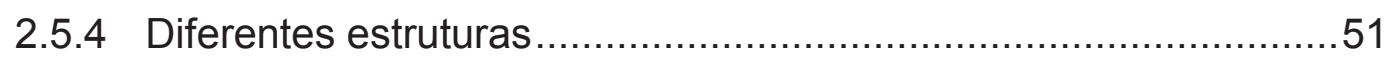

3 DISPOSITIVOS EXPERIMENTAIS E SIMULAÇÕES ............................53

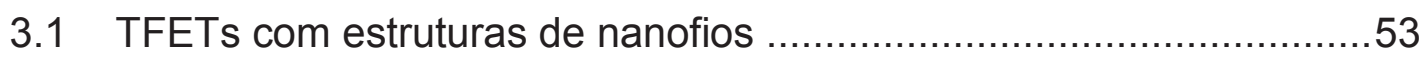

3.1.1 Dispositivos TFETs com estruturas de nanofios experimentais ...53

3.1.2 Dispositivos TFETs com estruturas de nanofios simulados ..........54

3.2 TFETs Planares com Uso de Materiais III-V ....................................57

3.2.1 Dispositivos TFETs Planares Experimentais .............................57

3.2.2 Dispositivos TFETs Planares Simulados ………………...........59

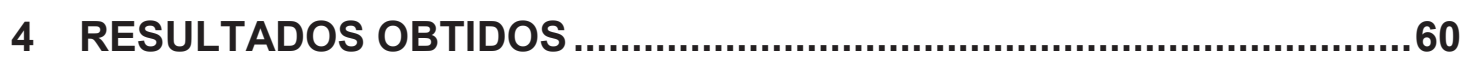

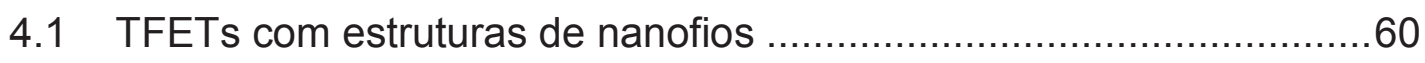

4.1.1 Influência do diâmetro nos TFETs .............................................60

4.1.2 Analise em alta temperatura dos parâmetros analógicos …..........77

4.1.3 Estudo da composição de fonte ................................................ 84

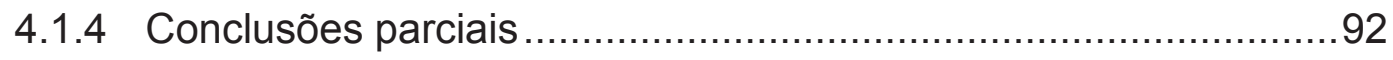

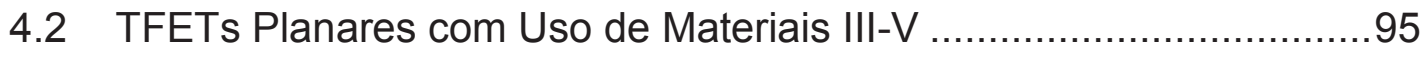

4.2.1 TFETs com dopagem de fonte por fonte sólida ..........................95

4.2.1.1 Análise em temperatura ambiente .......................................95

4.2.1.2 Influência da variação da temperatura ....................................101

4.2.2 TFETs com dopagem de fonte por difusão de fase gasosa ........111

4.2.2.1 Análise em temperatura ambiente …………........................111

4.2.2.2 Influência da variação da temperatura ....................................119 
4.2.3 Comparação de TFETs com dopagem de fonte por fonte sólida e por fase gasosa 126

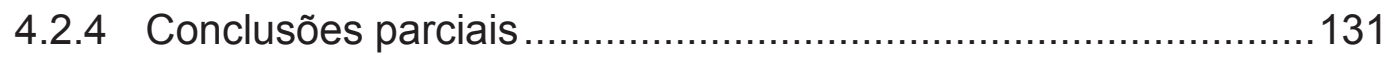

5 CONCLUSÕES E PROPOSTAS DE TRABALHOS FUTUROS ............135

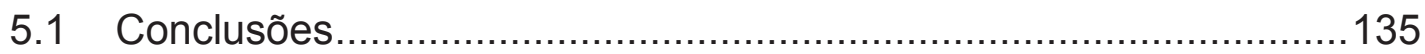

5.2 Propostas de Trabalhos Futuros …………………………......138

TRABALHOS GERADOS DURANTE O DOUTORADO...............................139

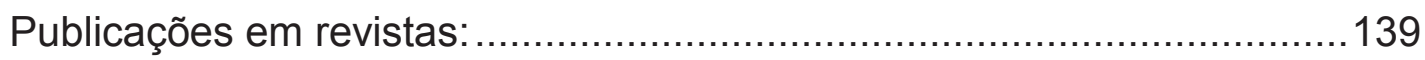

Submissões em revistas que ainda não foram avaliadas: .........................140

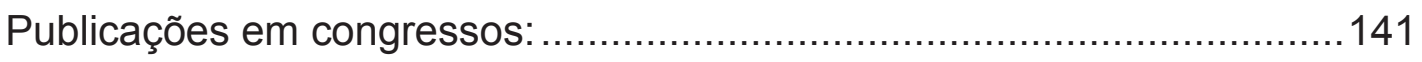

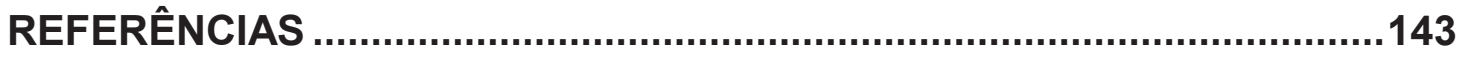




\section{INTRODUÇÃO}

O uso de circuitos integrados motivou a miniaturização dos componentes com a finalidade de aumentar o número de transistores em uma lâmina e assim melhorar seu desempenho (1). Uma lei muito utilizada para prever o número de transistores em uma mesma área de silício é a Lei de Moore (2), (3), a qual prevê um crescimento exponencial do número de transistores em um chip no tempo com o mesmo custo.

A necessidade de aumentar o número de transistores e a evolução apresentada pela tecnologia MOSFET fez com que eles fossem aplicados em circuitos integrados, principalmente porque a estrutura MOSFET permite uma maior densidade de integração. Transistores MOSFETs são os principais componentes utilizados em circuitos integrados ao longo das últimas décadas.

Porém, com a agressiva redução das dimensões dos transistores MOSFET, surgem efeitos parasitários indesejados chamados de efeitos de canal curto, que começaram a ser altamente significativos nos nós tecnológicos mais recentes.

Uma solução encontrada para minimizar estes efeitos foi o uso da tecnologia silício sobre isolante (SOI - Silicon on Insulator) (4)- (6). Esta tecnologia utiliza uma camada de silício sobre um isolante, mantendo a parte ativa do silício isolada do restante do substrato. Os dispositivos que usam estruturas SOI possuem melhores características elétricas quando comparadas a dispositivos MOS convencionais devido à redução das capacitâncias parasitárias, a isolação dielétrica entre os dispositivos e a supressão do efeito de tiristor parasitário (Latch up) (7). A tecnologia de silício sobre isolante tornou-se a principal tecnologia na fabricação de microprocessadores, deixando de ser uma alternativa para se tornar uma tecnologia muito utilizada pela indústria atualmente.

Quando a dimensão dos transistores foi demasiadamente reduzida, os efeitos de canal curto, para tecnologias abaixo de $22 \mathrm{~nm}$, se tornaram importantes mesmo em dispositivos SOI MOSFETs. Para continuar minimizando estes efeitos parasitários, novas estruturas de transistores com múltiplas portas (MuGFETs), como FinFETs e nanofios, estão sendo estudados porque apresentam melhor acoplamento eletrostático. 
Cada vez mais se faz necessário o estudo de novos materiais, desenvolvimento de novas estruturas e dispositivos com princípios de funcionamentos diferentes. A Figura 1.1 apresenta o gráfico da evolução da tecnologia dos transistores a partir dos anos 2000, apresentando as novas tecnologias e estruturas mais promissoras a suceder a tecnologia MOSFET (8).

Figura 1.1 - Evolução da tecnologia dos transistores

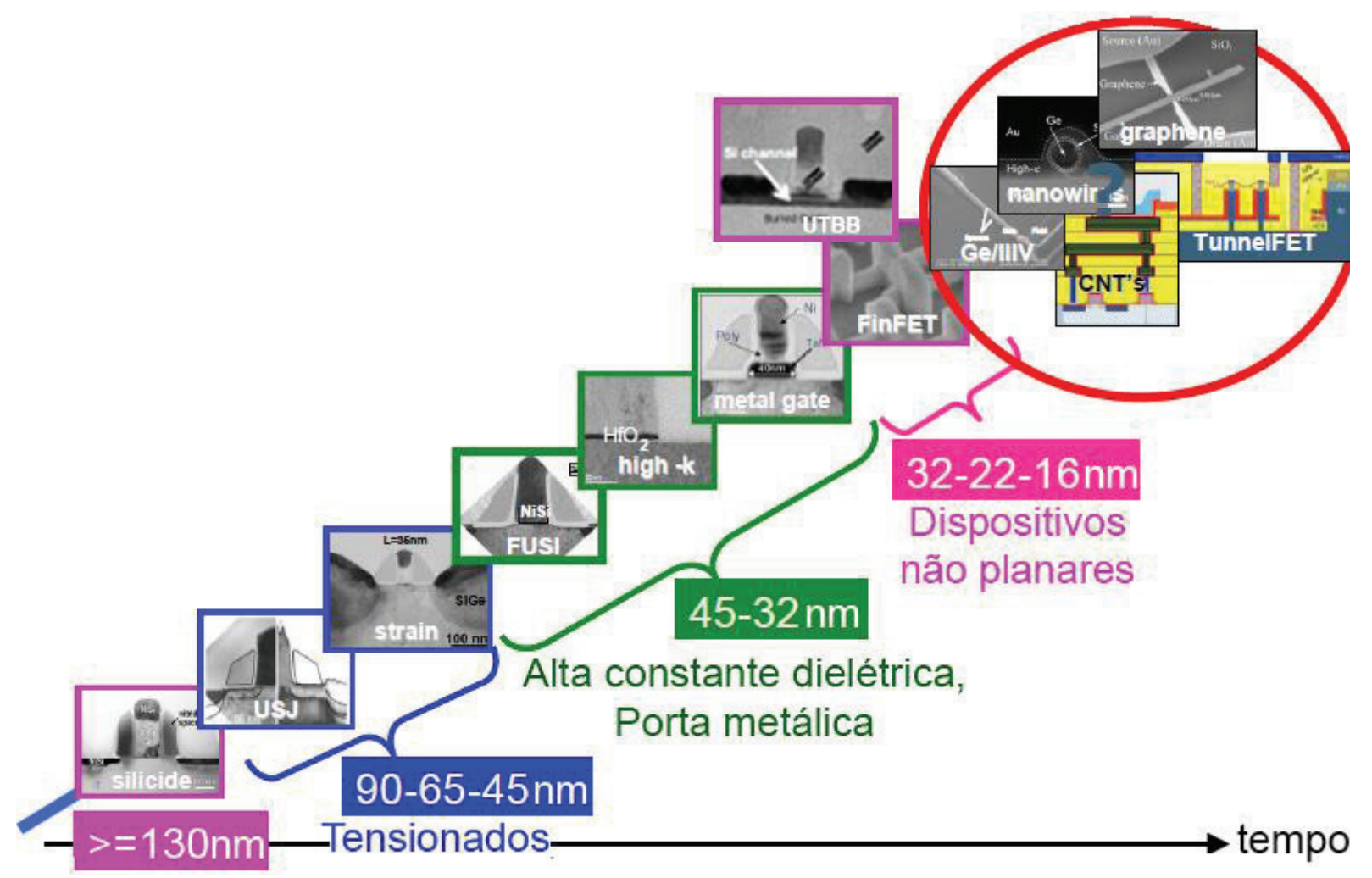

Fonte: Claeys, C. (2009)

Além de desempenho, devido ao grande número de transistores, uma característica que deve ser melhorada é a eficiência energética. Para isso, é necessário que um transistor apresente correntes de estado desligado (lofr) extremamente baixas. Outra característica que têm grande relevância é a velocidade de chaveamento de um transistor. Em transistores MOSFET, quanto maior o acoplamento eletrostático, maior essa velocidade de chaveamento. Porém, a tecnologia MOSFET apresenta velocidade de chaveamento limitada a $60 \mathrm{mV} / \mathrm{dec}$ pela sua condução de corrente em temperatura ambiente, devido ao fato da corrente ser gerada pelo processo de difusão na região de sublimiar (6). 
Enquanto os MOSFETs têm como princípio de operação os mecanismos de difusão e deriva, os transistores de tunelamento por efeito de campo (Tunnel Field Efect Transitors - TFET) (9),(10) operam com tunelamento quântico de elétrons induzido pelo campo elétrico aplicado à porta e por isso possuem um potencial muito grande para serem sucessores dos MOSFETs em aplicações de baixa potência. Ao contrário dos MOSFETs, que possuem sua inclinação de sublimiar (SS) limitada a 60 $\mathrm{mV} / \mathrm{dec}$ em temperatura ambiente, o mecanismo de tunelamento isenta os TFETs deste limite, possibilitando maior velocidade de chaveamento que os dispositivos MOSFETs. Outra característica favorável ao uso de TFET é seu baixo loff, o que reduz bastante a sua potência dissipada (11). Além disso, é importante ressaltar que o tunelamento nos TFETs ocorre muito perto da junção fonte/canal, em um curto espaço do comprimento do canal, minimizando os efeitos de canal curto (12).

Apesar de muito promissor, os TFETs ainda apresentam algumas características que precisam ser melhoradas, como a baixa corrente de estado ligado (loN) e o efeito ambipolar. Muito se tem estudado para melhorar estas características do TFETs, como o uso de novas geometrias (13)-(16), que aumentam a área de tunelamento, e novos materiais (17)-(20) para aumentar lon, e também o uso de underlap de porta na junção canal/dreno para suprimir o efeito ambipolar (21).

\subsection{Objetivos}

O objetivo deste trabalho de doutorado foi realizar o estudo e a caracterização elétrica dos principais parâmetros de diversas estruturas TFETs, com diferentes materiais, através de simulações numéricas e de medidas experimentais, em temperatura ambiente e em diferentes temperaturas. Os dispositivos TFETs que foram usados neste trabalho foram fabricados no centro de pesquisas IMEC, localizado na Bélgica.

O objetivo inicial deste projeto foi estudar os transistores de efeito de campo por tunelamento feitos de Silício, fabricados em estruturas de nanofios verticais. Para reduzir a área utilizada pelos transistores, e então poder aumentar a quantidade de transistores em uma lâmina foi necessário diminuir o diâmetro dos transistores fabricados em estruturas de nanofios verticais. Portanto, foi estudada a influência da redução do diâmetro nos mecanismos de condução de corrente e nos principais 
parâmetros digitais e analógicos dos TFETs, experimentalmente e também utilizando simulações numéricas.

Para melhorar o desempenho dos dispositivos TFET de Si, que possuem baixa corrente, foi necessário utilizar diferentes materiais com menor largura da banda proibida de energia. Foi então estudada a influência do uso de diferentes materiais, como Germânio e ligas de Silício e Germânio, nos principais parâmetros digitais e analógicos obtidos experimentalmente.

Com o intuito melhorar ainda mais o desempenho dos transistores TFET, foram estudados novos dispositivos fabricados com Arseneto de Indio-Galio (InxGa1-xAs). Os transistores feitos com este material, que pode possuir largura da banda proibida de energia ainda menor que do Ge, foram estudados, analisando a influência da composição de In ( $\left.\ln \times G_{1} \times A s\right)$ nos principais parâmetros digitais e analógicos, experimentalmente e também utilizando simulações numéricas. O uso destes transistores de InGaAs tem como objeto melhorar as características digitais, chegando a inclinações de sumlimiar menores que $60 \mathrm{mV} / \mathrm{dec}$ e melhor desempenho analógico.

Com o foco em aplicações analógicas em diferentes temperaturas, seguindo a norma de variação de temperatura militar, foi também estudada a influência de diferentes temperaturas nos principais parâmetros digitais e analógicos dos transistores TFET estudados. A variação de temperatura também é de considerável importância no estudo da influência de cada mecanismo de transporte dos TFET.

\subsection{Estrutura do trabalho}

Este trabalho está dividido em cinco capítulos. O capítulo 1 apresenta um breve histórico e introdução ao tema.

O capítulo 2 apresenta uma revisão bibliográfica, onde são apresentados os conceitos teóricos sobre o funcionamento básico dos TFETs e os diferentes mecanismos de condução de portadores envolvidos.

No capítulo 3 são descritos os dispositivos utilizados nas medidas experimentais e simulações, e a metodologia utilizada na realização das medidas das grandezas elétricas. 
O capítulo 4 apresenta os principais resultados, os quais foram subdivididos em duas seções. No item 4.1, são apresentados os estudos feitos com os TFETs de Si, mostrando a análise da redução de diâmetro, a influência da temperatura e a influência do uso de diferentes fontes nestes dispositivos. No item 4.2, são apresentados os estudos feitos com os TFETs de InGaAs, mostrando a análise da influência das diferentes composições de In, a influência da temperatura e um estudo comparativo de dois processos de difusão na fonte, nestes dispositivos.

No capítulo 5 são listadas as principais conclusões obtidas no desenvolvimento do trabalho e algumas perspectivas futuras. 


\section{CONCEITOS BÁSICOS}

Neste capítulo são apresentados os principais conceitos dos transistores TFET, sua estrutura e modo de funcionamento. São ainda mostradas algumas melhorias tecnológicas destes transistores.

\subsection{Estrutura de um TFET}

A estrutura de um transistor TFET é semelhante a estrutura de um diodo PIN. Diodos PIN são diodos que quando reversamente polarizados, se houver uma incidência de luz, conduzem corrente elétrica. A estrutura de um diodo PIN é composta por um lado com silício tipo $\mathrm{P}$ altamente dopado $(\mathrm{P}+)$, silício intrínseco no meio e o outro lado com silício tipo $\mathrm{N}$ altamente dopado $(\mathrm{N}+)$, como mostra a Figura 2.1.

Figura 2.1 - Estrutura de um diodo PIN.

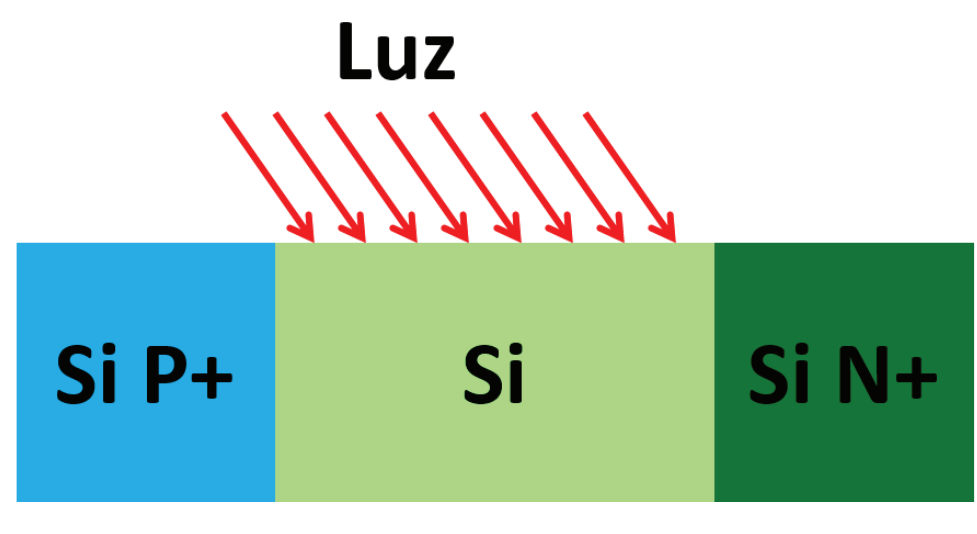

Fonte: Autor.

A estrutura de um TFET consiste um diodo PIN com uma porta em cima da região de silício intrínseca (dopagem natural da lâmina), usando um material isolante entre a porta e a região de silício (9). As regiões altamente dopadas tipo $\mathrm{P}$ e tipo $\mathrm{N}$ dão origem ao dreno e à fonte, conforme pode ser observado na Figura 2.2.

Um TFET pode ser do tipo N (nTFET) ou do tipo P (pTFET). Um TFET é considerado nTFET quando o dreno é dopado tipo $\mathrm{N}$ e a fonte tipo $\mathrm{P}$, analogamente, um TFET é considerado pTFET quando o dreno é dopado tipo $\mathrm{P}$ e a fonte tipo $\mathrm{N}$. 
Figura 2.2 - Estrutura de um nTFET de porta de simples.

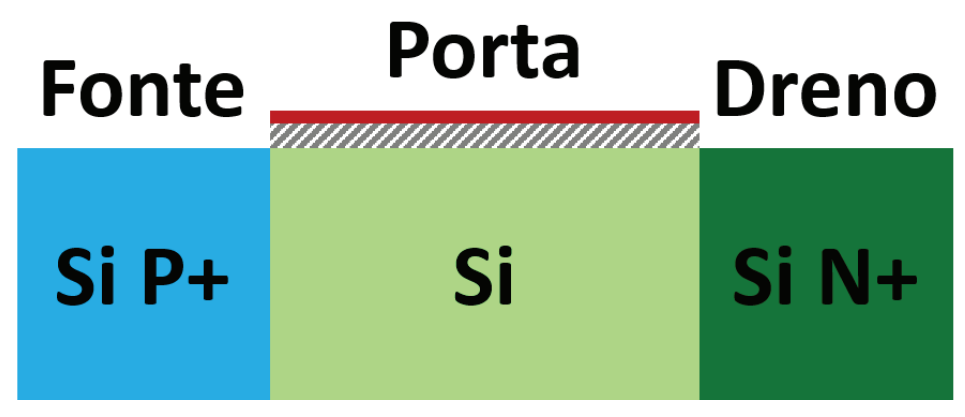

Fonte: Autor.

O dispositivo TFET tem seu funcionamento baseado no mecanismo de tunelamento entre bandas (BTBT - Band to band tunneling). O tunelamento entre bandas ocorre quando o potencial de porta é suficiente para que o topo da banda de valência do lado $P$ tenha energia maior ou igual ao fundo da banda de condução do lado intrínseco, possibilitando a passagem de portadores da banda de valência do lado P para a banda de condução do intrínseco da junção, como pode ser observado na Figura 2.3.

Figura 2.3 - Tunelamento entre bandas em uma junção de um TFET com alta polarização de porta.

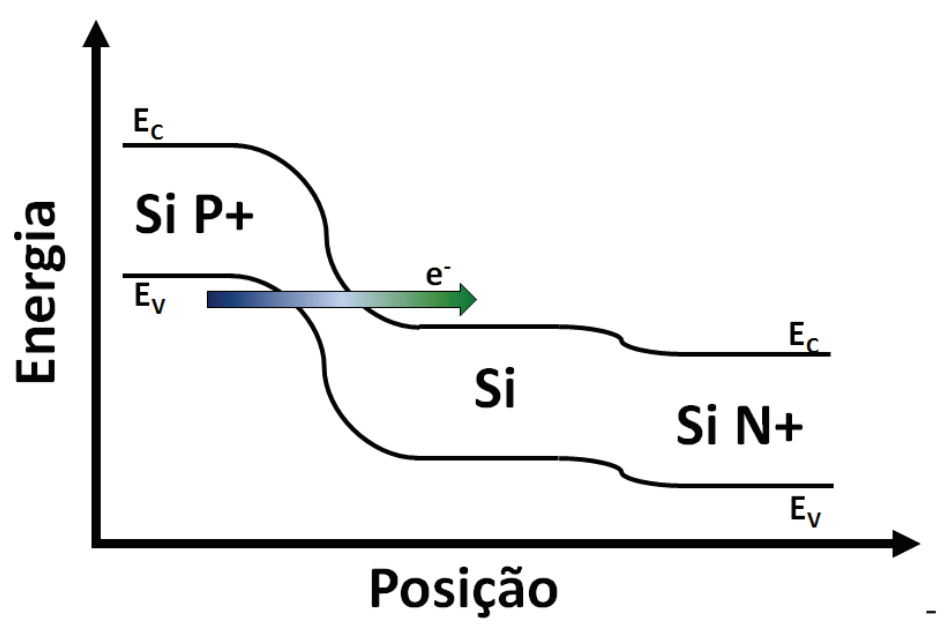

Fonte: Autor.

O funcionamento de um dispositivo nTFET, com polarização positiva entre fonte e dreno $\left(V_{D S}\right)$, pode ser analisado em três situações distintas, mudando-se a polarização aplicada à porta do dispositivo, conforme mostrado na Figura 2.4 . 
O dispositivo estará no estado desligado se a tensão entre a porta e a fonte ( $\left.V_{G S}\right)$ for próxima de zero (Figura 2.4(a)). Nesta situação o tunelamento entre bandas é impedido, pois a banda de valência do lado $P$ da junção (Fonte) é menor que a banda de condução do lado intrínseco (Canal) (11).

Figura 2.4 - Diagrama de faixas de energia para um nTFET polarizado com VGs próximo de 0 (a), VGS positivo (b) e $V_{G S}$ negativo (c).
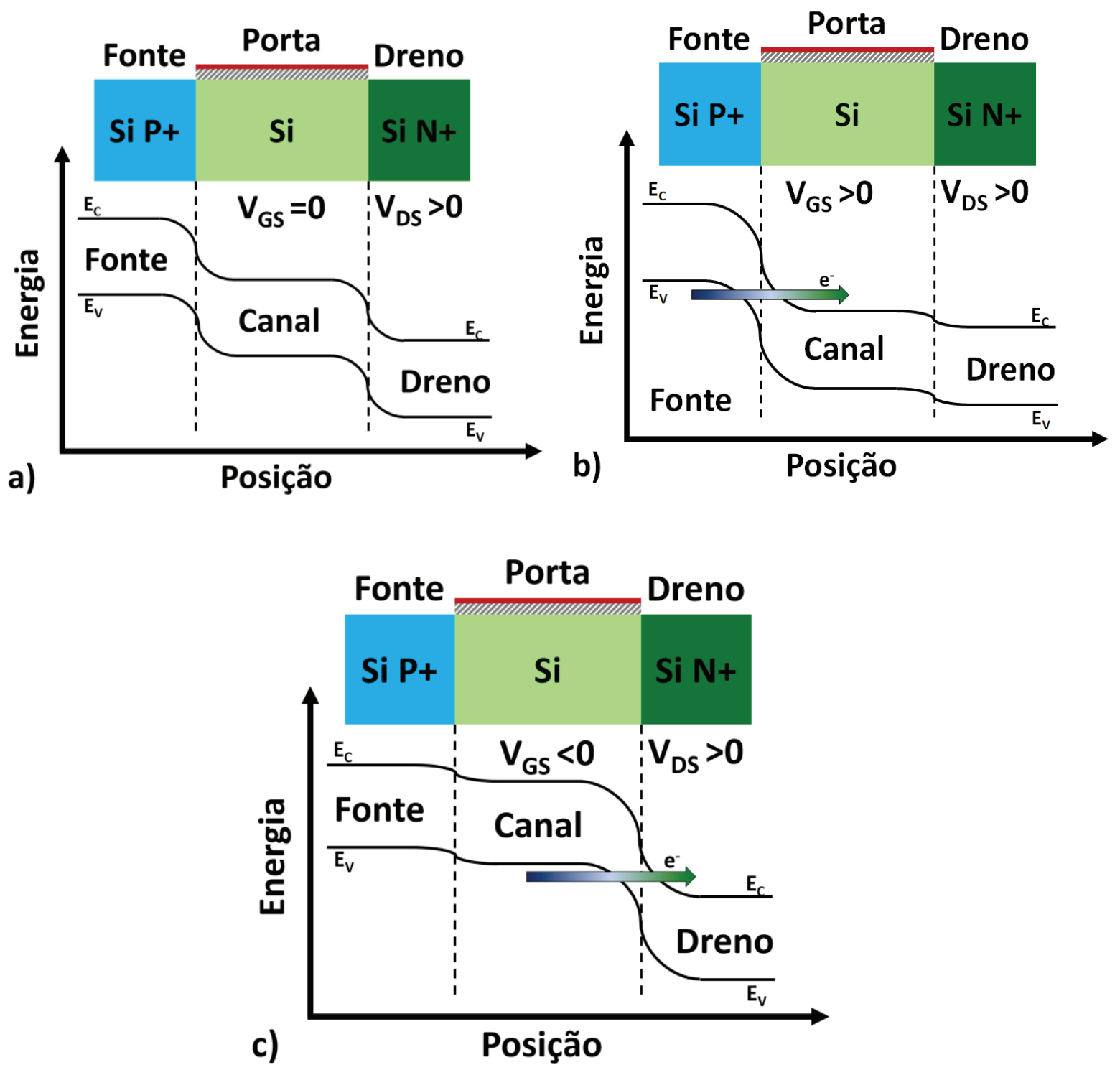

Fonte: Autor.

Aumentando $V_{G S}$, a banda de valência da fonte (lado $P$ da junção) passa a ser maior que a banda de condução do canal (lado intrínseco da junção), possibilitando 
então o tunelamento de elétrons da banda de valência da fonte para a banda de condução do canal (Figura 2.4(B)).

Aplicando tensões negativas na porta em nTFETs, um efeito indesejável pode ser observado (Figura 2.4(C)). A banda de valência do canal (lado intrínseco da junção) passa a ser maior que a banda de condução do dreno (lado $\mathrm{N}$ da junção), possibilitando então o tunelamento de elétrons da banda de valência do canal para a banda de condução do dreno. A corrente elétrica nesta condição de polarização é indesejável, pois eleva a corrente de estado desligado (loff). Este efeito indesejável de alta condução de corrente elétrica para o estado desligado é chamado de efeito ambipolar (21).

Assim como a estrutura nTFET mostrada na Figura 2.2, os dispositivos TFET também podem do tipo $\mathrm{P}$, caso o dreno seja dopado tipo $\mathrm{P}$ e a fonte tipo $\mathrm{N}$. Analogamente aos dispositivos MOSFETs, tensões positivas são aplicadas para os nTFETs e negativas para os pTFETs. O tipo de dopagem do dreno é sempre do mesmo tipo do transistor, ou seja, em um nTFET o dreno é tipo $\mathrm{N}+$, assim como mostrado no dispositivo da Figura 2.2, e em um pTFET o dreno é tipo P+. Isto ocorre porque em TFETs o canal se torna uma extensão do dreno, a qual então permite o tunelamento de banda para banda na junção fonte/canal.

\subsection{Mecanismos de condução do TFET}

O transistor TFET opera principalmente através de três mecanismos de condução de corrente. Recombinação e geração Shockley-Read-Hall (SRH), o tunelamento assitido por armadilhas (TAT - Trap Assisted Tunneling) e o BTBT.

\subsubsection{Recombinação e geração Shockley-Read-Hall (SRH)}

O processo de geração de pares elétron-lacuna ocorre quando ligações covalentes de redes cristalinas são rompidas por excitações térmicas gerando lacunas na banda de valência e elétrons na banda de condução. A presença de uma lacuna 
na banda de valência faz com que um elétron livre da banda de condução tente se recombinar com essa lacuna, eliminando o par elétron lacuna (22).

Como a energia da banda proibida é relativamente elevada nos semicondutores utilizados na microeletrônica, os elétrons se valem de transições indiretas através de defeitos na rede cristalina ou de impurezas contaminantes no semicondutor para para serem promovidos para a banda de valência. Esses defeitos e impurezas possuem níveis de energia situados dentro da banda proibida e podem armadilhar elétrons tanto provenientes da banda de valência quanto da banda de condução, e podem liberar elétrons tanto para a banda de valência quanto para a de condução. Toda a energia que é absorvida ou emitida por geração e recombinação é convertida em vibrações na rede cristalina por meio de fônons (23),(24).

A taxa de recombinação $\mathrm{SRH}\left(\mathrm{R}_{\mathrm{SRH}}\right)$ para armadilhas pode ser representada pela equação 2.1. E a equação 2.2, a qual é utilizada pelos simuladores (Capítulo 3), mostra a densidade de corrente (JSRH) simplificada, a qual deixa em destaque todos os fatores exponenciais. (23),(25),(26).

$$
\begin{gathered}
R_{S R H}=\frac{n \cdot p-n_{i}^{2}}{\tau_{p}\left(n+n_{i} \cdot e^{\left(\frac{E_{d}-E_{i}}{k \cdot T}\right)}\right)+\tau_{n}\left(p+n_{i} \cdot e^{-\left(\frac{E_{d}-E_{i}}{k \cdot T}\right)}\right)} \\
J_{S R H} \propto C_{S R H} \cdot e^{\left(-\frac{\frac{E g}{2}+\left(E_{d}-E_{i}\right)}{k \cdot T}\right)}
\end{gathered}
$$

onde $\mathrm{n}$ é a concentração de elétrons, $\mathrm{p}$ a concentração de lacunas, $\mathrm{n}_{\mathrm{i}}$ a concentração intrínseca de portadores, $\tau_{p}$ o tempo de vida das lacunas, $\tau_{n}$ o tempo de vida dos elétrons, $E_{d}$ a energia da armadilha, $E_{i}$ o nível de fermi intrínseco, $k$ a constante de Boltzmann, T a temperatura, $\mathrm{E}_{\mathrm{G}}$ a energia da banda proibida e CsRH a constante que simplifica a parte pré-exponencial da densidade de corrente para o SRH.

É possível notar através da equação 2.2 que a densidade de corrente elétrica gerada através de SRH tem uma grande influência da temperatura, diretamente no expoente, gerando uma considerável dependência direta da temperatura na densidade de corrente elétrica. 


\subsubsection{Tunelamento}

Tunelamento, segundo a mecânica quântica, é um mecanismo de transporte de portadores que é definida pela probabilidade finita de um elétron ou lacuna atravessarem uma barreira de potencial maior que a energia dos mesmos.

O valor desta probabilidade depende da forma, altura e largura da barreira de potencial (27)(28). Considerando uma barreira de potencial como da Figura 2.5, levando em consideração apenas a mecânica clássica, se a partícula estiver do lado esquerdo da barreira de potencial ela somente a atravessaria caso ela possuísse energia maior que a mesma, caso contrário seria totalmente refletida (28).

Figura 2.5 - Barreira de potencial e função de onda de um elétron.

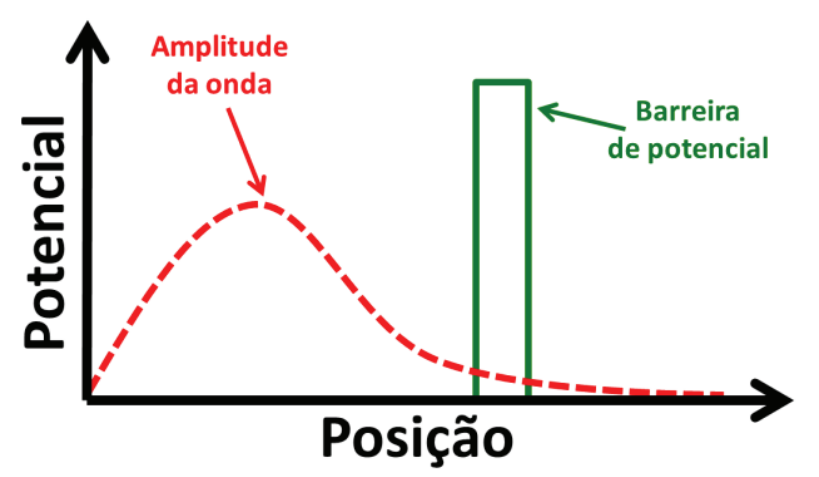

Fonte: Autor.

Porém, segundo a mecânica quântica, as partículas possuem comportamento ondulatório e há a probabilidade de a partícula estar em qualquer lado da barreira. No exemplo da Figura 2.5, mesmo com a onda da partícula possuindo energia menor do que a barreira, há a probabilidade de ela estar em qualquer lado da barreira, pois a função de onda possui uma componente não nula capaz de penetrar na barreira, perdendo sua energia exponencialmente com a distância. Quanto mais estreita for esta barreira, maior a probabilidade de a partícula ser encontrada do lado direito da barreira de potencial. 


\subsubsection{Tunelamento induzido por armadilhas (TAT)}

O TAT ocorre quando o tunelamento é auxiliado por defeitos que armadilham elétrons em níveis energéticos intermediários na faixa proibida. Devido ao auxílio das armadilhas o TAT pode ocorrer sem que ocorra a sobreposição entre as bandas de condução e de valência de duas camadas adjacentes. Uma representação esquemática de TAT pode ser observada na Figura 2.6.

Figura 2.6 - Representação esquemática do tunelamento assistido por armadilhas.

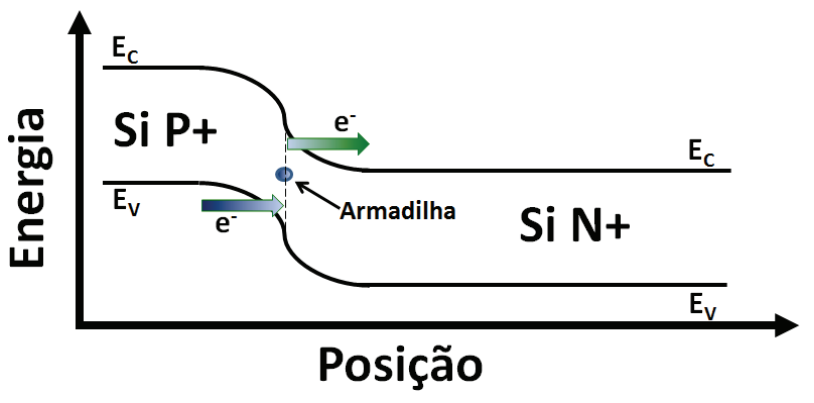

Fonte: Autor.

O modelo de TAT proposto por Hurkx (29) é baseado no modelo SRH, mas com o acréscimo da função de efeito de campo $\left(\Gamma_{n}^{T A T}\right.$ para elétrons e $\Gamma_{p}^{T A T}$ para lacunas). A nova equação acrescida deste termo é mostrada na equação 2.3.

$$
R_{S R H+T A T}=\frac{n \cdot p-n_{i}^{2}}{\frac{\tau_{p}}{1+\Gamma_{p}^{T A T}}\left(n+n_{i} \cdot e^{\left(\frac{E_{d}-E_{i}}{k \cdot T}\right)}\right)+\frac{\tau_{n}}{1+\Gamma_{n}^{T A T}}\left(p+n_{i} \cdot e^{-\left(\frac{E_{d}-E_{i}}{k \cdot T}\right)}\right)}
$$

Sendo os termos da função de efeito de campo definidos nas equações 2.4 e 2.5:

$$
\begin{gathered}
\Gamma_{n}^{T A T}=\frac{\Delta E_{n}}{k \cdot T} \int_{0}^{1} e^{\left(\frac{\Delta E_{n}}{k \cdot T} \cdot u-\frac{4}{3} \frac{\sqrt{2 \cdot m_{0} \cdot m_{t} \cdot \Delta E_{n}^{3}}}{3 \cdot q \cdot \hbar \cdot|E|} \cdot u^{\frac{2}{3}}\right)} d u \\
\Gamma_{p}^{T A T}=\frac{\Delta E_{p}}{k \cdot T} \int_{0}^{1} e^{\left(\frac{\Delta E p}{k \cdot T} \cdot u-\frac{4}{3} \frac{\sqrt{2 \cdot m_{0} \cdot m_{t} \cdot \Delta E_{p}^{3}}}{3 \cdot q \cdot \hbar \cdot|E|} \cdot u^{\frac{2}{3}}\right)} d u
\end{gathered}
$$

onde $\Delta \mathrm{E}_{\mathrm{n}}$ é a faixa de energia para qual ocorre o tunelamento de elétrons, $\Delta \mathrm{E}_{\mathrm{p}}$ é a mesma faixa para lacunas, $k$ é a constante de Boltzmann, T é a temperatura, u é uma variável de integração, $m_{0}$ é a massa do elétron em repouso, $m_{t}$ a massa efetiva do elétron e $\hbar$ a constante de Planck reduzida $(h / 2 \pi)$. 
Como a taxa de recombinação de TAT é baseado no modelo de $\mathrm{SRH}$, a sua densidade de corrente é analogamente bem semelhante. A equação 2.6 mostra a densidade de corrente de TAT (JTAT) simplificada, proveniente da integração de volume da equação 2.3 , a qual deixa em destaque todos os fatores exponenciais (26).

$$
J_{T A T} \propto C_{T A T} \cdot e^{\left(-\frac{\frac{E_{g}}{2}+\left(E_{d}-E_{i}\right)}{k \cdot T}\right)}
$$

onde CTAT é a constante que simplifica a parte pré-exponencial da densidade de corrente para o TAT.

Devido ao modelo do TAT ser baseado no modelo do SRH, é possível notar, através da equação 2.2 , que assim como o $\mathrm{SRH}$, a temperatura também exerce uma grande influência na densidade de corrente.

\subsubsection{Tunelamento entre bandas (BTBT)}

O tunelamento entre bandas, como já mencionado no item 2.1 , é gerado quando o topo da banda de valência do lado $P$ tenha energia maior ou igual do que o fundo da banda de condução do lado intrínseco (dopagem natural da lâmina). O modelo proposto por Hurkx (29) considerando o mecanismo de geração de portadores por tunelamento é dado pela equação 2.7. A equação 2.8 mostra a equação simplificada da densidade de corrente (Ј exponenciais (26).

$$
\begin{gathered}
R_{B T B T}=A \cdot \frac{n \cdot p-n_{i}^{2}}{\left(n+n_{i}\right)\left(p+n_{i}\right)} \cdot \xi^{P} \cdot e^{\left(\frac{B \cdot E_{g}(T)^{3 / 2}}{E_{g}(300)^{3 / 2} \cdot \xi}\right)} \\
J_{B T B T} \propto \cdot C_{B T B T} \cdot e^{\left(-C_{B T B T} \cdot \frac{E_{g}^{3 / 2}}{\xi}\right)}
\end{gathered}
$$

onde $n$ é a concentração de elétrons, $p$ a concentração de lacunas, $n_{i}$ a concentração intrínseca de portadores, $\zeta$ é a magnitude do campo elétrico, $E_{G}$ é a energia da banda proibida, $T$ a temperatura em kelvin, o coeficiente A é parâmetro pré-exponencial, o B 
é parâmetro exponencial, $\mathrm{P}$ é o parâmetro de correção do campo elétrico e $\mathrm{C}_{\mathrm{BTBT}}$ é o parâmetro de simplificação de BTBT.

Diferentemente do SRH e TAT, onde pode ser verificado que a temperatura afeta a parte exponencial do modelo da densidade de corrente elétrica (Equações 2.2 e 2.6), a temperatura não tem influência direta no mecanismo de geração de corrente no BTBT, como pode ser visto na equação 2.8. Neste mecanismo a temperatura somente possui uma influência indireta, gerando redução da banda proibida de energia, causando um aumento da corrente loN.

\subsection{Dependência com a temperatura}

Ao aumentar a temperatura em um TFET, a taxa de geração de todos os mecanismos de condução, BTBT, TAT e SRH, aumentam. Para valores relativamente pequenos de tensão de porta, os mecanismos dominantes de condução de corrente elétrica são o SRH e o TAT. Como estes mecanismos de condução de corrente são mais fortemente influenciados pela temperatura do que o mecanismo de BTBT, é possível notar um aumento mais pronunciado em loff quando comparado a lon, cujo mecanismo dominante de condução de corrente elétrica é o BTBT ( Figura 2.7).

Figura 2.7 - Representação do efeito da temperatura em TFETs.

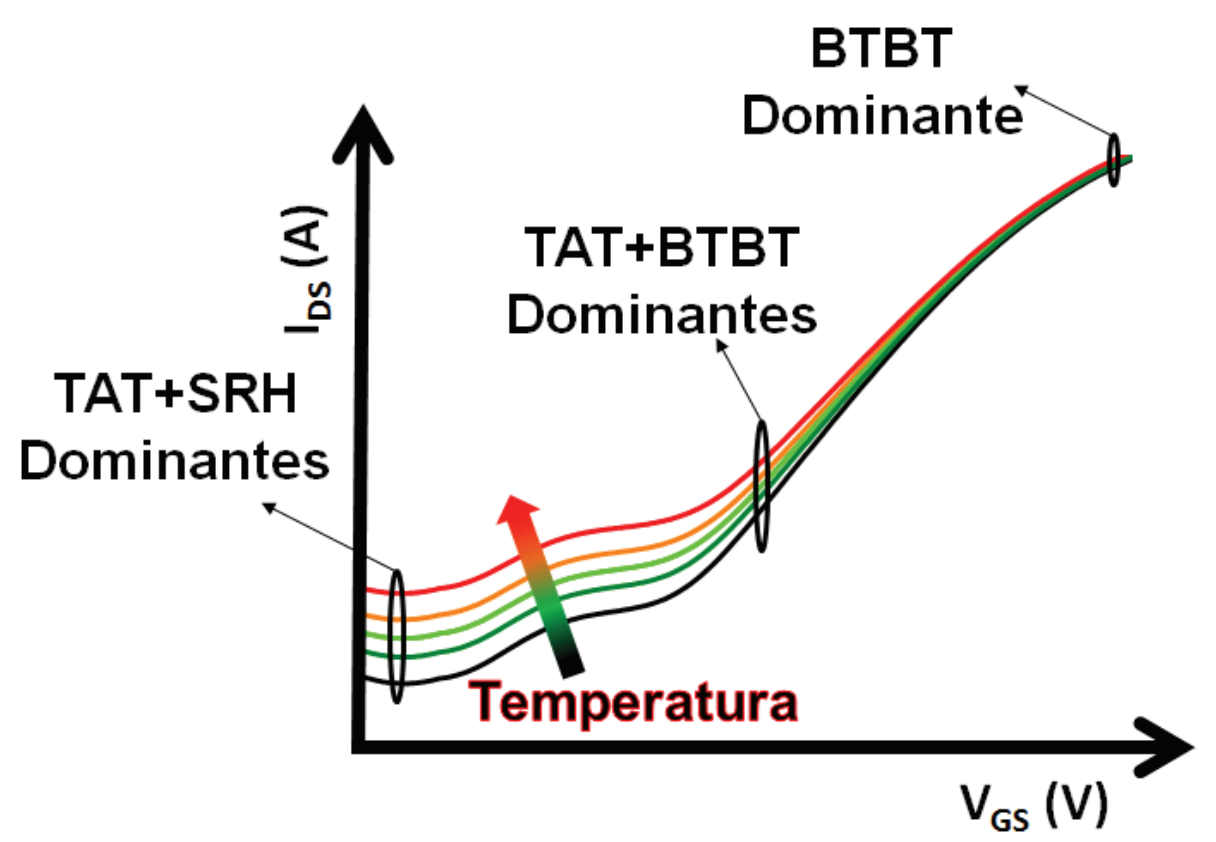

Fonte: Autor. 


\subsection{Parâmetros dos dispositivos TFET}

Assim como os dispositivos MOSFETs, os TFET podem ser caracterizados a partir de curvas experimentais e simuladas. Através desta caracterização podem ser extraídos parâmetros, os quais podem mensurar a qualidade dos dispositivos testados. Nesta seção alguns parâmetros que já foram estudados para os TFETs serão apresentados.

\subsubsection{Tensão de limiar $\left(V_{T}\right)$}

A tensão de limiar ( $\mathrm{V}_{\mathrm{T}}-$ Threshold Voltage) é um parâmetro tecnológico muito importante, pois está relacionada ao início da condução de corrente elétrica. Este parâmetro é bastante conhecido em dispositivos MOSFETs, a qual está relacionada ao potencial necessário para a formação do canal de inversão entre a fonte e o dreno. Porém, em TFETs, o mecanismo de condução de corrente é diferente de difusão e deriva como em dispositivos MOSFETs, e a formação de canal em TFETs não está relacionada com o início de condução de uma corrente significativa.

Alguns métodos foram propostos para se estimar um valor para tensão de limiar, como o método da razão entre corrente e transconcondutância (CTR - Current and Transconductance Ratio (30)).

Um método ainda utilizado, o qual é bem aplicado em dispositivos MOSFETs, que é bem simples e prático, é o método da corrente constante (31). Através deste método, adota-se um valor de corrente de dreno (IDS) baseado nas dimensões físicas do dispositivo, a partir da qual é extraída a polarização de porta relacionada, sendo esta adotada como tensão de limiar. Este método pode ser aplicado facilmente através de uma curva simples IDSXVGS.

Outro método que pode ser considerado, leva em conta os princípios físicos de operação do dispositivo, em analogia ao transistor MOSFET cuja tensão de limiar indica a polarização necessária para formação do canal de inversão. A tensão de limiar em TFETs pode ser definido como a polarização necessária para que o BTBT seja o mecanismo de condução de corrente dominante ( $\left.\bigvee_{O N}\right)$. 
Uma maneira de obter esta polarização pode ser através da obtenção da energia de ativação $\left(E_{A}\right)$. A energia de ativação mostra o quanto influenciado pelo aumento da temperatura o dispositivo é, e como visto nas equações 2.2, 2.4 e 2.8, o BTBT é o mecanismo de condução que apresenta menor influência da temperatura na corrente elétrica (somente possui influência indireta em $E_{G}$ ), portanto, quando o dispositivo está polarizado em uma região na qual o BTBT é dominante, o valor de $E_{A}$ deve que ser baixo. Em (32) foi proposto que o BTBT é o mecanismo dominante quando $E_{A}$ apresenta valores menores que $0,1 \mathrm{eV}$, o qual é um valor muito pequeno, indicando pouca influência de temperatura.

Um método que pode ser utilizado para a extração da energia de ativação é o método de Arrhenius (33), o qual utiliza a variação da corrente de dreno com a temperatura, conforme a equação 2.9 .

$$
E_{A}=-K \cdot\left[\frac{\Delta \ln \left(I_{D S}\right)}{\Delta\left(\frac{1}{T}\right)}\right]
$$

\subsubsection{Inclinação de Sublimiar (SS)}

Inclinação de sublimiar (SS - Subthreshold Swing) é o parâmetro que descreve o desempenho de chaveamento de corrente entre a corrente de estado desligado (loff) e a corrente de estado ligado (ION) de um dispositivo. SS pode ser definido como a taxa de variação da corrente de dreno, analisada em sua escala logarítmica, com a variação da tensão de porta, como demonstrado na equação 2.10. É importante salientar que esta análise é usualmente feita em transistores MOS na região de sublimiar, para valores baixos de tensão de dreno.

$$
S S=\frac{d V_{G S}}{d\left(\log I_{D S}\right)}
$$

Em dispositivos MOSFETs, onde o mecanismo de condução de corrente na região de sublimiar é o de difusão, o SS é limitado a $60 \mathrm{mV} / \mathrm{dec}$ em temperatura ambiente. Já nos TFETs não há esse tipo de limitação, pois o mecanismo de condução 
principal é o BTBT. A Figura 2.8 mostra SS de um MOSFET otimizado (SS $\cong 60$ $\mathrm{mV} / \mathrm{dec}$ ) e o SS do TFET.

Figura 2.8 - Representação de SS de um MOSFET otimizado (SS $\cong 60 \mathrm{mV} / \mathrm{dec}$ ) e o SS potencial de um TFET.

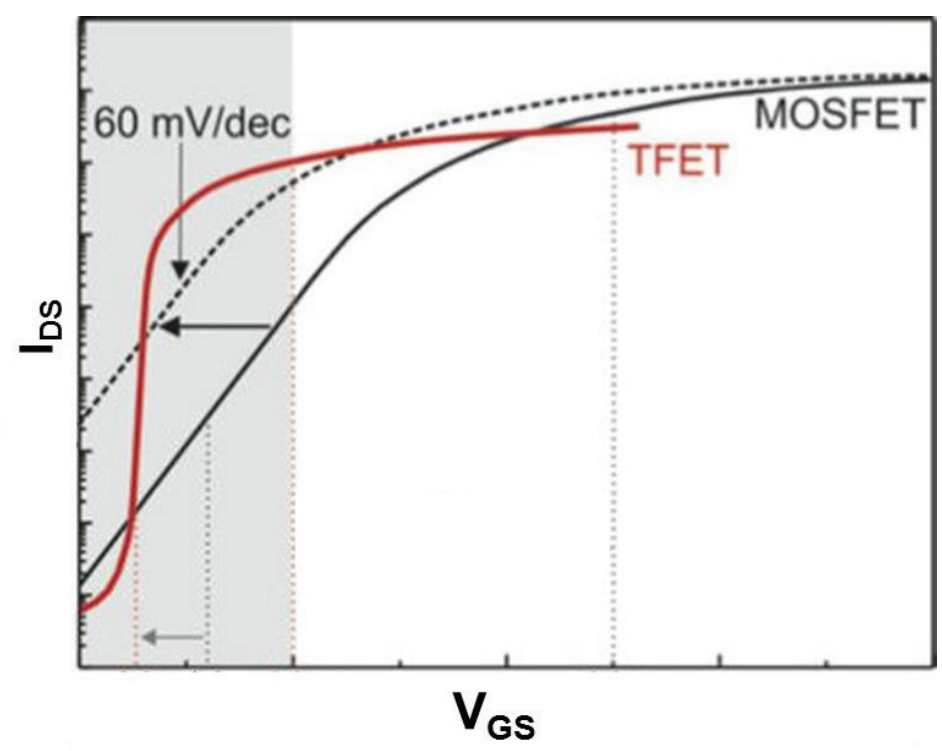

Fonte: IBM Research Zurich, 2013.

Para determinar valores teóricos de SS é necessário utilizar um modelo de corrente influenciado pela porta. A equação 2.11 mostra uma expressão da corrente de tunelamento simplificada (34).

$$
I=a \cdot V_{\text {eff }} \cdot \xi \cdot \exp \left(-\frac{b}{\xi}\right)
$$

onde a é um coeficiente determinado pela área da secção transversal do dispositivo, $\xi$ é a magnitude do campo elétrico $V_{\text {eff }}$ a tensão reversa aplicada à porta e b é um coeficiente determinado pelas propriedades do material.

Ao se aplicar a equação 2.11 na equação 2.10 obtemos a expressão de SS para os TFETs, a qual está mostrada na equação 2.12 .

$$
S S=\ln (10)\left[\frac{1}{V_{e f f}} \frac{d V_{e f f}}{d V_{G S}}+\frac{\xi+b}{\xi^{2}} \frac{d \xi}{d V_{G S}}\right]^{-1}
$$


Observa-se a partir desta equação que para se melhorar SS é preciso melhorar a relação $d V_{\text {eff }} / d V_{G S}$, através de aumento no acoplamento eletrostático, e melhorar também a relação $d \xi / d V_{G S}$, que pode ser melhorada através de melhor alinhamento entre o campo elétrico transversal e o campo da junção. Essas melhorias podem ser obtidas através do uso de novas geometrias (47).

\subsubsection{Transcondutância (gm)}

A transcondutância ( $\mathrm{gm}$ ) é um parâmetro muito importante de um dispositivo, o qual reflete o controle das cargas do canal pela tensão aplicada na porta do transistor. A transcondutância pode ser definida pela equação 2.13 (35).

$$
g m=\frac{d I_{D S}}{d\left(V_{G S}\right)}
$$

Ao contrário de um dispositivo MOSFET, cujo gm é degradado pelo campo elétrico para altos $V_{G S}$, o gm TFET não decai com o aumento de $V_{G s}$. Isso ocorre porque o mecanismo de condução do MOSFET é dependente da mobilidade $(\mu)$, a qual é degradada para altos campos elétricos transversais, diferentemente dos dispositivos TFET onde a corrente é gerada através de BTBT. Essa diferença de comportamento de gm entre os dispositivos pode ser observada na Figura 2.9.

Apesar de a transcondutância em TFETs, assim como em MOSFETs, ser dependente das dimensões do transistor, nos transistores TFET a transcondutância é diretamente dependente da área de tunelamento, enquanto nos MOSFETs é dependente da relação entre a largura e o comprimento (W/L). 
Figura 2.9 - Representação da transcondutância em um MOSFET e em um TFET.

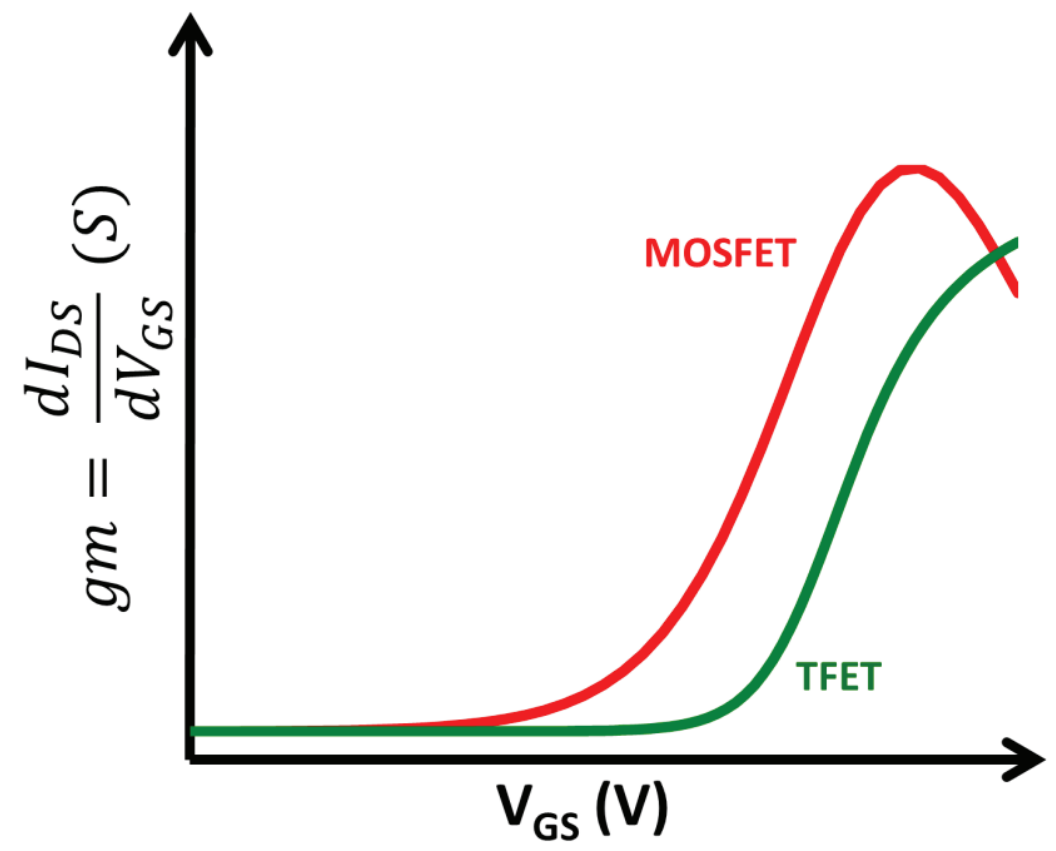

Fonte: Autor.

\subsubsection{Eficiência do transistor (gm/los)}

Eficiência é um parâmetro importante de um transistor, ele indica a capacidade de produzir ganho em um determinado nível de potência. A eficiência pode ser definida como a relação entre a transcondutância e a corrente de dreno $(\mathrm{gm} / \mathrm{l} \mathrm{D})(36)$.

A Figura 2.10 mostra a representação da eficiência em transistores TFET e MOSFET em função de lDs. Como pode ser observado na figura, para valores menores de IDS o dispositivo TFET apresenta uma eficiência maior que o MOSFET para baixos valores de lDs (Inversão fraca). A eficiência é muito dependente do inverso de SS e, como o TFET pode atingir valores de SS menores que o limite teórico mínimo (60 mV/dec) dos MOSFETs, acaba resultando em maior eficiência para TFETs. Entretanto, para valores maiores de lDs, esta tendência se inverte. Isso se deve à baixa corrente gerada por TFETs. 
Figura 2.10 - Representação da eficiência de transistores TFET e MOSFET em função de lDs.

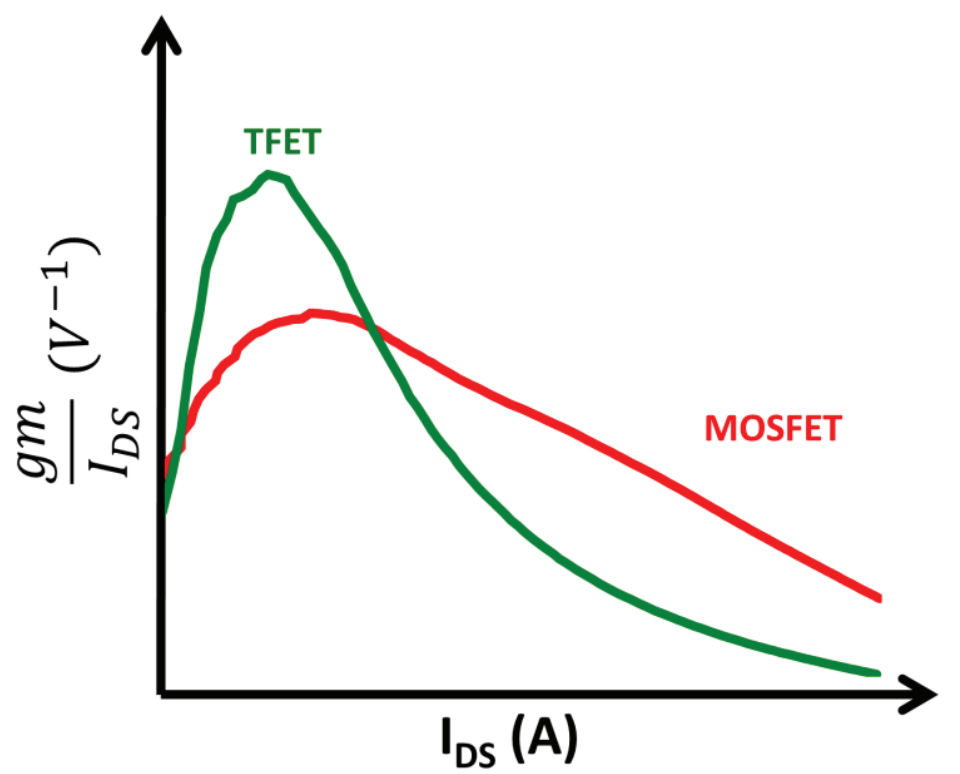

Fonte: Autor.

\subsubsection{Condutância de saída (gD)}

A condutância de saída (gD) é um parâmetro importante a ser analisado em transistores MOSFETs. Este parâmetro indica o quanto a saída do dispositivo é diretamente influenciada pelas resistências e capacitâncias parasitárias. A condutância de saída pode ser definida pela variação na corrente de dreno conforme se varia a tensão no dreno. Idealmente a corrente deveria ser mantida constante na região de saturação mesmo com a variação da tensão de dreno (VDS) (38). A equação (2.14) indica esta variação.

$$
g_{D}=\frac{d I_{D S}}{d\left(V_{D S}\right)}
$$

O transistor TFET possui menor variação de IDS com a variação de VDS quando comparado a um transistor MOSFET, pois o tunelamento ocorre somente na junção fonte/canal, dificultando a influência do potencial de dreno em IDS para um $V_{G S}$ constante.

\subsubsection{Tensão Early (}

Em transistores MOSFET, o efeito Early (conceito adaptado dos transistores bipolares de junção) representa o efeito de modulação de canal conforme VDS é 
aumentado. À medida que se aumenta $\bigvee_{D S}$, a região de depleção gerada na junção canal/dreno aumenta, gerando diminuição no comprimento efetivo de canal, resultando em um aumento em lDs. A tensão Early ( $\left.V_{E A}\right)$ é um parâmetro que, da mesma forma que gD, quantifica a influência de $V_{D S}$ em IDs, porém inversamente proporcional, obtendo-se valores menores de $V_{E A}$ (mais negativos) quando $O$ dispositivo possui pouca influência de $V_{D S}(6)$, (38).

Pode-se extrair o $V_{E A}$ através da curva de lDs em função de $V_{D S}$, extrapolando a parte linear da curva até o ponto de corrente nula. O ponto de $V_{D S}$ onde a corrente é nula nesta extrapolação é $V_{E A}$, como pode ser observado na Figura 2.11.

Figura 2.11 - Representação da extração de $V_{E A}$ em uma curva los em função de VDS.

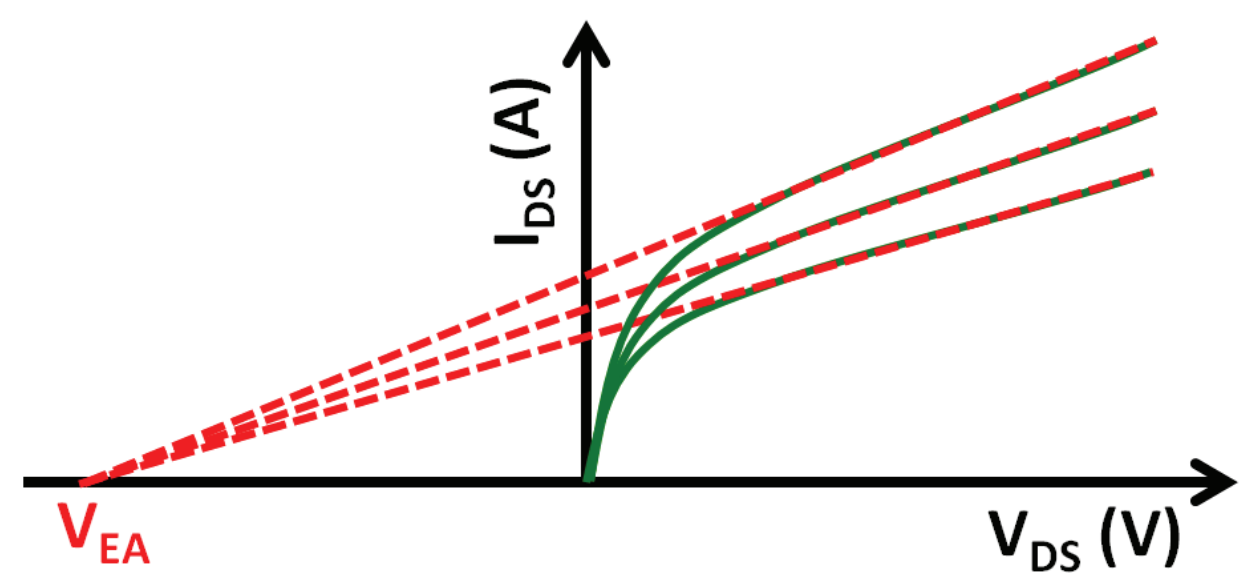

Fonte: Autor.

Transistores TFET apresentam algo semelhante à modulação de canal, onde o aumento de VDS acarreta apenas na deformação das bandas de energia no canal, e como o tunelamento somente ocorre próximo a fonte, gera pouca influência em IDS, resultando em valores elevados de $V_{E A}$ (36). Devido a isso $V_{E A}$ é alto em TFETs mesmo possuindo níveis mais baixos de corrente. 


\subsubsection{Ganho Intrínseco de Tensão (Av)}

Ganho intrínseco de tensão (Av) é um dos principais parâmetros analógicos de um transistor. O conceito do ganho intrínseco de tensão se dá ao calcular o ganho de um amplificador formado apenas pelo próprio transistor. O cálculo deste ganho pode ser feito através da equação 2.15 (35).

$$
A_{V} \cong-\frac{g m}{g_{D}}
$$

Através desta equação é possível notar que o $A_{v}$ relaciona efetividade do controle de corrente, considerando também a resistência de saída.

Outra forma de calcular Av é através da eficiência do transistor, que quando multiplicada por $V_{E A}$ tem como resultado Av. Observe essa relação na equação 2.16.

$$
A_{V} \cong-\frac{g m}{I_{D S}} \cdot V_{E A}
$$

Através destas duas expressões é possível notar que quanto maior o controle da porta sobre a corrente e quanto menor for a influência do dreno, maior será o ganho do dispositivo, tanto para MOSFETs, quanto para TFETs.

\subsubsection{Ponto invariante com a temperatura (ZTC)}

Dispositivos MOSFETs, possuem uma característica interessante em diferentes temperaturas, eles apresentam um ponto invariante com a temperatura (ZTC), como pode ser visto na Figura 2.12. Esse fenômeno ocorre devido a dois fatores causados pela variação da temperatura, o aumento de loff e a redução de loN causada pela degradação da mobilidade (39).

Entretanto, em dispositivos TFET este efeito não ocorre. Em TFETs todos os mecanismos de condução, BTBT, TAT e SRH, aumentam com o aumento da temperatura. Assim, a curva inteira é deslocada no sentido positivo da corrente (Figura 2.12), mesmo a região dominada por BTBT (maior $V_{G S}$ ) sendo menos influenciada pela temperatura. 
Figura 2.12 - Representação de IDs variando com a temperatura em um MOSFET, com o aparecimento do ZTC, e em um TFET, sem a presença de ZTC.

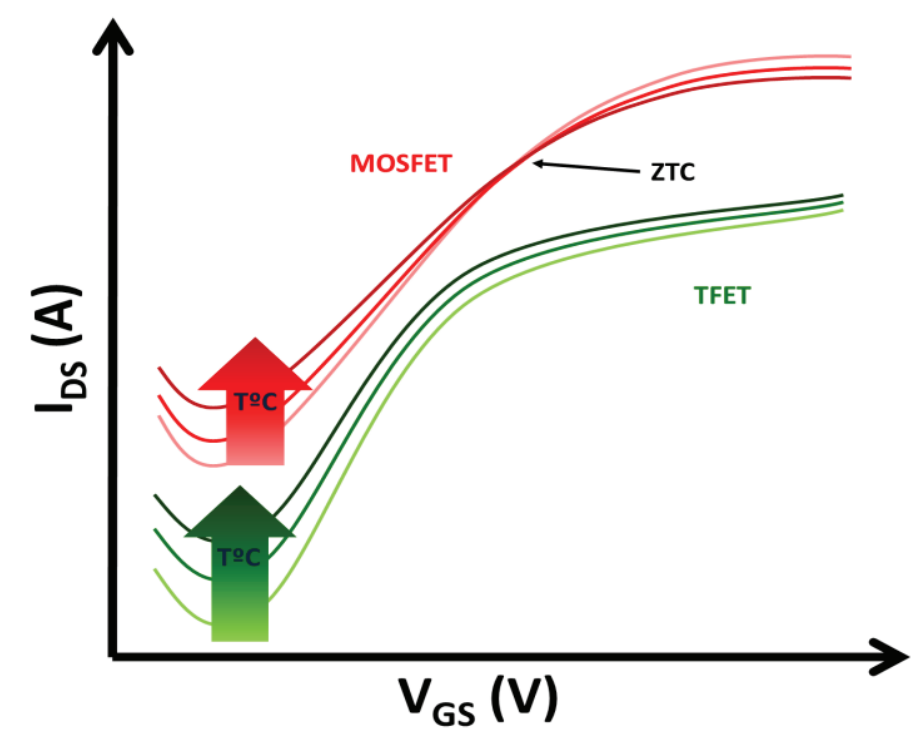

Fonte: Autor.

\subsection{Evolução da Tecnologia}

A evolução da tecnologia é necessária para conseguir diminuir as dimensões dos dispositivos, minimizando efeitos parasitários. Assim como houve muitas melhorias estudadas para problemas dos transistores MOSFETs, em transistores TFET algumas melhorias tem sido propostas, como a subposição de porta, uso de diferentes materiais na fonte e no dielétrico de porta, além de novas estruturas e geometrias para otimizar o seu comportamento.

\subsubsection{Underlap de porta na junção canal/dreno}

Um problema muito comum em transistores TFET é efeito ambipolar, o qual é causado pelo tunelamento de elétrons entre o canal e o dreno (Figura 2.13 (a)). Este efeito é indesejado, pois faz com que o transistor continue conduzindo corrente elétrica quando aplicada uma tensão oposta à $V_{\text {ON }}$ na porta (Tensões negativas para nTFET e positivas pra pTFET), causando um aumento da corrente lofF nestes transistores (40). 
Figura 2.13 - Diagrama de faixas de energia para um nTFET sem (a) e com (b) underlap de porta na junção canal/dreno polarizado com $V_{G S}$ negativo e suas respectivas curvas IDVG.
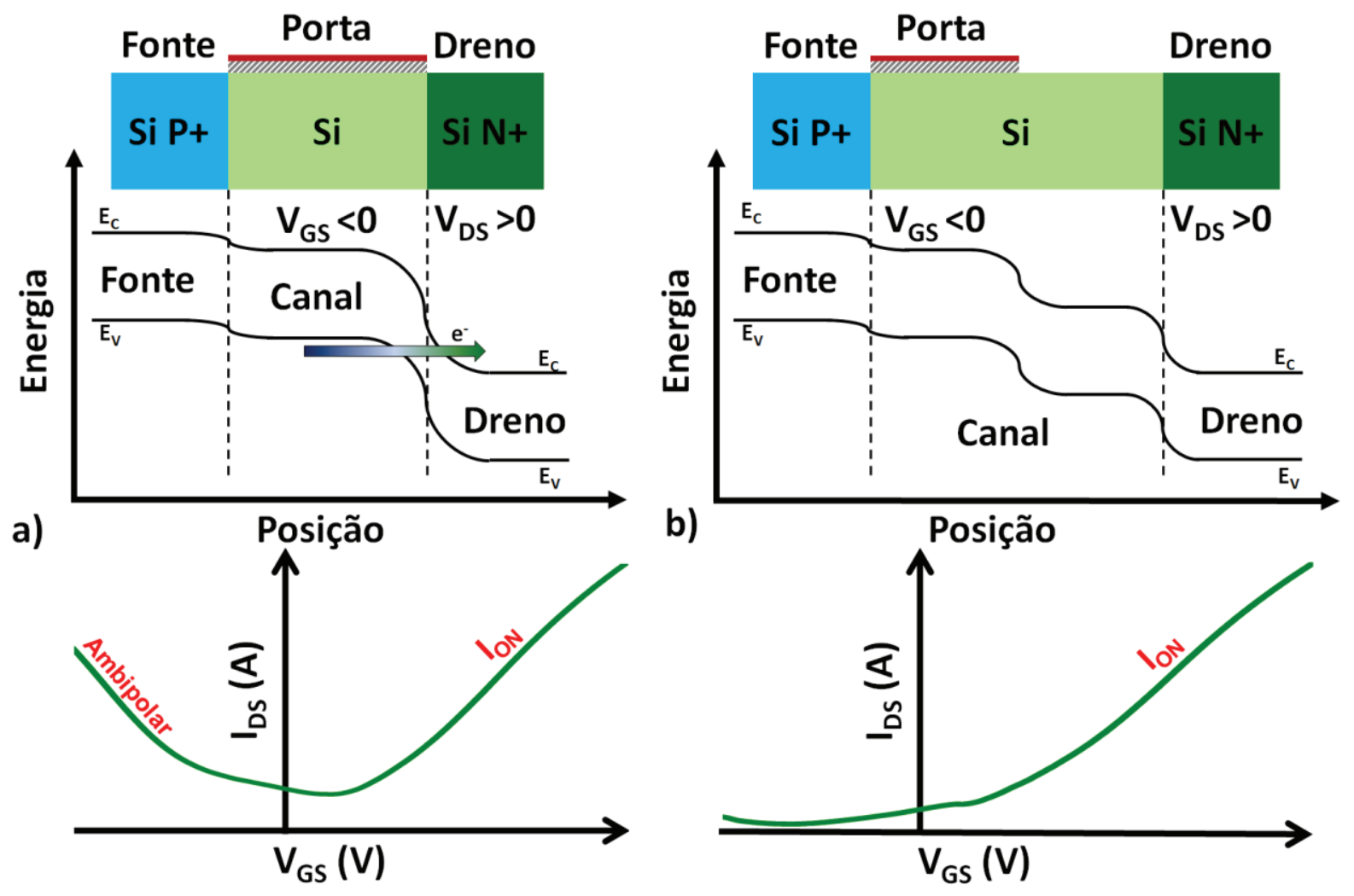

Fonte: Autor.

Uma solução que vem sendo estudada para este problema é o uso de underlap de porta na junção canal/dreno. Underlap é uma região no canal onde há uma influência muito menor da porta, o que dificulta o tunelamento de elétrons indesejável entre o canal e o dreno, como pode ser visto na Figura 2.13 (b).

\subsubsection{Uso de diferentes materiais}

Além do efeito ambipolar, outro grande problema da tecnologia TFET é a baixa corrente no estado ligado. Como lon é dependente do tunelamento entre bandas na junção fonte/canal (sobreposição da banda de valência da fonte com a banda de condução do canal), uma forma de se aumentar este tunelamento é aumentar a sobreposição de bandas, isto é, aumentar a energia entre a banda de energia de valência da fonte e a banda de energia de condução do canal. Esse aumento da sobreposição de bandas resulta em um menor comprimento de tunelamento, o que facilita o tunelamento entre bandas (37). 
Uma das soluções que tem sido bastante estudada para se aumentar essa sobreposição de bandas é a utilização de novos materiais. Como cada material possui um valor diferente de energia da banda proibida, pode se obter uma maior sobreposição de bandas usando materiais com menor banda proibida. Um dos materiais semicondutores mais utilizados é o Germânio $(\mathrm{Ge})$ que possui energia da banda proibida de $0,661 \mathrm{eV}$.

Apesar de o uso de novos materiais melhorarem a parcela de BTBT da corrente, esta técnica também aumenta o número de defeitos na interface dielétrico/semicondutor, aumentando a corrente gerada por TAT e, portanto, degradando a região de sublimiar (37). Outra solução encontrada é o uso de heteroestruturas (estruturas compostas por diferentes materiais na fonte, no dreno e no canal), como pode ser observado na Figura 2.14.

Como o BTBT ocorre na junção fonte/canal, é possível usar novos materiais apenas nas fontes, mantendo toda a estrutura do canal de Si, o qual já é bem conhecido e desenvolvido, além de ter boa interface com $\mathrm{SiO}_{2}$. Desta forma o uso de heteroestruturas reduz a influência do TAT quando comparado ao uso de novos materiais usando homoestruturas (estrutura composta por apenas um material na fonte, no dreno e no canal).

Figura 2.14 - Diagrama de faixas de energia para um nTFET com fonte de Germânio polarizado com VGs negativo.

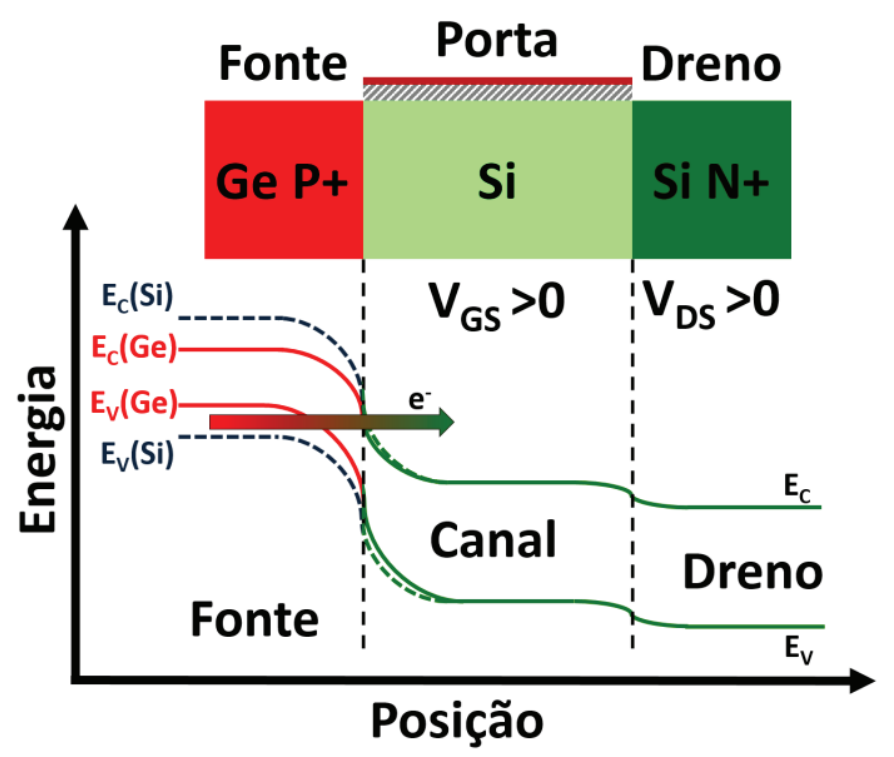

Fonte: Autor. 


\subsubsection{Materiais de alta constante dielétrica}

Para ajudar a minimizar os efeitos de canal curto em transistores MOSFETs faz-se necessário aumentar ainda mais o controle eletrostático das cargas. Em dispositivos TFETs o controle eletrostático também é importante, pois aumenta o efeito da tensão na modulação das bandas do canal, resultando em uma maior sobreposição de bandas. Este controle eletrostático pode ser modelado proporcionalmente conforme a equação 2.17 .

$$
\text { Controle Eletrostático } \propto \frac{\mathrm{n} \cdot \varepsilon_{o x}}{\varepsilon_{s i}} \cdot \frac{1}{t_{s i} \cdot t_{o x}}
$$

onde n é o número de portas, tsi é a espessura do silício, tox é a espessura do óxido de porta, $\varepsilon_{\text {si }}$ a constante dielétrica do silício e $\varepsilon_{o x}$ a constante dielétrica do óxido de porta.

Para se aumentar o controle eletrostático das cargas é necessário ou diminuir $t_{s i}$ ou tox ou aumentar $\varepsilon_{\text {ox }}$. Como há limites para se diminuir tsi (difícil realização de processo de fabricação) e tox (aumento da corrente de fuga pela porta) a única alternativa viável é o aumento da constante dielétrica $\varepsilon_{o x}$.

Com materiais que possuem altas constantes dielétricas, dielétricos de porta mais espessos podem ser utilizados, tornando o dispositivo menos susceptíveis às correntes de fuga pela porta e ainda assim aumentar o desempenho do dispositivo. Com o intuito de facilitar os cálculos, como nas equações de corrente ou tensão de limiar, é utilizado um parâmetro que indica qual seria a espessura de óxido equivalente (EOT) se fosse utilizado $\mathrm{SiO}_{2}$ na porta do dispositivo, como é definido (41) na equação 2.18 .

$$
C_{o x}=\frac{\varepsilon_{o x}}{E O T}=\frac{\varepsilon_{h i g h-k}}{t_{h i g h-k}}
$$

Para evitar um número excessivo de armadilhas de interface, o que resultaria em uma piora no desempenho causado pelo aumento da condução por TAT, evita-se colocar diretamente o material de alta constante dielétrica em contato com o canal de silício. Para melhorar a qualidade da interface é primeiramente produzida uma 
camada pelicular interfacial de $\mathrm{SiO}_{2}$, para então ser depositada sobre esta camada o óxido de alta constante dielétrica (42).

Entretanto, a constante dielétrica não é o único parâmetro que aumenta a corrente de fuga pela porta. Outro fator que deve ser considerado é a largura da banda proibida de energia, ou seja, o material que deve substituir o $\mathrm{SiO}_{2}$ não deve só apresentar alta constante dielétrica como também deve apresentar uma grande largura da banda proibida de energia (43),(44).

Materiais como óxido de háfnio e zircônio têm sido bastante estudados pois além de apresentarem uma constante dielétrica maior, apresentam também uma grande largura da banda proibida de energia, comparada ao do óxido de silício, e uma boa estabilidade termodinâmica com o silício (45),(46).

\subsubsection{Diferentes estruturas}

Como a estrutura de um TFET é bem similar à de um MOSFET, divergindo apenas na dopagem da fonte, pode-se utilizar qualquer tipo de estrutura MOSFET (47) com a dopagem de fonte invertida para se construir um TFET. Pode-se construir TFET em uma estrutura SOI, em estrutura FinFET ou mesmo em estruturas nanofios.

A grande vantagem do uso de nanofios é o maior acoplamento eletrostático, o qual garante uma maior sobreposição entre bandas no canal (na junção fonte/canal), onde se suficientemente acoplado pode até gerar BTBT em toda junção fonte/canal, gerando assim um aumento significativo na corrente e uma melhoria nas características de sublimiar (48).

A Figura 2.15 mostra alguns exemplos de estruturas de TFETs. 
Figura 2.15 - Exemplos de estruturas de múltiplas portas.

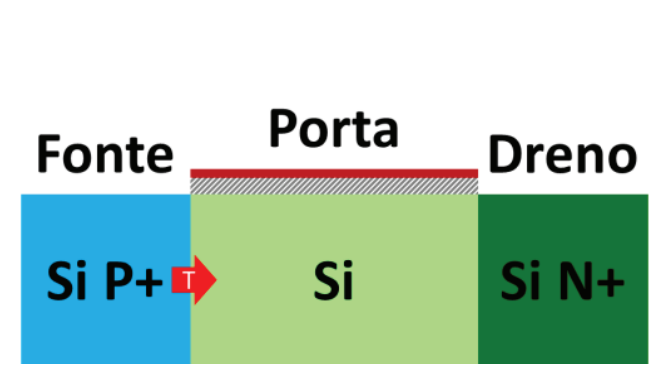

a) Planar

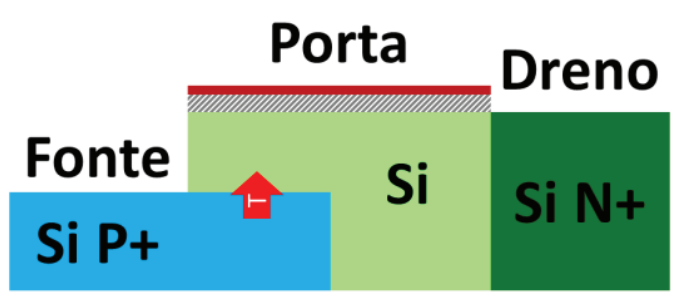

c) Line TFET

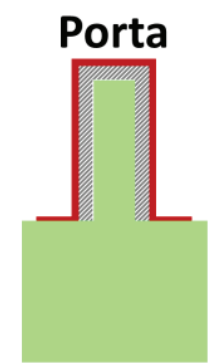

\section{Substrato}

b) Porta Tripla (FinFET)

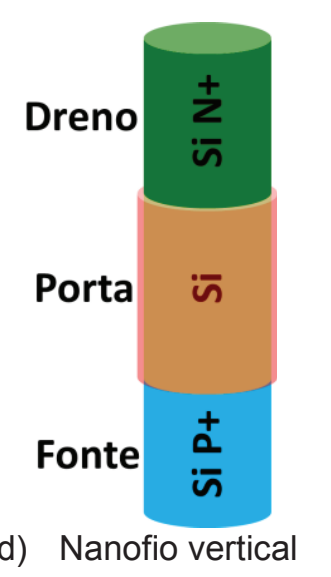

Fonte: Autor 


\section{DISPOSITIVOS EXPERIMENTAIS E SIMULAÇÕES}

Neste capítulo serão descritos os dispositivos experimentais utilizados, os equipamentos e métodos de caracterização elétrica. Também serão descritos os dispositivos simulados e seus parâmetros de ajuste.

\subsection{TFETs com estruturas de nanofios}

\subsubsection{Dispositivos TFETs com estruturas de nanofios experimentais}

Neste trabalho, um dos dispositivos estudados são TFET em estruturas de múltiplos nanofios (nanowire) verticais, fabricados no IMEC, na Bélgica. A Figura 3.1 mostra uma representação da estrutura do dispositivo utilizado, indicando as principais dimensões do TFET utilizado (49).

Figura 3.1 - Representação estrutural de um NW-TFET indicando suas dimensões.

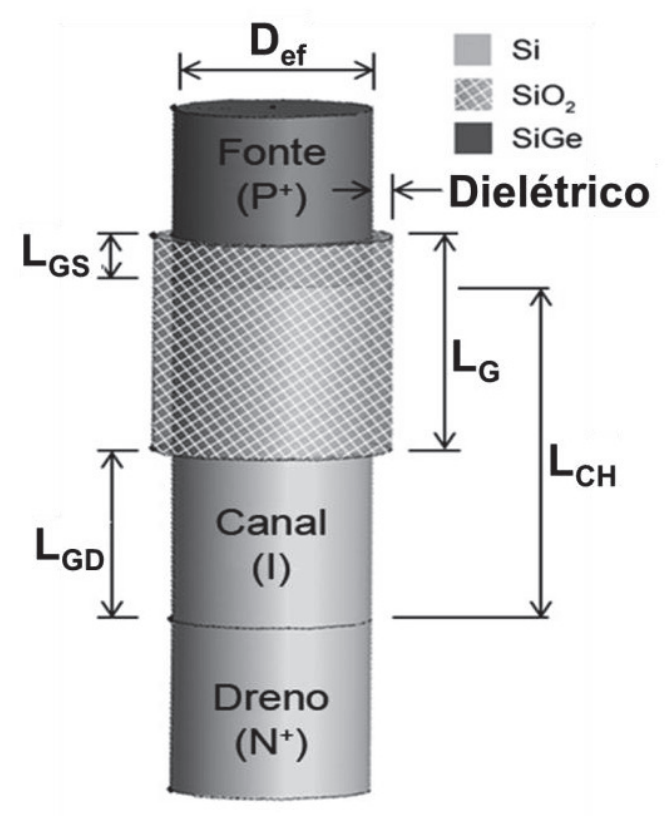

Fonte: (49).

Os transistores TFETs foram fabricados usando um processo descrito em (50), e possuem as seguintes dimensões: Comprimento total de canal ( $\left.\mathrm{LCH}_{\mathrm{c}}\right)$ de $220 \mathrm{~nm}$, comprimento de porta ( $\left.L_{G}\right)$ de $150 \mathrm{~nm}$, sobreposição de porta sobre a fonte (LGs) de $30 \mathrm{~nm}$ e um underlap entre a porta e o dreno (LGD) de $100 \mathrm{~nm}$, para evitar o efeito 
ambipolar. Neste estudo foram estudados dispositivos com diferentes diâmetros efetivos (Def), cujos valores variam entre $50 \mathrm{~nm}$ e $167 \mathrm{~nm}$.

A fonte dos dispositivos é dopada com $2 \times 10^{19} \mathrm{at} / \mathrm{cm}^{3}$ de boro, o canal é dopado com $1 \times 10^{16} \mathrm{at} / \mathrm{cm}^{3}$ de arsênico e o dreno é dopado com $2 \times 10^{19} \mathrm{at} / \mathrm{cm}^{3}$ de arsênico. $O$ dielétrico de porta destes dispositivos é constituído de $3 \mathrm{~nm}$ de $\mathrm{HfO}_{2}$ sobre $1 \mathrm{~nm}$ de $\mathrm{SiO}_{2}$, resultando em uma espessura de óxido equivalente (EOT) de $2 \mathrm{~nm}$. O material de porta é composto por TiN e a-Si. Neste estudo foram utilizados três materiais de fonte diferentes, uma fonte de silício puro, outra com uma liga formada por $73 \%$ de silício e 27 \% de germânio $\left(\mathrm{Si}_{0,73} \mathrm{Ge}_{0,27}\right)$ e a última com fonte de germânio puro (50). Neste último, foi utilizado também um dispositivo com redução da espessura de $\mathrm{HfO}_{2}$, de $3 \mathrm{~nm}$ para $2 \mathrm{~nm}$.

Toda a caracterização elétrica destes dispositivos foi realizada utilizando um analisador de parâmetros de semicondutores Agilent B1500, localizado no Laboratório de Sistemas Integrados (LSI) da Escola Politécnica da Universidade de São Paulo.

As curvas de corrente por tensão (curva I-V), que são essenciais para a extração de muitos parâmetros de semicondutores, foram geradas através do B1500, utilizando de três terminais de alta resolução (HR-SMU), um deles ligado à porta e outro ligado à fonte através de pontas de provas e o último é ligado ao dreno (substrato) através do chuck do microprovador.

Devido à baixa corrente fornecida por dispositivos TFET, foi necessário configurar o analisador B1500 com precisão máxima em 10 pA (menor valor de corrente configurável) e com um tempo de integração muito longo (média de aproximadamente 10000 medidas para cada ponto extraído), para evitar ruídos que pudessem atrapalhar a medida.

\subsubsection{Dispositivos TFETs com estruturas de nanofios simulados}

Com o intuito de extrapolar o comportamento dos TFETs para dispositivos com diâmetros menores que $87 \mathrm{~nm}$ foram feitas simulações numéricas utilizando o simulador Atlas, da Silvaco (26). Para isso é necessário primeiramente calibrar os parâmetros dos modelos de modo a ajustar a curva do dispositivo simulado à curva obtida experimentalmente. 
Os principais modelos utilizados nas simulações deste trabalho são apresentados a seguir:

Modelo de Mobilidade de Shirahata (SHI) - Shirahata Mobility Model: Modelo de mobilidade que considera efeitos de espalhamento na interface óxido/silício e degradação pelo campo elétrico transversal.

Modelo de Dependência do Campo Elétrico Paralelo (FLDMOB) - Parallel Electric Field Dependence: Modelo de mobilidade que complementa outros modelos de mobilidade para altos valores de campo elétrico (26), em que os elétrons já atingiram a velocidade de saturação causando a não proporcionalidade da mobilidade com o campo elétrico.

Modelo de estreitamento da largura da banda proibida de energia (BGN) Bandgap Narrowing: Modelo de estreitamento da largura da banda proibida de energia que considera a dopagem e a temperatura do semicondutor (52).

Modelo de Geração e Recombinação (SRH) - Schockley-Read-Hall Recombination: Modelo que considera o processo de geração e recombinação SRH (23), descrito no item 2.2.1 e equacionado no simulador através da equação 3.1. Os parâmetros de ajuste TAUNO e TAUP0, que são respectivamente os tempos de vida dos elétrons e das lacunas, são utilizados para a calibração da curva simulada em relação à curva experimental.

$$
R_{S R H}=\frac{p n-n_{i e}^{2}}{T A U P 0\left[n+n_{i e} \exp \left(\frac{E T R A P}{k T_{L}}\right)\right]+T A U N 0\left[p+n_{i e} \exp \left(\frac{-E T R A P}{k T_{L}}\right)\right]}
$$

Modelo de Tunelamento Induzido por Armadilhas (Trap.tunnel) - Trap-Assisted Tunneling: Modelo de TAT, que é introduzido junto do modelo SRH através da equação 3.1, conforme mostrado no item 2.2.2.1. Para calibrar a curva simulada utiliza-se como parâmetro de ajuste a concentração de cargas na interface do óxido.

Modelo de tunelamento de Kane (BBT.KANE) - Kane Band-To-Band Tunneling Model: O modelo de tunelamento entre bandas proposto por Kane (59) é equacionado no simulador através da equação 3.2. Os parâmetros de ajuste BBT.A_KANE e 
BBT.B_KANE, que são os parâmetros pré-exponencial e exponencial, respectivamente, são utilizados para a calibração da curva simulada. Este modelo tem como padrão o uso Local do seu modelo, o qual não considera a variação espacial das bandas de energia. O modelo utilizado considera a variação espacial das bandas de energia, utilizando o comando BBT;NONLOCAL.

$$
G_{B B T}=\frac{D \quad B B T \cdot A_{-} K A N E}{\sqrt{E_{g}}} F^{B B T \cdot G A M M A} \exp \left(-B B T . B \_K A N E \frac{E_{g}^{3 / 2}}{F}\right)
$$

A fim de analisar a influência de cada parâmetro de ajuste do modelo, analisouse cada um deles separadamente, variando-se seu valor enquanto os outros eram mantidos constantes. Através da observação de seu efeito no comportamento do dispositivo simulado, foi possível escolher uma combinação de valores para esses parâmetros que resultasse em uma curva simulada ajustada em relação à experimental.

A partir da simulação foram gerados TFETs semelhantes aos experimentais, e extrapolados para diâmetros variando entre $15 \mathrm{~nm}$ e $110 \mathrm{~nm}$. 


\subsection{TFETs Planares com Uso de Materiais III-V}

\subsubsection{Dispositivos TFETs Planares Experimentais}

Neste trabalho, também foram estudados dispositivos nTFET em estruturas planares, fabricados no IMEC. Dois dispositivos com a mesma estrutura foram fabricados com materiais de canal diferentes. Um dispositivo é composto de um homojunção de $\ln _{0,53} \mathrm{Ga}_{0,47} \mathrm{As}$. O outro é composto da mesma homojunção de In ${ }_{0,53} \mathrm{Ga}_{0,47} \mathrm{As}$, porém, com uma camada de $8 \mathrm{~nm}$ de $\ln _{0,7} \mathrm{Ga}_{0,3} \mathrm{As}_{\mathrm{s}}$ depositada sobre a mesma. A Figura 3.2 (A) e (B) mostram as representações das estruturas do dispositivo de $\ln _{0,53} \mathrm{Ga}_{0,47} \mathrm{As}$ e In $\mathrm{n}_{0,7} \mathrm{Ga}_{0,3} \mathrm{As}$, respectivamente. Estas estruturas seguem a abordagem introduzida pela Universidade de Tóquio(53),(54) no Japão, e foram otimizadas no IMEC (55),(56).

Figura 3.2 - Representação estrutural do TFET de $\ln _{0,53} \mathrm{Ga}_{0,47} \mathrm{As}(\mathrm{A})$ e de $\ln _{0,7} \mathrm{Ga}_{0,3} \mathrm{As}$ (B) e suas dimensões.

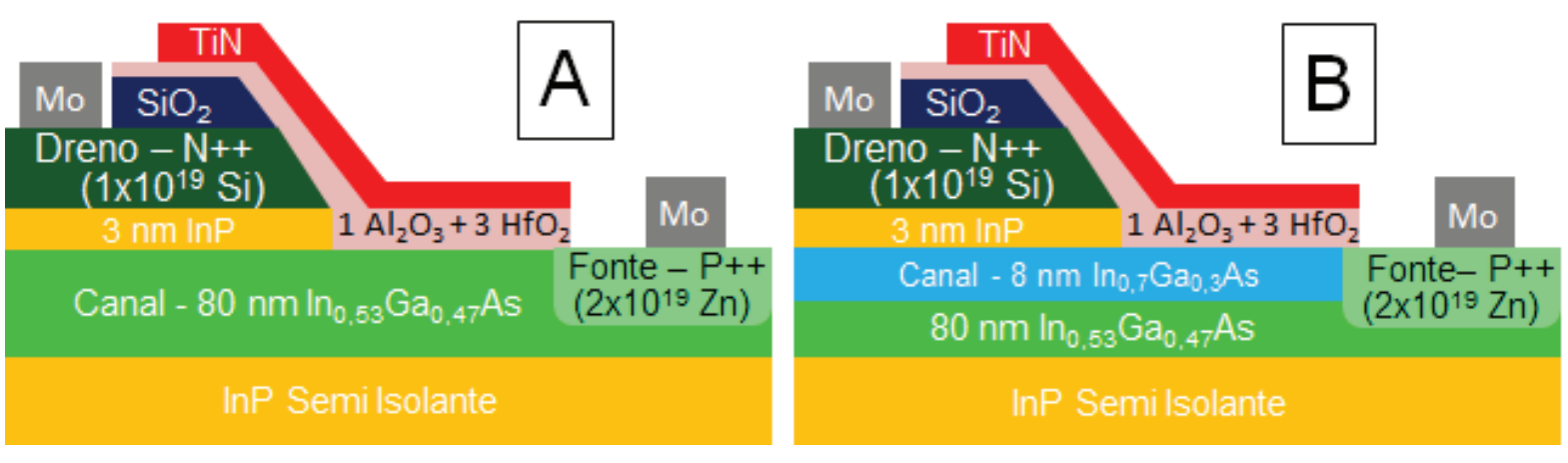

Fonte: Author.

O dielétrico de porta é composto por $3 \mathrm{~nm}$ de $\mathrm{HfO}_{2}$ depositado sobre $1 \mathrm{~nm}$ de $\mathrm{Al}_{2} \mathrm{O}_{3}$, com TiN como metal de porta. O dreno é dopado com $1 \times 10^{19} \mathrm{~cm}^{-3}$ de $\mathrm{Si}(\mathrm{N}++)$ utilizando dopagem in situ durante o crescimento molecular epitaxial (MBE). O canal é dopado com a dopagem natural da lâmina. A fonte é dopada com $2 \times 10^{19} \mathrm{~cm}^{-3} \mathrm{de} \mathrm{Zn}$ $(\mathrm{P}++)$ utilizando dois diferentes processos.

No primeiro processo, a difusão de Zn é realizada com uso de fonte gasosa, utilizando a mesma temperatura de $500^{\circ} \mathrm{C}$ por 60 segundos (55). Este processo foi utilizado nos dispositivos estudados no item 4.2.1. Nesta item foi também utilizada uma variação deste primeiro processo, onde a temperatura de difusão foi elevada para $520^{\circ} \mathrm{C}$, pelo mesmo tempo de 60 segundos. 
No segundo processo, a difusão de Zn é feita utilizando fonte sólida utilizando a técnica de spin on glass à temperatura de $500^{\circ} \mathrm{C}$ por 60 segundos (56). Este processo foi utilizado nos dispositivos estudados no item 4.2.2. Neste item foi utilizada também uma variação do dispositivo inicial, com uma redução da espessura de $\mathrm{HfO}_{2}$, de $3 \mathrm{~nm}$ para $2 \mathrm{~nm}$.

O item 4.2.3 mostra uma comparação entre o efeito destes dois processos nos TFETs estudados.

Estes dispositivos utilizam um leiaute de anel com a largura total de $400 \mu \mathrm{m}$ e comprimento de $5 \mu \mathrm{m}$, conforme a Figura 3.3 .

Figura 3.3 - Representação do leiaute do TFET de InGaAs (A) e foto vista de cima do dispositivo (B).

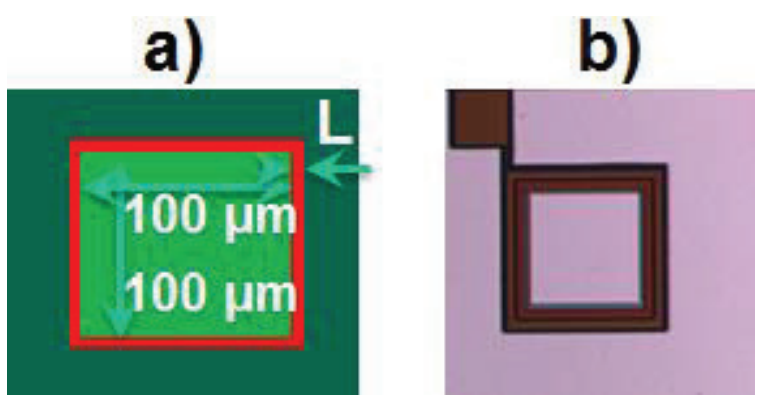

Fonte: Author.

A caracterização elétrica destes dispositivos foi realizada no laboratório de caracterização elétrica do IMEC (AMSIMEC), onde dois sistemas deste laboratório foram utilizados.

No primeiro sistema, a caracterização elétrica dos dispositivos estudados foi realizada utilizando um analisador de parâmetros de semicondutores Agilent B1500. Neste sistema há um microprovador que pode variar a temperatura em seu interior de $-40{ }^{\circ} \mathrm{C}(233 \mathrm{~K})$ a $200{ }^{\circ} \mathrm{C}(473 \mathrm{~K})$.

No segundo sistema, a caracterização elétrica dos dispositivos estudados foi realizada utilizando um analisador de parâmetros de semicondutores HP 4156A. Este segundo é um sistema criogênico a vácuo micromanipulado Lakeshore CPX, o qual pode variar a temperatura em seu interior de $27^{\circ} \mathrm{C}(300 \mathrm{~K})$ a $-269^{\circ} \mathrm{C}(4 \mathrm{~K})$. 
As curvas de corrente por tensão, usadas para a extração de muitos parâmetros de semicondutores, que foram geradas através do B1500 e do HP 4156A, utilizam três terminais de alta resolução (HR-SMU), um deles ligado à porta, um deles ligado ao dreno e outro ligado à fonte através de pontas de provas. Como o substrato destes dispositivos são semi isolantes, a ligação do substrato nestes dispositivos deve ser flutuante, para evitar correntes parasitas entre o dreno e o substrato.

\subsubsection{Dispositivos TFETs Planares Simulados}

Com o intuito de entender melhor alguns efeitos observados nos nTFETs com o canal uniforme de $\ln _{0,53} \mathrm{Ga}_{0,47} \mathrm{As}$ (Figura 3.2(A)), apresentados o item 3.2.1, foram feitas simulações numéricas utilizando o simulador Sentaurus, da Synopsys (57). Foram considerados os modelos de SRH dependente da dopagem, o modelo de SRH não local de Schenck (Simulação de TAT), o modelo de BTBT não local e o modelo de estreitamento da banda proibida. Os parâmetros iniciais obtidos para a calibração destes modelos foram obtidos em (58).

Modelo de estreitamento da largura da banda proibida de energia - BandGap Narrowing: Modelo de estreitamento da largura da banda proibida de energia que considera a dopagem e a temperatura do semicondutor.

Modelo de Geração e Recombinação (SRH) - Schockley-Read-Hall Recombination: Modelo que considera o processo de geração e recombinação $\mathrm{SRH}$ (23), descrito no item 2.2.1. Os parâmetros de ajuste taun e taup, que são respectivamente os tempos de vida dos elétrons e das lacunas, são utilizados para a calibração da curva simulada em relação à curva experimental. Foi utilizado com o sub modelo, DopingDep, que considera o efeito da concentração de dopantes. Na

simulação de TAT, foi acrescentado também 0 sub modelo NonLocal(Lifetime=Schenck), que considera o efeito da variação espacial das bandas de energia.

Modelo de Tunelamento entre bandas - Band2Band(Model=NonLocalPath): Modelo de tunelamento entre bandas, descrito no item 2.2.2.2, considerando a variação espacial das bandas de energia. 


\section{RESULTADOS OBTIDOS}

Neste capítulo é apresentada a análise de transistores TFETs experimentais e simulados, mostrados nas seções 3.1 e 3.2. Dentre os estudos realizados estão à análise do efeito do diâmetro e do aumento da temperatura nos parâmetros analógicos de transistores TFETs em estruturas de nanofios e a análise de diferentes materiais e processos em transistores TFET de InGaAs.

\subsection{TFETs com estruturas de nanofios}

Nesta seção são apresentados os estudos realizados da análise do efeito do diâmetro, do aumento da temperatura nos parâmetros analógicos e da composição de fonte de transistores TFETs de Si em estruturas de nanofios.

\subsubsection{Influência do diâmetro nos TFETs}

Devido à alta necessidade de escalamento de dispositivos faz-se necessário o estudo do efeito do diâmetro de TFETs fabricados em estruturas de nanofios. Nesta seção são analisados parâmetros analógicos como a transcondutância, condutância de saída, ganho intrínseco de tensão e eficiência, considerando também a condição de inversão do dispositivo.

Inicialmente é analisada a curva da corrente de dreno em função da tensão na porta para dois dispositivos com materiais de fontes diferentes, uma fonte de Si puro e outra de $\mathrm{Si}_{0,73} \mathrm{Ge}_{0,27}$, para diferentes valores efetivos de diâmetro (Figura 4.1).

Através destas curvas é possível notar que a corrente Ion do TFET com fonte de $\mathrm{Si}_{0,73} \mathrm{Ge}_{0,23}$ supera em mais de uma ordem de grandeza a do dispositivo com fonte de Si puro, pois a liga de $\mathrm{Si}_{0,73} \mathrm{Ge}_{0,23}$ possui menor largura da banda proibida, promovendo, no estado ligado, uma maior sobreposição de bandas entre a banda de valência da fonte e a banda de condução do dreno. Esta maior sobreposição de bandas leva à redução do comprimento de tunelamento, e consequentemente aumentando muito a corrente de tunelamento entre bandas do transistor (60). 
Figura 4.1 - Corrente de dreno experimental em função da tensão na porta do nTFET nanofio para diferentes diâmetros e composições de fonte.

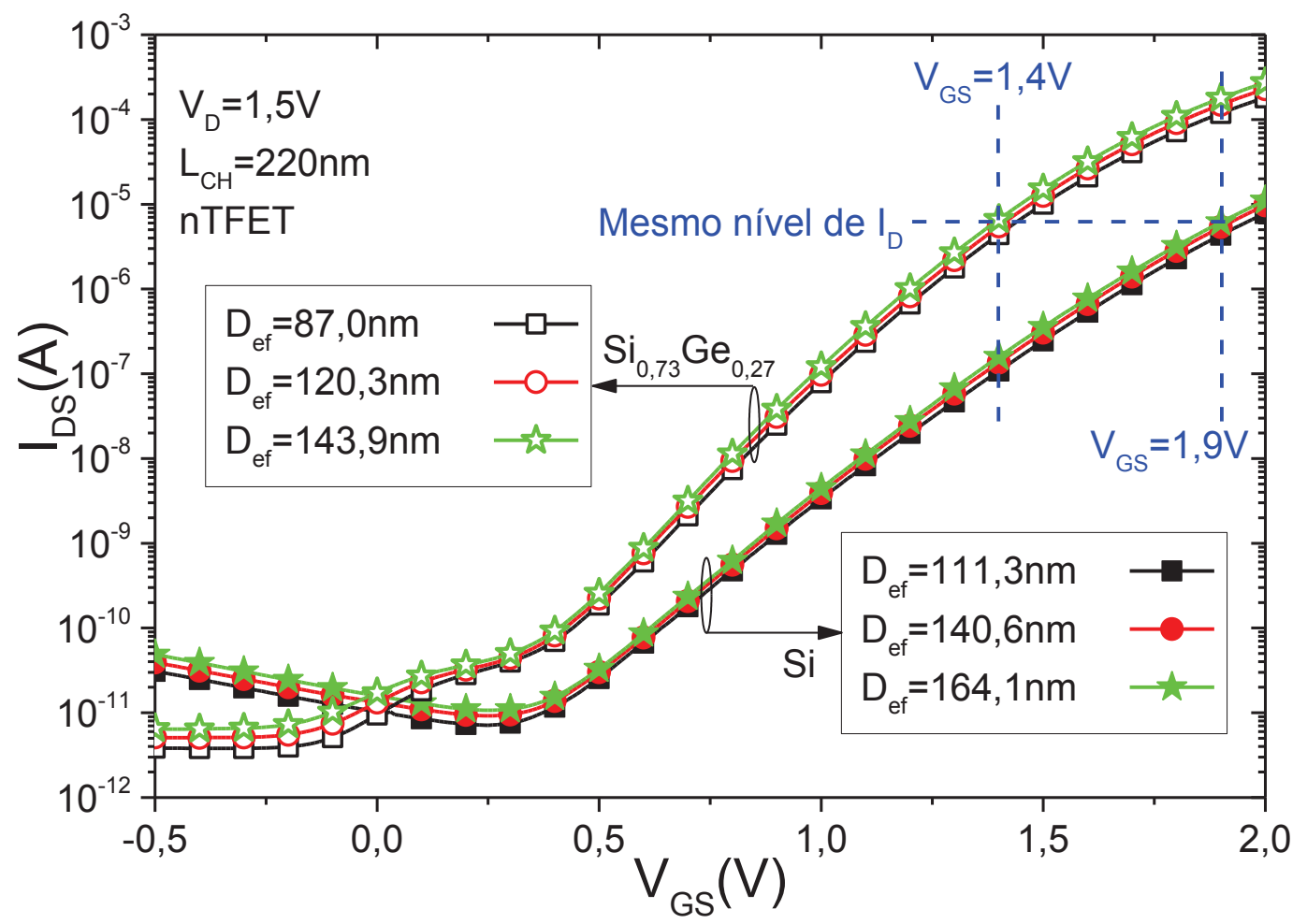

Fonte: Autor.

Para melhor entender os efeitos causados pela redução do diâmetro nos transistores TFET, os parâmetros analógicos descritos nas próximas curvas foram analisados em função do diâmetro efetivo. Para analisar esses efeitos foram considerados três métodos de comparação diferentes, como mostrado na Tabela 4-1.

Tabela 4-1 - Sumarização da polarização de porta usada para comparação entre os três métodos.

\begin{tabular}{|c|c|c|c|}
\hline Polarização de $\mathrm{V}_{\mathrm{G}}$ & $\begin{array}{c}1^{\circ} \text { Método } \\
\text { Mesmo Nível de } \mathrm{V}_{\mathrm{GS}}\end{array}$ & $\begin{array}{c}2^{\circ} \text { Método } \\
\text { Mecanismo de condução }\end{array}$ & $\begin{array}{c}3^{\circ} \text { Método } \\
\text { Mesmo nível de IDS }\end{array}$ \\
\hline $\mathrm{Si}$ & $1,9 \mathrm{~V}$ & $1,9 \mathrm{~V}$ & $1,9 \mathrm{~V}$ \\
\hline $\mathrm{Si}_{0,73} \mathrm{Ge}_{0,27}$ & $1,9 \mathrm{~V}$ & $1,56 \mathrm{~V}$ & $1,4 \mathrm{~V}$ \\
\hline
\end{tabular}

O primeiro método, o qual foi usado em (61), compara os dois dispositivos usando a mesma polarização de porta. A polarização de 1,9 V foi escolhida porque ambos os dispositivos possuem o BTBT como mecanismo dominante de condução de corrente. Nesta polarização, como pode ser observado na Figura 4.2, a energia de ativação nos dois dispositivos é próxima ou menor a $0,1 \mathrm{eV}$, portanto, conforme visto no item 2.4.1, possui o BTBT como mecanismo dominante de corrente. A energia de 
ativação foi obtida através da equação 2.9 , utilizando medidas de correntes realizadas em diferentes temperaturas para cada $V_{G s}$ utilizado.

Figura 4.2 - Energia de ativação para materiais com diferentes composições de fonte.

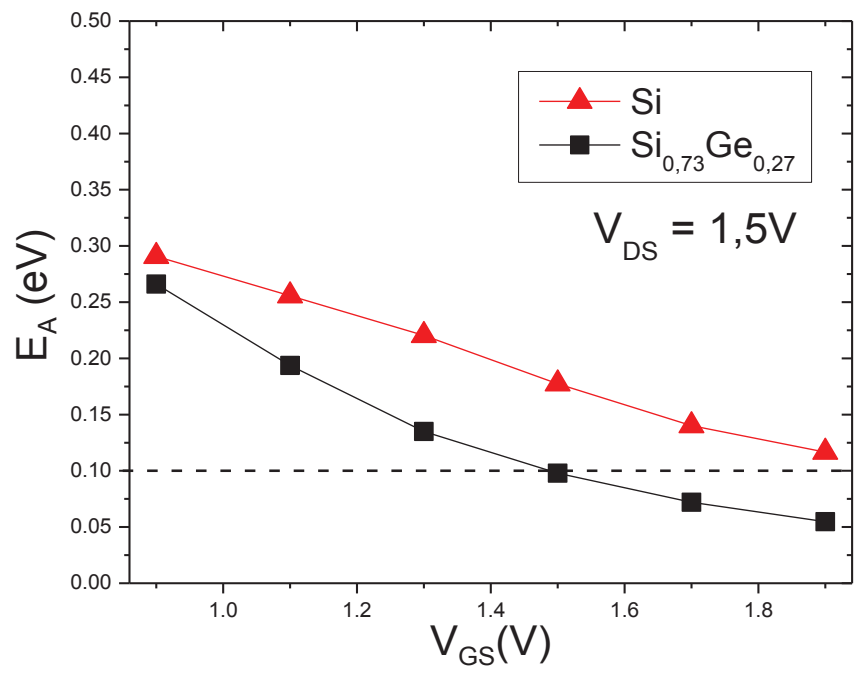

Fonte: (61).

O segundo método (62) se baseia na mínima polarização necessária para cada um dos dispositivos ter o BTBT como o mecanismo de transporte dominante na condução de corrente. Como pode ser visto na Figura 4.2, o dispositivo com fonte de Si ${ }_{0,73} \mathrm{Ge}_{0,23}$ atinge energia de ativação de $0,1 \mathrm{~V}$ com 1,56 $\mathrm{V}$ de polarização de porta. Já o dispositivo com a fonte de Si puro com junção abrupta possui uma energia de ativação próxima de $0,1 \mathrm{~V}$ apenas com a polarização de $1,9 \mathrm{~V}$ na porta.

O terceiro método compara os dois dispositivos em uma polarização de porta que faz com que ambos possuam a mesma corrente de dreno. Como pode ser visto na Figura 4.1, a corrente de dreno correspondente à polarização de $1,9 \mathrm{~V}$ no dispositivo de fonte de Si puro é $6 \times 10^{-6} \mathrm{~A}$. O dispositivo com fonte de $\mathrm{Si}_{0,73} \mathrm{Ge}_{0,23}$ atinge este nível de los quando polarizado com 1,4 V na porta.

A Figura 4.3 apresenta a curva da transcondutância em função do diâmetro dos dispositivos com duas fontes diferentes para os três métodos de comparação. Através desta figura é possível observar inicialmente que o dispositivo com fonte de $\mathrm{Si}_{0,73} \mathrm{Ge}_{0,23}$ possui uma maior transcondutância para qualquer um dos três métodos de comparação devido à maior sobreposição de bandas, resultando em um maior nível de transcondutância. 
Figura 4.3 - Transcondutância experimental em função do diâmetro efetivo do nTFET nanofio para diferentes composições de fonte.

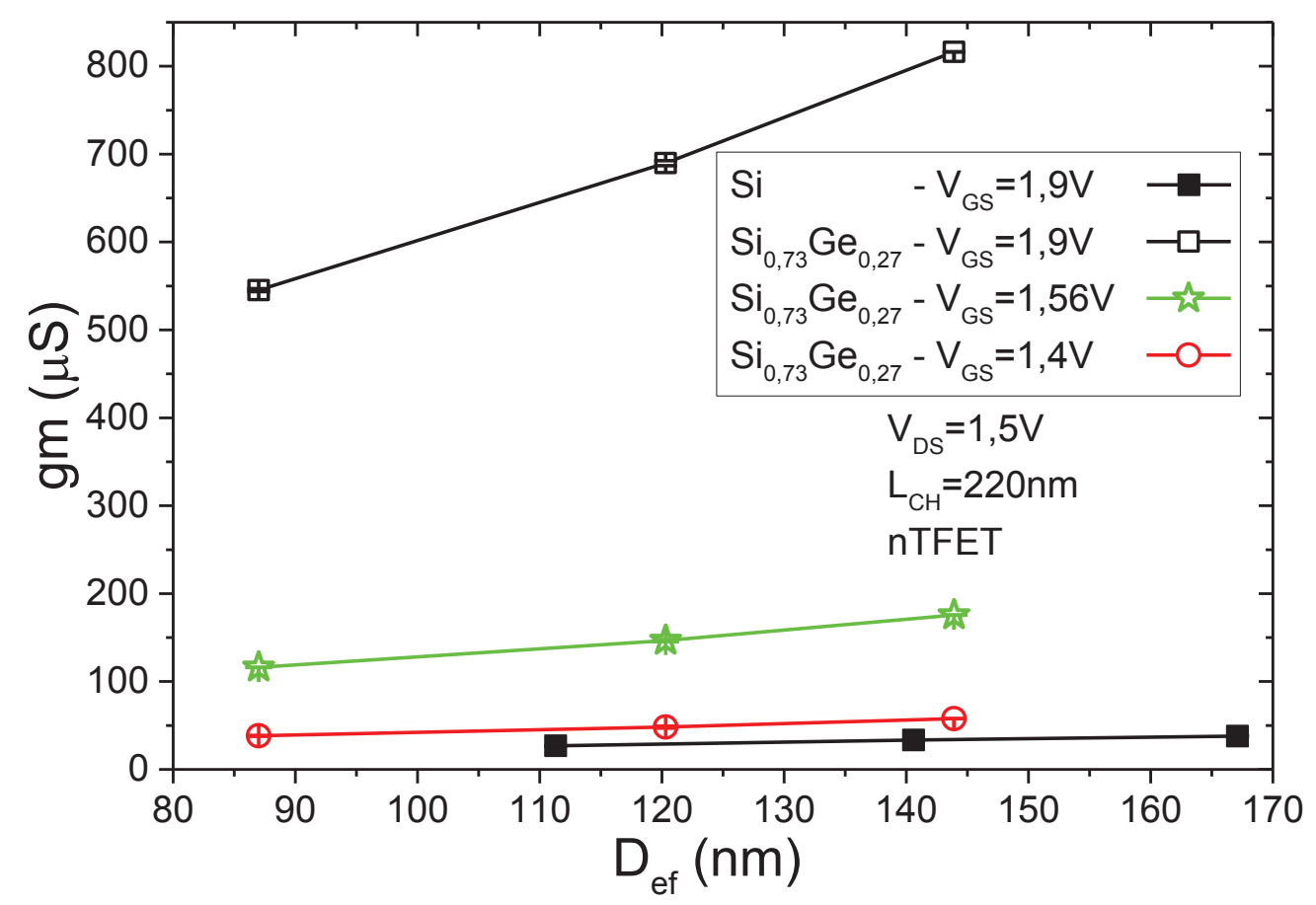

Fonte: Autor.

Considerando o efeito do diâmetro, pode-se observar que conforme o diâmetro diminui, a transcondutância diminui também devido à sua menor área de condução de corrente. Como os dispositivos experimentais possuem diâmetros relativamente largos, a corrente do dispositivo passa predominantemente próximo da interface $\mathrm{Si} / \mathrm{SiO}_{2}$ do nanofio, e a sua área de condução de corrente pode ser aproximada ao perímetro da interface porta/canal, ao redor da junção de fonte, como pode ser visto na equação 4.1:

$$
\text { Perímetro }=\pi \cdot D_{e f}
$$

Ao usar o primeiro método (mesma polarização de porta) nos TFETs com fonte

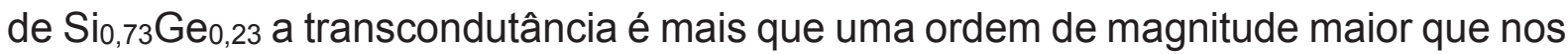
TFETs com fonte de $\mathrm{Si}$, pois o mecanismo de condução do dispositivo com fonte de $\mathrm{Si}_{0,73} \mathrm{Ge}_{0,23}$ possui o BTBT como mecanismo dominante de condução de corrente desde a polarização de $1,56 \mathrm{~V}$ e, para a fonte de $\mathrm{Si}$, o BTBT apenas começa a ser dominante a partir de $1,9 \mathrm{~V}$.

Se os dois dispositivos forem comparados utilizando o método da menor polarização para se atingir o BTBT como mecanismo dominante de condução de 
corrente, pode ser observado que o dispositivo com fonte de $\mathrm{Si}_{0,73} \mathrm{Ge}_{0,23}$ ainda continua com uma transcondutância maior, devido à maior sobreposição de bandas.

Mesmo pelo terceiro método de comparação, o de mesmo nível da corrente de dreno, o dispositivo com fonte de $\mathrm{Si}_{0,73} \mathrm{Ge}_{0,23}$ possui transcondutância levemente maior. Embora nesta última comparação o TFET com fonte de $\mathrm{Si}_{0,73} \mathrm{Ge}_{0,23}$ estar polarizado com $1,4 \mathrm{~V}$ na porta, tensão insuficiente para BTBT ser o mecanismo dominante, a melhora causada pela diminuição de $E_{G}$ no dispositivo com fonte de Si $0,73 \mathrm{Ge}_{0,23}$ é bem efetiva, resultando nesta melhor transcondutância.

Analisando-se percentualmente a redução da transcondutância com o diâmetro efetivo é possível observar que o dispositivo com fonte de $\mathrm{Si}_{0,73} \mathrm{Ge}_{0,23}$ reduz aproximadamente 34 \% (variação de $144 \mathrm{~nm}$ até $87 \mathrm{~nm}$ ) para todas as polarizações utilizadas, enquanto o dispositivo com fonte de Si reduz 29 \% (variação de 164 nm até $111 \mathrm{~nm}$ ). Estes resultados sugerem que a redução da transcondutância com o diâmetro é independente do mecanismo de condução de corrente, sendo relacionado apenas à área de condução de corrente.

Outro parâmetro que é influenciado pelo diâmetro do dispositivo é a condutância de saída. A Figura 4.4 apresenta a curva da condutância de saída em função do diâmetro do dispositivo, e através dela é possível notar, em uma análise da redução percentual dos diâmetros que o dispositivo com fonte de Si tem sua condutância de saída decrescida de $7 \%$, enquanto o dispositivo com fonte de $\mathrm{Si}_{0,73} \mathrm{Ge}_{0,23}$ reduz de $47 \%$ para $\mathrm{V}_{\mathrm{GS}}=1,9 \mathrm{~V}$, de $70 \%$ para $\mathrm{V}_{\mathrm{GS}}=1,56 \mathrm{~V}$ e $84 \%$ para $V_{G S}=1,4 \mathrm{~V}$, indicando que há grande dependência do mecanismo de condução na variação da condutância de saída com o diâmetro efetivo, sendo o TAT mais influenciado que o BTBT.

Apesar do tunelamento ocorrer próximo à junção fonte/canal, e, portanto, tornar os dispositivos TFETs menos susceptíveis à polarização do dreno comparado aos MOSFETs, quando comparamos a susceptibilidade dos mecanismos de transporte (TAT e BTBT) ao potencial de dreno, é possível notar que o BTBT mostra ser mais influenciado por VDS do que o TAT, o qual se mostra praticamente independente de VDS. 
Figura 4.4 - Condutância de saída experimental em função do diâmetro efetivo do nTFET nanofio para diferentes composições de fonte.

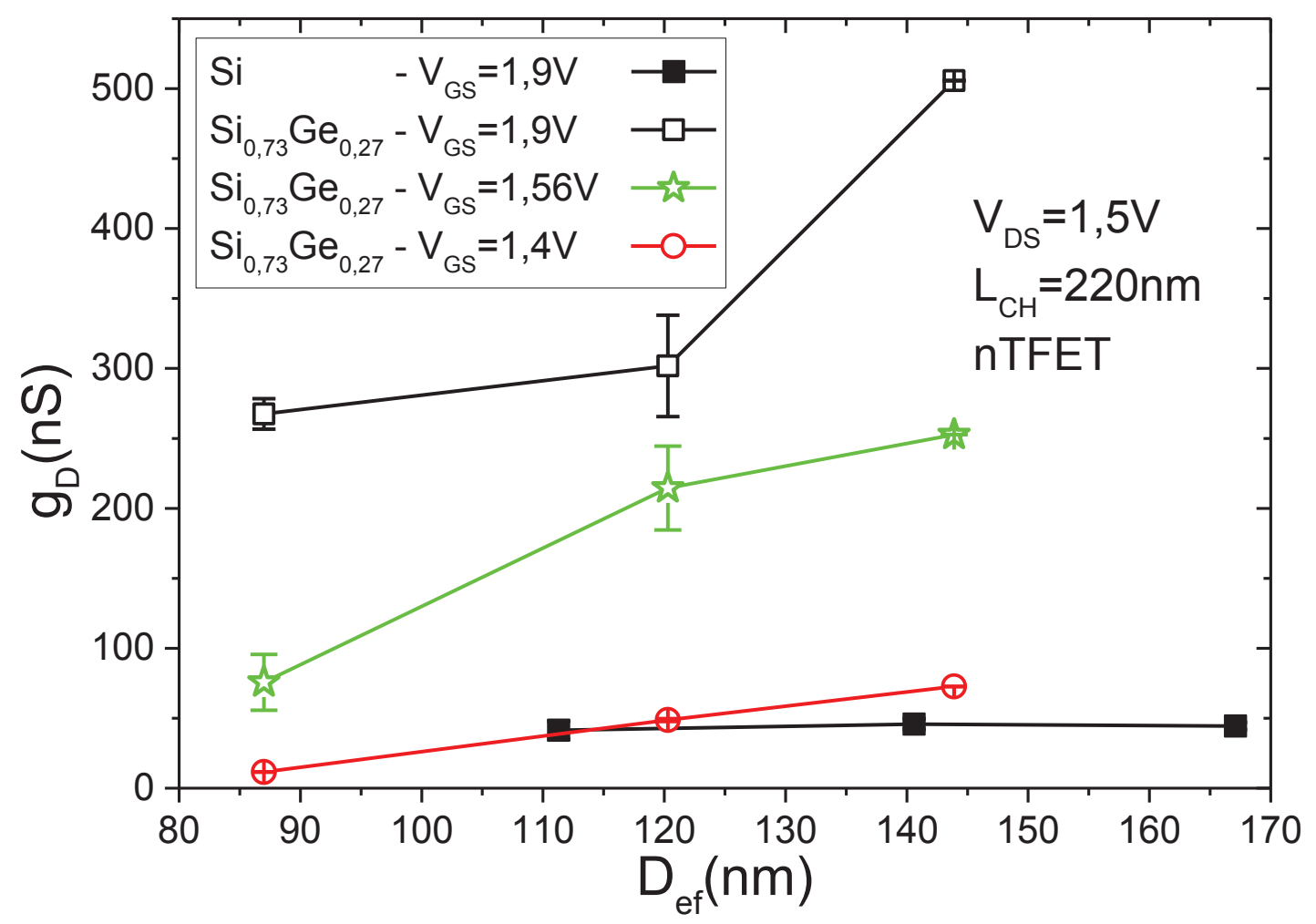

Fonte: Autor.

Esta dependência com $V_{D S}$ pode ser observada através da Figura 4.4, onde os dispositivos que possuem BTBT como mecanismo dominante apresentam maior degradação da condutância de saída. Essa degradação da condutância de saída é causada pela maior influência do campo elétrico de dreno no BTBT quando comparado ao TAT.

Devido à relação entre a transcondutância e a condutância de saída no ganho intrínseco de tensão (Equação 2.15), com a variação do diâmetro, variando ambos os parâmetros, o ganho também é afetado. A Figura 4.5 apresenta a curva do ganho intrínseco de tensão em função do diâmetro efetivo.

Para o dispositivo com fonte de Si o ganho diminui com a redução do diâmetro, pois a degradação da transcondutância é maior que a melhoria (redução) na condutância de saída. Entretanto, para o dispositivo com fonte de $\mathrm{Si}_{0,73} \mathrm{Ge}_{0,23}$ um comportamento oposto é observado, devido à redução da condutância de saída que é maior que a redução da transcondutância. 
Figura 4.5 - Ganho intrínseco de tensão experimental em função do diâmetro efetivo do nTFET nanofio para diferentes composições de fonte.

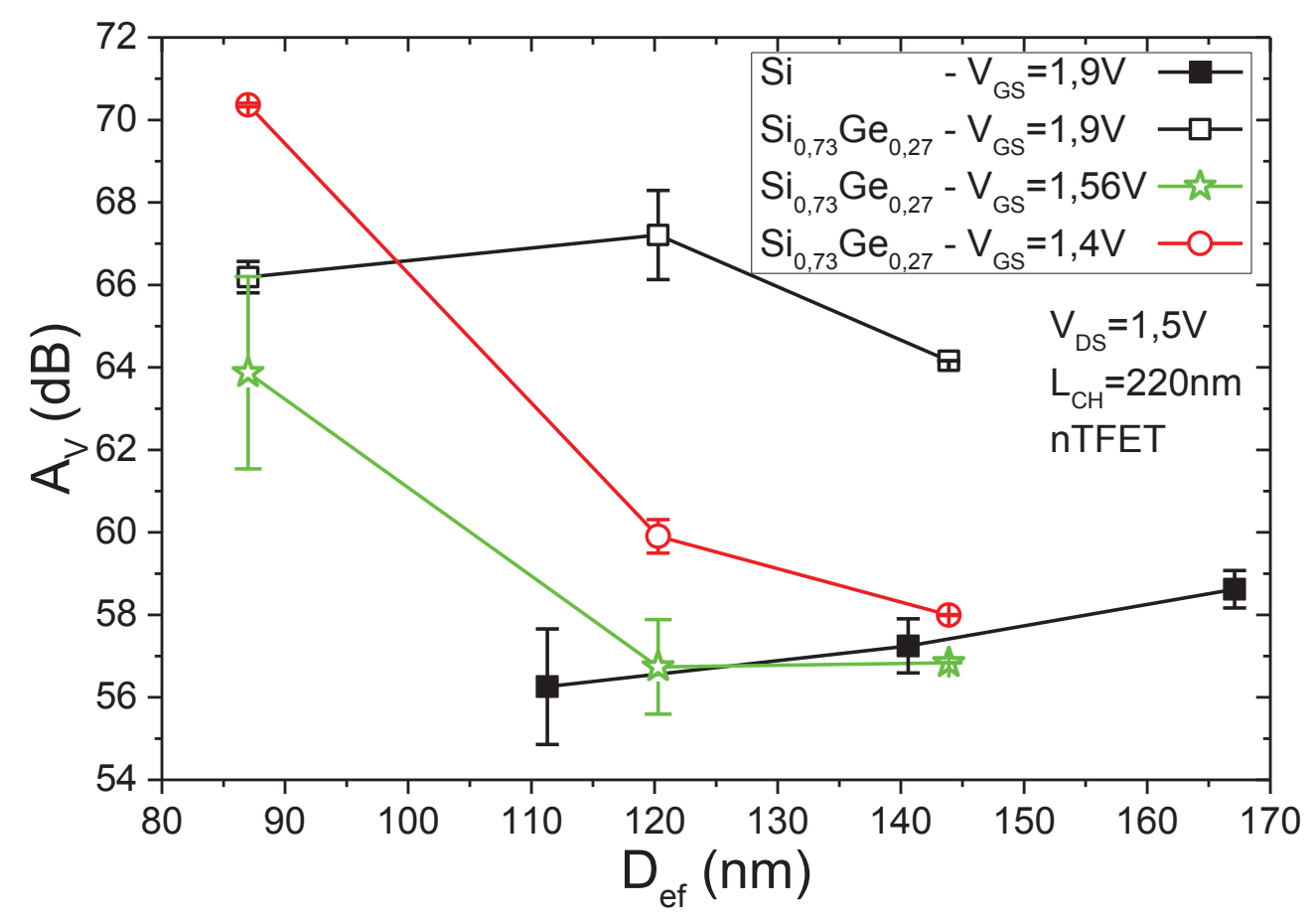

Fonte: Autor.

Como no dispositivo com fonte de $\mathrm{Si}_{0,73} \mathrm{Ge}_{0,23}$ com polarização de porta de $1,4 \mathrm{~V}$ o mecanismo dominante de corrente é o TAT, a condutância de saída é muito menor do que com polarização de $1,56 \mathrm{~V}$, cujo mecanismo dominante é o BTBT. Ao mesmo tempo, a variação de gm não é tão grande pois a redução da tensão de porta não é muito grande e o mecanismo de transporte não tem grande influência em gm. Esse efeito faz com que o ganho intrínseco de tensão seja maior em $1,4 \mathrm{~V}$ do que em $1,56 \mathrm{~V}$. Se compararmos os dispositivos através do segundo método, o da mínima tensão para o mecanismo de condução seja BTBT, é possível observar que para diâmetros entre $120 \mathrm{~nm}$ e $140 \mathrm{~nm}$ o comportamento do ganho intrínseco de tensão é similar para ambos os dispositivos.

Com o intuito de se extrapolar os dispositivos com fonte de Si para diâmetros menores, foram realizadas simulações numéricas conforme estão descritas no item 3.1.2. A Figura 4.6 apresenta a corrente de dreno normalizada simulada em função da tensão de porta, para diâmetros variando de $15 \mathrm{~nm}$ até $90 \mathrm{~nm}$. No gráfico inserido na Figura 4.6 é mostrada a calibração da curva simulada com a curva experimental.

Um fenômeno decorrente do escalamento do diâmetro é a redução da tensão mínima necessária para que o BTBT se torne o mecanismo dominante de condução 
de corrente. Essa redução ocorre porque à medida que diminuímos o diâmetro do nanofio de um TFET haverá um maior acoplamento eletrostático, aumentando a predominância de BTBT ao longo da profundidade (direção ao centro do nanofio).

Como a corrente é normalizada o efeito do aumento da condução devido à área é eliminado, restando apenas o efeito do mecanismo de condução. Através da Figura 4.6 é possível observar que para diâmetros maiores que aproximadamente $25 \mathrm{~nm}$ a corrente normalizada é praticamente constante. Abaixo de $25 \mathrm{~nm}$ é possível observar um aumento de lon normalizado (em relação à largura do canal) com a redução do diâmetro, o qual está relacionado com o mecanismo de corrente dominante. Estes resultados sugerem que para dispositivos de nanofios mais finos, o acoplamento eletrostático é melhor, resultando em maior corrente de BTBT.

Figura 4.6 - Corrente de dreno normalizada em relação à largura em função da tensão de porta para um dispositivo nTFET nanofio com fonte de Si puro simulado para diferentes diâmetros.

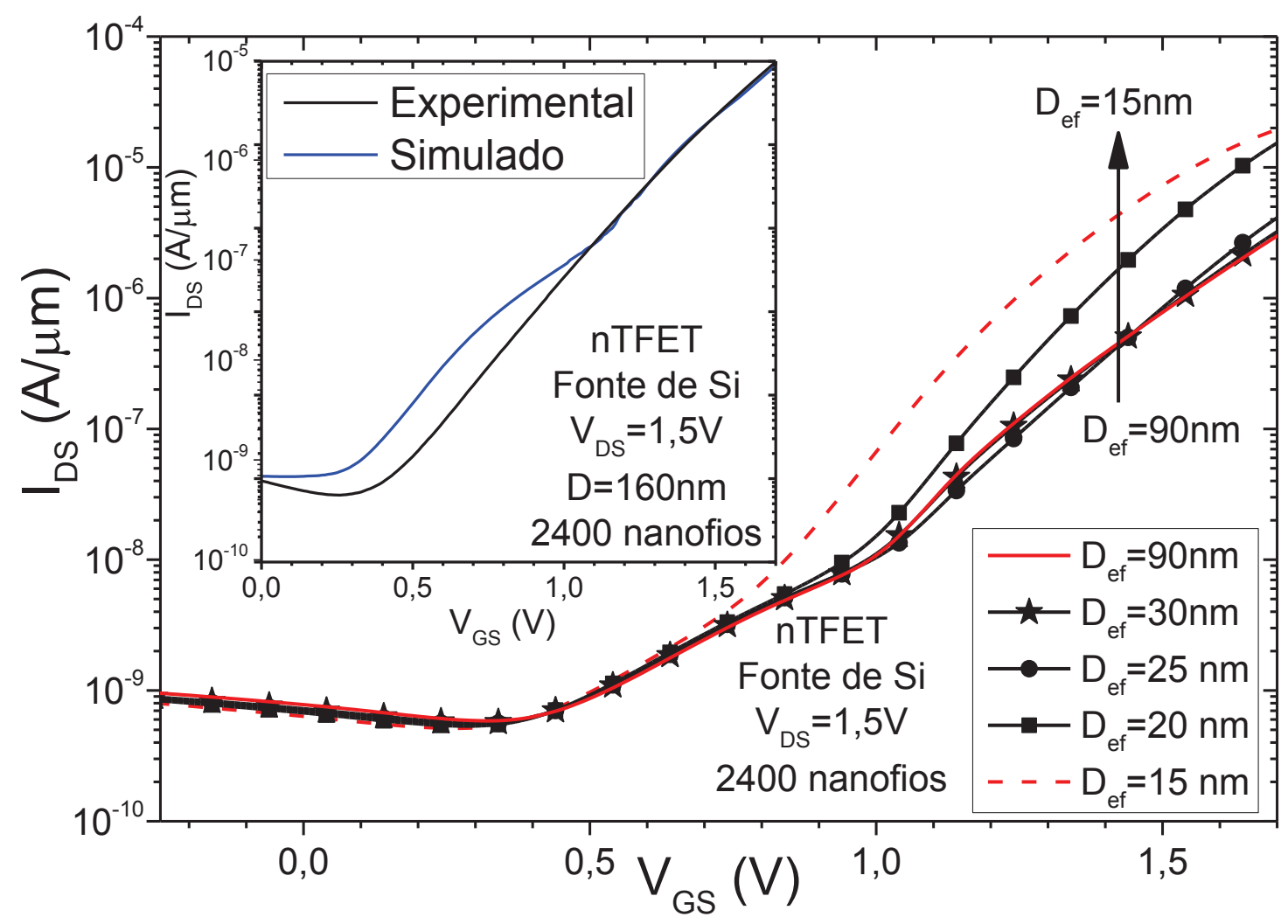

Fonte: Autor.

A Figura 4.7 apresenta a IDs simulada, onde os mecanismos de condução de corrente são separados para diferentes diâmetros. Nesta figura é possível observar que o aumento de IDs é devido apenas ao aumento do mecanismo de BTBT, sendo praticamente independente de dos mecanismos de TAT e SRH. 
Figura 4.7 - Componentes da corrente de dreno em função da tensão de porta para um dispositivo nTFET nanofio com fonte de Si puro simulado para diferentes diâmetros.

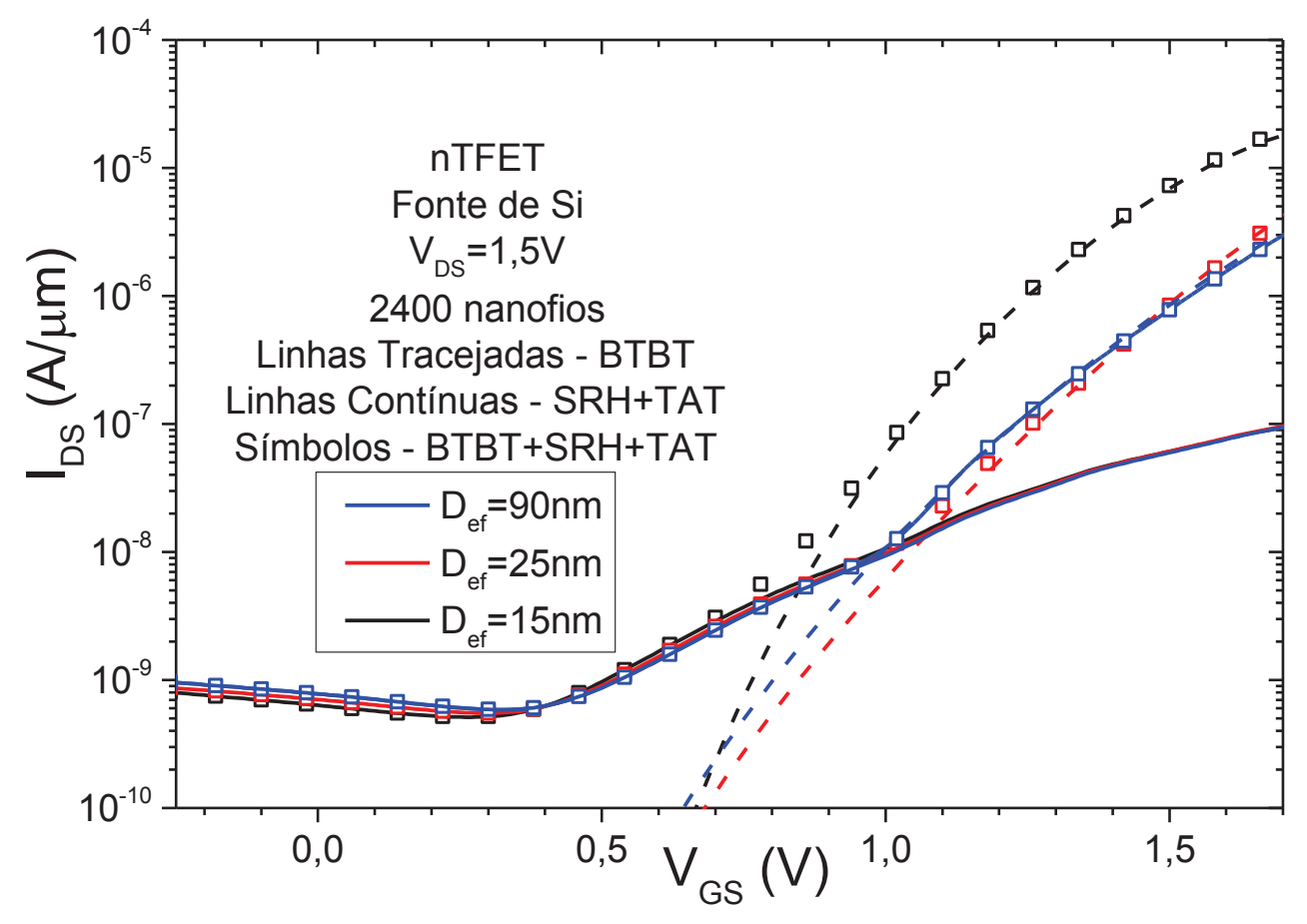

Fonte: Autor.

Complementando esta figura, uma representação da secção transversal da junção entre a fonte o canal em TFETs de nanofios é mostrada na Figura 4.8. É possível notar que em diâmetros mais largos (Figura 4.8(A)), o mecanismo de condução dominante é o BTBT somente mais perto da interface entre o dielétrico de porta e o Si. Conforme o potencial diminui em direção ao centro do nanofio, a banda de condução do canal fica mais distante da banda de valência da fonte. Isto faz com que apareça uma transição nos mecanismos de condução de corrente predominante ao longo do diâmetro, com BTBT o mecanismo de condução predominante apenas nas proximidades da interface com o dielétrico, o TAT predominante em posições intermediárias e o $\mathrm{SRH}$ predominante apenas perto do centro do nanofio.

Para diâmetros um pouco menores (Figura 4.8(B)), há uma maior interação entre o potencial da porta e o centro do nanofio, aumentando a influência dos mecanismos de BTBT e TAT no centro do nanofio. Isto resulta em uma predominância de BTBT mais perto da interface entre o dielétrico de porta e o $\mathrm{Si}$, avançando agora um pouco mais ao centro do nanofio, e em predominância de TAT em seu centro. Para diâmetros muito menores (Figura 4.8(C)), o impacto do potencial da porta no centro do nanofio é forte o bastante para garantir o BTBT como o mecanismo dominante por toda a extensão do diâmetro. 
Figura 4.8 - Representação esquemática da secção transversal de um TFET vertical em estrutura de nanofios com diâmetros grandes (a), médios (b) e pequenos (c).
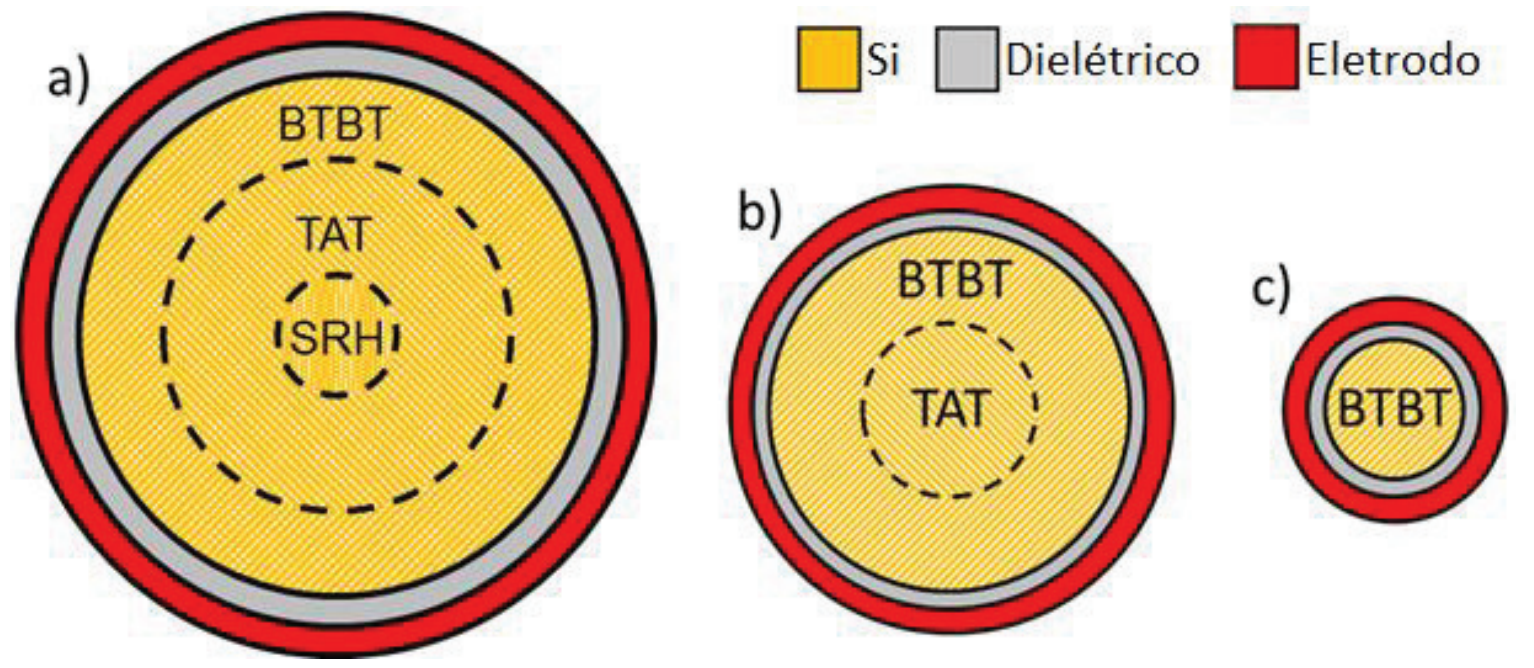

Fonte: Autor.

A fim de demonstrar esse efeito ao longo da profundidade do nanofio, a Figura 4.9 apresenta a taxa de geração e recombinação de portadores em função da profundidade do nanofio para o nTFET simulado com dois diâmetros diferentes, um de $110 \mathrm{~nm}$ e outro de $30 \mathrm{~nm}$. Pode-se observar que para o diâmetro efetivo de $110 \mathrm{~nm}$ a taxa de geração e recombinação é maior na interface com o dielétrico de porta e $\mathrm{Si}$, sendo dominado por BTBT. Essa taxa vai reduzindo mais afastado da interface, onde os mecanismos dominantes são o TAT e o SRH.

Figura 4.9 - Taxa de geração e recombinação em função da profundidade para um dispositivo nTFET nanofio com fonte de Si puro simulado para diâmetros efetivos de $30 \mathrm{~nm}$ e $110 \mathrm{~nm}$.

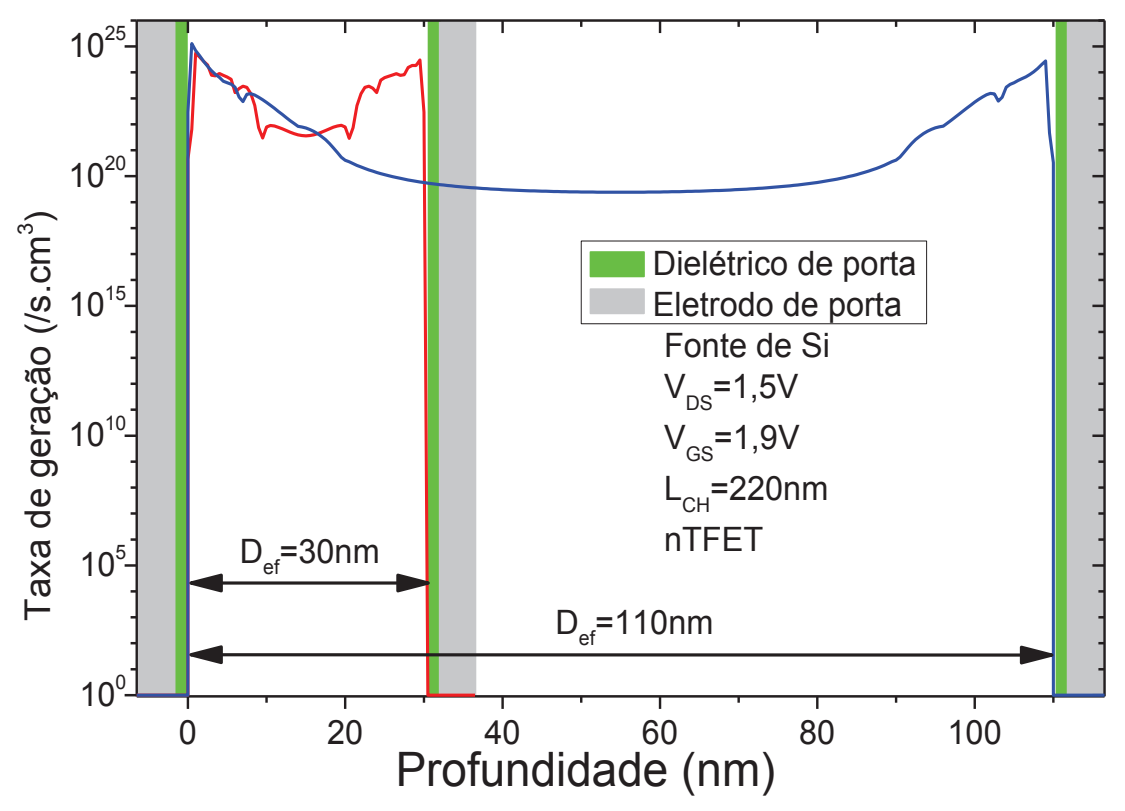

Fonte: Autor. 
Entretanto, para o dispositivo com diâmetro efetivo de $30 \mathrm{~nm}$, devido a um maior acoplamento entre às interfaces $\mathrm{Si} / \mathrm{SiO}_{2}$ em direção ao centro do nanofio, o mecanismo de BTBT é mais dominante na maior parte da junção.

Esta maior influência de BTBT ao longo de toda a secção transversal é responsável pelo aumento de IDs e pela redução da tensão necessária para que o BTBT seja o mecanismo de corrente dominante (VON) para diâmetros pequenos, conforme pode ser visto na Figura 4.6.

Com o intuito de se observar melhor o efeito da redução de Von para diâmetros pequenos, foi extraído VoN (gráfico inserido na Figura 4.10) a partir do critério da energia de ativação (Figura 4.10). Este critério define que o BTBT é o mecanismo de condução de corrente dominante para valores de $\mathrm{E}_{\mathrm{A}}$ menores que 0,1 eV.

A energia de ativação, obtida através da equação 2.9, é apresentada na Figura 4.10, para diferentes diâmetros. Nesta figura é possível notar que Von é praticamente constante para diâmetros maiores, porém, quando o diâmetro é reduzido para valores abaixo de $30 \mathrm{~nm}$, VoN decai bastante, devido à maior influência do mecanismo de BTBT.

Figura 4.10 - Energia de ativação em função da tensão de porta para um nTFET nanofio com fonte de Si puro simulado para diferentes diâmetros e $V_{O N}$ em função do diâmetro no gráfico inserido.

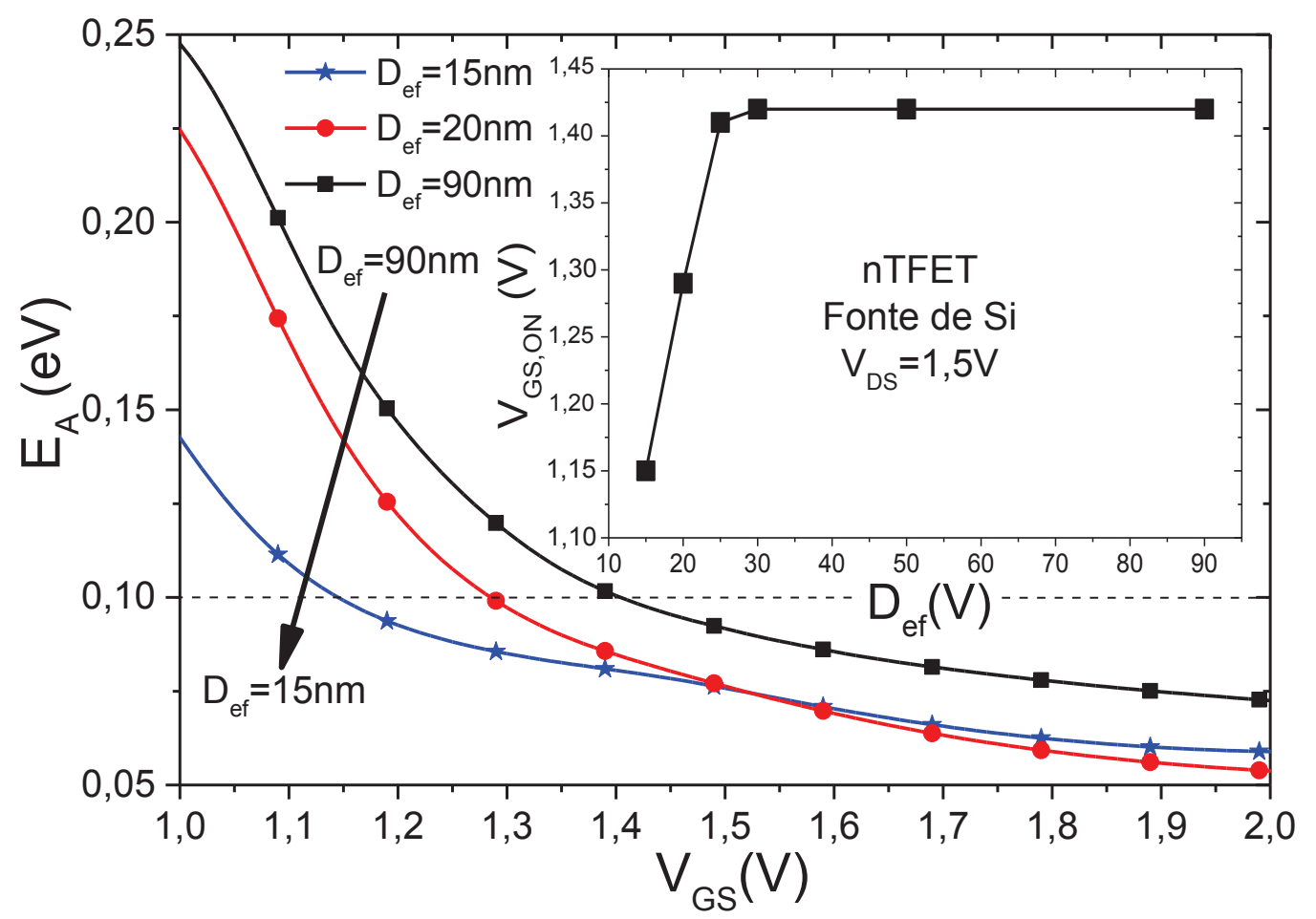

Fonte: Autor. 
Estes efeitos causados por diâmetros pequenos podem ser observado também nas características analógicas dos dispositivos. Um parâmetro analógico que descreve características muito importantes é a eficiência do transistor. Através da eficiência é possível analisar o ganho fornecido em um determinado nível de potência. Em transistores MOSFETs é possível dividir uma curva de eficiência em função de corrente em algumas regiões, como a inversão forte e a inversão fraca. Se extrapolarmos esse conceito para os TFETs podemos ter regiões similares, as quais serão chamadas de alta condução de corrente e baixa condução de corrente.

A análise de gm/lds nos dispositivos experimentais para os 2 materiais de fonte estudados (Figura 4.11) mostrou que como os dispositivos medidos possuem diâmetros muito largos, a variação do diâmetro tem muito pouca influência em $\mathrm{gm} / \mathrm{IDS}_{\mathrm{DS}}$ para ambos os regimes de condução de corrente.

Figura 4.11 - Eficiência do transistor em função da corrente de dreno normalizada dos dispositivos nTFET nanofio para diferentes diâmetros e composições de fonte.

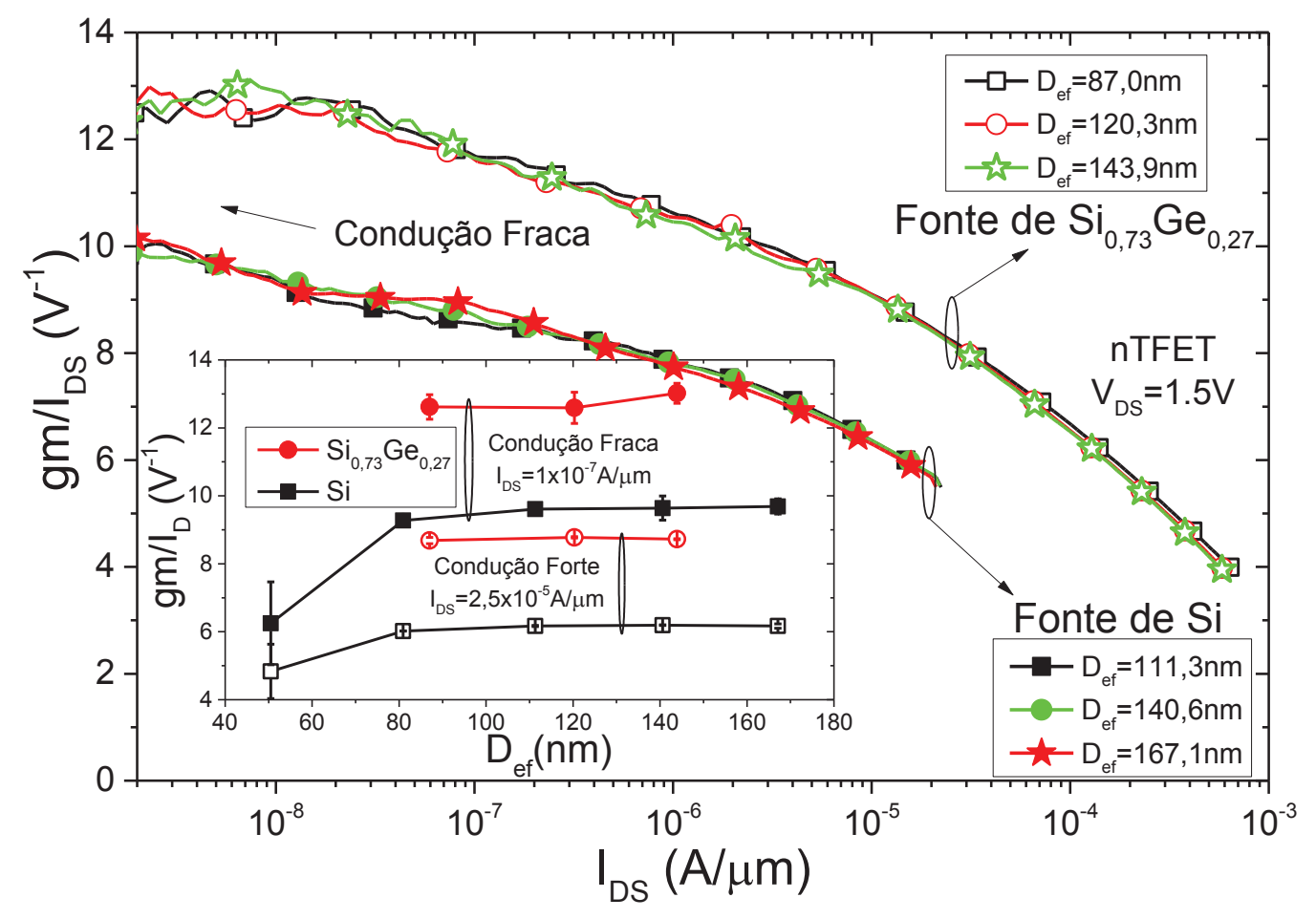

Fonte: Autor.

Embora o diâmetro tenha influência em $\mathrm{gm} / \mathrm{lDS}_{\mathrm{DS}}$ nestes dispositivos experimentais analisados, $\mathrm{gm} / \mathrm{l} \mathrm{Ds}$ é maior para o dispositivo com fonte de SiGe quando comparado ao dispositivo de Si, para ambas as condições de condução de corrente. 
Este comportamento é causado pelo menor $\mathrm{E}_{\mathrm{G}}$ do dispositivo de $\mathrm{SiGe}$, o qual aumenta todos os mecanismos de condução de corrente do mesmo.

Foram utilizadas simulações numéricas para extrapolar o efeito da redução do diâmetro nas características analógicas do dispositivo de Si. Analisando a eficiência para vários diâmetros (Figura 4.12), duas tendências opostas podem ser observadas. Uma para o regime de baixa condução de corrente $\left(\mathrm{I}_{\mathrm{DS}}=1 \times 10^{-7} \mathrm{~A} / \mu \mathrm{m}\right)$ e outra para o regime de alta condução de corrente $\left(\operatorname{lDS}_{\mathrm{DS}}=2,5 \times 10^{-5} \mathrm{~A} / \mu \mathrm{m}\right)$.

Em regime de baixa condução de corrente, onde gm/lDs reflete o comportamento de SS ( $\mathrm{gm} / \mathrm{IDS} \propto 1 / \mathrm{SS}$ ), gm/lDs é maior para diâmetros menores. Este comportamento pode ser explicado pela maior influência de BTBT em dispositivos com diâmetros menores. A corrente gerada pelo mecanismo de BTBT possui melhor características de chaveamento, o que reduz SS, resultando em melhoria de $\mathrm{gm} / \mathrm{IDS}$.

Entretanto, em regime de alta condução de corrente, os dispositivos mais estreitos não possuem área suficiente para proporcionar um aumento do mecanismo de BTBT, resultando em diminuição de gm/lDs.

Figura 4.12 - Eficiência em função da corrente de dreno normalizada em relação à largura para um dispositivo nTFET nanofio com fonte de Si puro simulado para diferentes diâmetros.

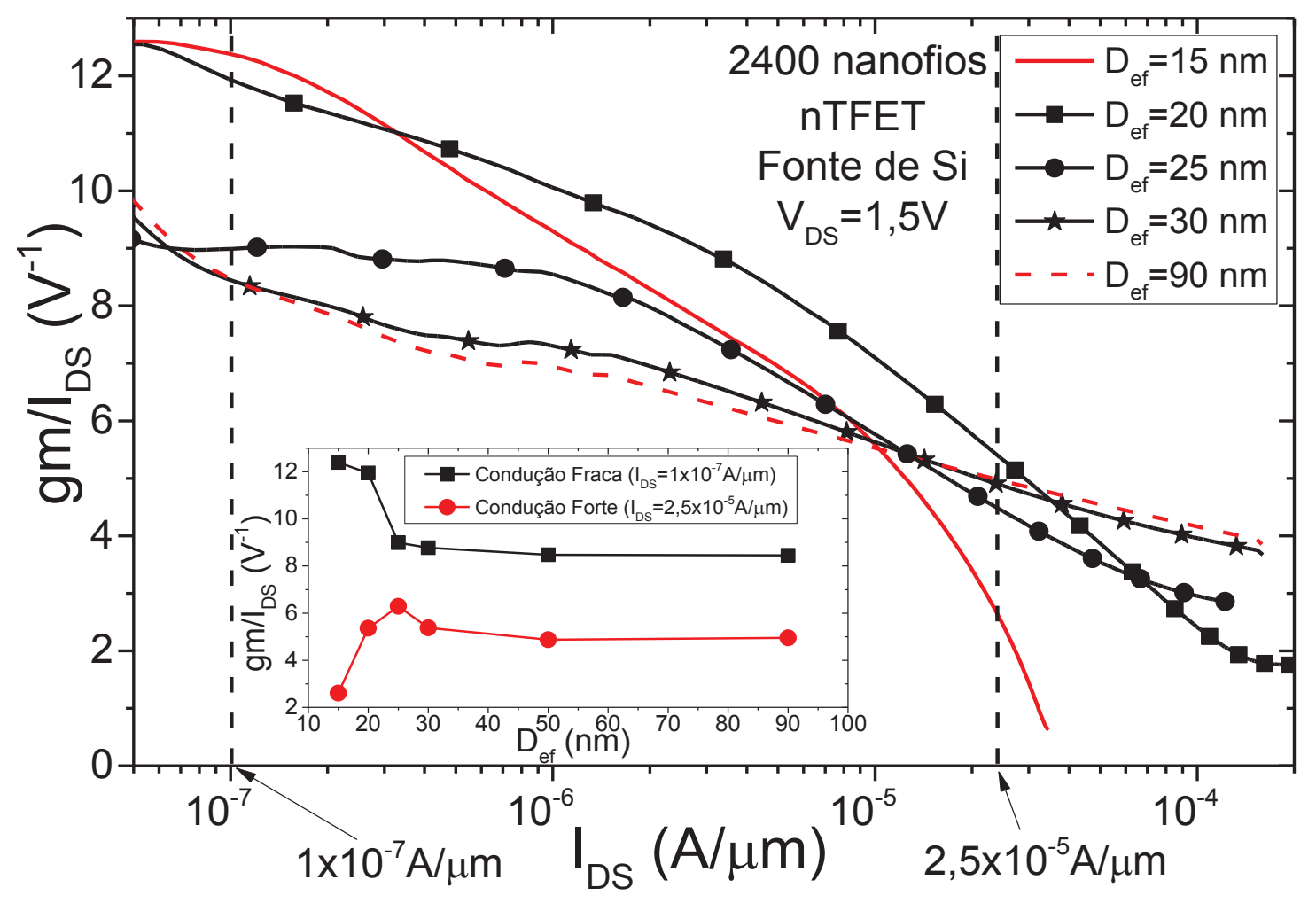

Fonte: Autor. 
Para entender melhor o efeito do diâmetro nos mecanismos de condução para os diferentes regimes de condução de corrente, a Figura 4.13 apresenta a taxa de geração de portadores em função da profundidade do nanofio.

Figura 4.13 - Taxa de geração e recombinação em função da profundidade para um dispositivo nTFET nanofio com fonte de Si puro simulado para condução fraca (a) e forte (b) de corrente.
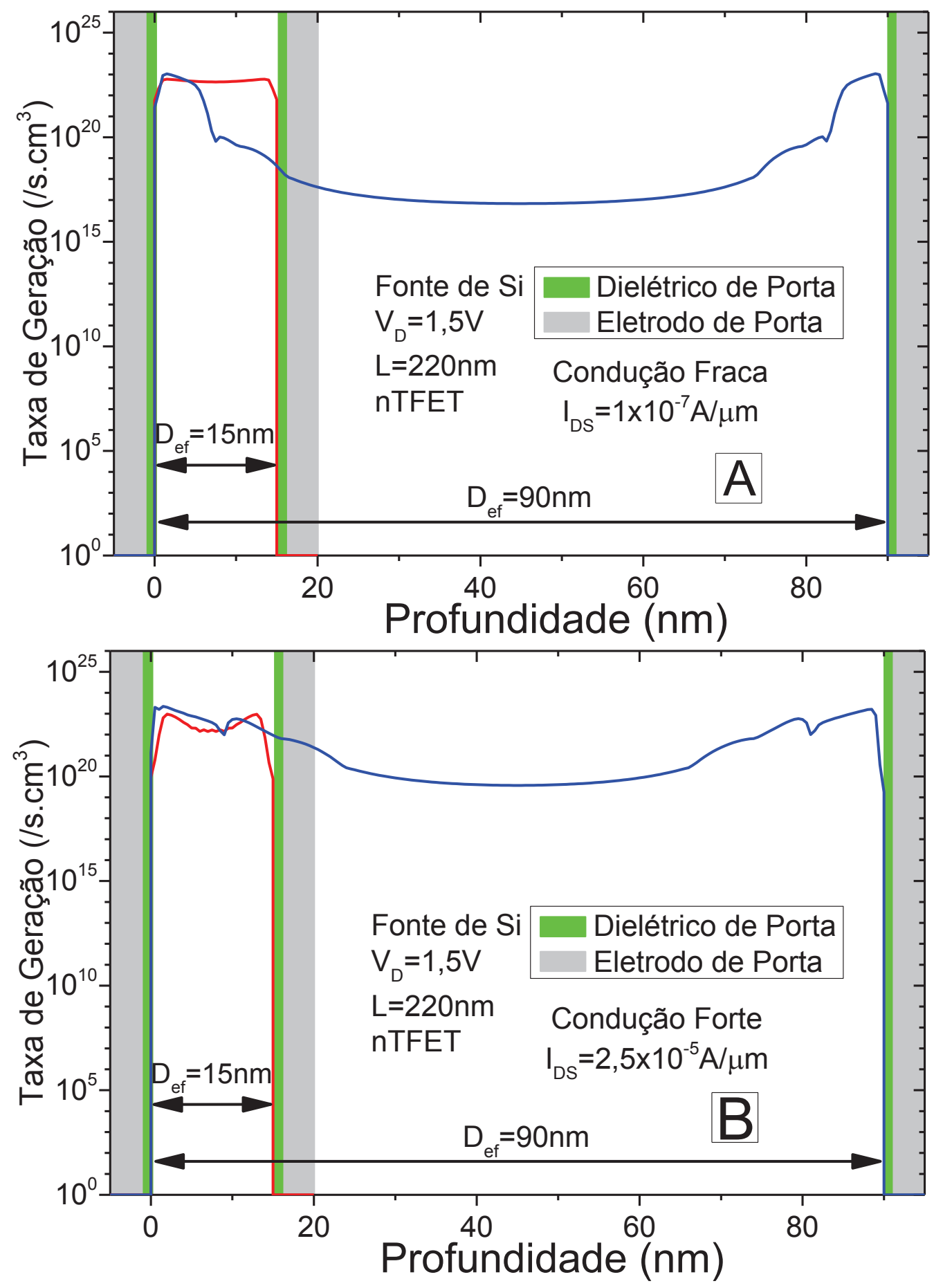

Fonte: Autor. 
Através desta figura é possível observar que para o regime de baixa condução de corrente (Figura 4.13 (A)), o dispositivo com baixo diâmetro possui BTBT por toda a extensão da junção entre canal e fonte, enquanto o dispositivo mais largo possui BTBT somente mais perto da interface entre o dielétrico e o Si. Entretanto, para o regime de alta condução de corrente (Figura 4.13 (B)), os dispositivos mais largos possuem o mecanismo de BTBT bem influente no centro do nanofio.

Os resultados apresentados na Figura 4.13 podem também explicar 0 comportamento de outros parâmetros analógicos, como gm e gD, que são ambos mostrados na Figura 4.14 .

Figura 4.14 - Transcondutância e condutância de saída em função do diâmetro em condução forte e fraca de corrente para um dispositivo nTFET nanofio com fonte de Si puro simulado.

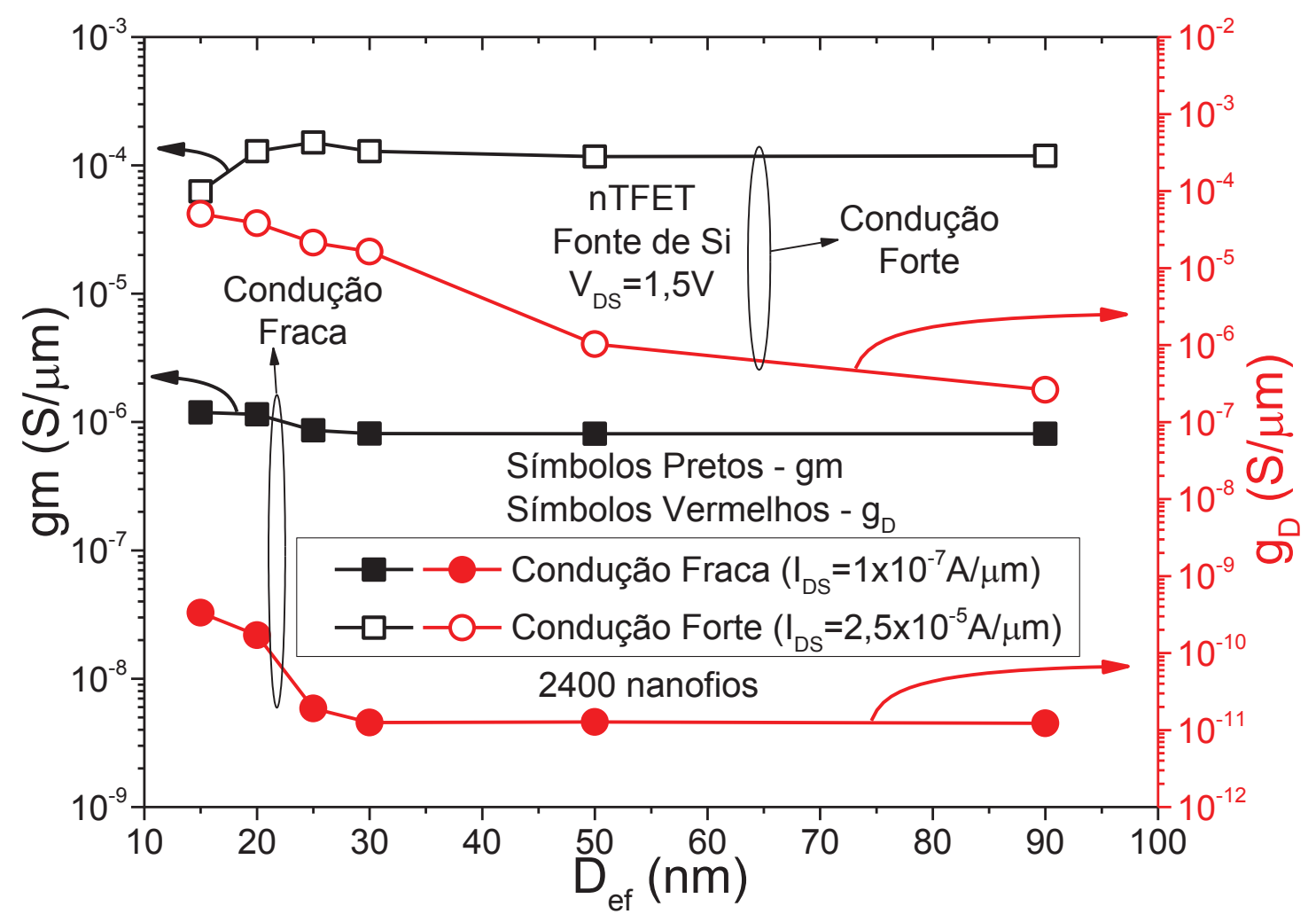

Fonte: Autor.

Analisando inicialmente gm normalizado em relação à largura do canal, pode ser notado que para o regime de baixa condução de corrente, quando o diâmetro é muito reduzido, gm é melhorado devido ao aumento do acoplamento eletrostático e, consequentemente, da predominância do mecanismo de BTBT na corrente do nanofio. Para a condição de alta condução de corrente, o a redução do diâmetro também melhora gm, porém, somente até que o dispositivo seja estreito o suficiente 
para que o mecanismo de BTBT domine totalmente a junção entre fonte e canal. Para diâmetros abaixo deste ponto, gm começa a ser degradado devido à limitação da área de BTBT.

Ao analisar a influência da variação do diâmetro em go é preciso entender a influência dos mecanismos de corrente em gD. O mecanismo de BTBT é mais susceptível à variação da polarização de dreno do que os mecanismos de TAT e SRH, pois o mecanismo de BTBT possui influência do campo elétrico total. Esta dependência pode ser observada no modelo de geração de BTBT, proposto por Hurkx (29), mostrado na equação (2.7).

Ao diminuir o diâmetro dos dispositivos, o BTBT passa a ser mais influente ao longo de toda a junção entre fonte e dreno. Como o mecanismo de BTBT é mais dependente de $V_{D S}$ que os mecanismos de TAT e SRH, para diâmetros menores os nanofios são mais dependentes de $V_{D S}$, aumentando assim gD. Este aumento é visível para ambas condições de condução de corrente, porém é ainda mais notável para o regime de alta condução de corrente, onde o mecanismo de BTBT é ainda mais forte.

O ganho intrínseco de tensão, que foi calculado através da relação entre gm e gD (equação(2.15)), é mostrado na Figura 4.15. Em regime de alta condução de corrente, para diâmetros menores, gd é aumentado mais do que gm, resultando em uma alta degradação de Av com a redução do diâmetro.

Analisando o dispositivo em regime de baixa condução de corrente, para diâmetros largos, a redução do diâmetro tem pouca influência em Av. Entretanto, para diâmetros menores, o aumento de gD é mais notável do que o de gm, consequentemente degradando Av. Como o aumento de gD com a redução do diâmetro é mais forte em regime de alta condução de corrente, este regime possui uma degradação de Av com a redução do diâmetro mais acentuada do que em regime de baixa condução de corrente. 
Figura 4.15 - Ganho intrínseco de tensão em função do diâmetro em condução forte e fraca de corrente para um dispositivo nTFET nanofio com fonte de Si puro simulado.

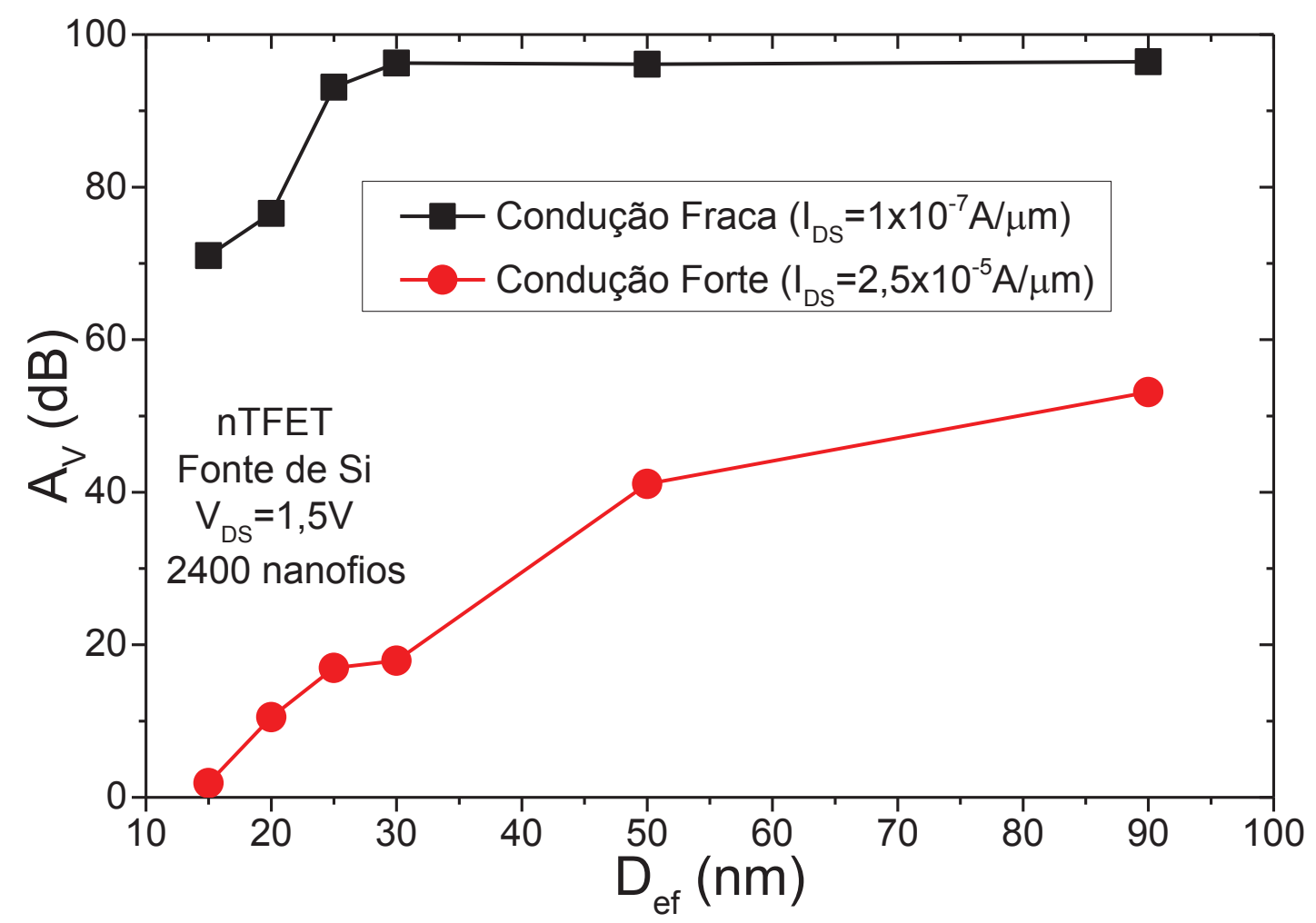

Fonte: Autor. 


\subsubsection{Analise em alta temperatura dos parâmetros analógicos}

Nesta etapa do trabalho a influência da temperatura nos principais parâmetros analógicos de transistores é analisada. Neste estudo estarão presentes os dispositivos de nanofios com fontes de Si puro e $\mathrm{Si}_{0,73} \mathrm{Ge}_{0,23}$, para o diâmetro de $110 \mathrm{~nm}$.

Primeiramente foi realizada a análise da corrente de dreno em função da tensão de porta para três diferentes temperaturas, como pode ser observado na Figura 4.16. A partir desta curva observou-se que há uma degradação na curva da corrente do TFET com fonte de $\mathrm{Si}_{0,73} \mathrm{Ge}_{0,23}$ em baixa polarização de porta $\left(\mathrm{V}_{\mathrm{GS}} \cong 0,2 \mathrm{~V}\right)$. A causa desta degradação é que embora a fonte de $\mathrm{Si}_{0,73} \mathrm{Ge}_{0,23}$ aumente a corrente gerada por BTBT, ela aumenta também a corrente gerada por TAT (63), devido ao maior número de defeitos na junção.

Ao analisar o efeito da temperatura em ambos os dispositivos é possível que o aumento da temperatura gere um aumento nas correntes geradas pelos mecanismos de BTBT, TAT e SRH. Porém, esse aumento é menos pronunciado no mecanismo de BTBT, ou seja, para maiores polarizações de porta.

Figura 4.16 - Curva experimental da corrente de dreno em função da tensão na porta em nTFETs de nanofios com fonte de Si puro para diferentes temperaturas.

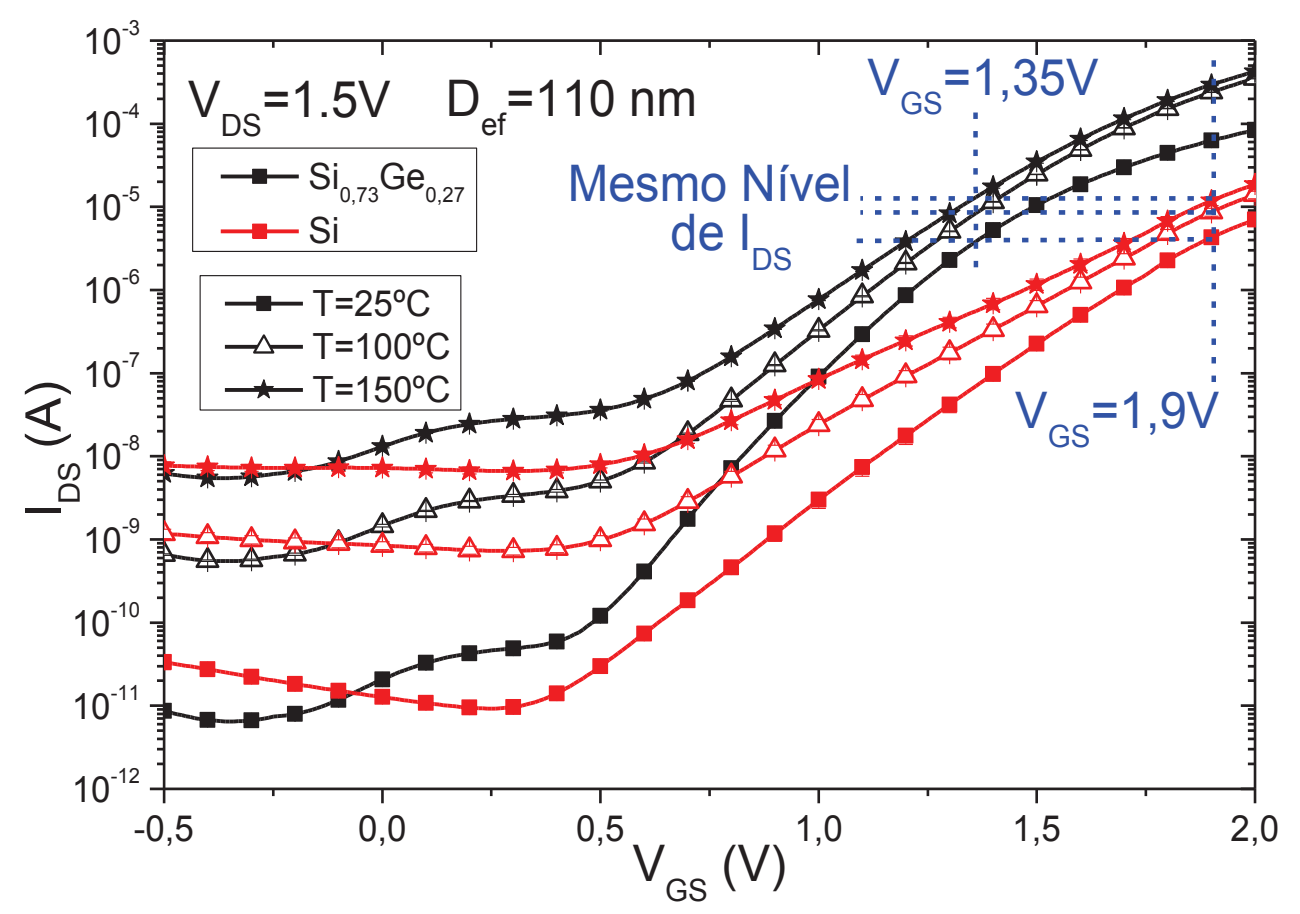

Fonte: Autor. 
Para se analisar o efeito da temperatura nos principais parâmetros analógicos os dispositivos foram comparados utilizando o método 1, que consiste na comparação com a mesma polarização de porta ( $V_{G S}=1,9 \mathrm{~V}$ para ambos dispositivos), e o método 3, comparação com a mesma corrente de dreno ( $\mathrm{VGS}=1,9 \mathrm{~V}$ para o dispositivo com fonte de Si e $V_{G S}=1,35 \mathrm{~V}$ para o dispositivo com fonte de $\mathrm{Si}_{0,73} \mathrm{Ge}_{0,23}$ ).

A Figura 4.17 apresenta a transcondutância em função da temperatura. Nesta figura é possível observar que na mesma condição de polarização de porta a transcondutância para o dispositivo com fonte de $\mathrm{Si}_{0,73} \mathrm{Ge}_{0,23}$ é maior que para o dispositivo com fonte de Si, devido ao BTBT ser o mecanismo dominante com tensões de porta maiores que 1,56 V (60), enquanto que para o dispositivo com fonte de silício é necessário uma polarização de 1,9 V. O dispositivo com fonte de $\mathrm{Si}_{0,73} \mathrm{Ge}_{0,23}$ possui uma maior transcondutância até com polarização de 1,35 V, polarização na qual BTBT não é o mecanismo dominante. Analisando o efeito da temperatura, ao aumenta-la todos os dispositivos, para todas as polarizações aumentam, pois a temperatura aumenta a condução por todos os mecanismos (BTBT, TAT e SRH).

Figura 4.17 - Transcondutância experimental em função da temperatura do nTFET nanofio para diferentes composições de fonte.

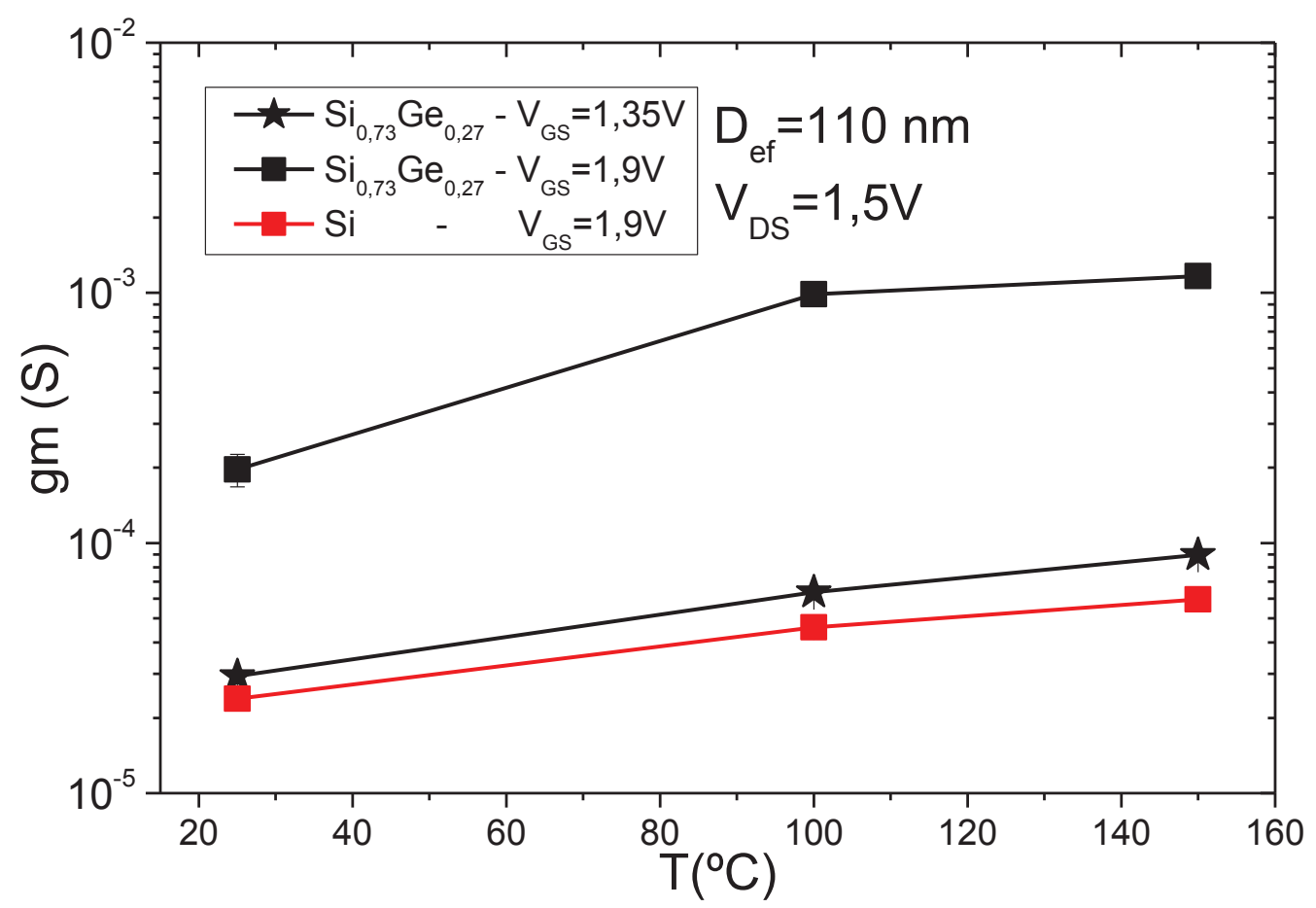

Fonte: Autor.

A condutância de saída em função da temperatura é apresentada na Figura 4.18 e através dela é possível observar que na mesma condição de polarização a 
condutância de saída é maior para o dispositivo com fonte de $\mathrm{Si}_{0,73} \mathrm{Ge}_{0,23}$ do que no dispositivo com fonte de Si. Como o BTBT é mais dependente da tensão no dreno, o dispositivo com fonte de $\mathrm{Si}_{0,73} \mathrm{Ge}_{0,23}$ possui uma condutância de saída mais pronunciada. Também deve ser levado em consideração o fato de este dispositivo possuir resistência série maior que o dispositivo com fonte de $\mathrm{Si}$, o que contribui com a degradação da condutância de saída.

Figura 4.18 - Condutância de saída experimental em função da temperatura do nTFET nanofio para diferentes composições de fonte.

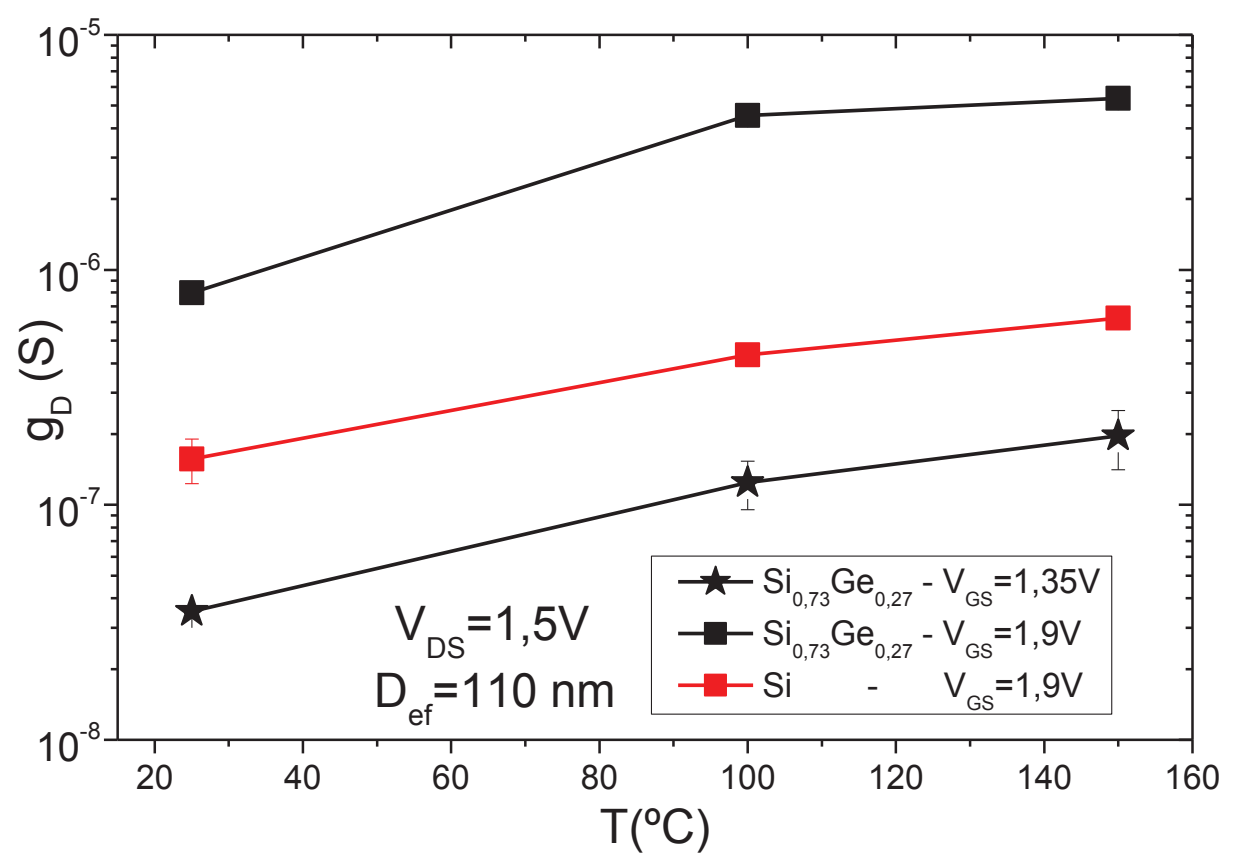

Fonte: Autor.

Comparando os dispositivos através da mesma corrente de dreno, é possível observar que o dispositivo de $\mathrm{Si}_{0,73} \mathrm{Ge}_{0,23} \mathrm{com}$ polarização de $1,35 \mathrm{~V}$ na porta possui uma energia de ativação de $0,15 \mathrm{eV}$, enquanto o dispositivo com fonte de Si possui $0,12 \mathrm{eV}$ (Figura 4.2). Assim como foi explicado no item 2.4.1, é possível afirmar que o BTBT é mais pronunciado no dispositivo com fonte de Si com 1,9 V de porta, do que no dispositivo $\mathrm{Si}_{0,73} \mathrm{Ge}_{0,23} \mathrm{com} 1,35 \mathrm{~V}$ de porta, o que resulta em uma maior condutância de saída para o dispositivo com fonte de Si.

Com o aumento da temperatura, independente da polarização de porta e do tipo do dispositivo, a condutância de saída aumenta. Quando considerado o dispositivo $\mathrm{Si}_{0,73} \mathrm{Ge}, 23$ com polarização de $1,9 \mathrm{~V}$ na porta é dominado principalmente por BTBT, a influência da tensão de dreno com a temperatura é ainda maior. 
Uma importante figura de mérito que também foi analisada é a eficiência do transistor, e sua curva em função da corrente de dreno para diferentes temperaturas é apresentada na Figura 4.19. Inicialmente, através desta figura, é possível observar que a eficiência para o dispositivo com fonte de $\mathrm{Si}_{0,73} \mathrm{Ge}_{0,23}$ é maior do que no dispositivo com fonte de Si devido à maior sobreposição entre bandas gerada pela menor largura da banda proibida de energia. Embora a eficiência seja maior nos dispositivos com fonte de $\mathrm{Si}_{0,73} \mathrm{Ge}_{0,23}$, o dispositivo com fonte de Si possui um platô em sua curva, indicando uma maior estabilidade do ganho com potências diferentes.

A análise da temperatura mostra que a eficiência, para ambos os dispositivos é deslocada para o sentido de maior corrente conforme se aumenta a temperatura. Este comportamento ocorre devido ao aumento de todos os mecanismos de condução de corrente com o aumento da temperatura. Com o aumento da corrente gerada por TAT e SRH, a corrente lofF aumenta, crescendo a corrente mínima dos dispositivos. Entretanto, o aumento de BTBT faz com que a corrente Ion cresça, levando a impressão de que a curva estaria deslocada.

Figura 4.19 - Curva experimental da eficiência em função da corrente de dreno para um dispositivo nTFET nanofio com fonte de Si puro para diferentes temperaturas.

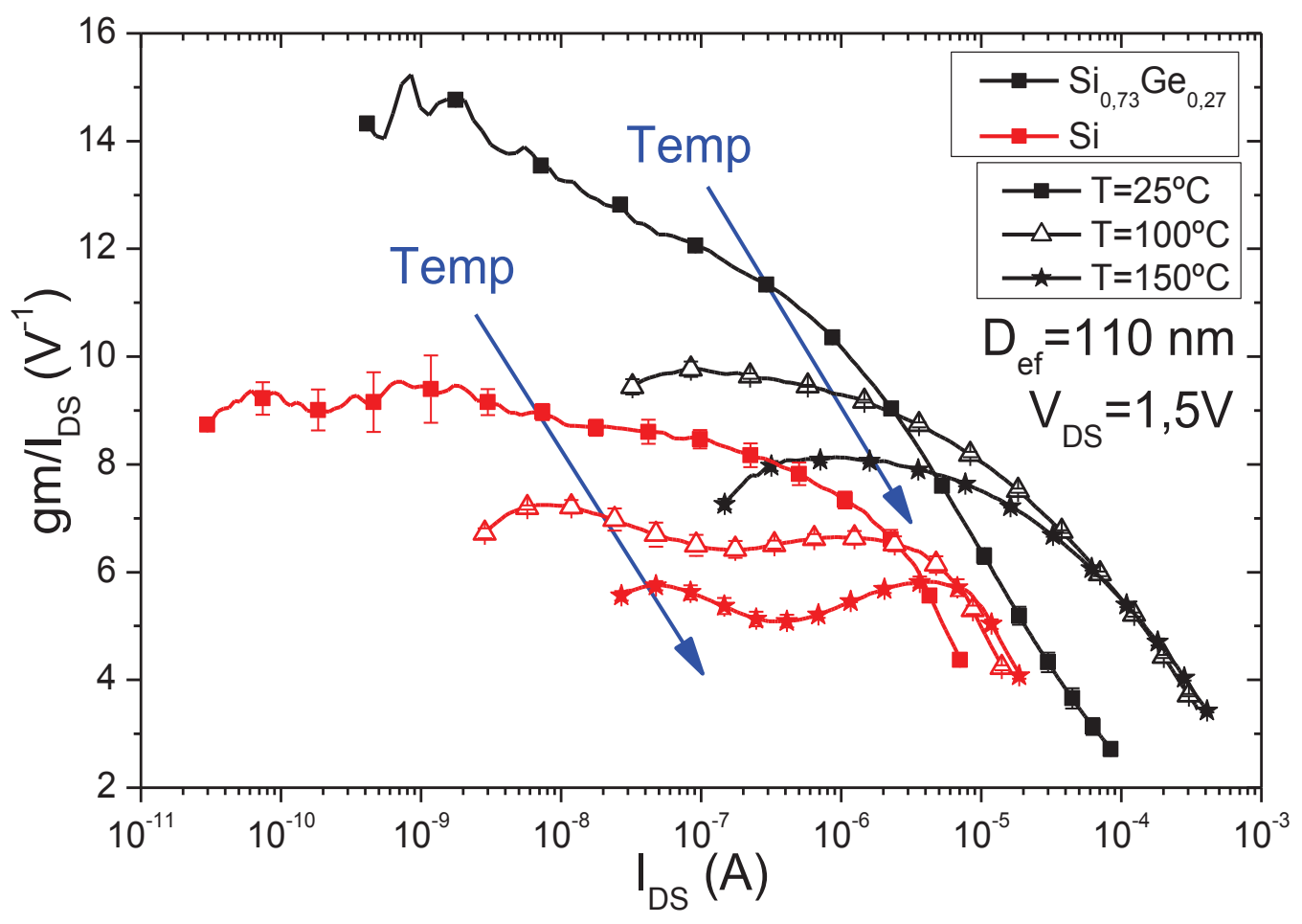

Fonte: Autor. 
Como a corrente loff cresce mais do que a corrente lon, devido a maior vulnerabilidade do TAT e do SRH com a temperatura, a inclinação de sublimiar aumenta. Esse aumento gera a degradação da eficiência devido à alta dependência da eficiência com a inclinação de sublimiar na condição de baixa condução de corrente.

Temperaturas altas na região de alta condução de corrente levam a um aumento da corrente lon e da transcondutância, o que resultam em uma melhora da eficiência. Devido a ambos os fatores, a curva da eficiência possui um ponto de cruzamento entre as curvas de diferentes temperaturas, tanto no dispositivo com fonte de $\mathrm{Si}_{0,73} \mathrm{Ge}_{0,23}$, quanto no dispositivo com fonte de Si.

Outro parâmetro que deve ser estudado para melhor entender a influência da temperatura nos dispositivos TFETs é a tensão Early. A Figura 4.20 mostra a tensão Early em função da temperatura. Para o dispositivo com fonte de Si, a tensão Early é menor quando comparada a ambas as polarizações do dispositivo com fonte de $\mathrm{Si}_{0,73} \mathrm{Ge}_{0,23}$ devido ao seu baixo nível de corrente.

Figura 4.20 - Tensão Early experimental em função da temperatura do nTFET nanofio para diferentes composições de fonte.

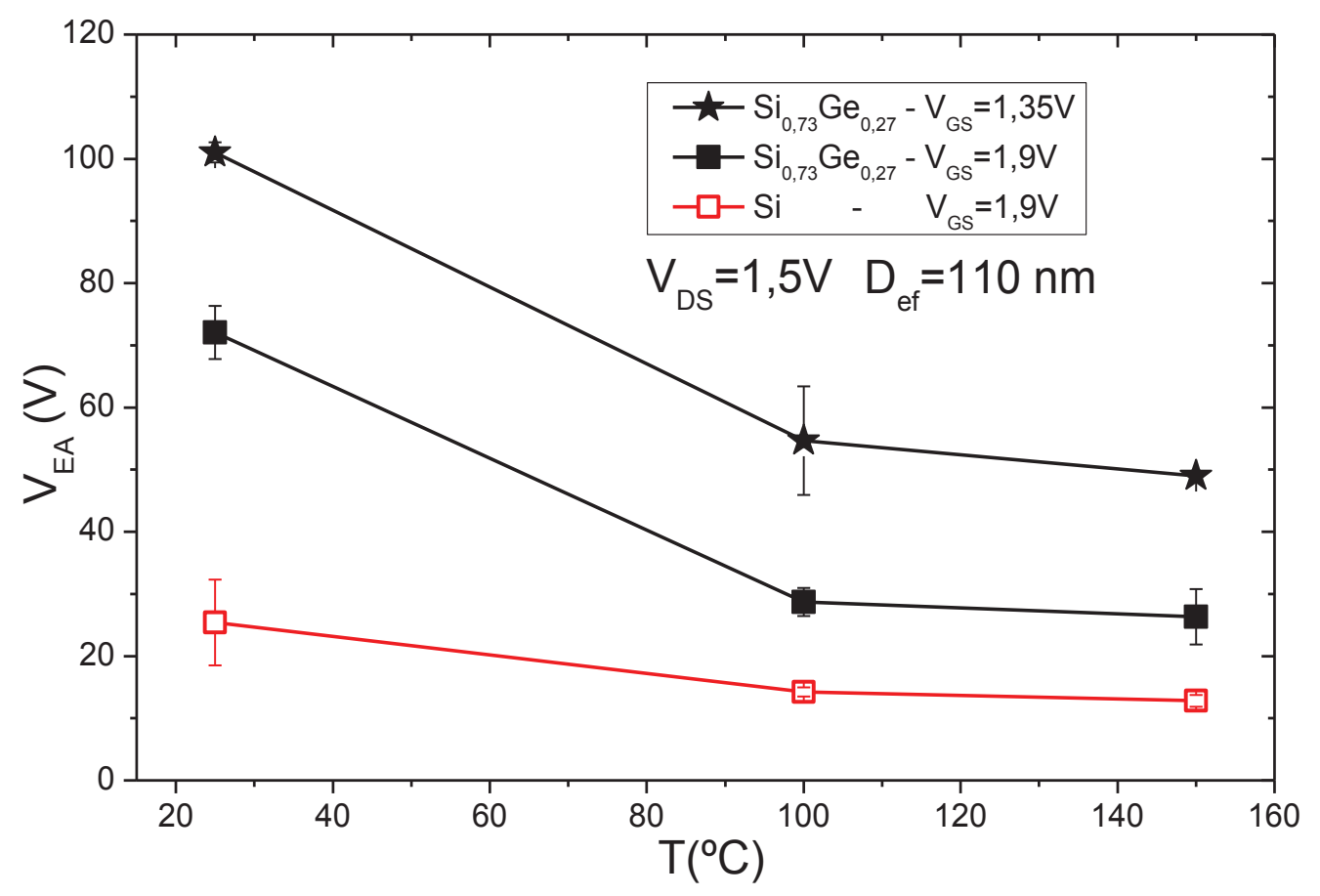

Fonte: Autor. 
O dispositivo com fonte de $\mathrm{Si}_{0,73} \mathrm{Ge}_{0,23}$ quando polarizado com 1,9 V na porta, embora possua uma alta condutância de saída, possui uma maior tensão Early que o dispositivo com fonte de Si devido a sua alta corrente. Embora o dispositivo com fonte de $\mathrm{Si}_{0,73} \mathrm{Ge}_{0,23}$ polarizado com 1,35 V possua corrente igual à corrente do dispositivo com fonte de Si, devido ao seu baixo valor de condutância de saída, ele possui a maior tensão Early.

Com o aumento da temperatura, para todos os dispositivos, embora a corrente de dreno aumente, a condutância de saída também aumenta, degradando a tensão Early.

A Tabela 4-2 apresenta o ganho intrínseco de tensão e a eficiência em função da temperatura, com o cálculo do ganho feito pela equação 2.16. É possível notar que o menor ganho obtido é para o dispositivo com fonte de $\mathrm{Si}$, pois ele possui a menor tensão Early. O dispositivo com fonte de $\mathrm{Si}_{0.73 \mathrm{Ge}} \mathrm{G}_{27}$ polarizado com tensão de porta em 1,9 V está perto do regime de saturação do BTBT, causando baixos valores de tensão Early e, como para valores mais altos de corrente de dreno a eficiência é menor, o ganho intrínseco de tensão é um pouco maior que no dispositivo com fonte de Si.

Tabela 4-2 - Tabela experimental da eficiência do transistor e do ganho intrínseco de tensão em um dispositivo nTFET nanofio com diferentes fontes para diferentes temperaturas.

\begin{tabular}{|c|c|c|c|c|c|c|}
\hline \multirow{2}{*}{$\mathrm{T}\left({ }^{\circ} \mathrm{C}\right)$} & \multicolumn{3}{|c|}{$\mathrm{gm} / \mathrm{IDS}_{\mathrm{DS}}\left(\mathrm{V}^{-1}\right)$} & \multicolumn{3}{c|}{$\mathrm{Av}(\mathrm{dB})$} \\
\cline { 2 - 7 } & \multicolumn{2}{|c|}{$\mathrm{Si}_{0.73 \mathrm{Ge}_{0.27}}$} & $\mathrm{Si}$ & \multicolumn{2}{c|}{$\mathrm{Si}_{0.73 \mathrm{Ge}_{0.27}}$} & $\mathrm{Si}$ \\
\cline { 2 - 7 } & $\mathrm{V}_{\mathrm{GS}}=1.35 \mathrm{~V}$ & $\mathrm{~V}_{\mathrm{GS}}=1.9 \mathrm{~V}$ & $\mathrm{~V}_{\mathrm{GS}}=1.9 \mathrm{~V}$ & $\mathrm{~V}_{\mathrm{GS}}=1.35 \mathrm{~V}$ & $\mathrm{~V}_{\mathrm{GS}}=1.9 \mathrm{~V}$ & $\mathrm{~V}_{\mathrm{GS}}=1.9 \mathrm{~V}$ \\
\hline 25 & 8.3 & 3.1 & 5.6 & 58.5 & 47.1 & 42.8 \\
\hline 100 & 8.2 & 4.1 & 5.3 & 53.0 & 41.4 & 37.5 \\
\hline 150 & 7.4 & 4.0 & 5.0 & 51.1 & 40.3 & 36.2 \\
\hline
\end{tabular}

O dispositivo com fonte de $\mathrm{Si}_{0.73} \mathrm{Ge}_{0.27}$ polarizado com $1,35 \mathrm{~V}$ no dreno é o que apresenta o maior valor de tensão Early devido ao TAT ser mais influente nele do que no dispositivo com fonte de Si. Neste caso, como a corrente de dreno não é alta, a eficiência não é prejudicada, resultando no maior ganho intrínseco para este dispositivo, nesta polarização. 
Ao considerar o efeito da temperatura, para todos os tipos de dispositivos e polarizações, a eficiência e a tensão Early tendem a cair, resultando em uma maior degradação do ganho intrínseco de tensão. 


\subsubsection{Estudo da composição de fonte}

Nesta seção é realizada uma análise comparativa entre tipos de fonte diferentes para estes dispositivos nTFET com estruturas de nanofios com canal e dreno de Si. Além das fontes de $\mathrm{Si}$ e de $\mathrm{Si}_{0,73} \mathrm{Ge}_{0,27}$, neste estudo foi acrescentada uma fonte pura de Ge, para avaliar melhor o comportamento dos NW-TFETs de heterojunção.

A curva de IDs experimental em função de VGS para os três dispositivos é apresentado na Figura 4.21. Nesta figura é possível observar que o dispositivo com fonte de Ge possui a mais alta IoN, devido ao seu menor $E_{G}(0,66 \mathrm{eV})$. A redução de EG faz com que o comprimento tunelamento seja reduzido, aumentando a componente de BTBT na corrente. Esta redução de $E_{G}$ também é responsável pela redução de VoN, como podem ser vistos os dispositivos de $\mathrm{Ge}$ e $\mathrm{Si}_{0,73} \mathrm{Ge}_{0,27}$.

Apesar do uso da fonte de Ge apresentar alto Ion, ele aumenta muito pouco loff, comparado ao dispositivo com fonte de Si, resultando em uma melhoria também da relação lon/loff.

Figura 4.21 - Corrente de dreno experimental em função da tensão na porta do nTFET nanofio com diferentes composições de fonte.

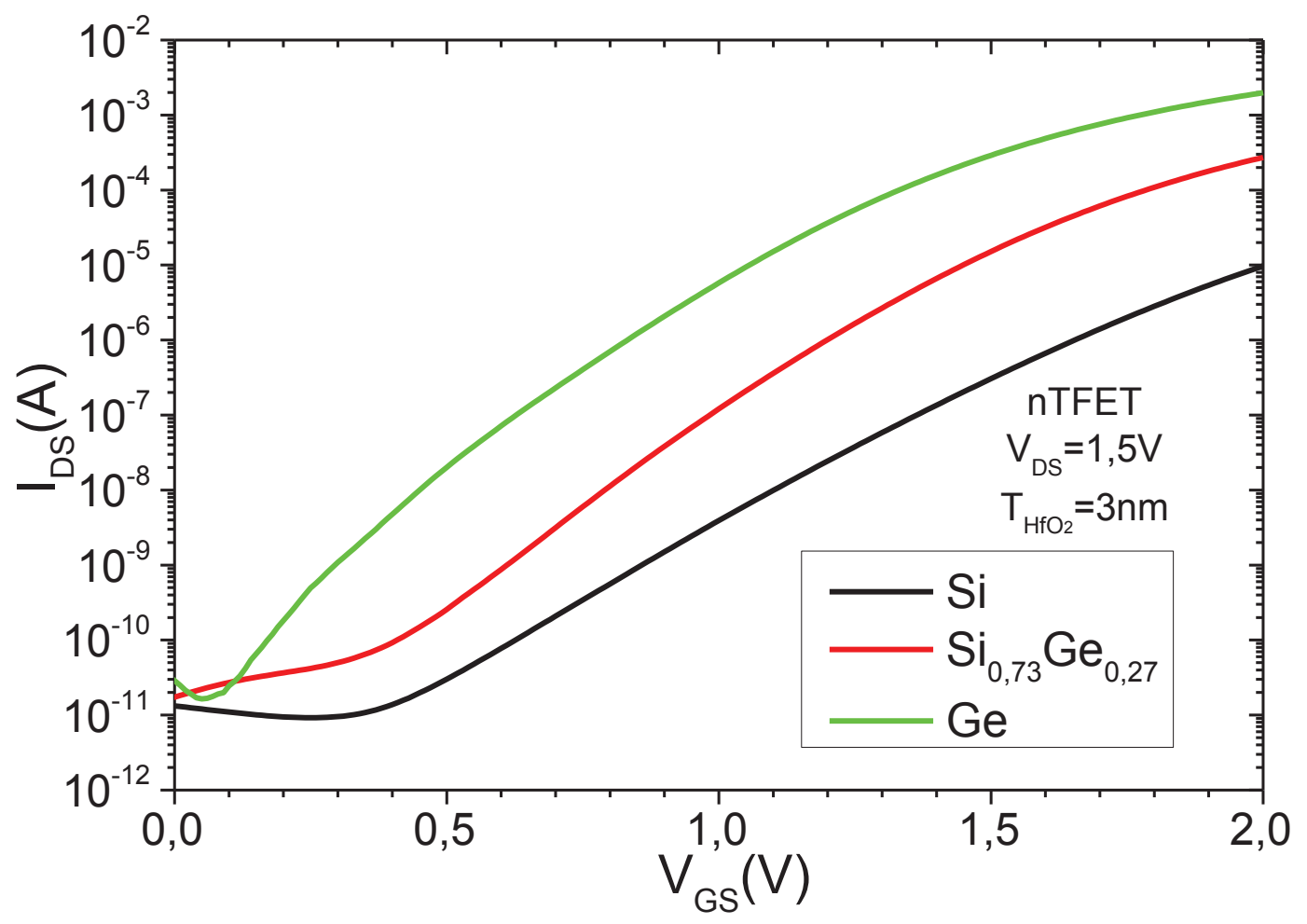

Fonte: Autor. 
Conforme a porcentagem de Ge na fonte aumenta, menor o seu $\mathrm{E}_{\mathrm{G}}$, aumentando a sua componente de BTBT. Essa maior componente de BTBT pode ser observada pela menor energia de ativação (Figura 4.22), onde $E_{A}$ é reduzida a medida que a porcentagem de Ge na fonte aumenta.

Figura 4.22 - Energia de ativação em função da tensão na porta do nTFET nanofio com diferentes composições de fonte.

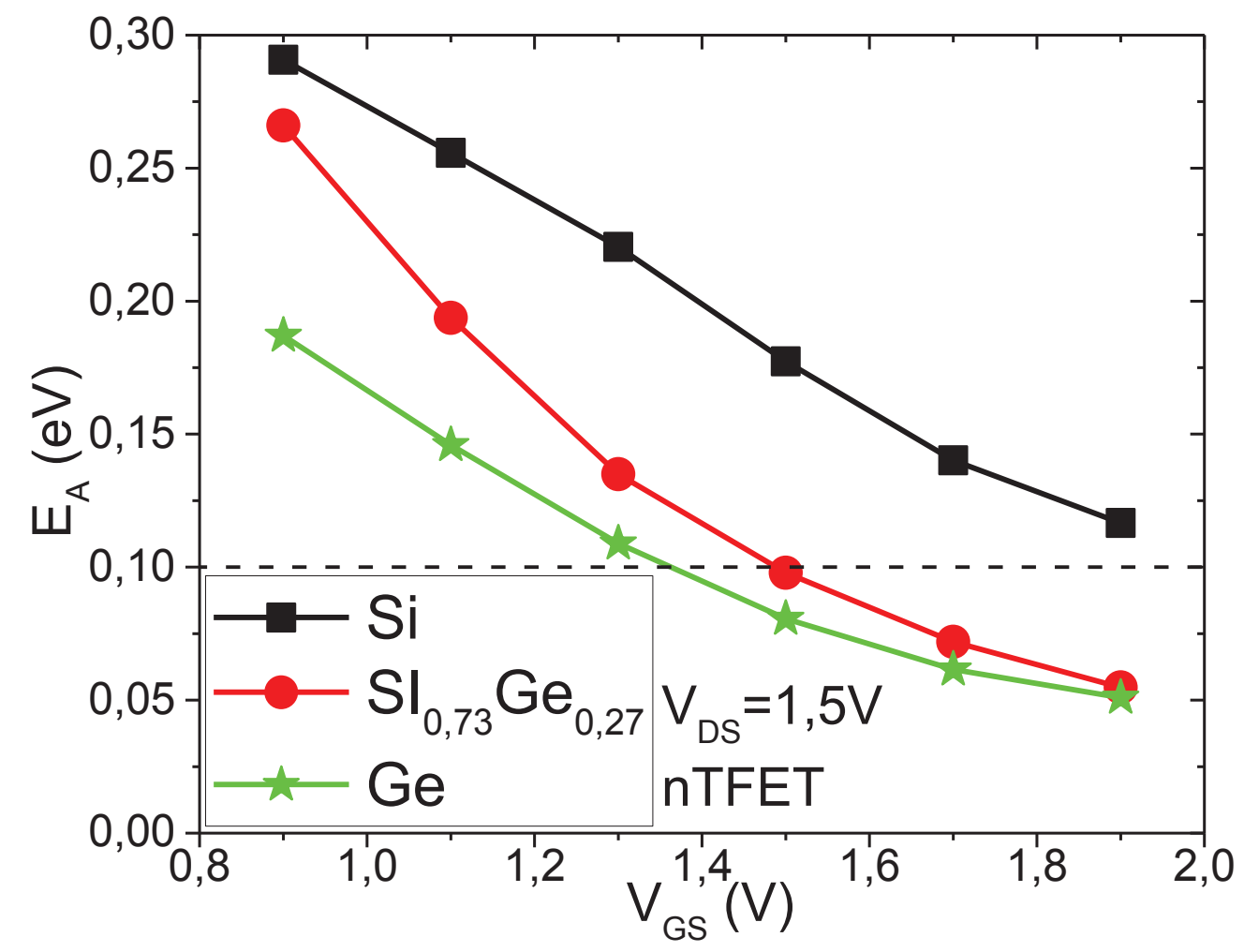

Fonte: Autor.

Observando a eficiência do transistor em função de IDs normalizada (Figura 4.23), é possível estudar o comportamento dos 3 dispositivos estudados para diferentes regimes de condução de corrente. Nesta figura, pode ser notado que para maiores porcentagens de Ge na fonte, gm/lDs aumenta para todo o range de IDS, devido à maior componente de BTBT, o que resulta em melhor SS (regime de baixa condução de corrente) e maior gm (regime de alta condução de corrente).

A Figura 4.24 apresenta os valores de gm/lDs extraídos para uma corrente fixa em regime de baixa condução de corrente, em regime de alta condução de corrente, e também para um $\mathrm{V}_{\mathrm{GS}}$ fixo de 1,9 V.

Em regime de baixa condução de corrente, a redução de $E_{G}$ em dispositivos com maior porcentagem de Ge na fonte causa uma redução de SS. Essa redução de 
SS é responsável pelo aumento de gm/lDs. Em regime de alta condução de corrente, como a comparação é feita utilizando a mesma IDs, e a transcondutância é maior para dispositivos com maior porcentagem de Ge, gm/lDs também é maior nos dispositivos de Ge.

Figura 4.23 - Eficiência do transistor em função da corrente de dreno de nTFET nanofios com diferentes composições de fonte.

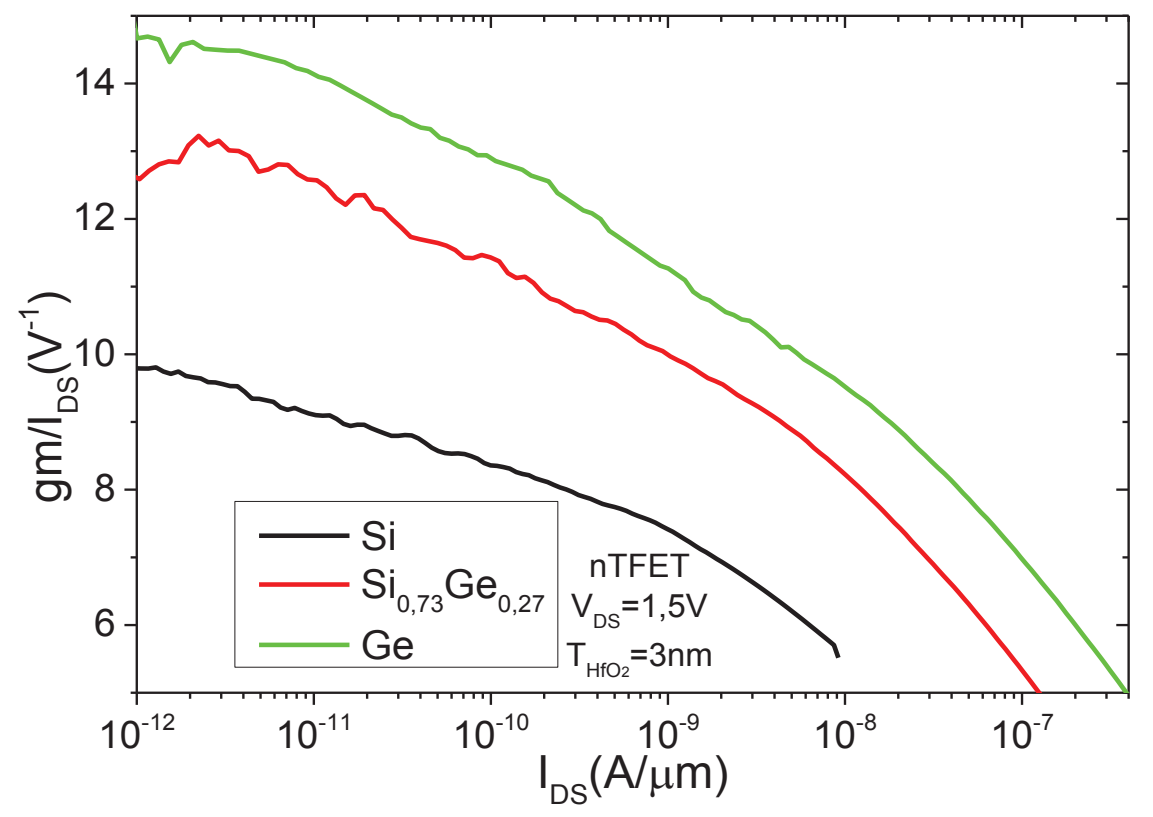

Fonte: Autor.

Figura 4.24 - Valores extraídos da eficiência do transistor em diferentes condições de condução de corrente para nTFET nanofios com diferentes composições de fonte.

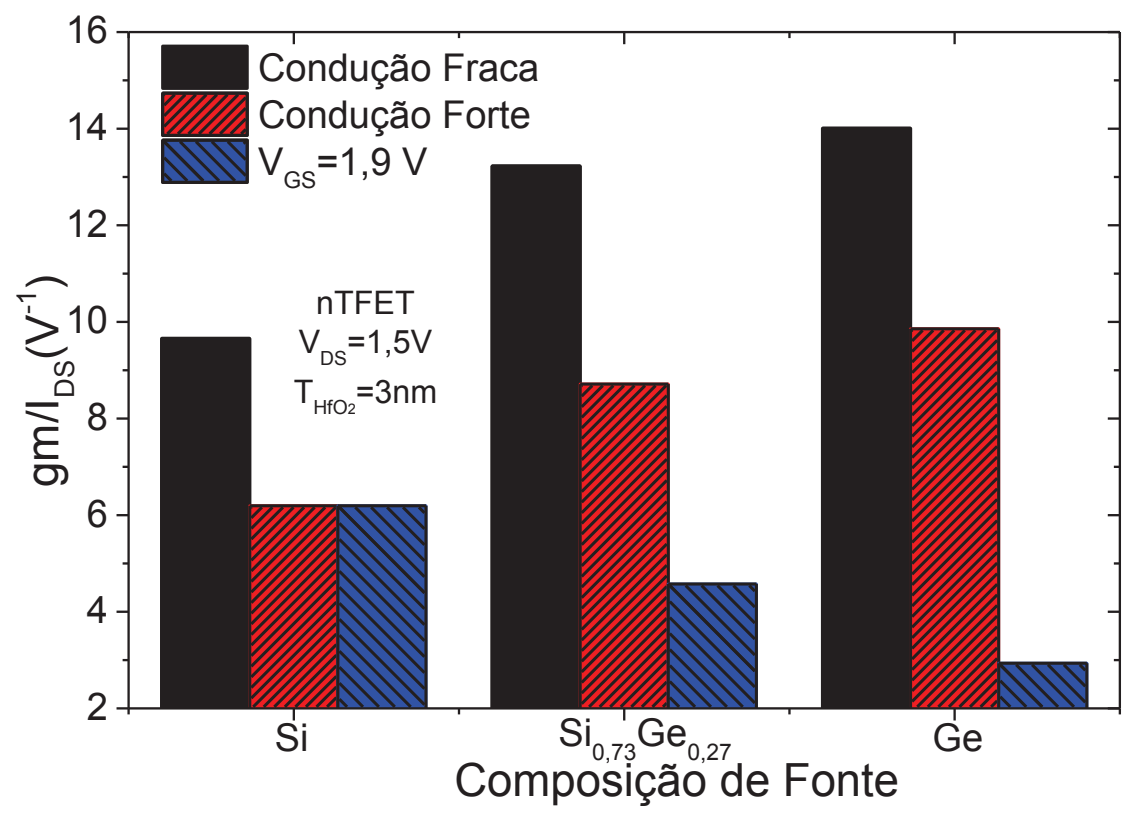

Fonte: Autor. 
Entretanto, quando comparados com uma polarização fixa ( $\left.\mathrm{V}_{\mathrm{GS}}=1,9 \mathrm{~V}\right)$, um comportamento oposto pode ser observado. Neste caso, o aumento da porcentagem de $\mathrm{Ge}$ degrada gm/lDs. Este comportamento pode ser explicado pela maior IDs em dispositivos de $\mathrm{Ge}$, ficando mais evidenciado que a melhoria em gm nesta polarização.

A figura Figura 4.25 apresenta os valores de $V_{E A}$ para as diferentes composições de fonte. Considerando a mesma corrente, em ambos os regimes de condução de corrente, dispositivos com maior porcentagem de Ge apresentam maior VEA. Isto ocorre porque quando comparados à mesma corrente, os dispositivos de $\mathrm{Ge}$ apresentam menor componente BTBT. Como pode ser observado na Figura 4.26, comparando em um mesmo nível de corrente, o nível de $\mathrm{E}_{\mathrm{A}}$ aumenta com o aumento da porcentagem de $\mathrm{Ge}$, mostrando que os dispositivos de menor porcentagem de $\mathrm{Ge}$ possuem maior componente de BTBT quando comparados à mesma corrente. Como a componente $B$ TBT é mais influenciada por $V_{D S}$, faz com que dispositivos com maior porcentagem de $\mathrm{Ge}$ apresentem maior $\mathrm{VEA}_{\mathrm{EA}}$ quando comparados sob a mesma corrente.

Figura 4.25 - Tensão Early em diferentes condições de condução de corrente para nTFET nanofios com diferentes composições de fonte.

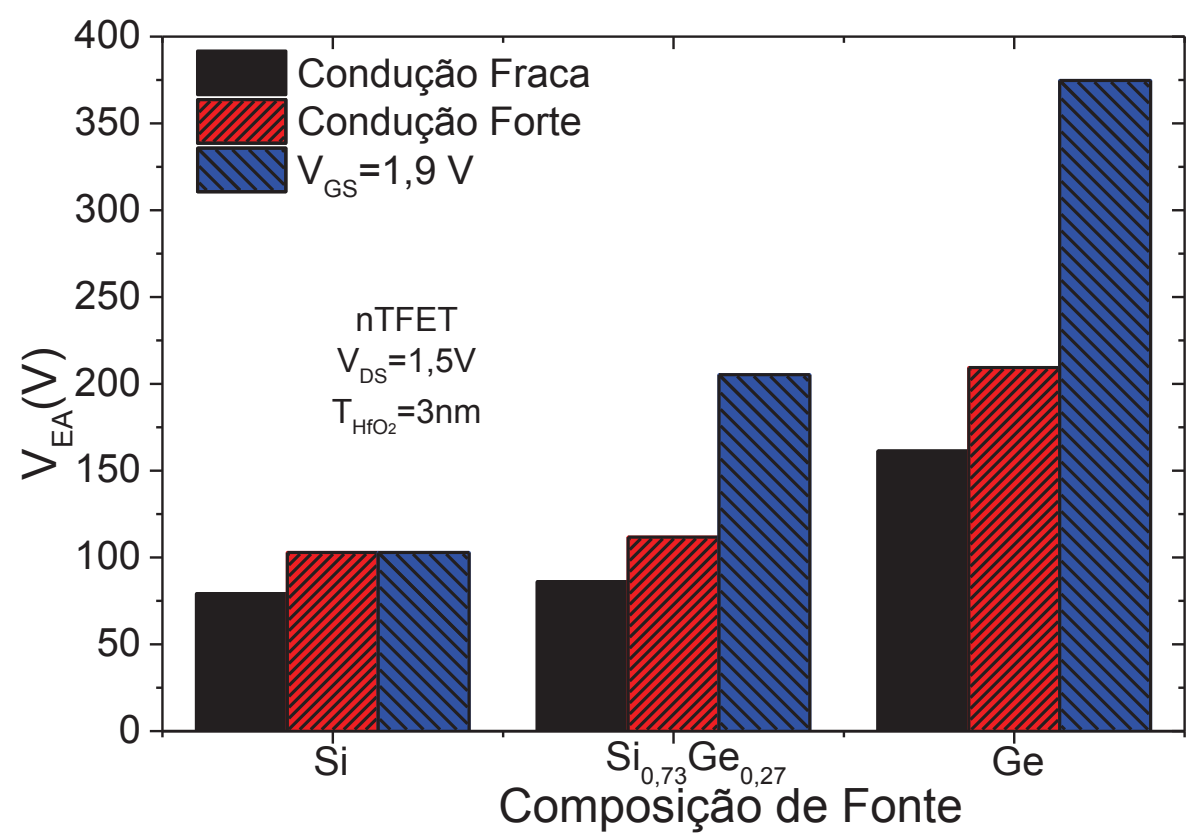

Fonte: Autor.

Quando a porta é polarizada em $1,9 \mathrm{~V}$, há uma competição de fatores, entre o mecanismo de condução e o nível de corrente. Como Von é menor para maiores 
porcentagens de $\mathrm{Ge}$, à mesma polarização de porta eles possuem maior influência da componente de BTBT, como pode ser observado na Figura 4.26, onde os valores de $E_{A}$ diminuem para maiores concentrações de Ge, quando comparadas com uma mesma polarização. $\mathrm{O}$ aumento da componente de BTBT para dispositivos com maior porcentagem de Ge na fonte faz com que a influência de VDs aumente, degradando $V_{E A}$. Entretanto, o aumento de lDS para dispositivos com maiores porcentagens de Ge tende a aumentar $V_{E A}$. Como o aumento de lDs é maior do que a degradação gerada pela maior influência de $V_{D S}$, uma grande melhoria de $V_{E A}$ pode ser observada. Uma representação desta competição de fatores pode ser melhor observada na Figura 4.27 .

Figura 4.26 - Energia de ativação em diferentes condições de condução de corrente para nTFET nanofios com diferentes composições de fonte.

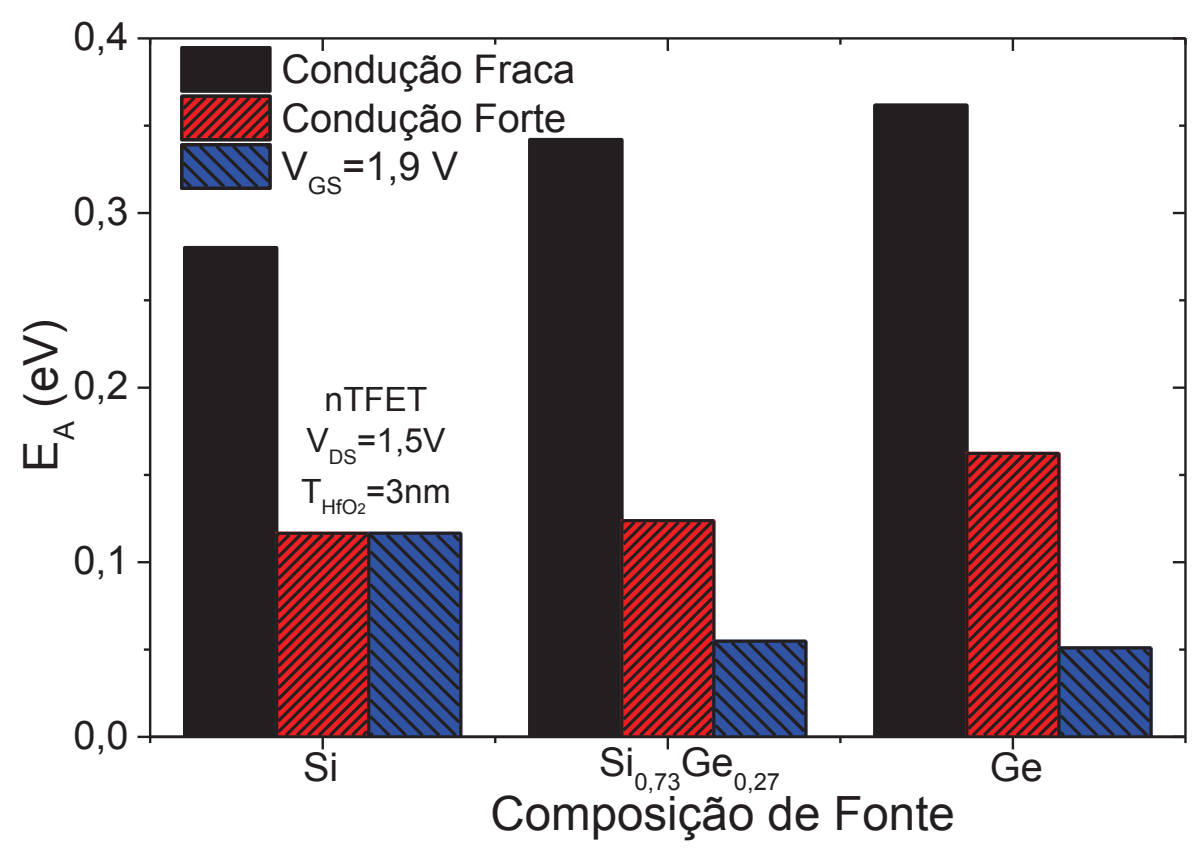

Fonte: Autor.

$A$ análise de $A v$ (Figura 4.28) foi feita também comparando com a mesma polarização ( $V_{G S}=1,9 \mathrm{~V}$ ), e o mesmo nível de corrente em condição de condução fraca e forte. Entre todas as comparações, os melhores ganhos foram obtidos em regime de baixa condução de corrente. Embora o mecanismo de TAT possui forte influência neste regime de condução e os valores de $\mathrm{V}_{\mathrm{EA}}$ sejam menores que os valores obtidos para alta condução de corrente, em regime de baixa condução de corrente gm/lDS passa a ser o fator predominante em Av. 
Figura 4.27 - Energia de ativação em diferentes condições de condução de corrente para nTFET nanofios com diferentes composições de fonte.

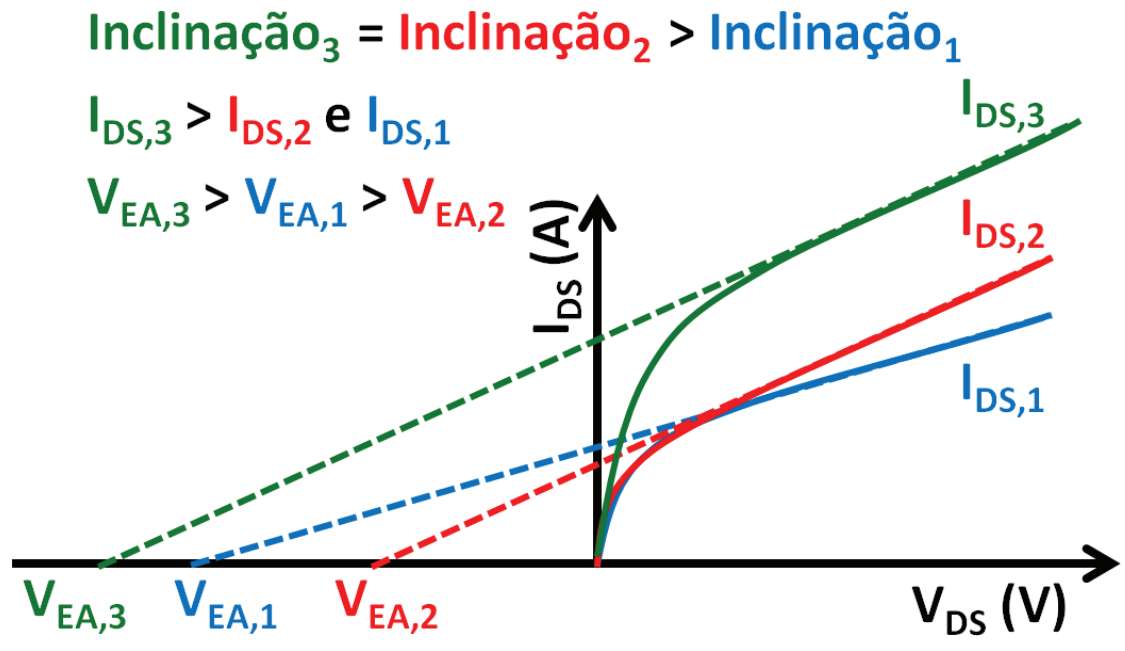

Fonte: Autor.

Considerando a influência da porcentagem de Ge, fica notável que para as 3 diferentes comparações feitas os dispositivos com maior porcentagem de $\mathrm{Ge}$ possuem maior Av. Comparando com a mesma polarização, mesmo com gm/lds diminuindo para porcentagens maiores de $\mathrm{Ge}, \mathrm{V}_{\mathrm{EA}}$ aumenta consideravelmente, resultando em um aumento de Av para maiores porcentagens de Ge.

Figura 4.28 - Ganho intrínseco de tensão em diferentes condições de condução de corrente para nTFET nanofios com diferentes composições de fonte.

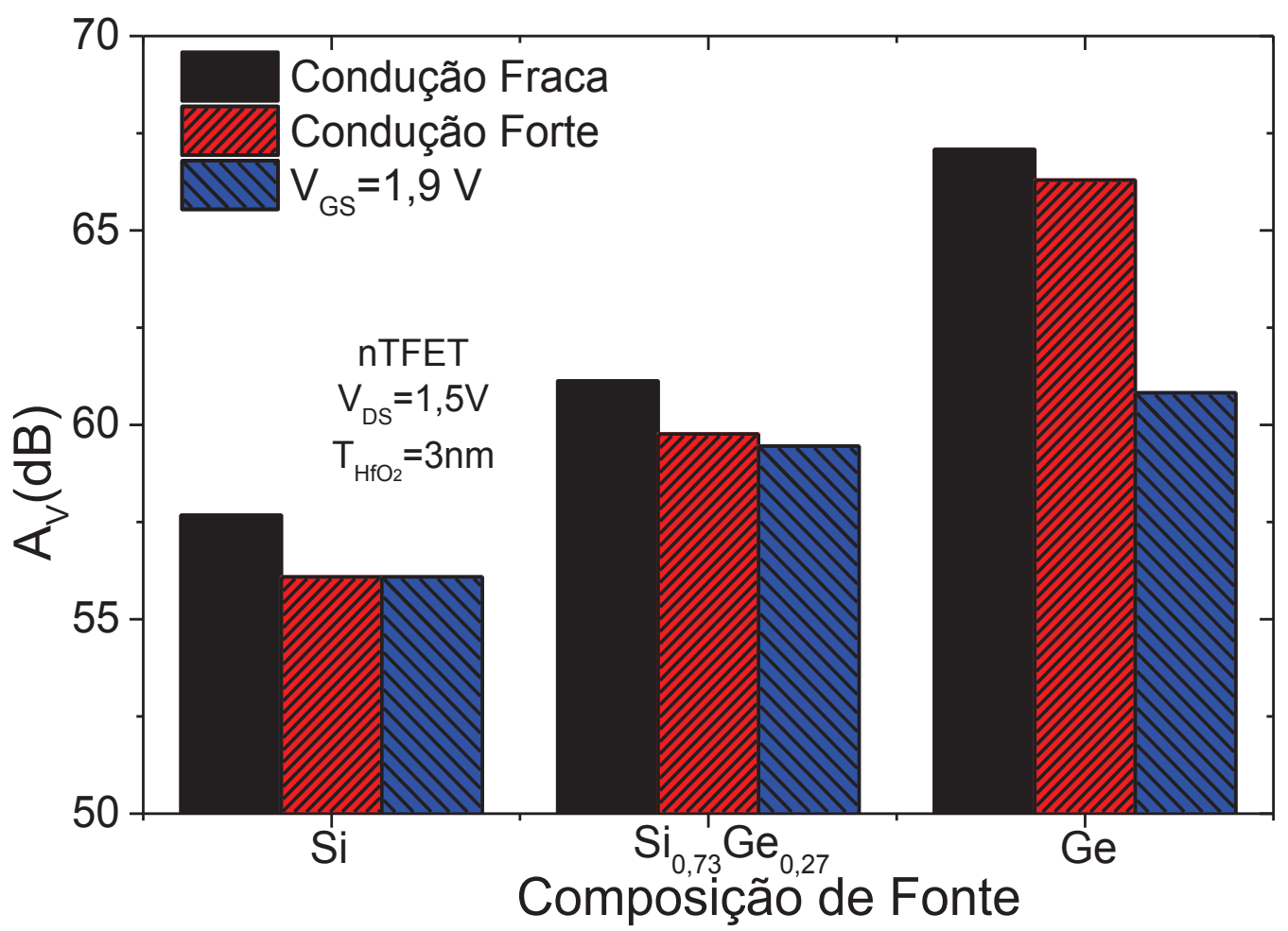

Fonte: Autor. 
Como os dispositivos com fonte de Ge se mostraram os melhores entre os dispositivos estudados, uma análise comparativa da redução da espessura de $\mathrm{HfO}_{2}$ de $3 \mathrm{~nm}$ para $2 \mathrm{~nm}$ na composição do dielétrico de porta foi realizada para estes dispositivos. A Figura 4.29 mostra a IDS em função de VGs para ambas as espessuras de $\mathrm{HfO}_{2}$. Nesta figura é possível notar que o dispositivo de $2 \mathrm{~nm}$ de $\mathrm{HfO}_{2}$, embora possua maior loff devido ao aumento da corrente de porta, possui melhor acoplamento eletrostático, resultando em maior lon e em melhorias nas características de sublimiar.

Figura 4.29 - Corrente de dreno experimental em função da tensão na porta para nTFET nanofio com fonte de $\mathrm{Ge}$, com diferentes espessuras de $\mathrm{HfO}_{2}$.

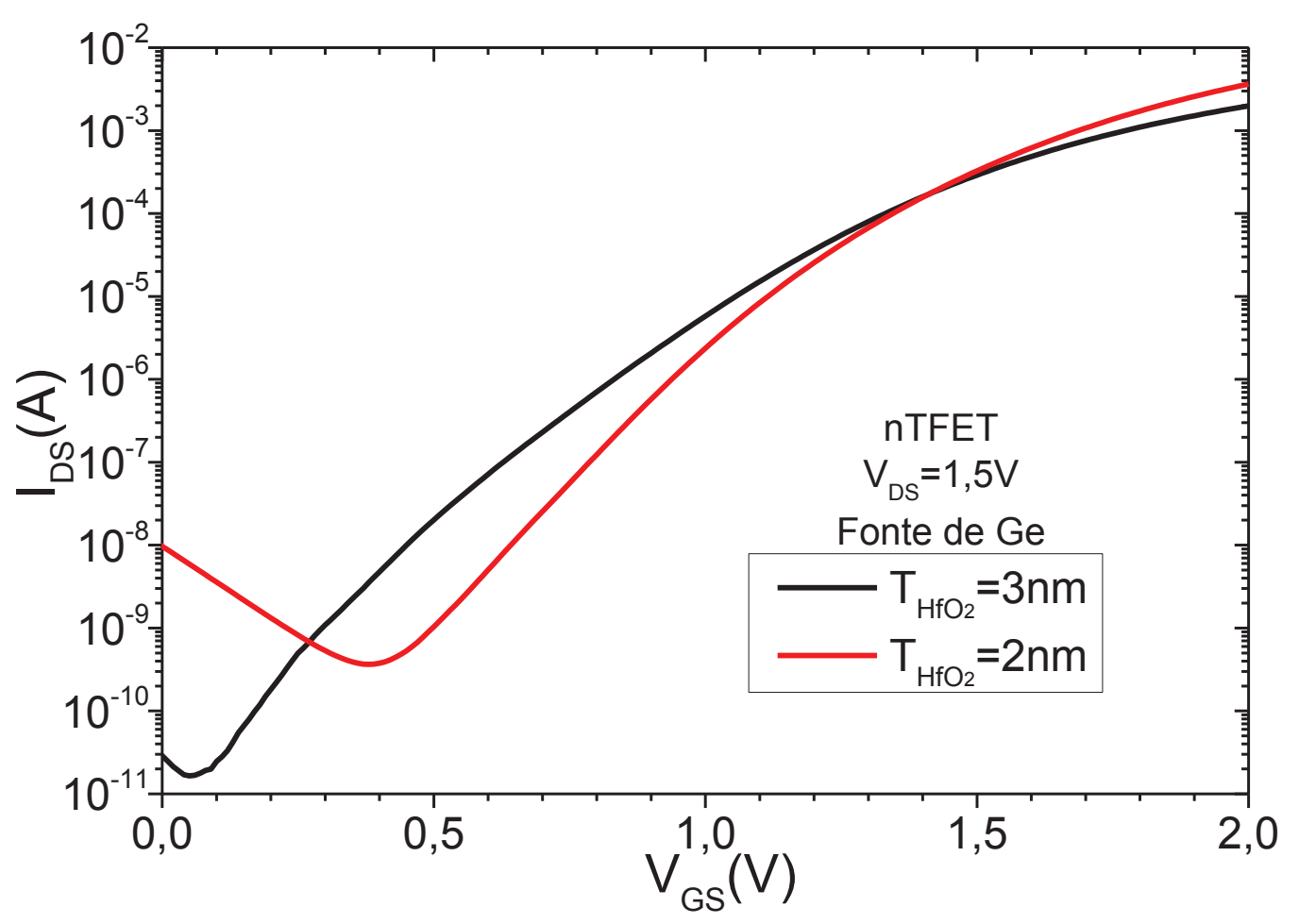

Fonte: Autor.

Estas melhorias podem ser também observadas na curva de gm/los em função de IDs normalizada (Figura 4.30), onde o dispositivo de $2 \mathrm{~nm}$ de $\mathrm{HfO}_{2}$ possui valores maiores valores de $\mathrm{gm} / \mathrm{IDS}_{\mathrm{DS}}$ tanto para o regime de baixa condução de corrente, devido a seu melhore SS, quanto em regime de alta condução, devido ao seu maior gm. Mesmo comparando à mesma polarização de porta o dispositivo com $2 \mathrm{~nm}$ de $\mathrm{HfO}_{2}$ possui valores de $\mathrm{gm} / \mathrm{l}$ Ds maiores.

A Tabela 4-3 mostra os valores de VEA e Av para ambos os dispositivos. O dispositivo de $2 \mathrm{~nm}$ de $\mathrm{HfO}_{2}$ possui maiores valores de $\mathrm{V}_{\mathrm{EA}}$ tanto para baixo quanto 
para alto regime de condução de corrente. Entretanto, quando comparado para o mesmo $\mathrm{V}_{\mathrm{GS}}$, o dispositivo de $2 \mathrm{~nm}$ de $\mathrm{HfO}_{2}$ possui uma degradação de $\mathrm{V}_{\mathrm{EA}}$, causada pela maior influência do mecanismo de BTBT neste dispositivo.

Figura 4.30 - Eficiência do transistor em função da tensão na porta para nTFET nanofio com fonte de $\mathrm{Ge}$, com diferentes espessuras de $\mathrm{HfO}_{2}$.

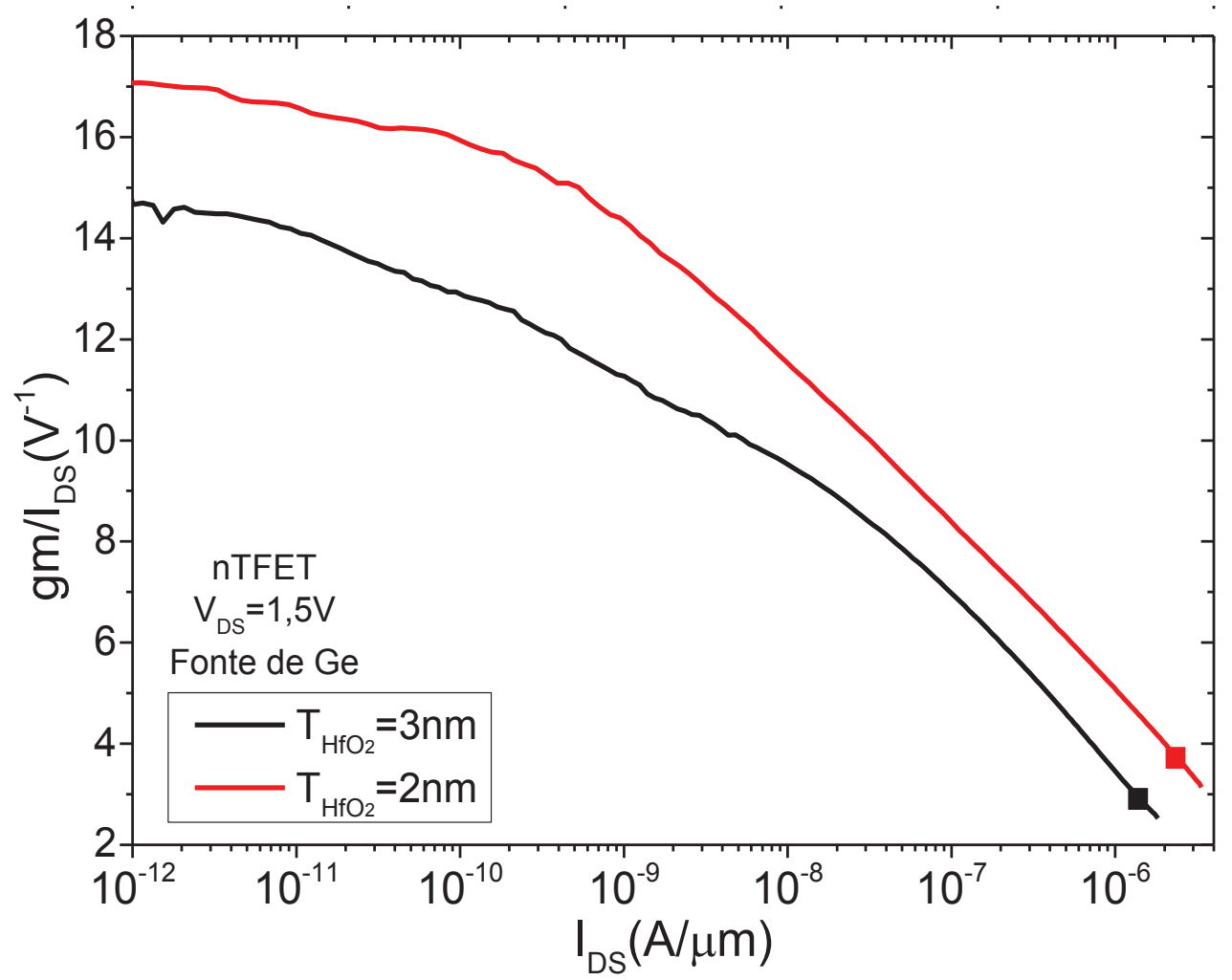

Fonte: Autor.

Considerando o $A v$, em ambos os regimes de condução de corrente o dispositivo com $2 \mathrm{~nm}$ de $\mathrm{HfO}_{2}$ possui maior $\mathrm{A}_{V}$ devido à melhoria de gm/lDs e de $\mathrm{V}_{\mathrm{EA}}$. Entretanto, para $\mathrm{V}_{\mathrm{GS}}=1,9 \mathrm{~V}$ o ganho para o dispositivo de $2 \mathrm{~nm}$ é degradado devido a degradação tanto de $V_{E A}$ quanto de gm/lDS.

Tabela 4-3 - Tabela da eficiência, tensão Early e ganho intrínseco para nTFET nanofio com fonte de $\mathrm{Ge}$, com diferentes espessuras de $\mathrm{HfO}_{2}$.

\begin{tabular}{|c|c|c|c|c|c|c|c|c|c|}
\hline \multirow{2}{*}{$\mathrm{T}_{\mathrm{HfO}_{2}}$} & \multicolumn{3}{|c|}{$\mathrm{gm} / \mathrm{IDS}_{\mathrm{DS}}\left(\mathrm{V}^{-1}\right)$} & \multicolumn{4}{c|}{$\mathrm{V}_{\mathrm{EA}}(\mathrm{V})$} & \multicolumn{3}{c|}{$\mathrm{AV}(\mathrm{dB})$} \\
\cline { 2 - 10 } & Fraca & Forte & $\mathrm{V}_{\mathrm{GS}}=1,9 \mathrm{~V}$ & Fraca & Forte & $\mathrm{V}_{\mathrm{GS}}=1,9 \mathrm{~V}$ & Fraca & Forte & $\mathrm{V}_{\mathrm{GS}}=1,9 \mathrm{~V}$ \\
\hline $3 \mathrm{~nm}$ & 14,01 & 9,86 & 2,93 & 161 & 209 & 375 & 67,1 & 66,3 & 60,8 \\
\hline $2 \mathrm{~nm}$ & 16,98 & 12,03 & 3,74 & 388 & 504 & 116 & 76,4 & 75,6 & 52,7 \\
\hline
\end{tabular}




\subsubsection{Conclusões parciais}

Neste capítulo foram estudados os efeitos da redução do diâmetro, do aumento da porcentagem de Ge na composição da fonte e do aumento da temperatura em dispositivos TFETs de Si em estruturas de nanofios verticais, com diâmetros do nanofios variando entre $15 \mathrm{~nm}$ e $167 \mathrm{~nm}$, e com comprimento de canal de $220 \mathrm{~nm}$. As principais influências destes efeitos estudados podem ser visualizadas na Tabela 4-4.

Tabela 4-4 - Tabela da influência da redução do diâmetro, do aumento da porcentagem de Ge e do aumento da temperatura nos parâmetros estudados.

\begin{tabular}{|c|c|c|c|}
\hline & Redução do diâmetro & $\begin{array}{c}\text { Aumento da } \\
\text { porcentagem de Ge }\end{array}$ & $\begin{array}{l}\text { Aumento da } \\
\text { temperatura }\end{array}$ \\
\hline $\mathrm{SRH}$ & Reduz a influência & Reduz a influência & Alta Influência \\
\hline TAT & Reduz a influência & Reduz a influência & Alta Influência \\
\hline BTBT & Aumenta a influência & Aumenta a influência & Baixa Influência \\
\hline IDS & Aumenta & Aumenta & Aumenta \\
\hline \multirow{2}{*}{ gm } & Baixo IDs: Aumenta & \multirow{2}{*}{ Aumenta } & \multirow{2}{*}{ Aumenta } \\
\hline & Alto IDs: Diminui & & \\
\hline gD & Aumenta & Aumenta & Aumenta \\
\hline \multirow{2}{*}{$\mathrm{gm} / \mathrm{l}_{\mathrm{DS}}$} & Baixo IDs: Aumenta & \multirow{2}{*}{ Aumenta } & Baixo IDS: Diminui \\
\hline & Alto IDS: Diminui & & Alto IDs: Aumenta \\
\hline$V_{E A}$ & Diminui & Aumenta & Diminui \\
\hline$A v$ & Diminui & Aumenta & Diminui \\
\hline
\end{tabular}

Ao reduzir o diâmetro observou-se que 0 diâmetro afeta algumas características e parâmetros dos transistores TFET. Tanto a transcondutância quanto a condutância de saída apresentaram redução com o estreitamento do diâmetro efetivo, devido à menor área de condução. Os resultados experimentais também sugeriram que quando a tensão na porta diminui, a corrente gerada pelo mecanismo de BTBT diminui, e, consequentemente, uma queda mais acentuada da condutância de saída (melhoria de gD) é observada com a redução do diâmetro.

Para diâmetros maiores, os dispositivos são menos influenciados pela redução do diâmetro. À medida que o diâmetro diminui, BTBT passa a ser o mecanismo de condução de corrente dominante ao longo da junção entre canal e fonte. Além disso, 
a tensão mínima para BTBT ser o mecanismo dominante também diminui. Esses dois efeitos combinados passam a gerar um aumento da corrente de dreno normalizada.

A simulação realizada, com o intuito de se obter valores menores de diâmetros, para extrapolar as análises realizadas experimentalmente, demonstrou que para diâmetros menores que $30 \mathrm{~nm}$, o BTBT é o mecanismo de condução dominante, ao longo de toda a profundidade na junção fonte/canal. Este comportamento, apesar de aumentar a transcondutância, resulta em uma maior degradação da condutância de saída e, consequentemente, degradando o ganho intrínseco de tensão.

Quando foi estudado o efeito da redução do diâmetro nas diferentes regiões de "condução" do transistor notou-se que a região equivalente a região de alta e de baixa condução de corrente possuem tendências de eficiência opostas. Na região de baixa condução de corrente, para o menor valor de diâmetro, a maior porcentagem da junção é dominada pelo mecanismo de BTBT, o que aumenta a eficiência devido ao melhor acoplamento e, portanto, melhor inclinação de sublimiar.

A predominância de BTBT para menores valores de diâmetro, apesar de melhorar a transcondutância e a eficiência, também degrada a condutância de saída devido a maior influência do potencial de dreno.

Apesar dos nTFETs de nanofios mais largos apresentarem melhor comportamento analógico na região de alta condução de corrente, diâmetros menores mostraram potencialidades para o uso em sistemas de baixa potência e baixa voltagem, pois dispositivos de diâmetros menores possuem melhor ganho intrínseco de tensão para tensões de porta mais baixas.

Ao analisar o efeito da temperatura em dispositivos com diferentes composições de fonte, foi possível observar que o aumento da temperatura aumenta tanto a corrente de estado ligado (ION), quanto a corrente de estado desligado (lofF). Esse aumento de ambas as correntes se deve ao aumento de todos os mecanismos de condução, BTBT, tunelamento induzido por armadilhas (TAT) e geração e recombinação $(\mathrm{SRH})$.

Na análise da eficiência do transistor a alta temperatura resultou na degradação do TFET na região de baixa condução de corrente, devido ao aumento de loff e 
melhora o TFET na região de alta condução de corrente, devido ao aumento da corrente lon.

A análise da influência do uso de materiais de fonte com diferentes porcentagens de Ge mostrou que o aumento a porcentagem de Ge na fonte reduz a largura da banda proibida de energia, que resulta em maior sobreposição entre a banda de valência da fonte e a banda de condução do canal e redução do comprimento de tunelamento, ambos contribuindo para o aumento da corrente de BTBT nos dispositivos.

Esse aumento de corrente de BTBT para maiores porcentagens de Ge é responsável também pela melhoria da transcondutância, porém, ao mesmo tempo resultam na degradação da condutância de saída. Apesar de aumentar os dois parâmetros, o uso de maiores porcentagens de Ge na fonte melhora o ganho intrínseco de tensão por resultar em um aumento mais pronunciado da transcondutância comparado à condutância de saída. 


\subsection{TFETs Planares com Uso de Materiais III-V}

Conforme apresentado no item 4.1.3, o uso de diferentes materiais pode resultar em uma melhoria muito significativa dos TFETs. Para tanto foram fabricados dispositivos utilizando InGaAs com o intuito de estudar a influência do uso deste material nos parâmetros dos TFETs. Devido à dificuldade de se obter transistores fabricados utilizando estruturas de nanofios com InGaAs, foi optado por utilizar dispositivos planares propostos pela universidade de Tóquio (53),(54), conforme já apresentado na Figura 3.2.

\subsubsection{TFETs com dopagem de fonte por fonte sólida}

Em dispositivos TFETs, para se obter mais corrente proveniente de tunelamento entre bandas é de extrema importância que a junção entre fonte e canal seja a mais abrupta possível. Para tanto nestes dispositivos a dopagem de Zn na fonte foi realizada inicialmente através de fonte sólida utilizando a técnica de spin on glass à temperatura de $500^{\circ} \mathrm{C}$ por 60 segundos (55).

\subsubsection{Análise em temperatura ambiente}

A análise realizada em temperatura ambiente levou em consideração 3 diferentes lâminas. O primeiro é um dispositivo de $\ln _{0,53} \mathrm{Ga}_{0,47} \mathrm{As}$, e o segundo é de $\mathrm{In}_{0,7} \mathrm{Ga}_{0,3} \mathrm{As}$, ambos com difusão de $\mathrm{Zn}$ na fonte à temperatura de $500{ }^{\circ} \mathrm{C}$ por 60 segundos. O último é de $\ln _{0,53} \mathrm{Ga}_{0,47} \mathrm{As}$, porém com uma temperatura de difusão um pouco mais alta $\left(520^{\circ} \mathrm{C}\right)$ por 60 segundos. Para facilitar a escrita este último dispositivo foi apelidado de "AltaTempDifZn".

Inicialmente é possível notar que tanto o dispositivo $\ln _{0,7} \mathrm{Ga}_{0,3} \mathrm{As}$ quanto o AltaTempDifZn possuem IDs (Figura 4.31) muito maiores que o In $0,53 \mathrm{Ga}_{0,47} \mathrm{As}$ devido ao aumento de BTBT. Para o dispositivo AltaTempDifZn este aumento de BTBT é causado pelo aumento da concentração de dopantes, o que resulta em menor comprimento de tunelamento. 
Para o dispositivo $\ln _{0,7} \mathrm{Ga}_{0,3} \mathrm{As}$ este aumento de BTBT é devido a dois fatores. O primeiro é a redução da largura de energia da banda proibida $\left(E_{G}=0,752 \mathrm{eV}\right.$ para In $0,53 \mathrm{Ga}_{0,47} \mathrm{As}$ e $\mathrm{E}_{\mathrm{G}}=0,588 \mathrm{eV}$ para $\operatorname{In}_{0,7} \mathrm{Ga}_{0,3} \mathrm{As}$ (64). O segundo causa é o aumento da

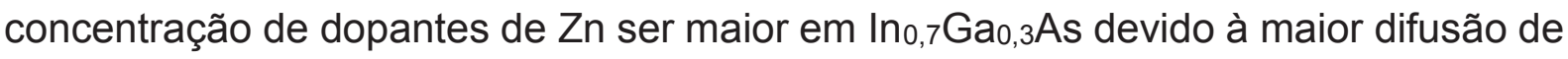
dopantes nesta liga (65).

Figura 4.31 - Corrente de dreno experimental normalizada em função da tensão na porta de TFET planares de InxGa1-XAs com diferentes porcentagens de In.

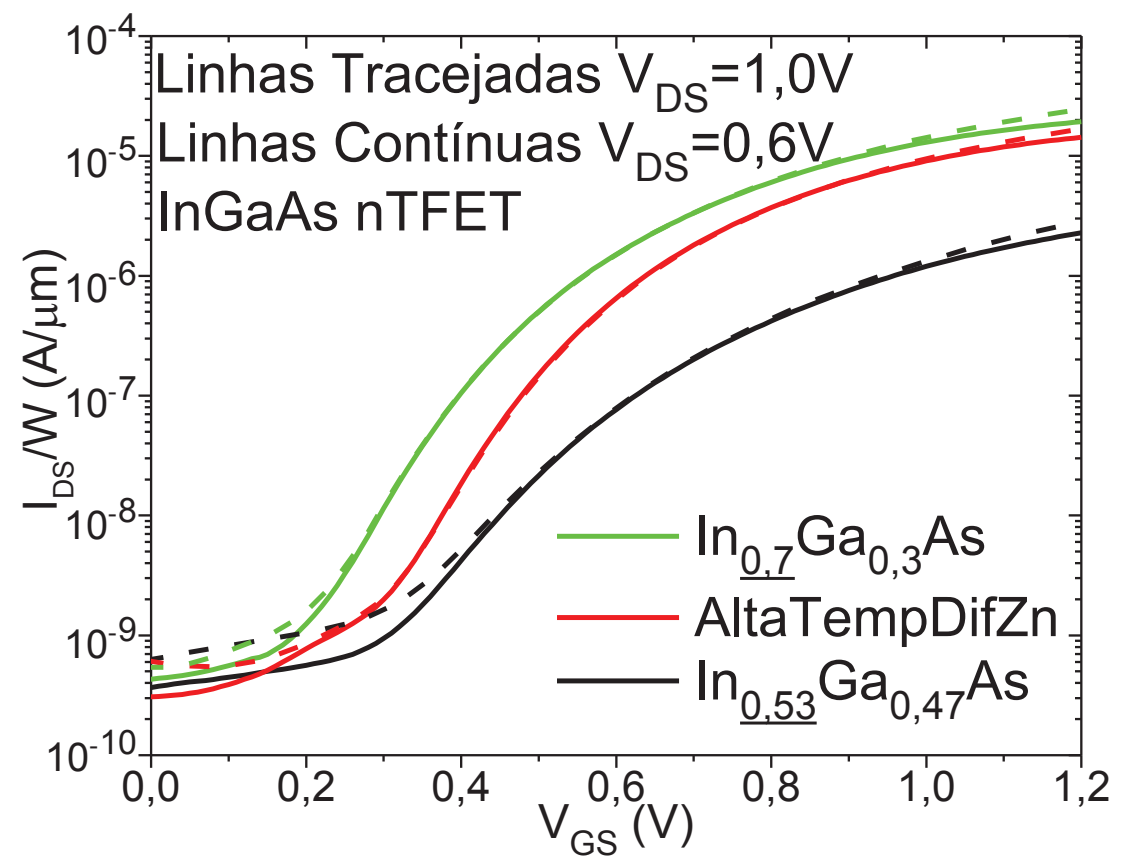

Fonte: Autor.

A comparação entre os dispositivos de InGaAs, mostrada na Figura 4.32, mostrou que os dispositivos In0,7 $\mathrm{Ga}_{0,3} \mathrm{As}$ e AltaTempDifZn apresentam menores $\mathrm{E}_{\mathrm{A}}$ que o Ino,53 $\mathrm{Ga}_{0,47} \mathrm{As}$, confirmando que o BTBT é mais dominante para esses 2 dispositivos.

Comparando os valores de lDs destes dispositivos de InGaAs com os dispositivos de Si estudados no item 4.1.3, é possível notar que a corrente normalizada é muito maior para os dispositivos InGaAs do que para os dispositivos de Si com diferentes fontes (Figura 4.33). Esta diferença tão acentuada é causada pela diferença da largura de energia da banda proibida, que reduz o comprimento de tunelamento, aumentando BTBT. Este aumento de BTBT pode ser observado através de $E_{A}$, onde é possível notar que os dispositivos de InGaAs (Figura 4.32) possuem $E_{A}$ muito menores que os dispositivos de Si (Figura 4.22). 
Figura 4.32 - Energia de ativação em função da tensão na porta de TFET planares de InxGa1-xAs com diferentes porcentagens de In.

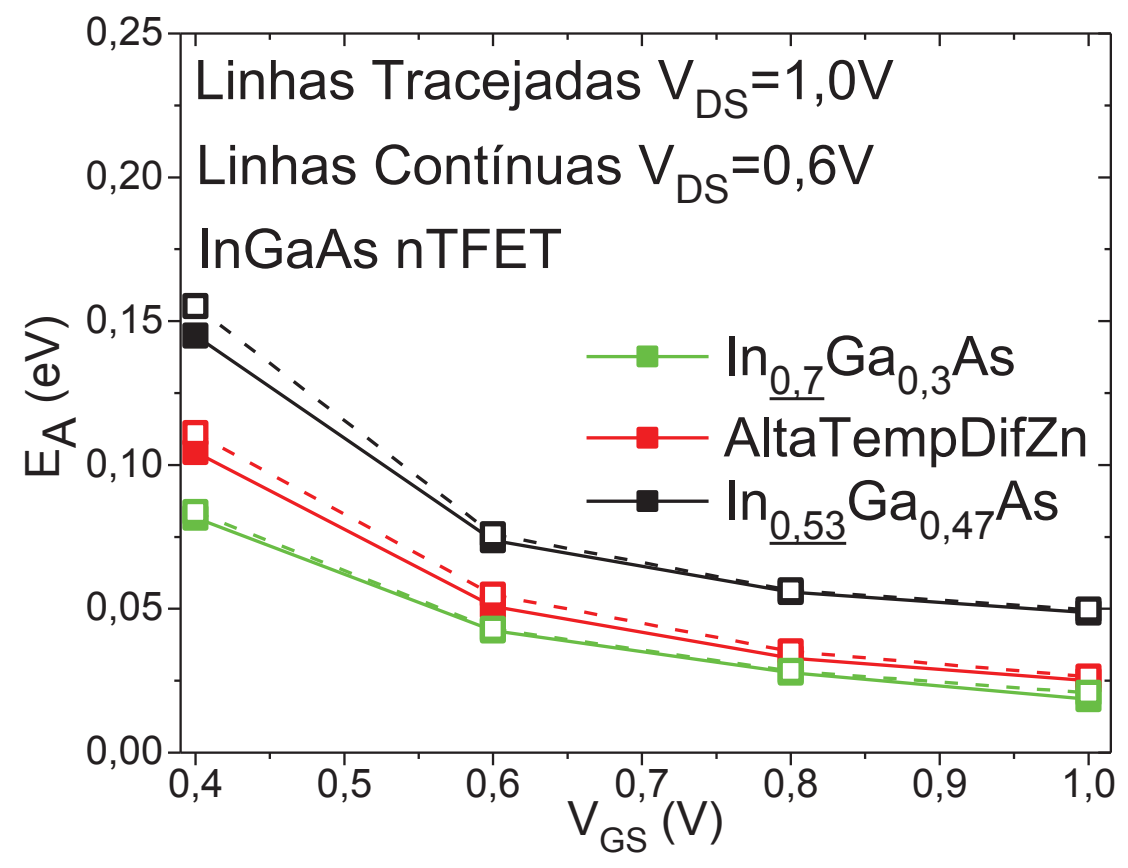

Fonte: Autor.

Figura 4.33 - Corrente de dreno experimental normalizada em função da tensão na porta de nTFETs de $\mathrm{Si}$ em estruturas de nanofios verticais e nTFETs planares de $\ln \times \mathrm{Ga}_{1-\mathrm{x} A s}$

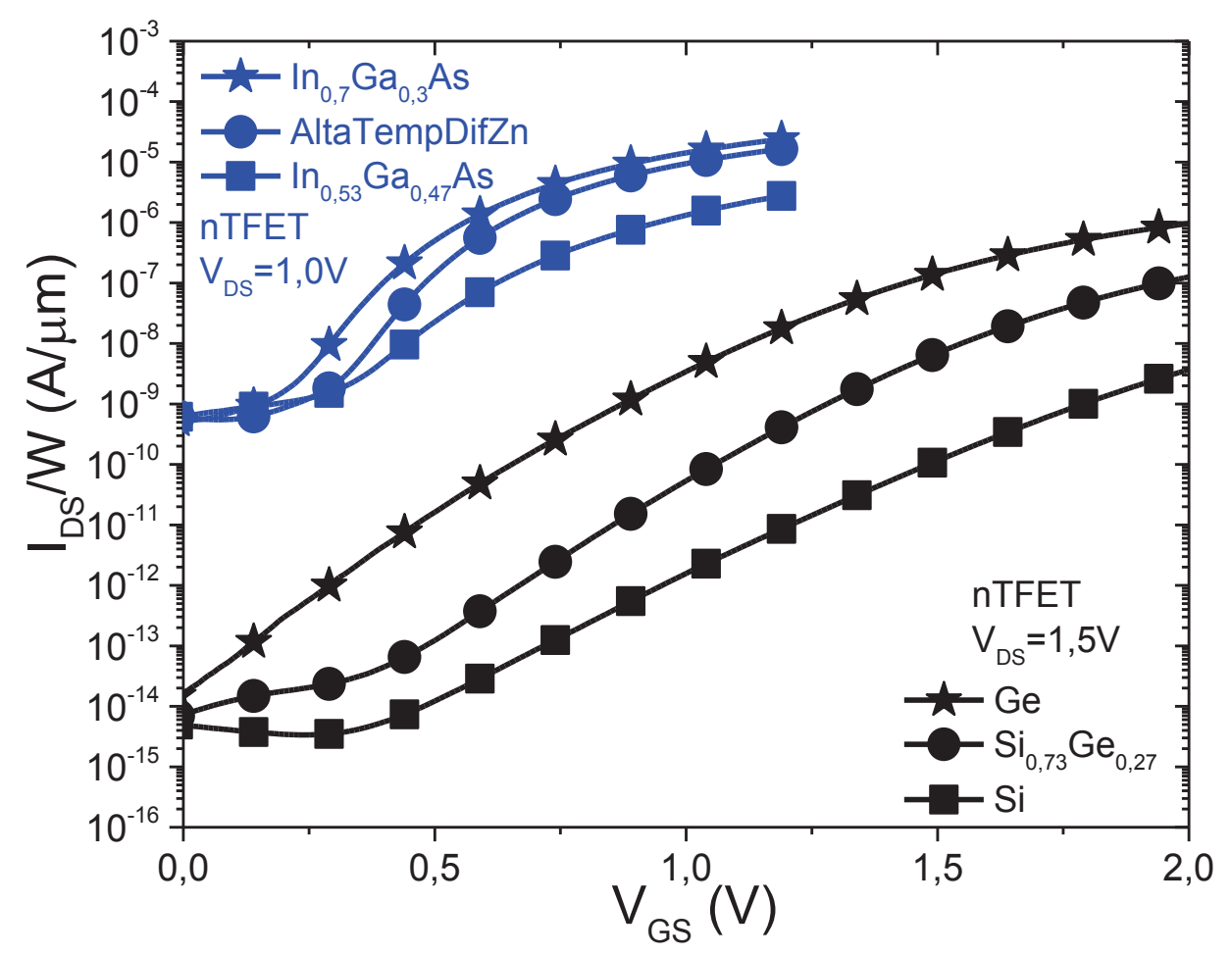

Fonte: Autor.

A Figura 4.34 mostra gm para os 3 diferentes dispositivos para diferentes polarizações de porta e dreno. Pode-se notar que embora gm aumente com $V_{G S}$ 
devido à redução do comprimento de tunelamento, gm permanece quase constante com a variação de $V_{D S}$.

Figura 4.34 - Transcondutância para diferentes tensões de porta e de dreno para nTFET planares de Inx $\mathrm{Ga}_{1-\mathrm{X}}$ As com diferentes porcentagens de In.

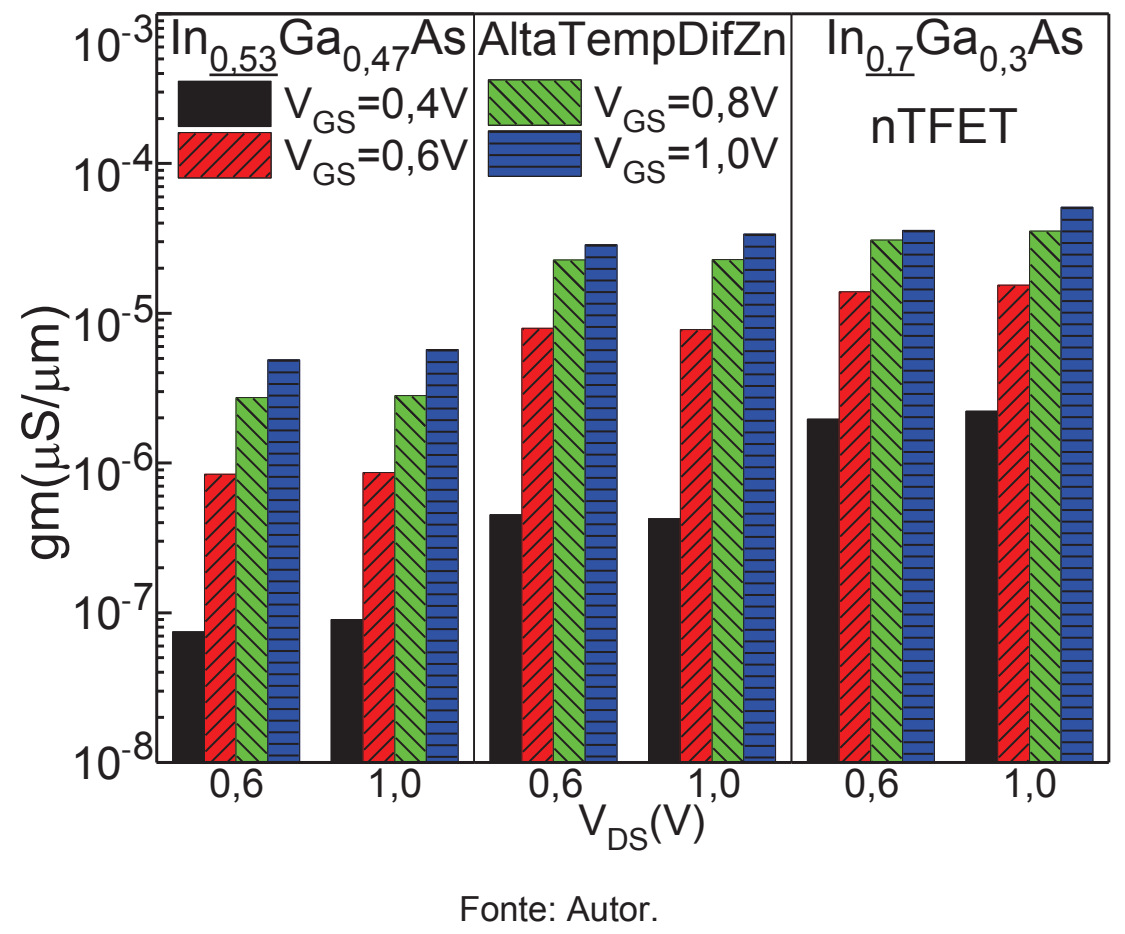

Entretanto, ao analisar gD (Figura 4.35), é possível notar que quando se aumenta $V_{G S}$, o gD é degradado devido à maior dependência de $V_{D S}$ na janela efetiva de energia de sobreposição na junção entre fonte e canal (Figura 4.36). Esta janela de energia, que é onde efetivamente ocorre o tunelamento, é a região limitada pela banda de valência da fonte, pela banda de condução do canal e do dreno, e também pelos respectivos níveis de Fermi. À medida que VDS é aumentado, esta janela de energia fica mais larga, o que faz com que a influência de $V_{D S}$ seja reduzida, resultando em melhoria (redução) de gD.

Analisando o ganho intrínseco de tensão, através da relação gm/gD, mostrado na Figura 4.37, é possível observar que os melhores valores de ganho foram obtidos para $V_{G S}=0,6 \mathrm{~V}$. No ganho há uma competição de fatores entre a melhoria da transcondutância e a degradação de gD, a qual é muito mais evidente para valores de $V_{G s}$ maiores que 0,6 V. Nesta figura também é possível notar que as lâminas que possuem melhoria na geração de BTBT (Ino,7 $\mathrm{Ga}_{0,3} \mathrm{As}$ e AltaTempDifZn) apresentam maiores ganhos devido á melhoria de gm. Para $V_{D S}=1,0 \mathrm{~V}$ os dispositivos operam 
mais na região semelhante à saturação das características de saída, consequentemente apresentando melhor gD e Av.

Figura 4.35 - Condutância de saída para diferentes tensões de porta e de dreno para nTFET planares de $\ln _{x} \mathrm{Ga}_{1-\mathrm{X}} \mathrm{As}$ com diferentes porcentagens de In.

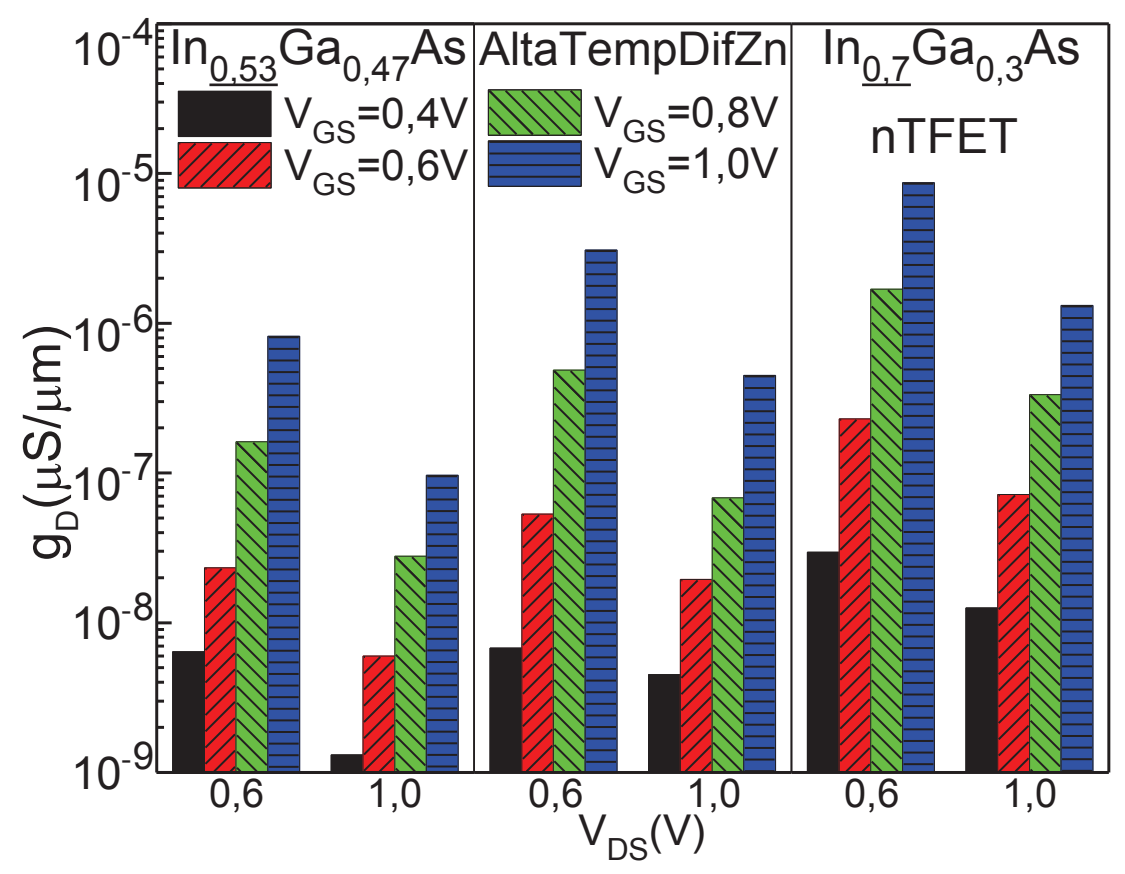

Fonte: Autor.

Figura 4.36 - Disposição da janela efetiva de energia de sobreposição na junção entre fonte e canal para baixos $V_{G S}(a)$ e altos $V_{G S}(b)$

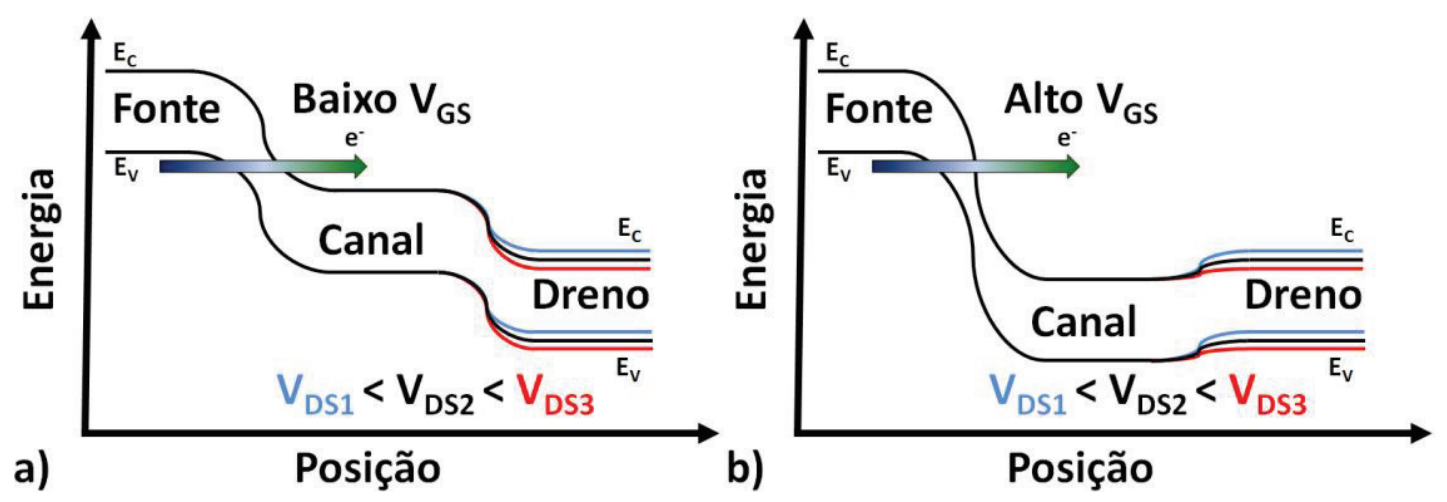

Fonte: Autor.

A Figura 4.38 apresenta a eficiência do transistor em função de IDs normalizada para os 3 dispositivos estudados. Como na região de condução fraca (baixa lDs) gm/lDS é inversamente proporcional a SS, os dispositivos com melhoria na geração de BTBT (Ino,7Ga0,3As e AltaTempDifZn), os quais possuem também menores SS (60 mV/dec em ambos dispositivos (55)), apresantaram gm/lDs maiores. Para correntes mais altas 
gm/los é mais dependente de gm, a qual é maior também para os dispositivos In $0,7 \mathrm{Ga}_{0,3}$ As e AltaTempDifZn.

Figura 4.37 - Ganho intrínseco de tensão para diferentes tensões de porta e de dreno para nTFET planares de $\operatorname{In} \times \mathrm{Ga}_{1-\mathrm{x}} \mathrm{As}$ com diferentes porcentagens de In.

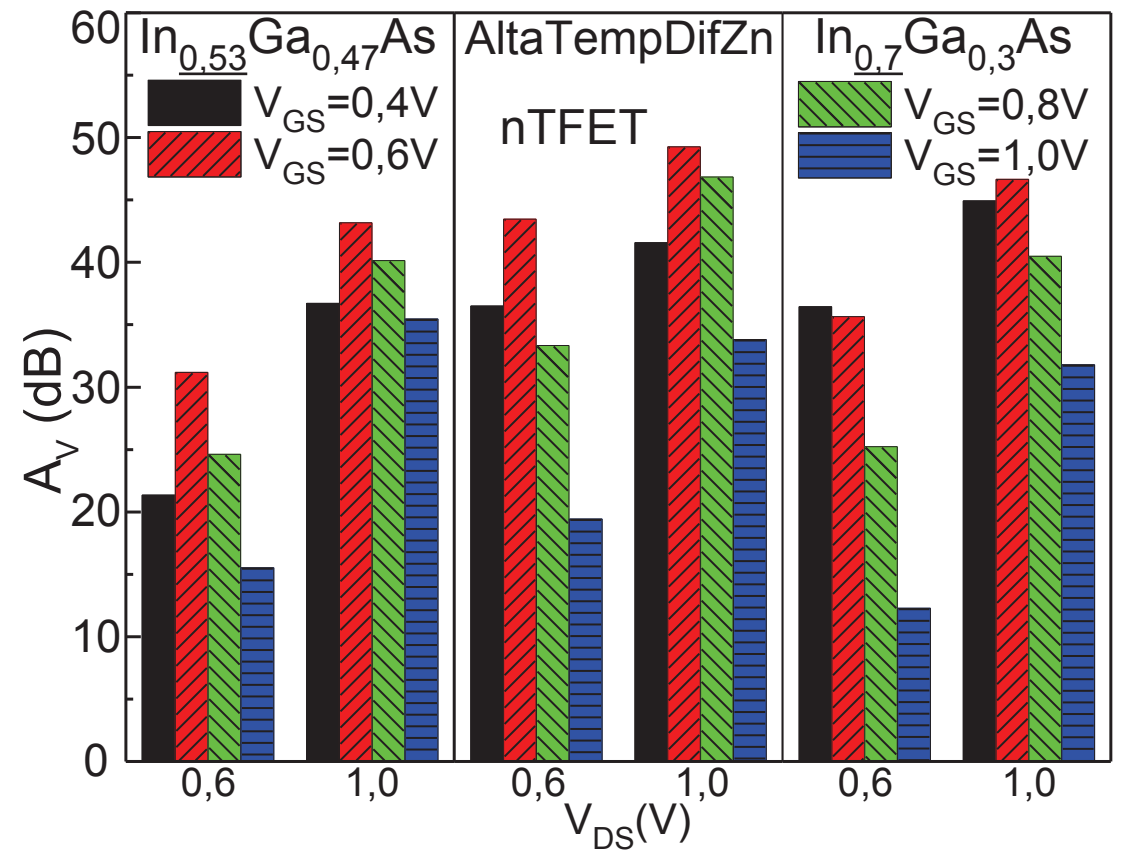

Fonte: Autor.

Figura 4.38 - Eficiência do transistor em função da corrente de dreno normalizada de nTFETs planares de InxGa1-xAs com diferentes porcentagens de In.

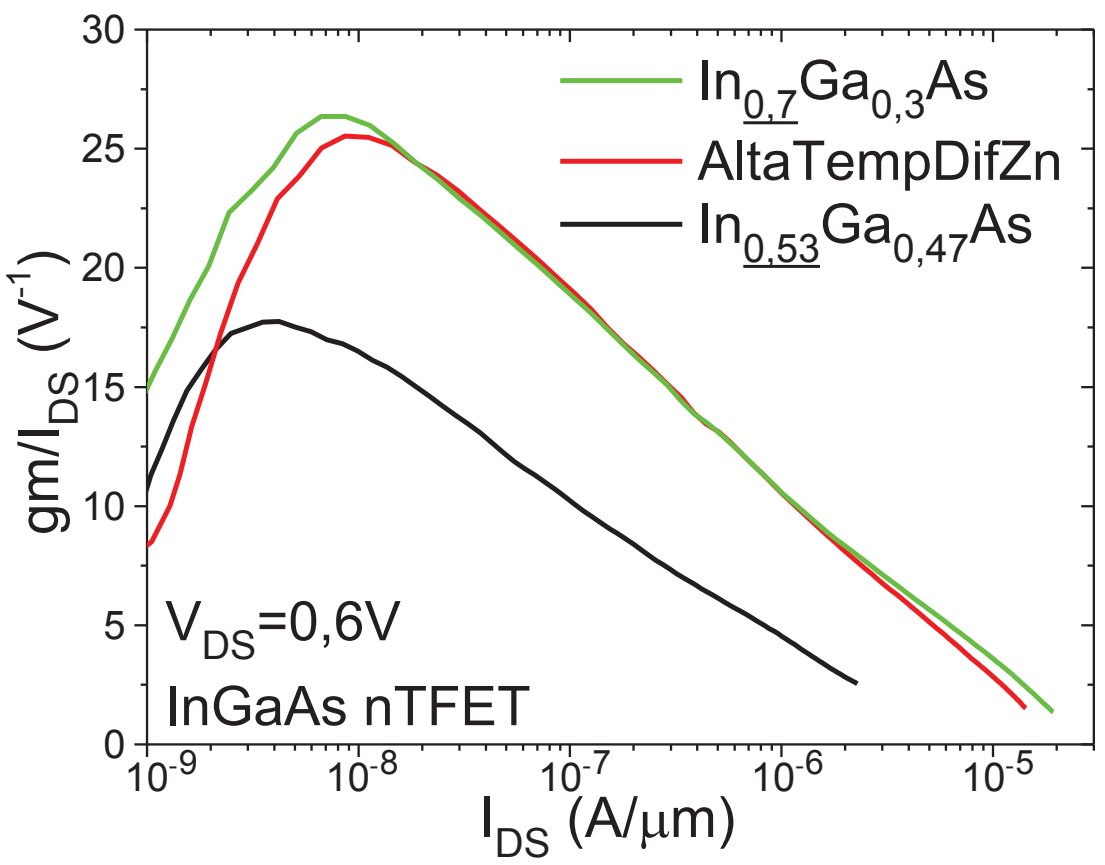

Fonte: Autor. 


\subsubsection{Influência da variação da temperatura}

Com o intuito de simplificar o estudo nesta fase, foi optado apenas por usar os dispositivos In0,53 $\mathrm{Ga}_{0,47} \mathrm{As}$ e In0,7 $\mathrm{Ga}_{0,3} \mathrm{As}$, que são os dispositivos que possuem a menor e a maior corrente de estado ligado.

A Figura 4.39 apresenta a corrente de dreno experimental normalizada (IDs/W) e a corrente de porta normalizada (IGS/W) em função de $V_{G S}$, para os dois dispositivos polarizados à $V_{D S}=1,0 \mathrm{~V}$, a temperaturas variando entre $300 \mathrm{~K}$ e $10 \mathrm{~K}$. Observando o efeito da temperatura é possível notar que, em contraste aos dispositivos MOSFETs, todos os mecanismos de condução de corrente diminuem a baixas temperaturas, reduzindo tanto lon quanto loff. Entretanto, loff diminui relativamente mais do que loN devido a diferente dependência dos mecanismos de condução com a temperatura. As equações (2.8), (2.6) e (2.2) são as equações simplificadas das correntes de BTBT, TAT e SRH, conforme mostradas no item 2.2.

Pode-se notar que há uma grande variação em loff com a temperatura (4 ordens de grandeza com a redução da temperatura de $300 \mathrm{~K}$ para $100 \mathrm{~K}$ ), devido aos componentes que o compõe, SRH e TAT, serem dependentes exponencialmente da temperatura. Em contraste, a corrente de BTBT, a qual é dominante em Ion, possui uma redução inferior a uma ordem de grandeza devido a influência indireta com a temperatura, a qual é causada pelo aumento de $E_{G}$ em baixas temperaturas. Este comportamento resulta em uma menor variação relativa do componente BTBT comparado com os componentes TAT e SRH. 
Figura 4.39 - Correntes de dreno e de porta experimentais normalizadas em função da tensão de porta de nTFETs planares de InxGa1-XAs em diferentes temperaturas.

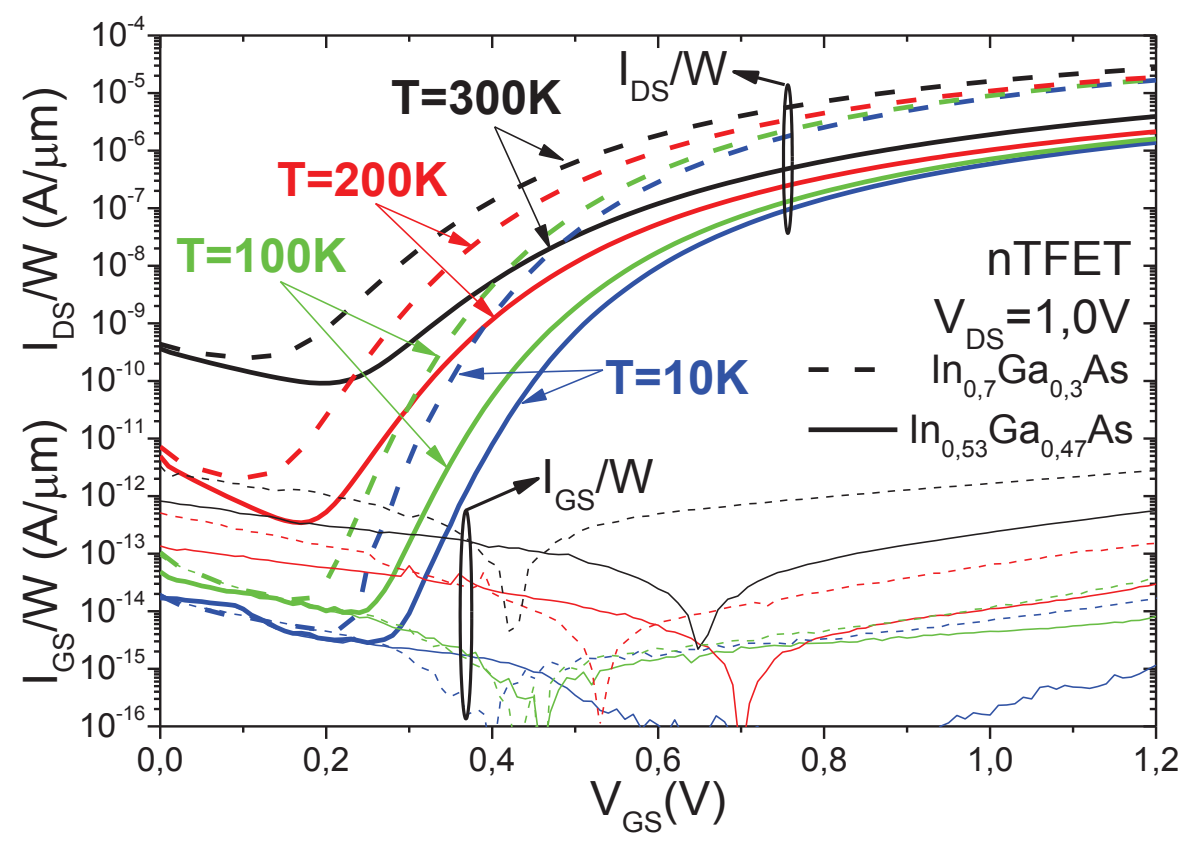

Fonte: Autor.

Esta pequena variação relativa pode ser observada também em $E_{\mathrm{A}}$, mostrada na Figura 4.40, a qual representa a variação logarítmica da corrente em função do inverso da temperatura, conforme mostrado na equação (2.9). É possível notar que para menores VGS, polarização a qual os mecanismos TAT e SRH são dominantes, $E_{A}$ é maior, indicando uma dependência com a temperatura mais alta. Em contrapartida, para polarizações mais altas de $\mathrm{V}_{G S}$, onde BTBT é o mecanismo de condução dominante, $E_{A}$ apresenta valores muito pequenos devido à menor dependência com a temperatura.

Quando ambos os dispositivos são comparados, é notável que o dispositivo Ino,7Gao,3As é menos influenciado pela temperatura, ou seja, apresenta um maior componente de BTBT, causado pelo seu menor comprimento de tunelamento.

Através da Figura 4.39 é também possível observar que para temperaturas mais baixas que $100 \mathrm{~K}$ os componentes de SRH e TAT são tão reduzidos que loFF passa a ser limitado pela corrente de porta. O mecanismo de condução dominante de Igs para dielétricos de porta muito finos é o tunelamento direto através da banda proibida de energia do dielétrico (Fowler-Nordheim), portanto, sua densidade de corrente pode ser modelada pela equação (4.2) (66),(67),(68). Este mecanismo de condução varia muito pouco com a temperatura, cuja variação é causada 
principalmente pela variação de $\mathrm{E}_{\mathrm{G}}$, influenciando muito pouco IGs. Como IGs varia menos que os mecanismos de TAT e SRH, a temperaturas muito baixas loff fica limitado à IGs.

Figura 4.40 - Energia de ativação em função da tensão de porta de nTFETs planares de InxGa1-xAs.

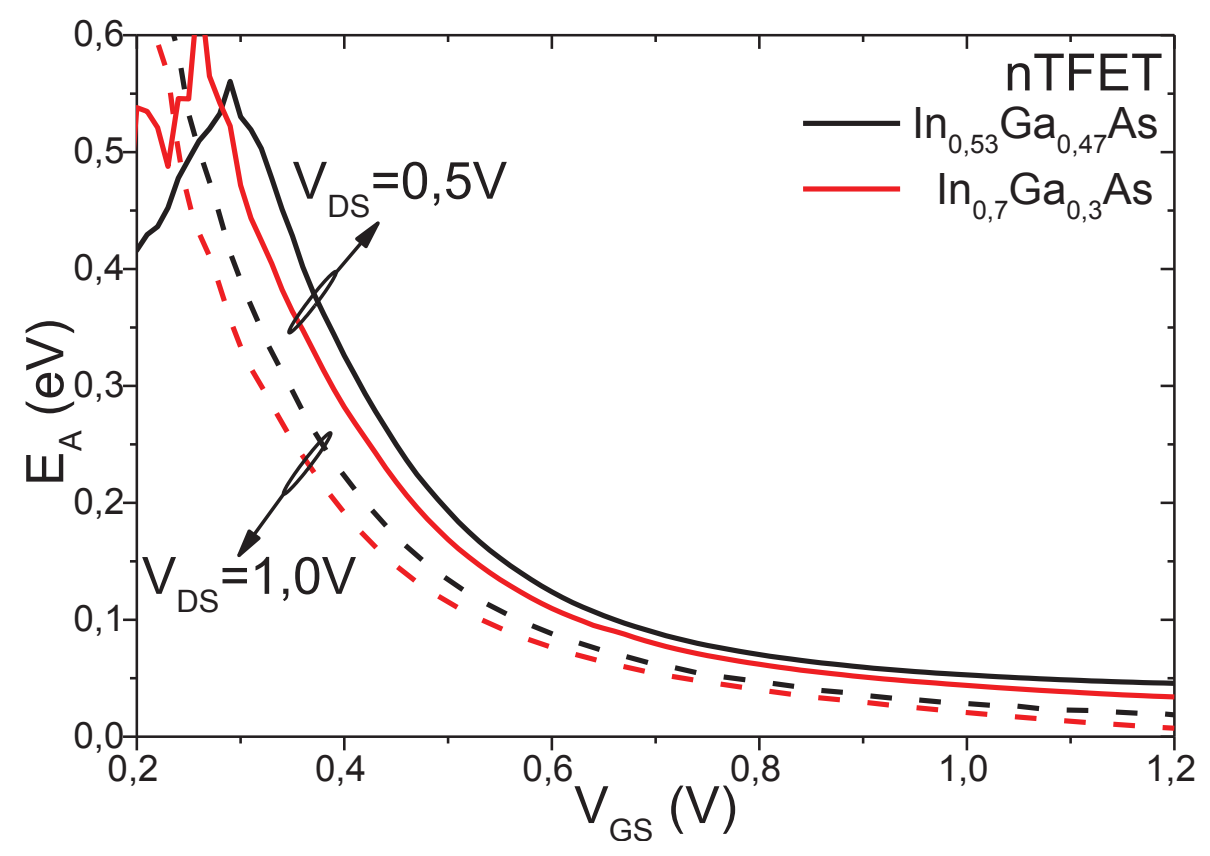

Fonte: Autor.

$$
J_{G} \cong \frac{C 1_{F-N}}{E_{G}} \cdot e^{\left(-C 2_{F-N} \frac{E_{G}^{3 / 2}}{\xi}\right)}
$$

onde $J_{G}$ é a densidade de corrente de porta, ६ é a magnitude do campo elétrico, $E_{G}$ é o nível de energia da banda proibida, T a temperatura em kelvin, o coeficiente C1F-N é parâmetro pré-exponencial e o C2F-N é parâmetro exponencial para as expressões simplificadas.

A Figura 4.41 apresenta a $\mathrm{gm} / \mathrm{W}$ em função da temperatura para ambos os dispositivos estudados. A Figura 4.41(a) possui $V_{D S}$ polarizado em $0,5 \mathrm{~V}$ e a Figura 4.41(b) em 1,0 V, ambos com $V_{G S}=0,5 \mathrm{~V}$ e 1,0 V. Inicialmente é possível notar que o dispositivo $\ln _{0,7} \mathrm{Ga}_{0,3} \mathrm{As}$ sempre apresenta gm maior que o $\ln _{0,53} \mathrm{Ga}_{0,47} \mathrm{As}$ devido ao seu menor $E_{G}$. 
Figura 4.41 - Transcondutância experimental em função da temperatura para nTFETs planares de Inx $\mathrm{Ga}_{1-\mathrm{X}} \mathrm{As}$, com tensões de dreno de 0,5 V (a) e 1,0 V (b).
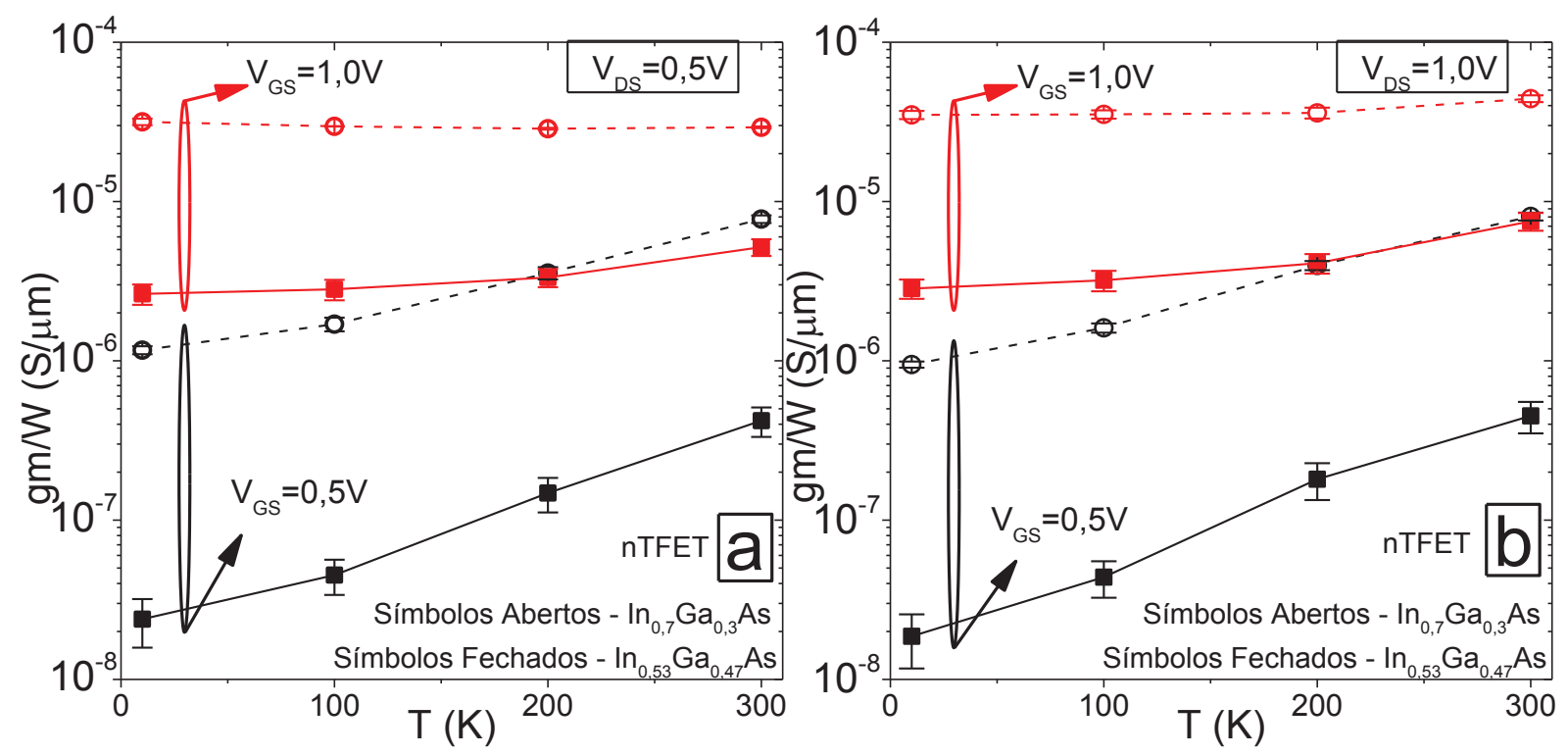

Fonte: Autor.

Para todas as condições experimentais gm diminui para temperaturas baixas, exceto para $\mathrm{V}_{\mathrm{GS}}=1,0 \mathrm{~V}$ e $\mathrm{V}_{\mathrm{DS}}=0,5 \mathrm{~V}$. Nesta específica polarização há um aumento bem pequeno no dispositivo In $\mathrm{n}_{0,7} \mathrm{Ga}_{0,3} \mathrm{As}$ em baixas temperaturas. Este comportamento pode estar relacionado com a grande resistência série que esses dispositivos possuem, a qual é aparentemente reduzida para baixas temperaturas. O dispositivo Ino,7Gao,3As nestas condições de polarização possui lDs alto, o que significa que o tunelamento está ocorrendo de forma eficiente, podendo então o efeito das resistências série ser observado. Desta forma, a redução das resistências série em baixas temperaturas podem resultar em melhoria de gm.

Quando é comparado o impacto da temperatura para os diferentes dispositivos, pode-se notar que o dispositivo $\ln _{0,7} \mathrm{Ga}_{0,3}$ As é menos influenciado pela temperatura que o $\ln _{0,53} \mathrm{Ga}_{0,47} \mathrm{As}$. Esta menor influência da temperatura é causada pela alta componente de BTBT presente neste dispositivo.

A eficiência do transistor em função de lDs normalizado em relação à largura do canal, polarizado em $V_{D S}=1,0 \mathrm{~V}$, com temperaturas variando entre $300 \mathrm{~K}$ e $10 \mathrm{~K}$, é mostrado na Figura 4.42. Para baixos valores de lDs, gm/lDs é inversamente proporcional à SS, o qual é mostrado no gráfico inserido na Figura 4.42. Nesta região de baixa condução de corrente, onde gm/lds apresenta seus valores mais altos, o 
dispositivo $\ln _{0,7} \mathrm{Ga}_{0,3}$ As possui maior eficiência comparado ao $\ln _{0,53} \mathrm{Ga}_{0,47} \mathrm{As}$, devido à menor influência de SRH e TAT, o que resulta em uma melhoria de SS.

Figura 4.42 - Eficiência do transistor experimental em função da corrente de dreno em nTFETs planares de $\ln _{x} \mathrm{Ga}_{1-\mathrm{x}} \mathrm{As}$ em diferentes temperaturas e inclinação de sublimiar em função da temperatura no gráfico inserido.

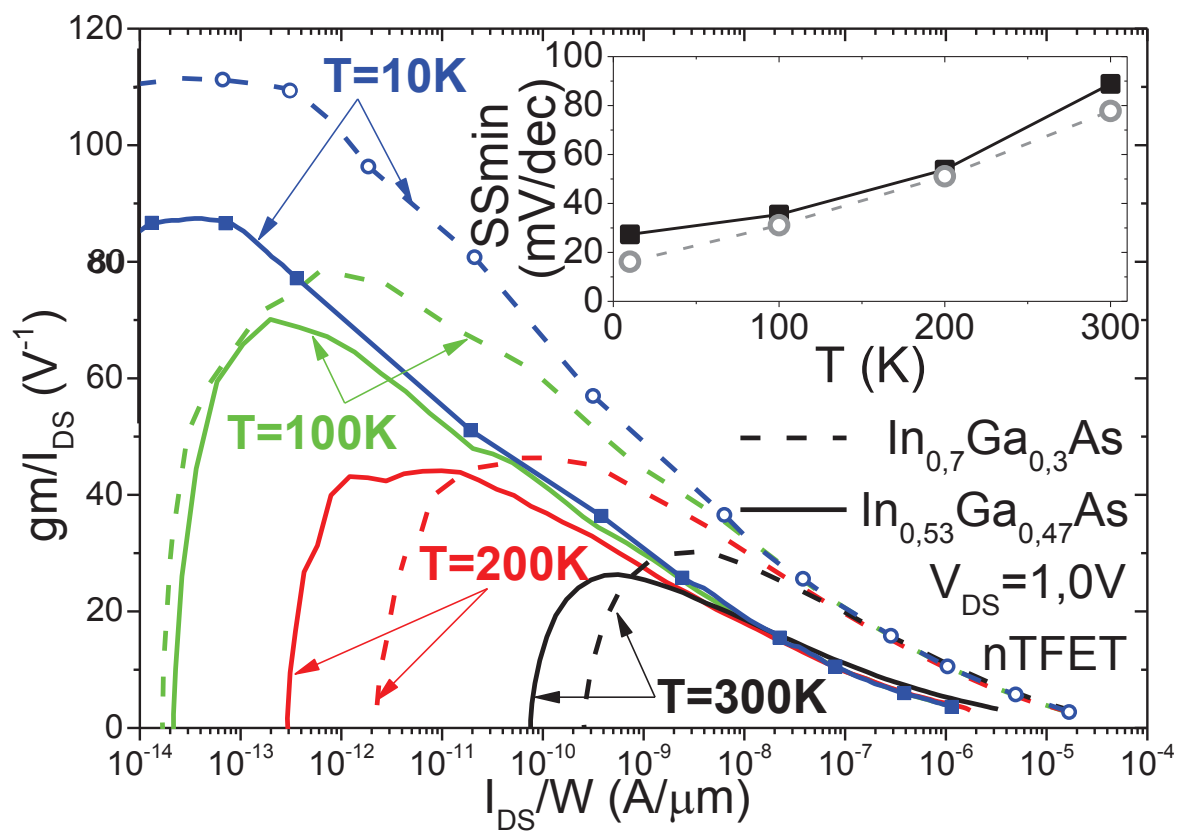

Fonte: Autor.

Considerando a região de maior condução de corrente, gm/los é mais dependente de gm, e como gm é maior para o $\ln _{0,7} \mathrm{Ga}_{0,3} \mathrm{As}$, ele também apresenta maior eficiência. Além de gm/lds ser mais imune nesta região pois em altas correntes o BTBT é o mecanismo de condução de corrente dominante, o qual é pouco dependente da temperatura, ambos gm e los são reduzidos para baixas temperaturas, resultando em uma variação muito pequena de $\mathrm{gm} / \mathrm{l}$ Ds com a temperatura.

Na curva lDs em função de VDS (Figura 4.43) pode ser observado que as curvas, que possuem $V_{G S}=0,5 \mathrm{~V}$, apresentaram grande influência relativa com a temperatura, e como o dispositivo $\ln _{0,53} \mathrm{Ga}_{0,47} \mathrm{As}$ possui maior $\mathrm{E}_{\mathrm{G}}$, ele é ainda mais influenciado pela temperatura. A inclinação da região de maior $V_{D S}$ desta curva, ou seja, a condutância de saída (Figura 4.44), é também uma importante figura de mérito. 
Figura 4.43 - Corrente de dreno experimental em função da tensão de dreno em nTFETs planares de Inx $\mathrm{Ga}_{1-\mathrm{x}}$ As em diferentes temperaturas.

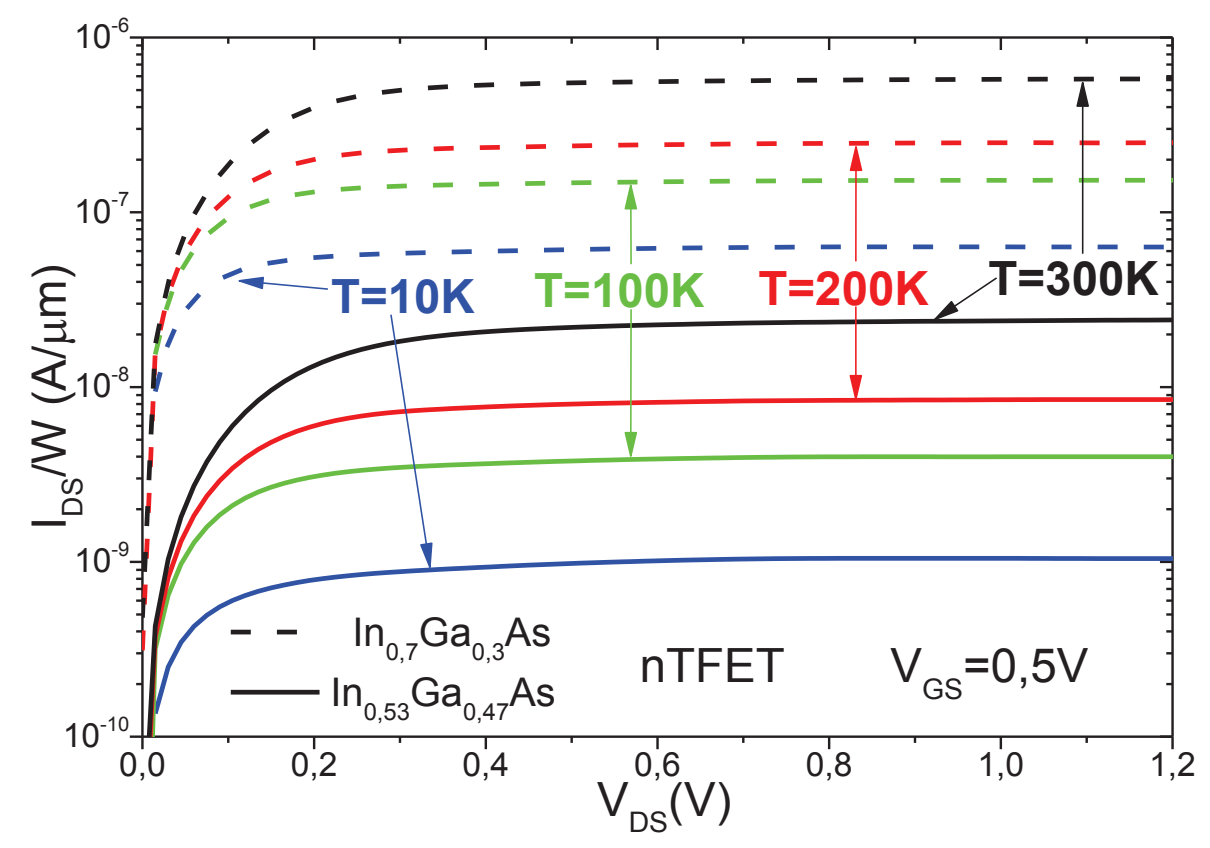

Fonte: Autor.

A Figura 4.44 apresenta a gD/W em função da temperatura para ambos os dispositivos estudados, polarizado em 0,5 V na Figura 4.44(a) e em 1,0 V na Figura 4.44(b), ambos com $V_{G S}=0,5 \vee$ e 1,0 V. Pode-se notar que em todos os casos há uma redução de gD em baixas temperaturas. Para entender melhor esse efeito da temperatura em gD, simulações numéricas do dispositivo In ${ }_{0,53} \mathrm{Ga}_{0,47} \mathrm{As}$ foram realizadas usando o software Sentaurus Device, descrito com mais detalhes no item 3.2.2.

A Figura 4.45 mostra a comparação da lds simulada com a experimental em função de $V_{G S}$ para o dispositivo $\ln _{0,53} \mathrm{Ga}_{0,47} \mathrm{As}$, mostrando uma boa similaridade entre o experimental e a simulação. A condutância de saída (Figura 4.46) foi obtida através do gráfico inserido na Figura 4.45, e, da mesma forma que o experimental, mostrando a redução de go para baixas temperaturas. 
Figura 4.44 Condutância de saída experimental em função da temperatura para nTFETs planares de

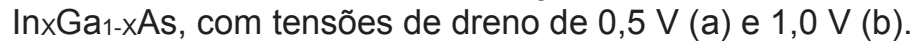

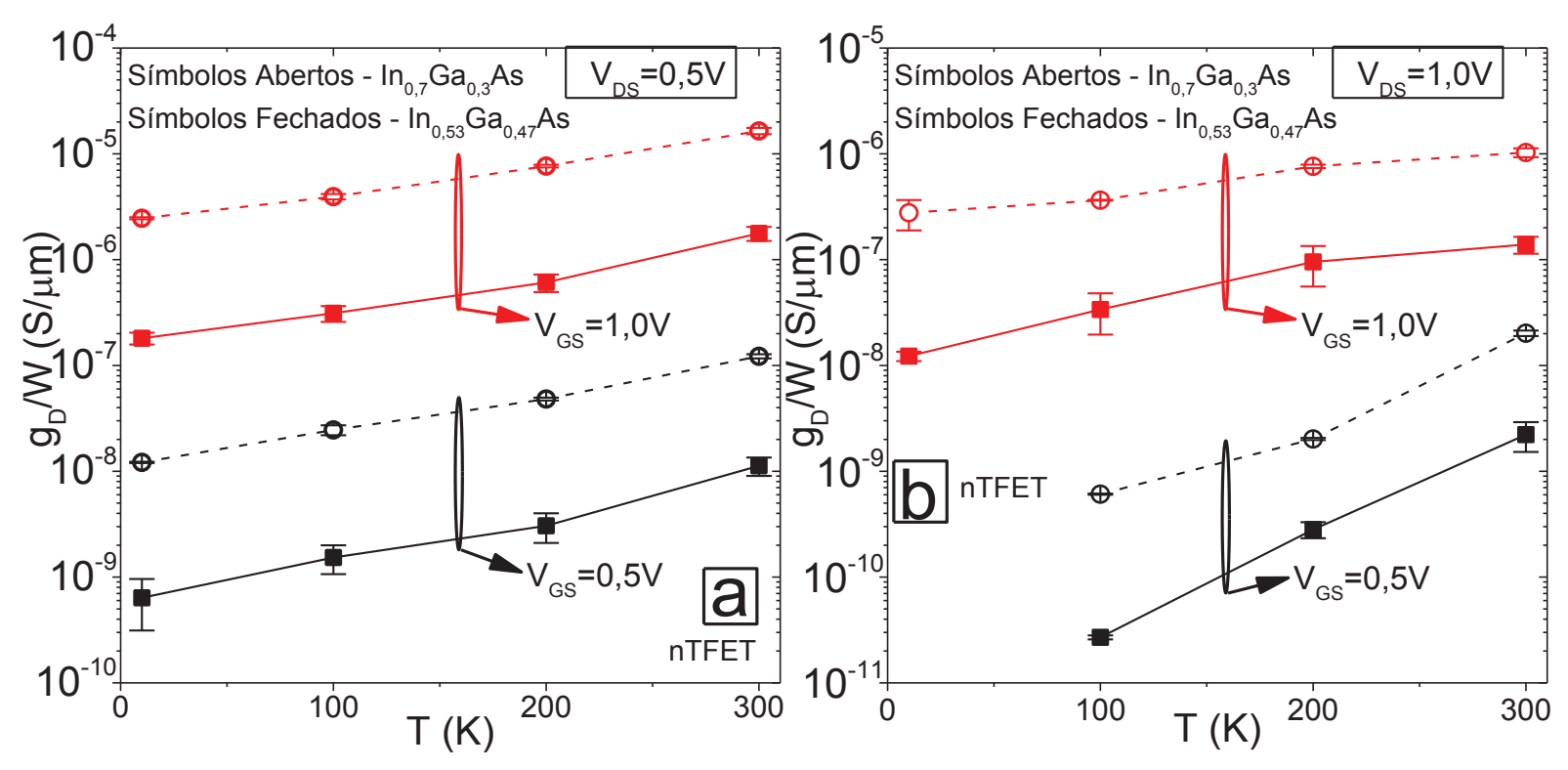

Fonte: Autor.

Figura 4.45 - Corrente de dreno experimental e simulada em função da tensão de porta em nTFETs planares de Ino,53Ga0,47As e corrente de dreno simulada em função da tensão de dreno em diferentes temperaturas.

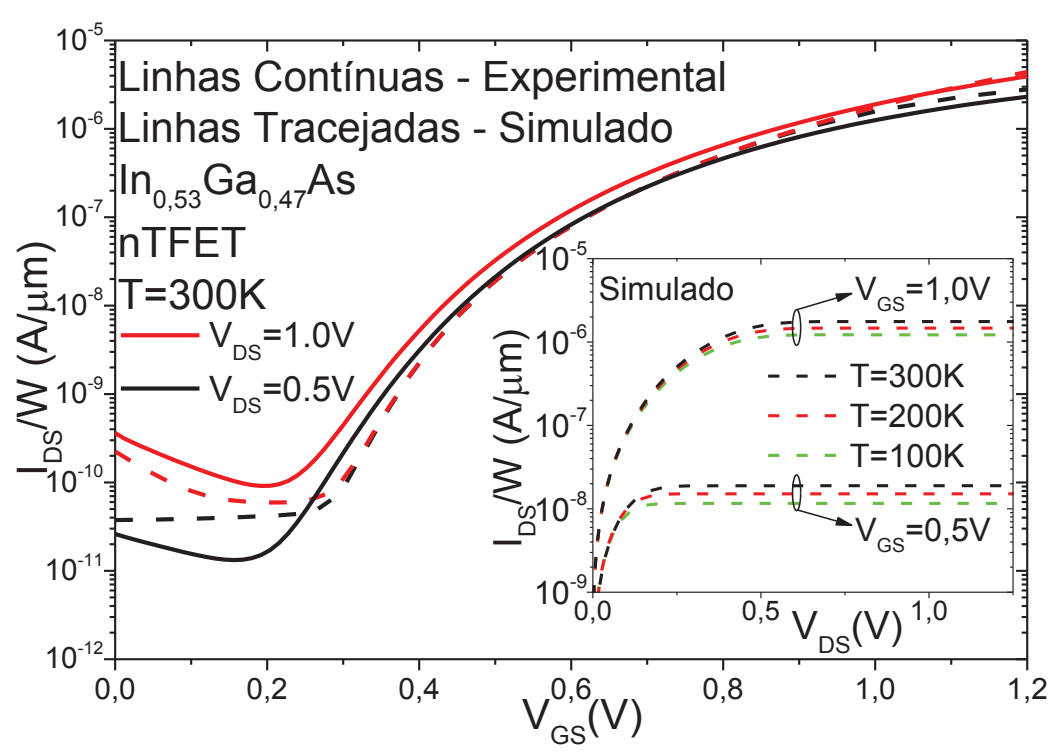

Fonte: Autor. 
Figura 4.46 - Condutância de saída simulada em função da temperatura para nTFETs planares de $\ln _{0,53} \mathrm{Ga}_{0,47} \mathrm{As}$.

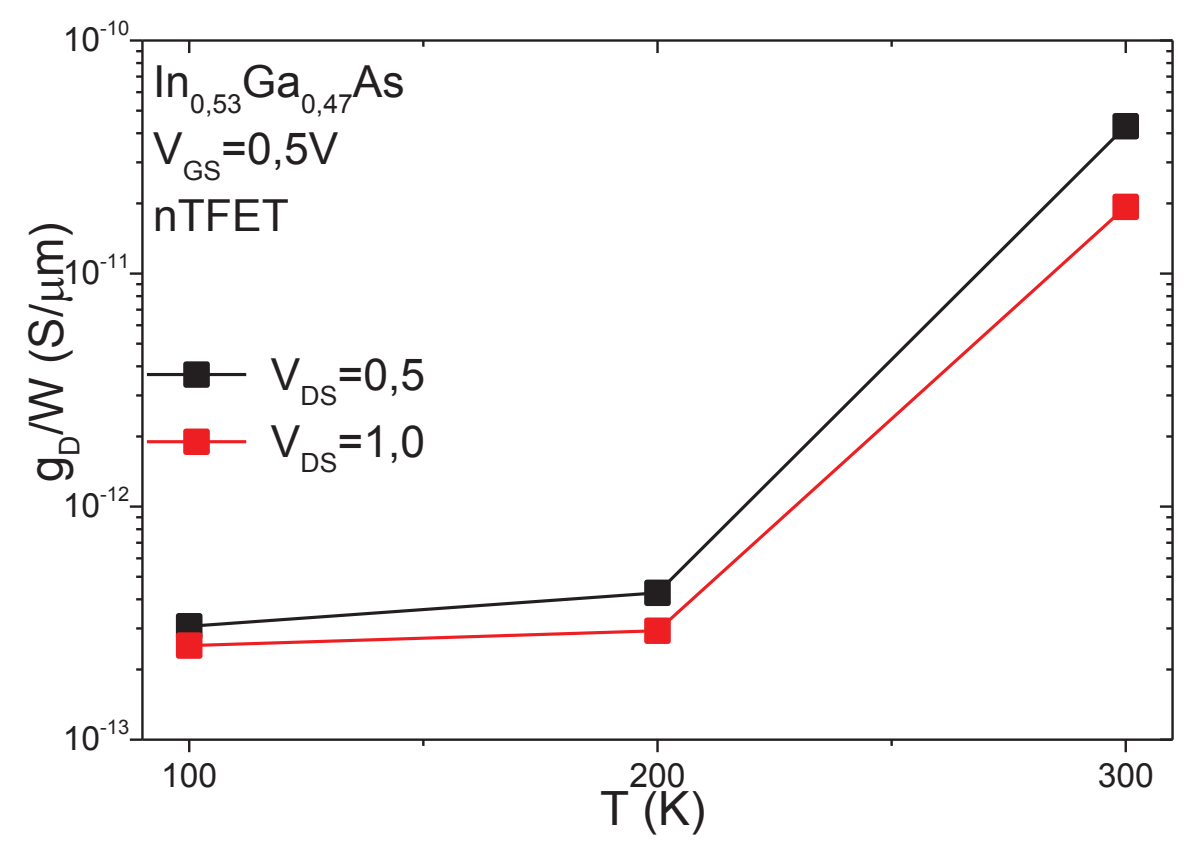

Fonte: Autor.

A Figura 4.47(a) apresenta o diagrama de bandas de energia (Ec, Ev) simulado de uma secção transversal inclinada, a qual atravessa as regiões com maior geração por BTBT, para 3 valores de $\mathrm{V}_{\mathrm{DS}}$, a temperatura ambiente e a $100 \mathrm{~K}$. As regiões com maior geração por BTBT foram obtidas através da curva em duas dimensões da geração de elétrons por BTBT (Figura 4.47(b)) e da geração de lacunas por BTBT (Figura 4.47(c)), para 3 valores de $V_{D S}$, a temperatura ambiente e a 100K. Através da Figura 4.47(a) pode se notar que devido ao pequeno aumento de Eg para temperaturas baixas, o comprimento de tunelamento aumenta. Este comportamento pode ser visto mais claramente no zoom deste gráfico, mostrado na figura inserida da Figura 4.47(a).

A Figura 4.47(d) mostra a taxa de geração por BTBT na junção entre fonte e canal. Pode se notar que, como consequência da redução do comprimento de tunelamento em baixas temperaturas, a taxa de geração de BTBT é reduzida, resultando em uma redução da corrente de BTBT. Na Figura 4.47(d) pode se observar também uma redução da influência de $V_{D S}$ na taxa de geração em baixas temperaturas, e, consequentemente, uma diminuição na corrente de BTBT. Esta diminuição da influência de $V_{D S}$ resulta em uma melhoria (redução) de gD, como mostrado experimentalmente na Figura 4.44. 
Figura 4.47 - Energia de condução e valência simulada em função da distância em uma secção transversal inclinada (a), a qual atravessa os valores máximos da taxa de geração de BTBT de elétrons (b) e lacunas (c). E a taxa de geração de BTBT em função da distância neste corte, para tensão de dreno de $0,4 \vee$ e $0,6 \vee(d)$.
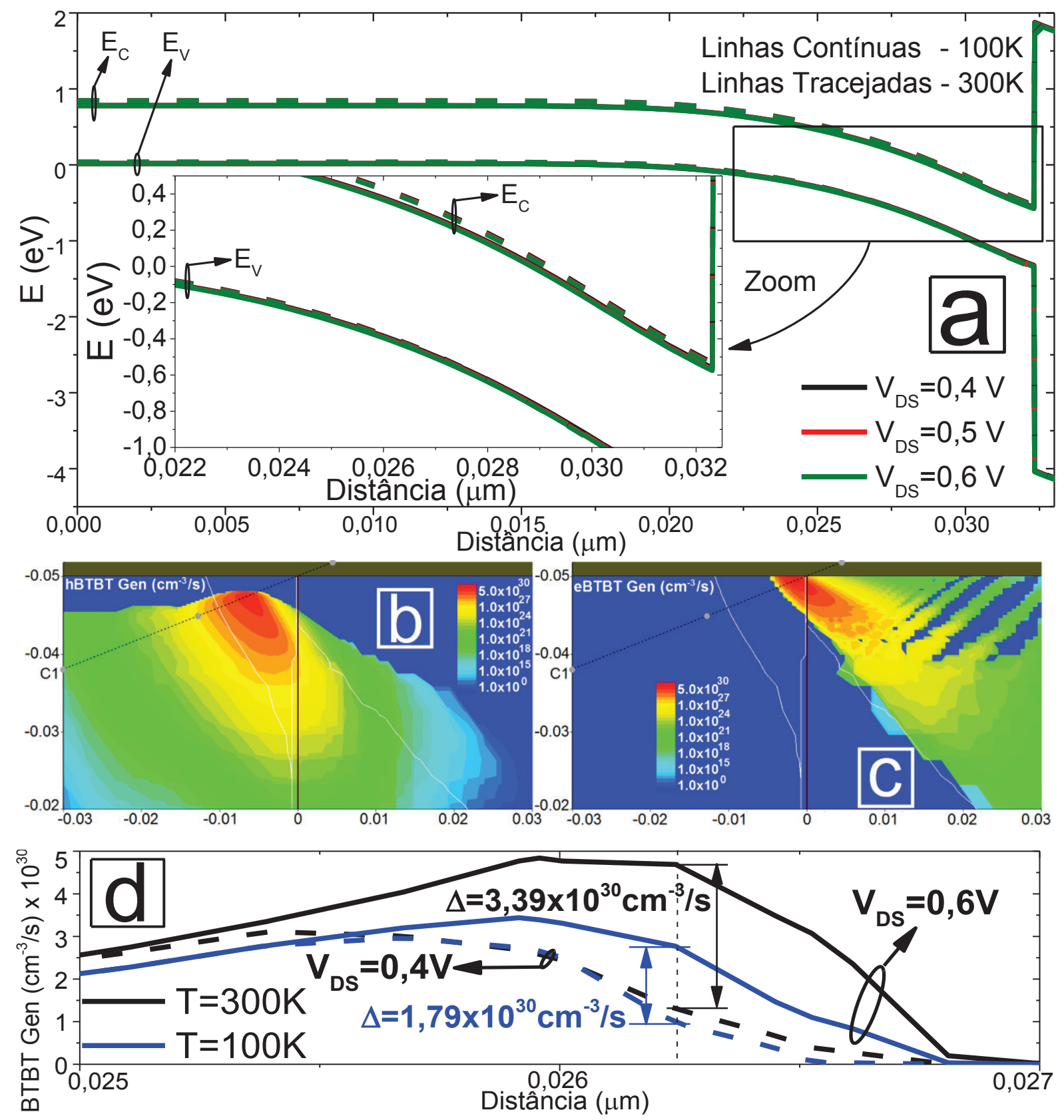

Fonte: Autor.

A Figura 4.48 apresenta o Av experimental, obtido através da relação entre gm e gD, em função da temperatura, para os dois dispositivos estudados, com $V_{D S}$ polarizado em 0,5 V (Figura 4.48(a)) e em 1,0 V (Figura 4.48(b)), com $\bigvee_{G S}=0,5 \mathrm{~V}$ e $1,0 \mathrm{~V}$ para ambos. É possível observar que para baixo $\mathrm{V}_{\mathrm{GS}}$ o dispositivo $\ln _{0,7} \mathrm{Ga}_{0,3} \mathrm{As}$ apresenta maior $A_{v}$ que o In ${ }_{0,53} \mathrm{Ga}_{0,47} \mathrm{As}$ devido a maior influência de BTBT, que é causada pelo menor EG. Entretanto, para $V_{G S}$ alto com $V_{D S}$ baixo, o dispositivo 
In $0,7 \mathrm{Ga}_{0,3} \mathrm{As}$ aparenta sofrer de efeitos de alta resistência série, resultando em menores gm e $A v$, sendo ainda mais influenciado pela temperatura.

A análise da influência da temperatura em Av mostrou que há uma competição de fatores entre a degradação de gm e a melhoria de gD em baixas temperaturas, uma vez que a resistência série é reduzida para baixas temperaturas. Para $V_{G S}=1,0 \mathrm{~V}$, como gm se mostrou menos influenciado pela temperatura, gD é o fator predominante em $A v$, resultando em um aumento de Av para baixas temperaturas.

Para $V_{G s}$ baixo com $V_{D S}=1,0 \mathrm{~V}$, como gD é muito baixo, um alto Av pode ser observado, porém, a influência da temperatura é muito maior. Para $V_{G S}$ baixo com $V_{D S}=0,5 \mathrm{~V}$, a competição de fatores entre gm e $g_{D}$ resulta em um $A v$ quase independente da temperatura, porque nesta polarização, gm é mais afetado pela temperatura devido à menor componente de BTBT. Esta polarização com $V_{G S}$ e $V_{D S}$ baixos é recomendada em aplicações que operem em diferentes temperaturas, pois a mesma se mostrou a menos sensível à redução da temperatura.

Figura 4.48 - Ganho intrínseco de tensão experimental em função da temperatura para nTFETs planares de $\ln \times \mathrm{Ga}_{1-\mathrm{XAs}}$.
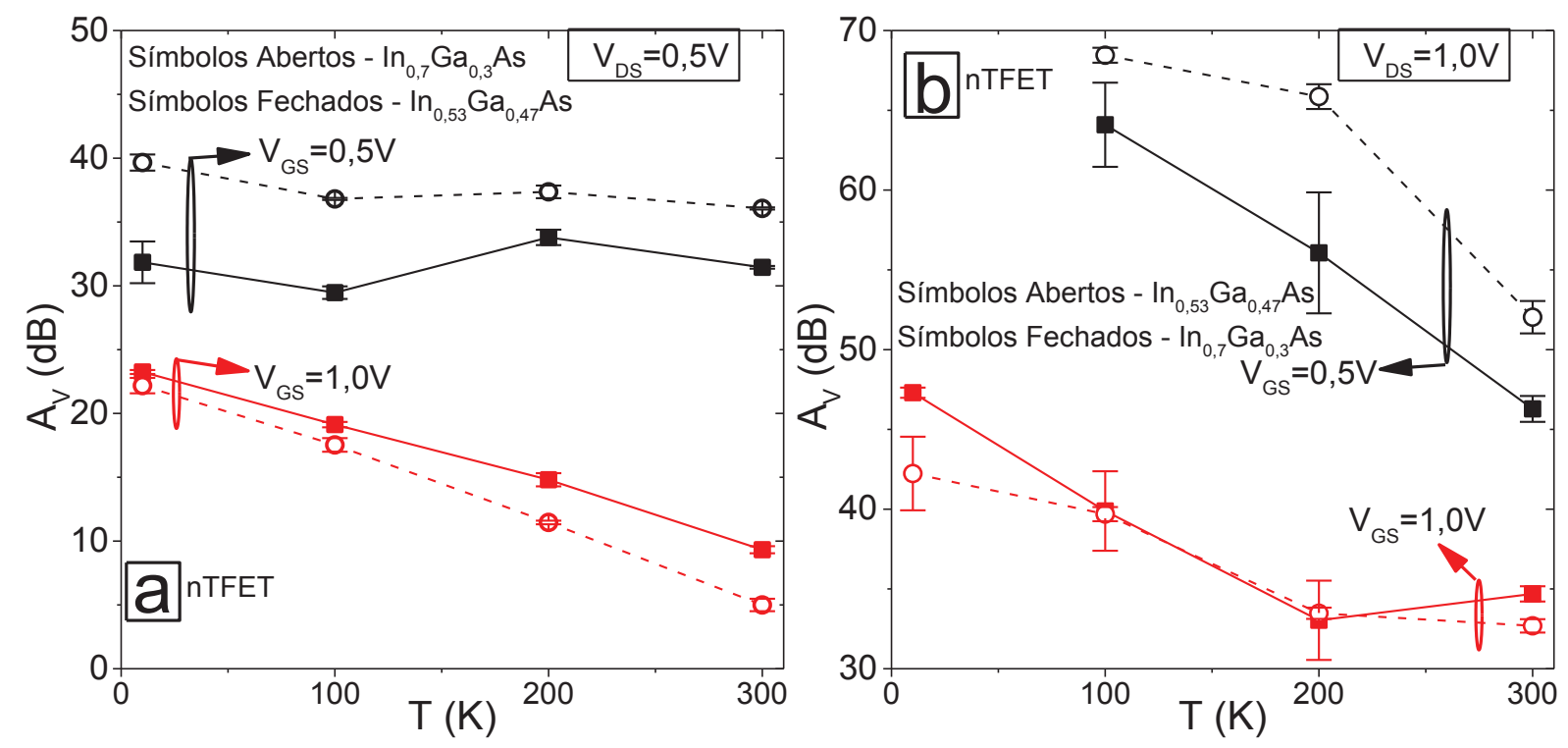

Fonte: Autor. 


\subsubsection{TFETs com dopagem de fonte por difusão de fase gasosa}

Como em dispositivos TFETs é de extrema importância que a junção entre fonte e canal seja a mais abrupta possível, um novo método de dopagem da fonte foi introduzido, utilizando agora dopagem por difusão de fonte gasosa. Foi utilizada a mesma temperatura de $500^{\circ} \mathrm{C}$ e o mesmo tempo de 60 segundos de difusão (56).

\subsubsection{Análise em temperatura ambiente}

A análise realizada em temperatura ambiente levou em consideração 3 diferentes dispositivos. O primeiro é um dispositivo de $\ln _{0,53} \mathrm{Ga}_{0,47} \mathrm{As}$, e o segundo é de In $0,7 \mathrm{Ga}_{0,3} \mathrm{As}$, ambos com os dielétricos de porta compostos por $3 \mathrm{~nm}$ de $\mathrm{HfO}_{2}$ em cima de $1 \mathrm{~nm}$ de $\mathrm{Al}_{2} \mathrm{O}_{3}$. O terceiro é um dispositivo de Ino,53 $\mathrm{Ga0} 0,47 \mathrm{As}$, porém com os dielétricos de porta compostos por $2 \mathrm{~nm}$ de $\mathrm{HfO}_{2}$ em cima de $1 \mathrm{~nm}$ de $\mathrm{Al}_{2} \mathrm{O}_{3}$.

A Figura 4.49 mostra a IDs normalizada em função de $V_{G S}$ para os 3 dispositivos estudados, com $V_{D S}$ polarizados em 0,6 e 1,0 V (Figura 4.49(a)) e em 0,05 e 0,2 V (Figura 4.49(b)). Assim como observado anteriormente nos dispositivos com difusão por fonte sólida, nestas lâminas com difusão de fase gasosa os dispositivos $\operatorname{In}_{0,7} \mathrm{Ga}_{0,3} \mathrm{As}$ mostraram IDs mais altas do que $\operatorname{In}_{0,53} \mathrm{Ga}_{0,47} \mathrm{As}$ devido ao menor $\mathrm{E}_{\mathrm{G}}$.

Nestas lâminas também se estudou o efeito da redução da espessura de $\mathrm{HfO}_{2}$ nos dispositivos de $\mathrm{In}_{0,53} \mathrm{Ga}_{0,47}$ As. Reduzindo a espessura de $\mathrm{HfO}_{2}$ de $3 \mathrm{~nm}$ para $2 \mathrm{~nm}$ é possível observar um pequeno aumento de IDs, causado pelo melhor acoplamento eletrostático proveniente da redução da espessura de $\mathrm{HfO}_{2}$. Este acoplamento eletrostático melhor também é responsável por melhorar as características de sublimiar do dispositivo, atingindo SS menores que $60 \mathrm{mV} / \mathrm{dec}$. 
Figura 4.49 - Corrente de dreno experimental normalizada em função da tensão na porta de nTFETs planares de InxGa1-XAs com diferentes porcentagens de In e espessuras de $\mathrm{HfO}_{2}$, com tensão de dreno altas (a) e baixas (b).
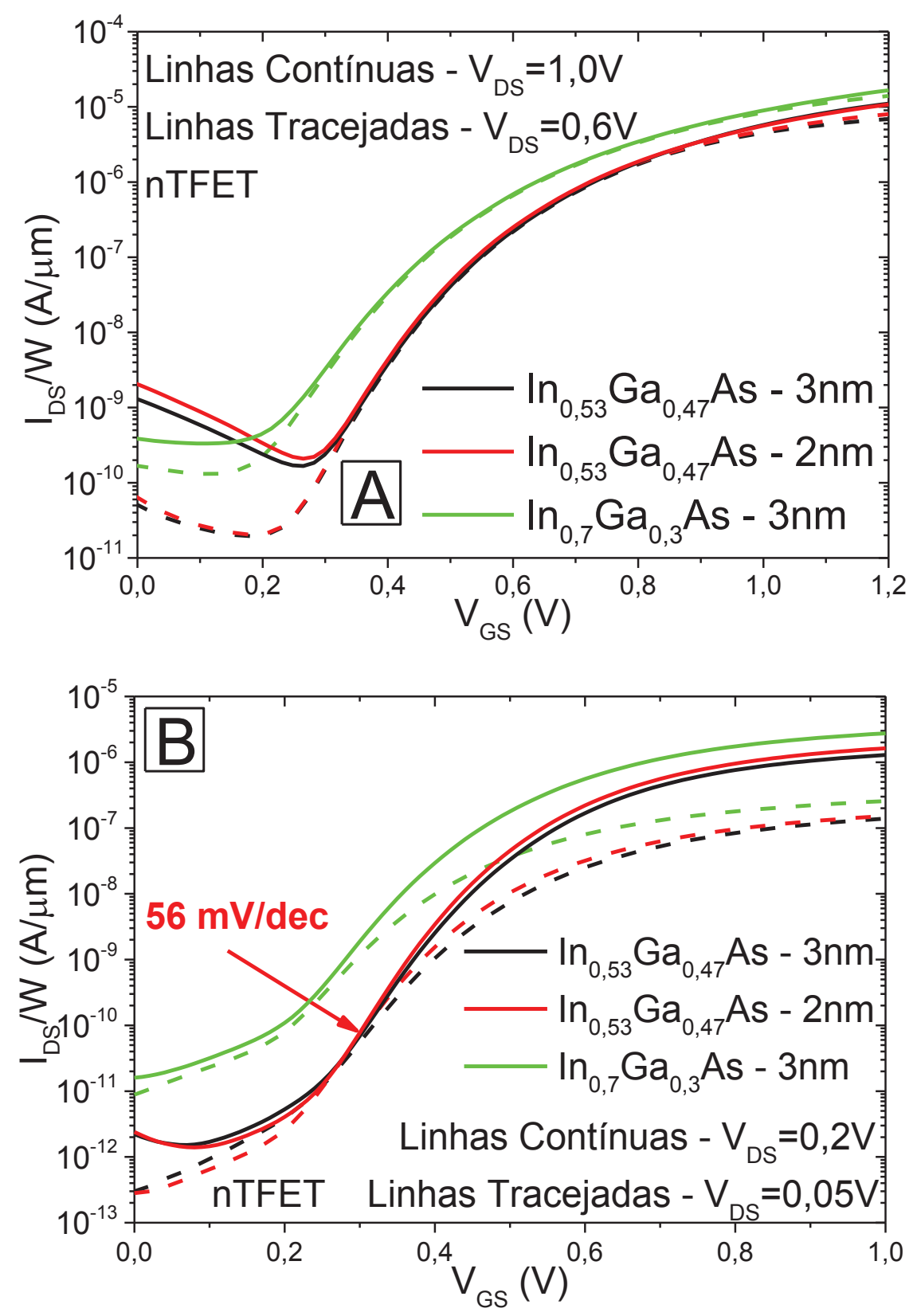

Fonte: Autor.

A transcondutância, a qual é apresentada na Figura 4.50, apresenta mesma tendência de IDs, mostrando o maior gm para o dispositivo de Ino,7Ga0,3As, com o menor gm sendo mostrado pelo dispositivo $\ln _{0,53} \mathrm{Ga}_{0,47} \mathrm{As}$ com $3 \mathrm{~nm}$ de $\mathrm{HfO}_{2}$. Já o dispositivo com $2 \mathrm{~nm}$ de $\mathrm{HfO}_{2}$ mostrou gm apenas um pouco maior que $3 \mathrm{~nm}$, da mesma forma que foi observada em los. 
Figura 4.50 - Transcondutância em função da tensão na porta de nTFETs planares de InxGa1-XAs com diferentes porcentagens de In e espessuras de $\mathrm{HfO}_{2}$.

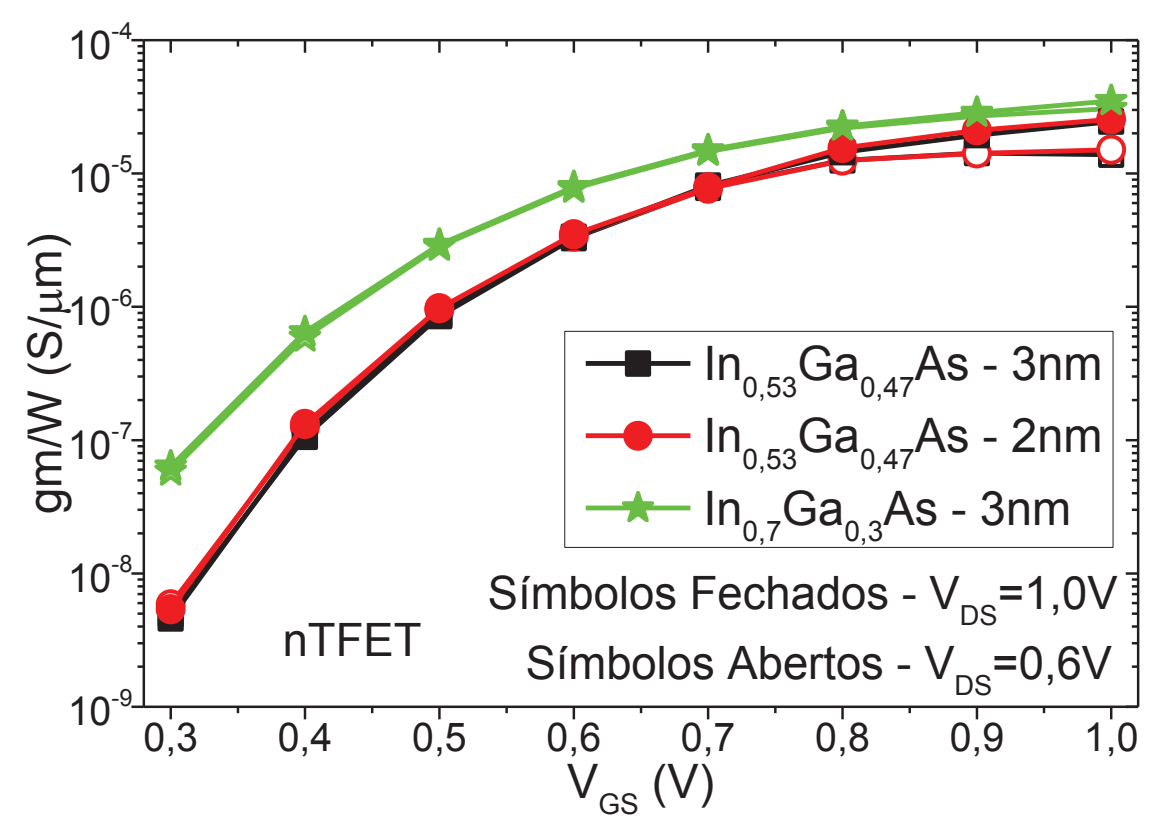

Fonte: Autor.

A Figura 4.51 mostra a condutância de saída em função de $V_{G s}$ para os 3 dispositivos estudados. Nestes dispositivos também é possível observar que quando se aumenta $V_{G S}$ há degradação de gD, causada pela maior dependência de $V_{D S}$ na janela efetiva de energia de sobreposição na junção entre fonte e canal.

Para polarizações de VDs maiores, a janela efetiva de energia fica mais larga, o que faz com que a influência de VDS seja reduzida, resultando em melhoria (redução) de gD. Esta melhoria pode ser observada também nas curvas de los (Figura 4.49) e gm (Figura 4.50) em função de $V_{G s}$. Estes dois parâmetros, para valores mais altos de $V_{G S}$, possuem um aumento para $V_{D S}$ mais altos.

Analisando a influência da porcentagem de In, é possível distinguir diferentes comportamentos nos dispositivos. O dispositivo $\operatorname{In}_{0,7} \mathrm{Ga}_{0,3} \mathrm{As}$ apresenta maiores valores de gD do que $\ln _{0,53} \mathrm{Ga}_{0,47} A s$ com baixos $V_{G S}$ (próximo de 0,5 V), entretanto, para valores mais altos de $V_{G S}$ ambos apresentaram valores bem similares.

Analisando a eficiência, que é mostrada na Figura 4.52, em regime de alta condução de corrente, onde $\mathrm{gm} / \mathrm{l} \mathrm{Ds}$ é mais dependente de gm, todos os dispositivos mostraram comportamentos similares para $\mathrm{V}_{\mathrm{DS}}=1,0 \mathrm{~V}$ devido ao $\mathrm{gm}$ similar à mesma corrente nas 3 lâminas. Porém, polarizado em $V_{D S}=0,6 \mathrm{~V}$, o dispositivo $\ln _{0,7} \mathrm{Ga}_{0,3} \mathrm{As}$ apresentou gm//Ds um pouco maior que nos dispositivos de $\ln _{0,53} \mathrm{Ga}_{0,47} \mathrm{As}$. 
Figura 4.51 - Condutância de saída em função da tensão na porta de nTFETs planares de InxGa1-XAs com diferentes porcentagens de In e espessuras de $\mathrm{HfO}_{2}$.

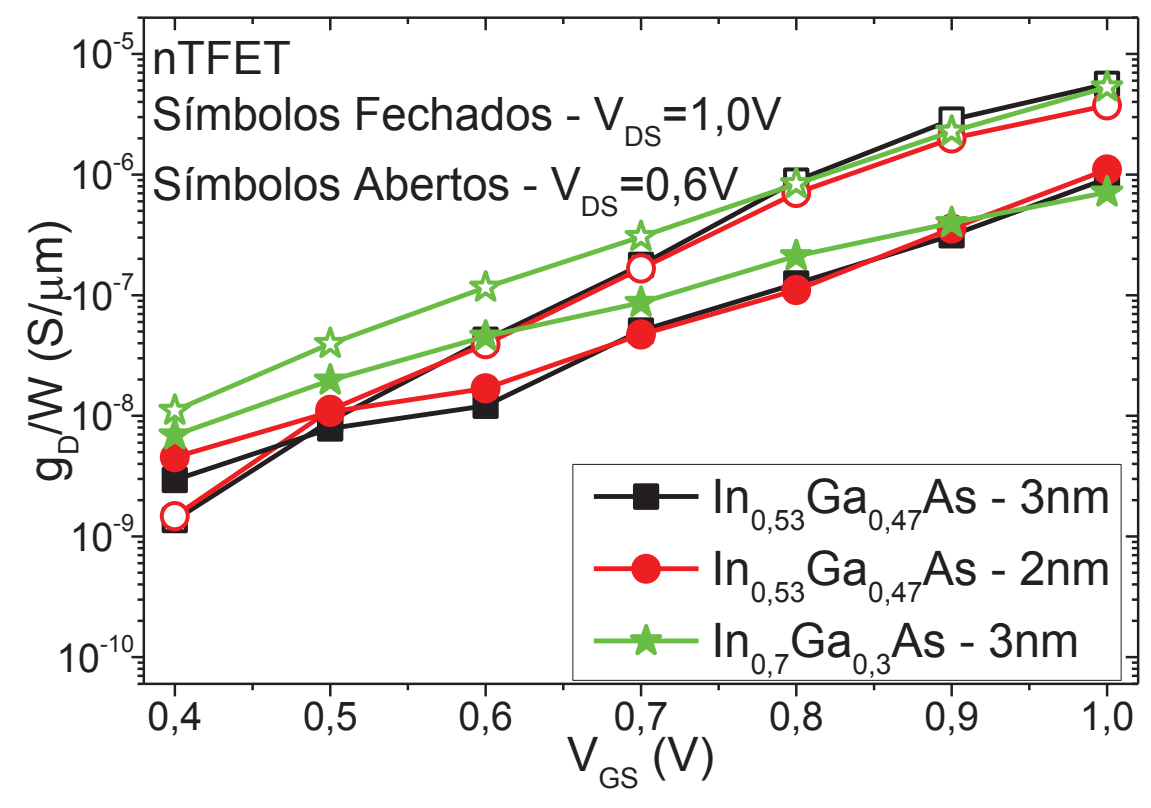

Fonte: Autor.

Figura 4.52 - Eficiência do transistor em função da corrente de dreno de nTFETs planares de InxGa1-XAs com diferentes porcentagens de In e espessuras de $\mathrm{HfO}_{2}$.

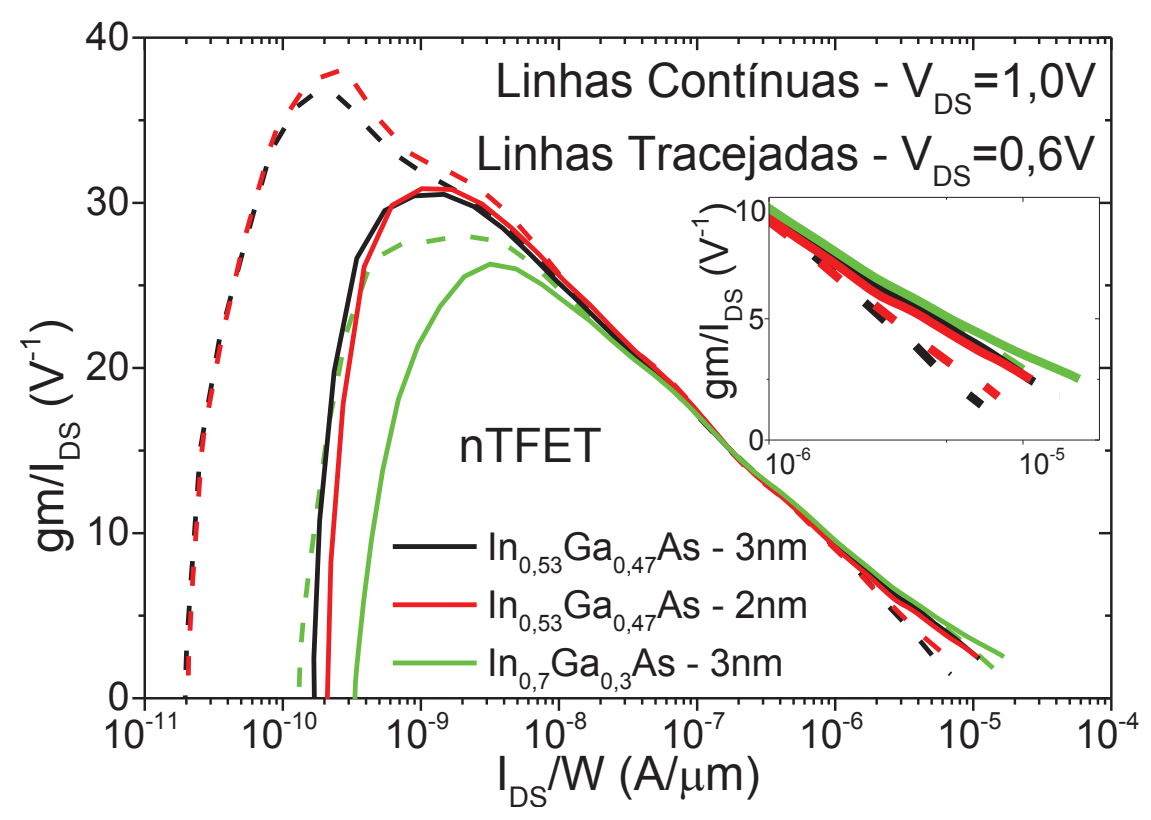

Fonte: Autor.

Em regime de baixa condução de corrente (região de pico), onde gm/los é inversamente relacionada com SS, é possível observar que o dispositivo de $\mathrm{In}_{0,53} \mathrm{Ga}_{0,47} \mathrm{As}$ com $2 \mathrm{~nm}$ de $\mathrm{HfO}_{2}$ apresenta a maior $\mathrm{gm} / \mathrm{lDs}_{\mathrm{Ds}}$. Este alto valor de $\mathrm{gm} / \mathrm{lDs}$ está relacionado com SS menor que $60 \mathrm{mV} / \mathrm{dec}$ apresentado por esse dispositivo, como mostrado na Figura 4.53. 
Embora o dispositivo de $\ln _{0,7} \mathrm{Ga}_{0,3} \mathrm{As}$ apresenta boa eficiência na região de alta condução de correte, ele mostra uma eficiência degradada na região de baixa condução de corrente, que faz com que gm/lDs fique muito pior que os dispositivos de Ino,53Ga0,47As. Esta degradação está relacionada com seu alto loff, como pode ser observado na Figura 4.49(b).

Figura 4.53 - Inclinação de sublimiar em função da corrente de dreno de nTFETs planares de In $\times \mathrm{Ga}_{1-\mathrm{X}} \mathrm{As}$ com diferentes porcentagens de In e espessuras de $\mathrm{HfO}_{2}$.

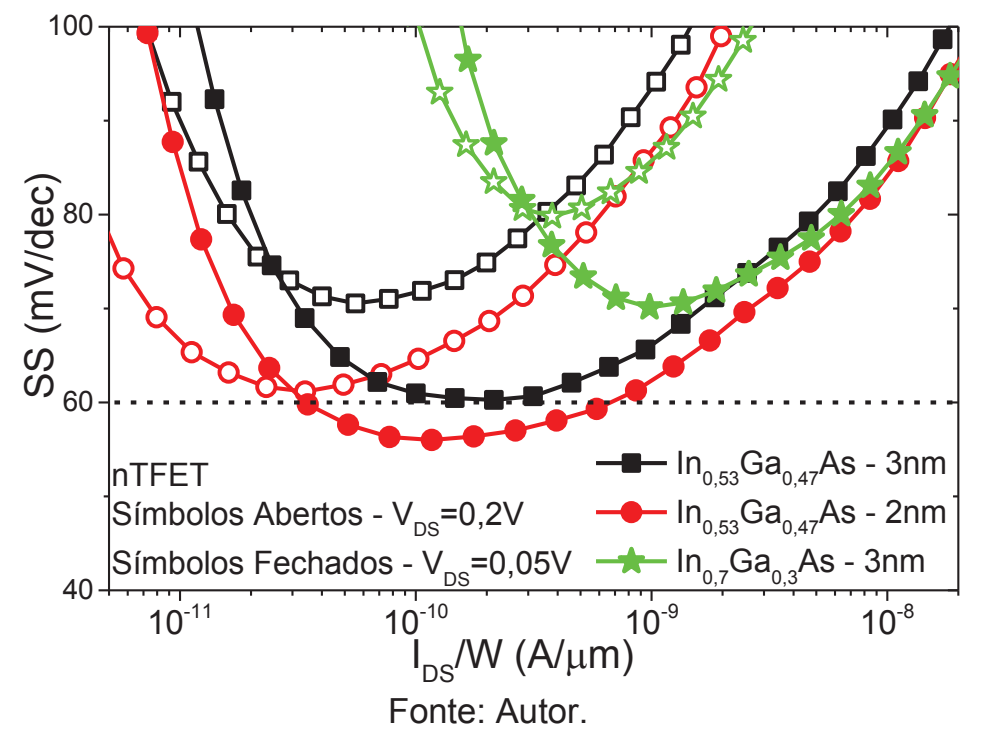

A Figura 4.54 apresenta IDs em função de $V_{D S}$, mostrando as características de saída dos 3 dispositivos estudados. A tensão Early é um importante parâmetro analógico que relaciona a características de saída de um dispositivo com IDs, e é apresentada na Figura 4.55.

Figura 4.54 - Corrente de dreno experimental normalizada em função da tensão no dreno de nTFETs planares de InxGa1-xAs com diferentes porcentagens de In e espessuras de $\mathrm{HfO}_{2}$.

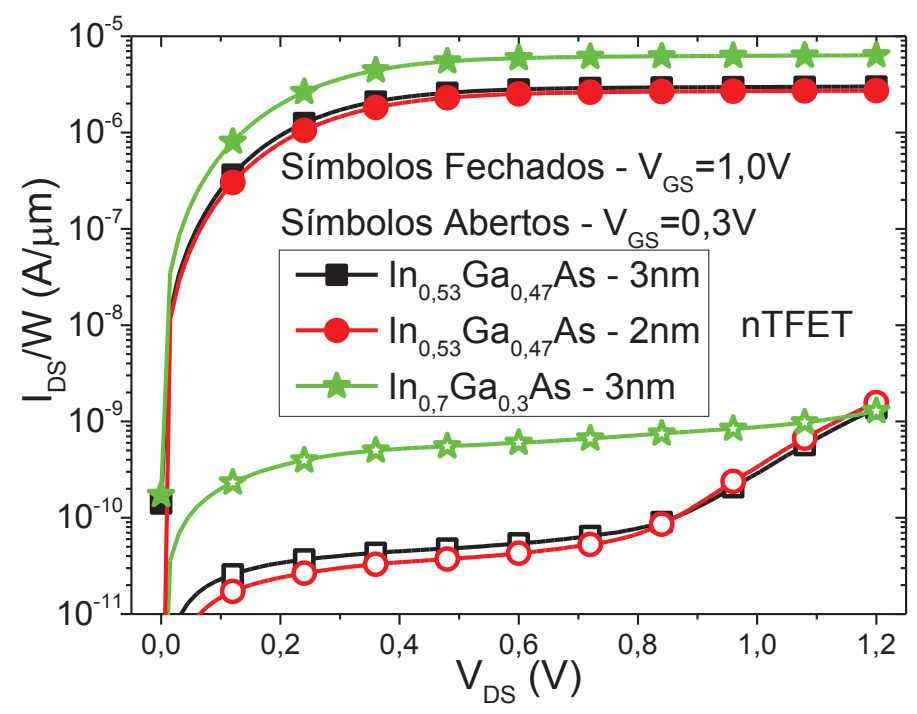

Fonte: Autor. 
É possível notar que para $V_{D S}=1,0 \vee V_{E A}$ apesenta valores maiores do que para $V_{D S}=0,6 \mathrm{~V}$ devido à sua maior lDs. Além disso, para $V_{D S}$ mais altos, os dispositivos operam em uma região semelhante à saturação, possuindo menos dependência de $V_{D S}$, resultando em um maior $V_{E A}$.

Figura 4.55 - Tensão Early em função da tensão na porta de nTFETs planares de InxGa1-xAs com diferentes porcentagens de In e espessuras de $\mathrm{HfO}_{2}$.

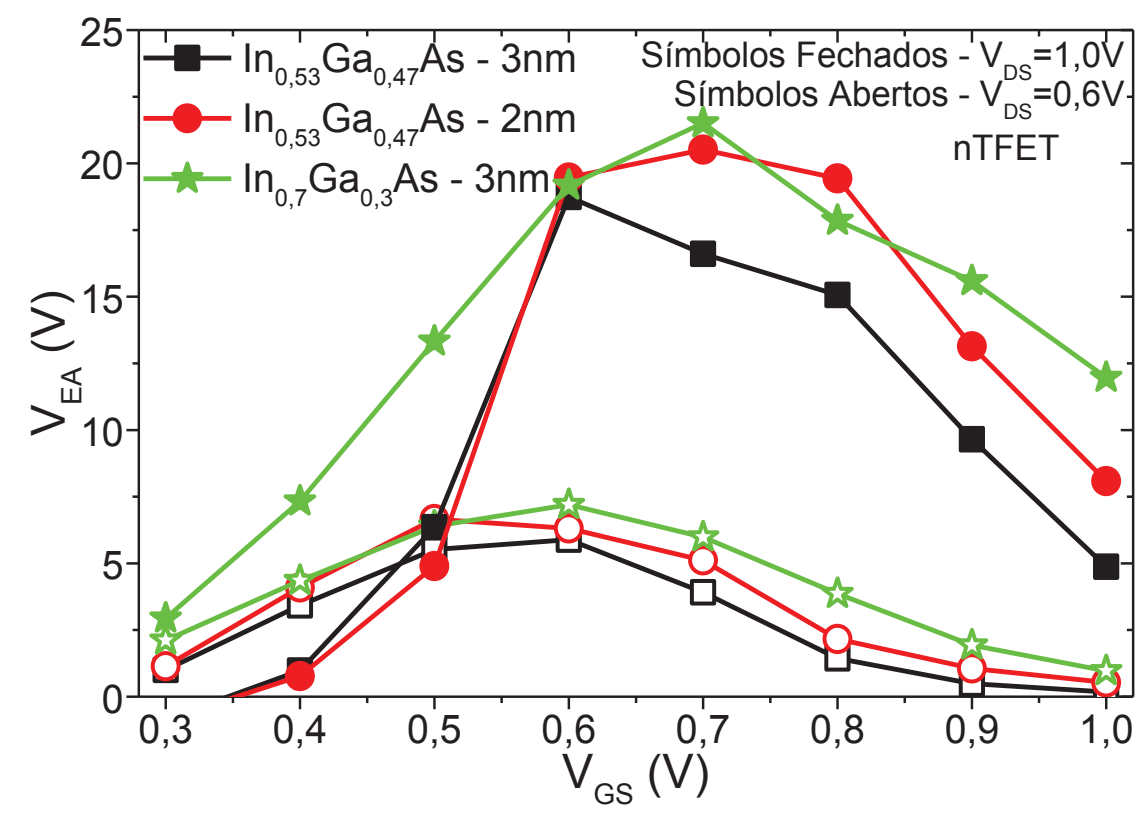

Fonte: Autor.

Para baixos $V_{G S}, V_{E A}$ também é baixo pois é dominada por baixos IDS. À medida que $V_{G S}$ é aumentado, IDS também aumenta, causando uma melhoria em VEA. Entretanto, aumentando ainda mais $V_{G S}$, além de aumentar IDS, a dependência com o dreno também aumenta (degradação de gD), resultando em redução de $V_{E A}$ para valores de $V_{G S}$ altos.

O dispositivo Ino,7Gao,3As mostrou alto $V_{E A}$, devido à sua alta IDs. Em baixa polarização de $V_{G S}$, as características de saída apresentam um comportamento anômalo na região semelhante à saturação, como pode ser observado na Figura 4.54, sendo o dispositivo In0,53Ga0,47As mais susceptível a esse comportamento anômalo.

A Figura 4.56 mostra a curva IDS em função de $V_{D S}$ para o dispositivo In 0,53Ga0,47As. Para baixos $V_{G S}$, quando $V_{D S}$ é aumentado, o TFET passa a ter tunelamento na junção entre o canal e o dreno, funcionando como um diodo túnel, aumentando a influência do dreno em lDS, resultando na degradação de $V_{\text {EA. }}$. 
Figura 4.56 - Corrente de dreno experimental normalizada em função da tensão no dreno de nTFETs planares de $\ln \times G_{1}$-xAs, com uma representação esquemática do tunelamento na junção canal/dreno em um diagrama de bandas de energia simplificado no gráfico inserido.

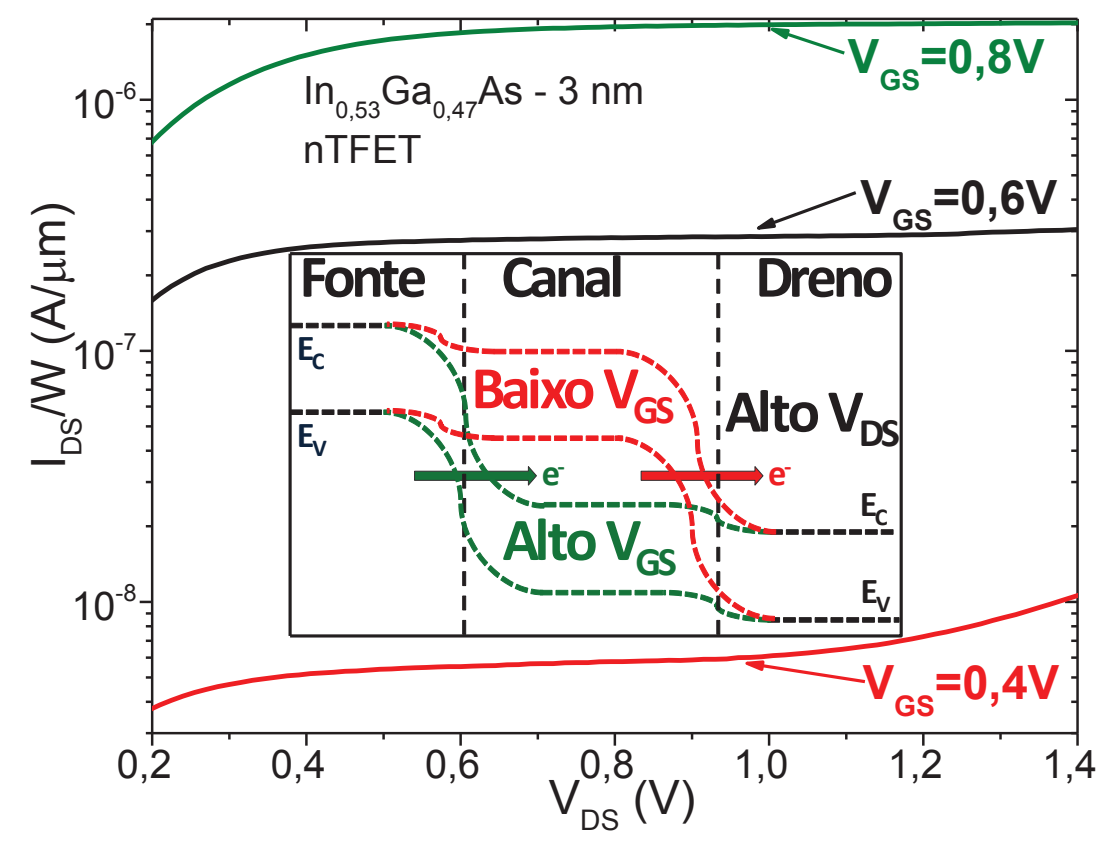

Fonte: Autor.

O Av, mostrado na Figura 4.57, foi calculado através da razão entre gm e gD. Nesta figura, pode-se observar 2 comportamentos distintos dos dispositivos, dependendo da polarização de $V_{G S}$.

Figura 4.57 - Ganho Intrínseco de tensão em função da tensão na porta de nTFETs planares de Inx $\mathrm{Ga}_{1-\mathrm{x}} \mathrm{As}$ com diferentes porcentagens de In e espessuras de $\mathrm{HfO}_{2}$.

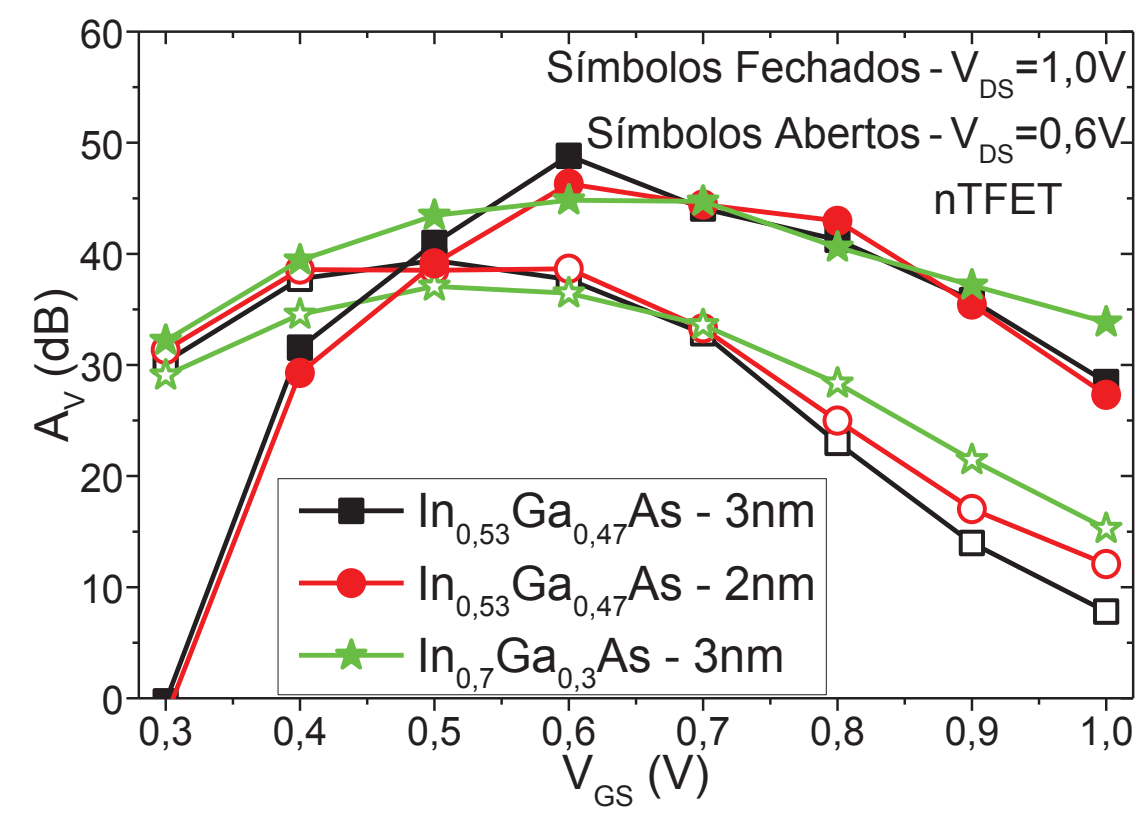

Fonte: Autor. 
Para baixos $\mathrm{V}_{\mathrm{GS}}$, o dispositivo In $0,7 \mathrm{Ga}_{0,3}$ As possui o pior desempenho com $V_{D S}=0,6 \mathrm{~V}$ devido a seu alto loFF, o que degrada a eficiência e gD. Entretanto, com $V_{D S}=1,0 \mathrm{~V}$, ele apresenta valores de $A \vee$ melhores que os dispositivos de $\ln _{0,53} G_{0} 0,47 A s$, pois estas amostras mostram um comportamento de diodo túnel muito evidente nesta polarização.

Para altos $V_{G S}$, é notável que o dispositivo $\ln _{0,7} \mathrm{Ga}_{0,3} A$ s possui ganho melhor que os demais dispositivos, devido ao seu alto gm e $V_{E A}$, independentemente do $V_{D S}$ aplicado. Comparando as diferentes espessuras de $\mathrm{HfO}_{2}$ nos dispositivos de Ino,53Ga0,47As com alta polarização de $V_{G S}$, é possível notar que o dispositivo com $2 \mathrm{~nm}$ de $\mathrm{HfO}_{2}$ possui melhor $A \vee$ para $\mathrm{V}_{\mathrm{DS}}=0,6 \mathrm{~V}$, devido a seu melhor acoplamento eletrostático.

Para $V_{G S}$ mais altos que 0,4 , onde o comportamento semelhante ao diodo túnel é suprimido, uma característica importante que pode ser observada é o pico presente na curva de Av para todos os dispositivos. Este pico em Av pode ser relacionado com o mecanismo de condução de IDs, podendo ser melhor analisado junto com $E_{A}$ (Figura 4.58).

Figura 4.58 - Condutância de saída e energia de ativação em função da tensão na porta de nTFETs planares de $\ln \times \mathrm{Ga}_{1-\mathrm{X}} \mathrm{As}$ com diferentes porcentagens de In e espessuras de $\mathrm{HfO}_{2}$.
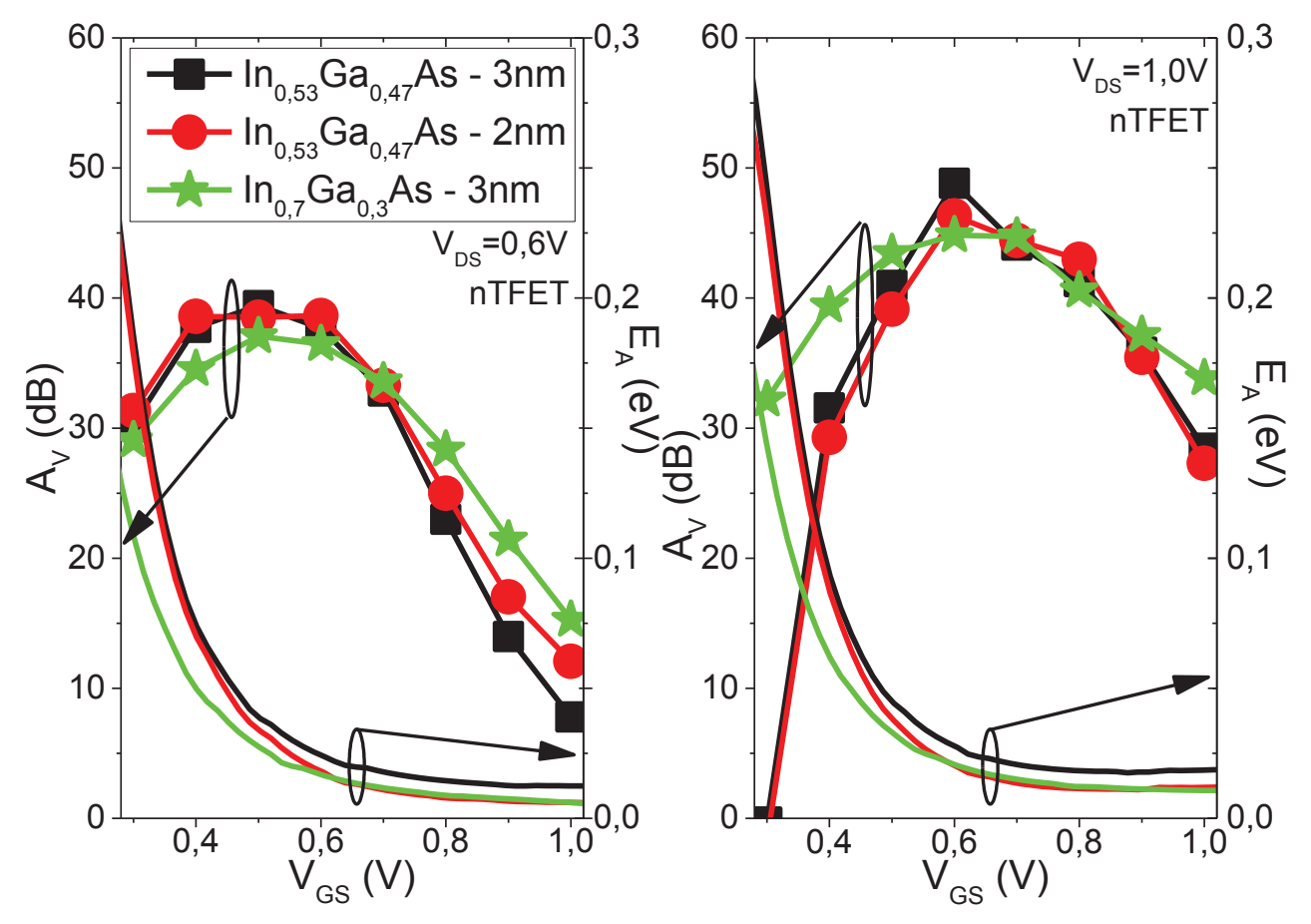

Fonte: Autor. 
Quando a componente de BTBT começa a dominar a corrente, gm apresenta sua taxa de crescimento máxima (Figura 4.50), o que coincide com a região onde $A_{v}$ começa a ficar mais constante. Com polarizações acima da polarização mínima para que BTBT seja o mecanismo dominante de corrente o go passa a crescer em uma progressão mais linear (Figura 4.51). Quando go passa a aumentar mais que gm, o $A_{v}$ tende a degradar, o que resulta neste comportamento de pico na curva de Av.

\subsubsection{Influência da variação da temperatura}

A análise realizada em diferentes temperaturas ambiente levou em consideração 2 diferentes dispositivos. Os dois dispositivos são $\ln _{0,53} \mathrm{Ga}_{0,47} \mathrm{As}$, porém com diferentes espessuras de $\mathrm{HFO}_{2}$, o primeiro com $3 \mathrm{~nm}$ e o segundo com $2 \mathrm{~nm}$.

A Figura 4.59 apresenta IDs normalizada em função de $V_{G S}$ para os 2 dispositivos estudados, polarizados com 1,0 V, a 230, 300 e $430 \mathrm{~K}$. Nesta figura, é possível ver que o dispositivo com $2 \mathrm{~nm}$ de $\mathrm{HfO}_{2}$ mostra menor variação com a temperatura.

Figura 4.59 - Corrente de dreno experimental normalizada em função da tensão na porta de nTFETs planares de $\mathrm{In}_{0,53} \mathrm{Ga}_{0,47} \mathrm{As}$ com diferentes espessuras de $\mathrm{HfO}_{2}$, em diferentes temperaturas.

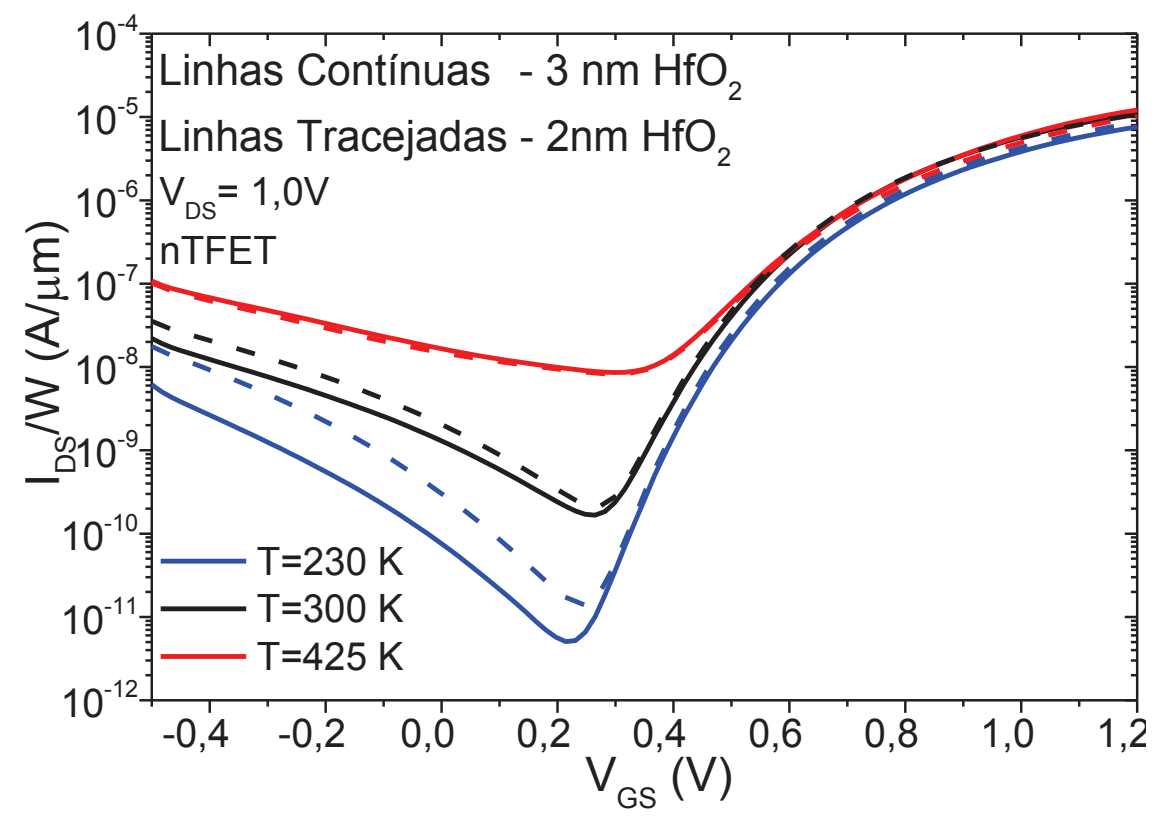

Fonte: Autor. 
Esta menor variação com a temperatura é decorrente pelo melhor acoplamento eletrostático, proveniente da redução da espessura de $\mathrm{HfO}_{2}$. A melhoria no acoplamento eletrostático aumenta a componente de BTBT na corrente o que faz com que o dispositivo com menor espessura de $\mathrm{HfO}_{2}$ seja mais imune a variação da temperatura. Este comportamento pode ser observado também em $E_{A}$ (Figura 4.60), onde o dispositivo com $2 \mathrm{~nm}$ de $\mathrm{HfO}_{2}$ apresenta valores mais baixos de $\mathrm{E}_{\mathrm{A}}$. Figura 4.60 - Energia de ativação em função da tensão na porta de nTFETs planares de
\[ \ln _{0,53} \mathrm{Ga}_{0,47} \mathrm{As} \text { com diferentes espessuras de } \mathrm{HfO}_{2} \text {. } \]

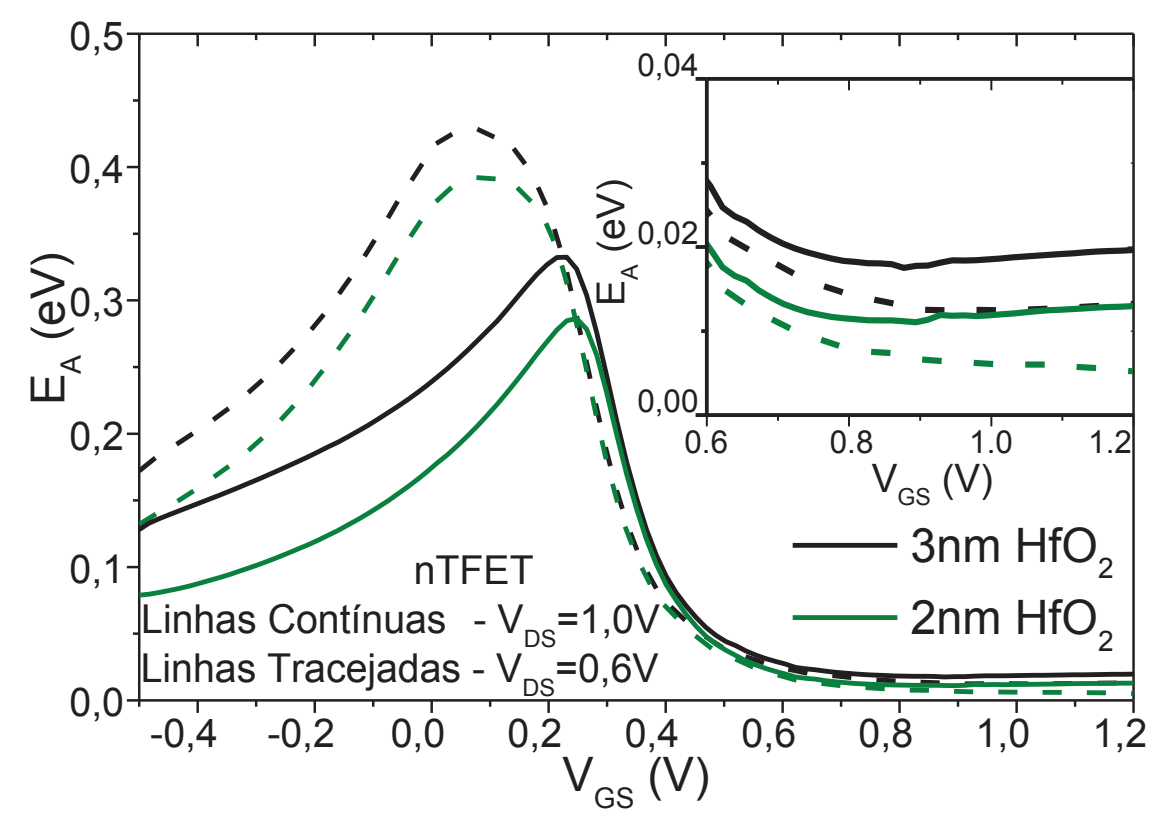

Fonte: Autor.

Na Figura 4.60 também é possível observar que para altos VGS EA é menor pois o BTBT passa a ser o mecanismo de condução dominante de corrente. Por outro lado, para baixos VGS há uma competição de fatores entre os mecanismos ativados termicamente (TAT e SRH) e o BTBT, este último tanto causado pelo BTBT convencional (Tunelamento entre fonte e canal) quanto causado pelo efeito ambipolar (Tunelamento entre canal e dreno).

Quando $V_{G S}$ é reduzido, TAT e SRH passam a ser mais dominantes, aumentando $E_{A}$. Diminuindo $V_{G S}$ ainda mais, $E_{A}$ passa a diminuir novamente devido a influência de BTBT causado pelo efeito ambipolar. Esta competição de fatores pode ser melhor observada utilizando simulação numérica, conforme mostrado na Figura 4.61 , onde foram separados a influência dos mecanismos termicamente ativados (TAT e SRH) e o BTBT. 
Figura 4.61 - Composição da corrente de dreno em função da tensão na porta de nTFETs planares de $\ln _{0,53} \mathrm{Ga}_{0,47} \mathrm{As}$ simulados em diferentes temperaturas.

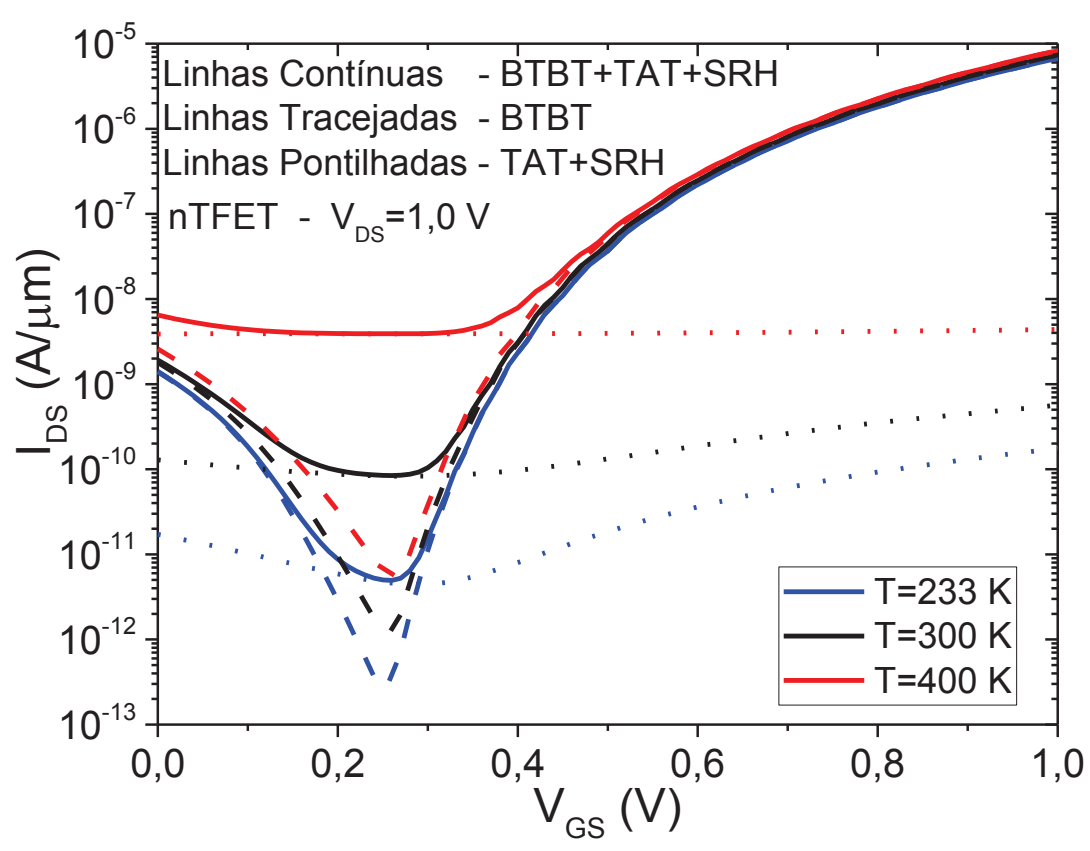

Fonte: Autor.

Ao analisar a eficiência em função de lDs para diferentes temperaturas (Figura 4.62) é possível notar que em regime de alta condução de corrente, os dispositivos são mais dominados pela componente de BTBT, fazendo com que gm/los seja pouco influenciada pela temperatura.

Figura 4.62 - Eficiência do transistor em função da corrente de dreno de nTFETs planares de In ${ }_{0,53} \mathrm{Ga}_{0,47}$ As com diferentes espessuras de $\mathrm{HfO}_{2}$, em diferentes temperaturas.

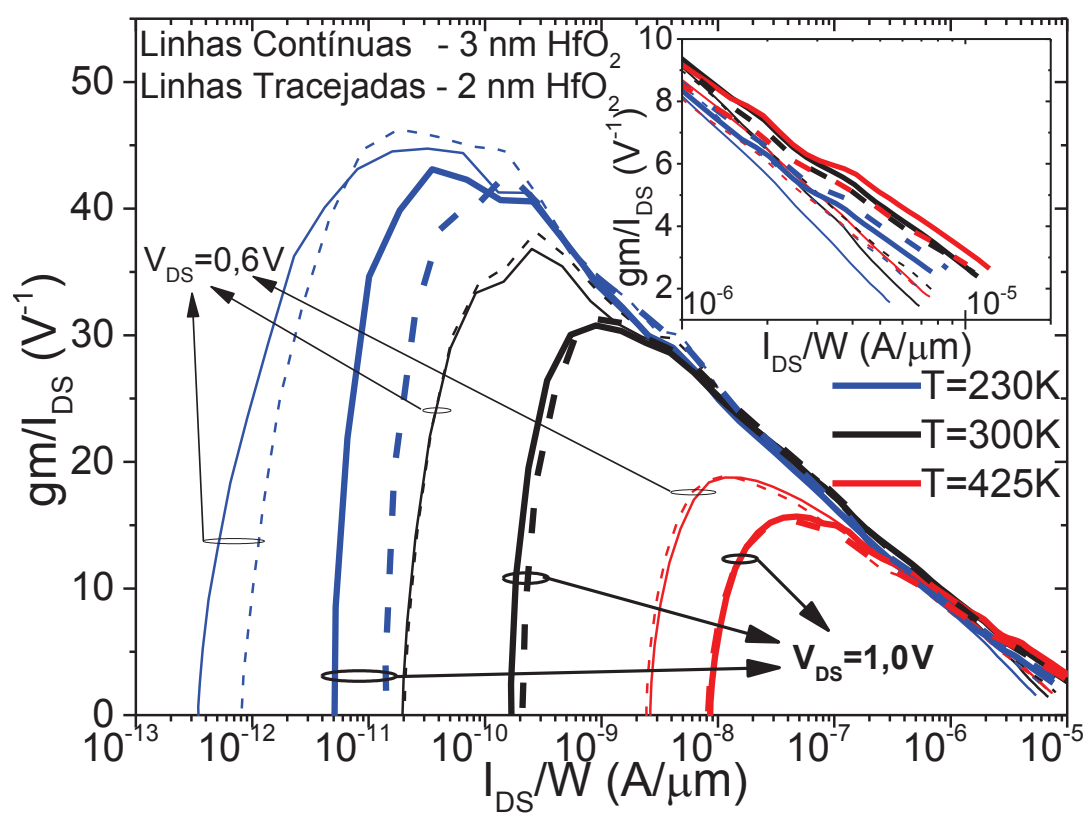

Fonte: Autor. 
Em regime de baixa condução e corrente ( $\mathrm{gm} / \mathrm{I}_{\mathrm{Ds}}$ inversamente proporcional à SS), gm/lDS diminui quando a temperatura é aumentada devido à degradação de SS, mostrada na Figura 4.63, a qual é causada pelo aumento da influência dos mecanismos de TAT e SRH. Pode ser observado que gm/lds é um pouco maior para o dispositivo com $2 \mathrm{~nm}$ de $\mathrm{HfO}_{2}$, pois este dispositivo possui melhor acoplamento eletrostático, que resulta em melhor SS.

Considerando a influência de $V_{D S}$, é notável que $\mathrm{gm} / \mathrm{l}_{\mathrm{DS}}$ em regime de baixa condução de corrente é degradado e deslocado na direção de altos valores de IDS para $V_{D S}$ altos (Figura 4.62). Esta degradação para altos $V_{D S}$ também ocorre em SS, como pode ser observado na Figura 4.63. A degradação de ambos é causada principalmente pelo aumento de loff devido ao aumento do efeito ambipolar para altos VDS. A corrente gerada pelo efeito ambipolar (tunelamento entre canal e dreno), observada para baixos valores de $V_{G S}$, é muito dependente de $V_{D S}$ por alterar muito facilmente o comprimento de tunelamento na junção entre canal e dreno.

Figura 4.63 - Inclinação de sublimiar em função da temperatura de nTFETs planares de $\ln _{0,53} \mathrm{Ga}_{0,47} \mathrm{As}$ com diferentes espessuras de $\mathrm{HfO}_{2}$.

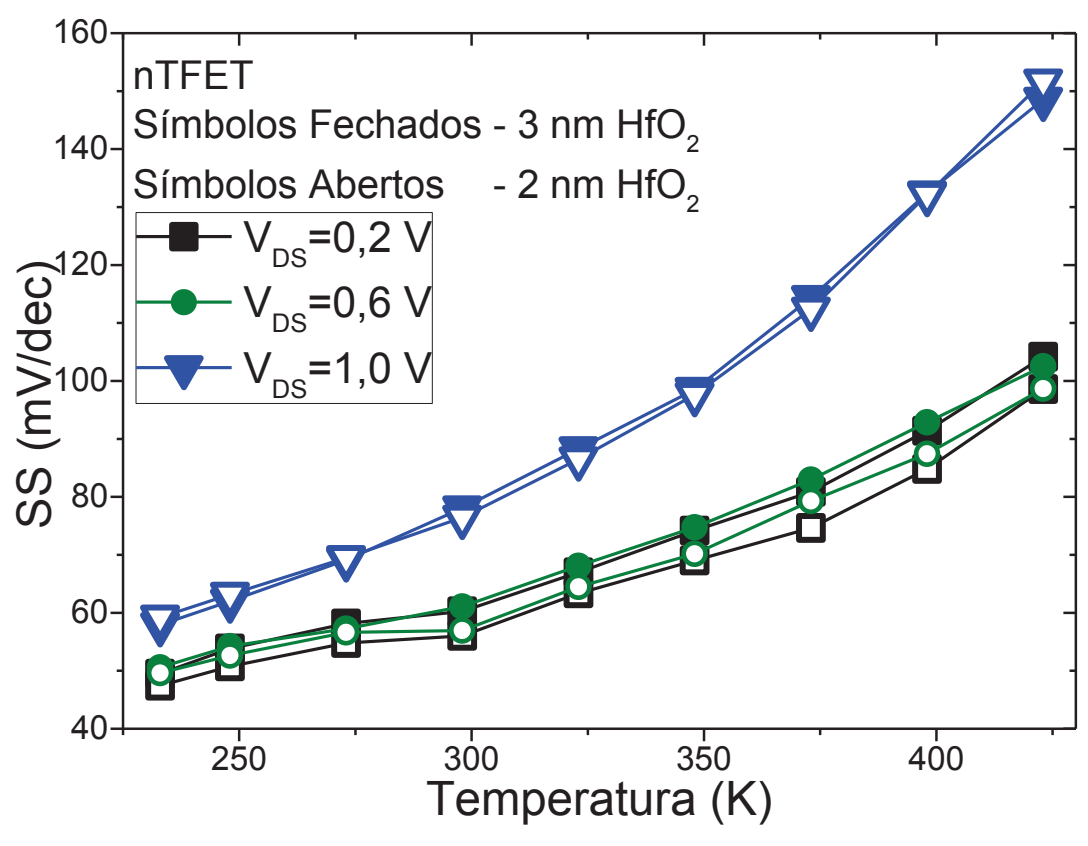

Fonte: Autor.

A transcondutância normalizada é mostrada em função da temperatura é mostrada na Figura 4.64. O melhor acoplamento eletrostático também faz com que gm seja um pouco maior para o dispositivo de $2 \mathrm{~nm}$ de $\mathrm{HfO}_{2}$. Quando a temperatura é aumentada gm tende a crescer, entretanto, para temperaturas maiores que $400 \mathrm{~K}$ 
gm começa a diminuir. Este comportamento, que é mais visível para o dispositivo de $2 \mathrm{~nm}$ de $\mathrm{HfO}_{2}$, pode ser relacionado à presença da resistência série nestes dispositivos.

Figura 4.64 - transcondutância em função da temperatura de nTFETs planares de $\ln _{0,53} \mathrm{Ga}_{0,47} \mathrm{As}$ com diferentes espessuras de $\mathrm{HfO}_{2}$.

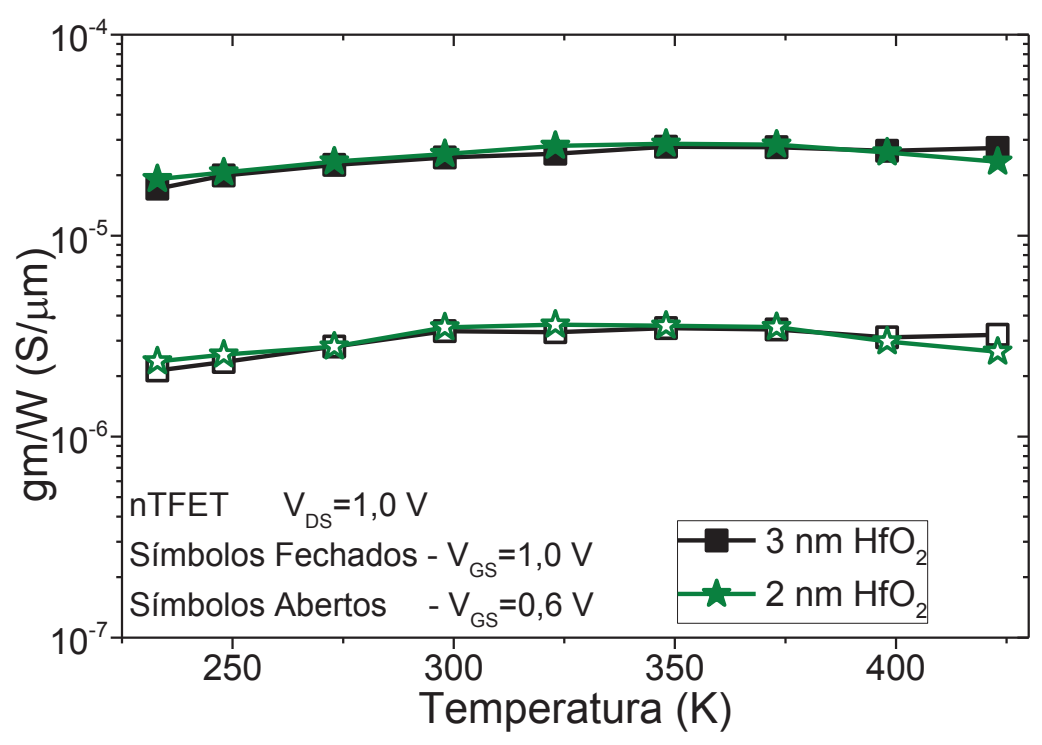

Fonte: Autor.

A Figura 4.65 mostra gD em função da temperatura. Pode ser observado que o efeito da temperatura em gD é maior que em gm. A influência da temperatura em gm é mais relacionado com o aumento de los em altas temperaturas. Porém, a influência da temperatura em gD também está relacionada com a taxa de geração por BTBT.

Figura 4.65 - Condutância de saída de sublimiar em função da temperatura de nTFETs planares de $\mathrm{In}_{0,53} \mathrm{Ga}_{0,47}$ As com diferentes espessuras de $\mathrm{HfO}_{2}$.

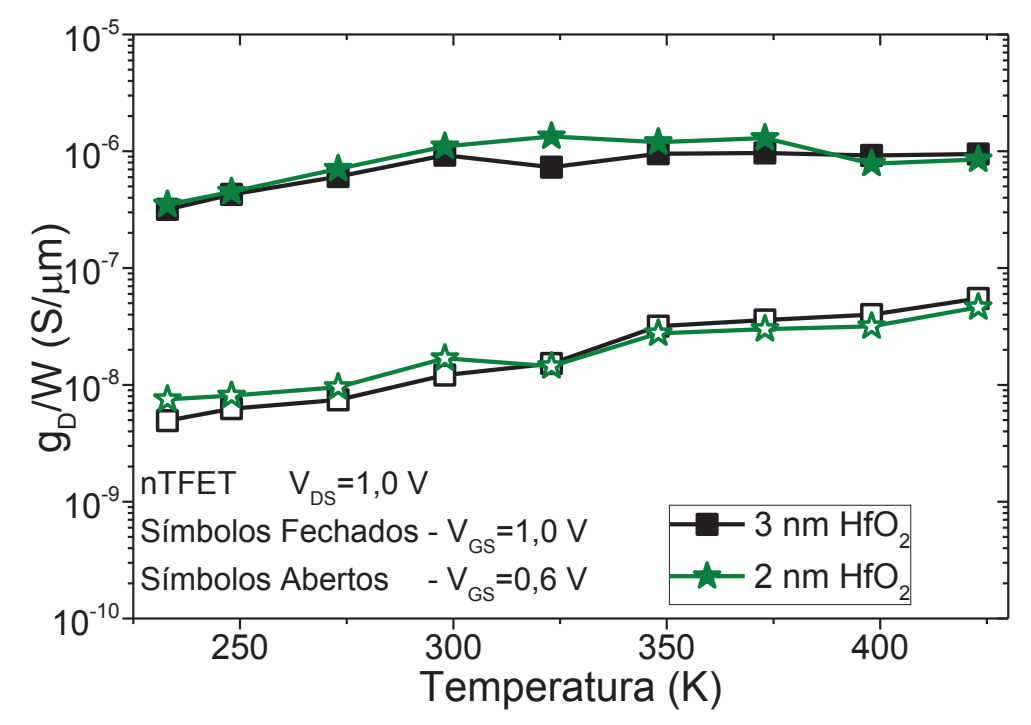

Fonte: Autor. 
O ganho intrínseco de tensão em função da temperatura é mostrado na Figura 4.66. Embora o aumento da temperatura aumente gm, degrada mais gD, resultando em redução de Av para altas temperaturas. Pode ser notado também que ambos os dispositivos, quando polarizados em $V_{G S}=1,0 \mathrm{~V}$, apresentaram menor $A v$, porém também apresentaram menor variação com a temperatura devido o mecanismo de condução de corrente dominante ser o BTBT.

Figura 4.66 - Ganho Intrínseco de tensão em função da temperatura de nTFETs planares de In ${ }_{0,53} \mathrm{Gaa}_{0,47}$ As com diferentes espessuras de $\mathrm{HfO}_{2}$.

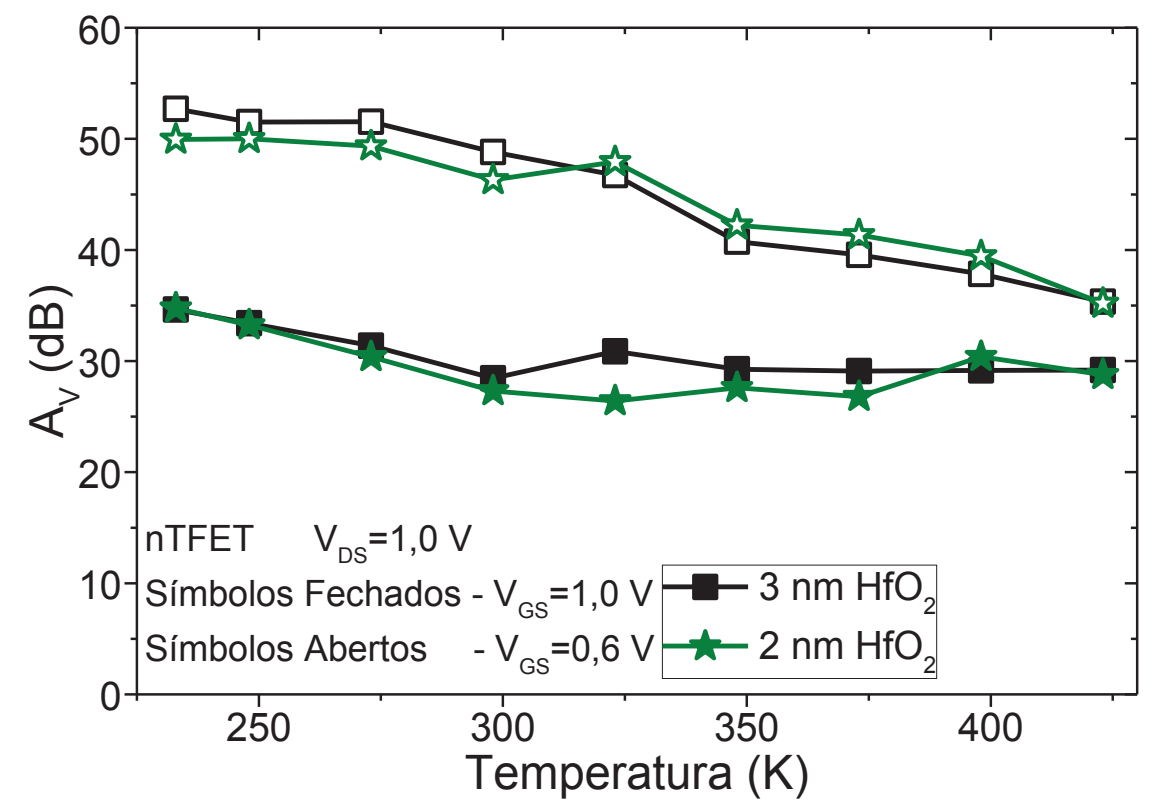

Fonte: Autor.

Olhando Av por uma abordagem diferente, em função de $V_{G S}$ para temperaturas diferentes (Figura 4.67), é possível notar um pico em Av. Este pico é relacionado com o ponto onde $E_{A}$ reduz significantemente devido à componente de BTBT começar a ser dominante na condução de corrente. Apesar de essa região possuir altos valores de $A v$ é possível notar também que o Av nessa região é muito influenciado pela temperatura. A causa para essa alta influência é a mudança do mecanismo de condução de corrente. Enquanto em baixas temperaturas o ponto de pico é na região onde o mecanismo de BTBT passa a ser dominante, ao aumentar a temperatura os mecanismos termicamente ativados (TAT e SRH) passar a ser dominantes nesse mesmo ponto, degradando Av neste ponto. Esta degradação faz com que o ponto de pico seja deslocado para maiores valores de VGS. 
Para $V_{G S}$ mais altos a variação de $A v$ com a temperatura é menor, sendo recomendado o seu uso para aplicações à diferentes temperaturas.

Figura 4.67 - Ganho intrínseco de tensão em função da tensão na porta de nTFETs planares de Ino,53 $\mathrm{Ga}_{0,47} \mathrm{As}$ com $2 \mathrm{~nm}$ (a) e $3 \mathrm{~nm}$ de $\mathrm{HfO}_{2}$, em diferentes temperaturas.
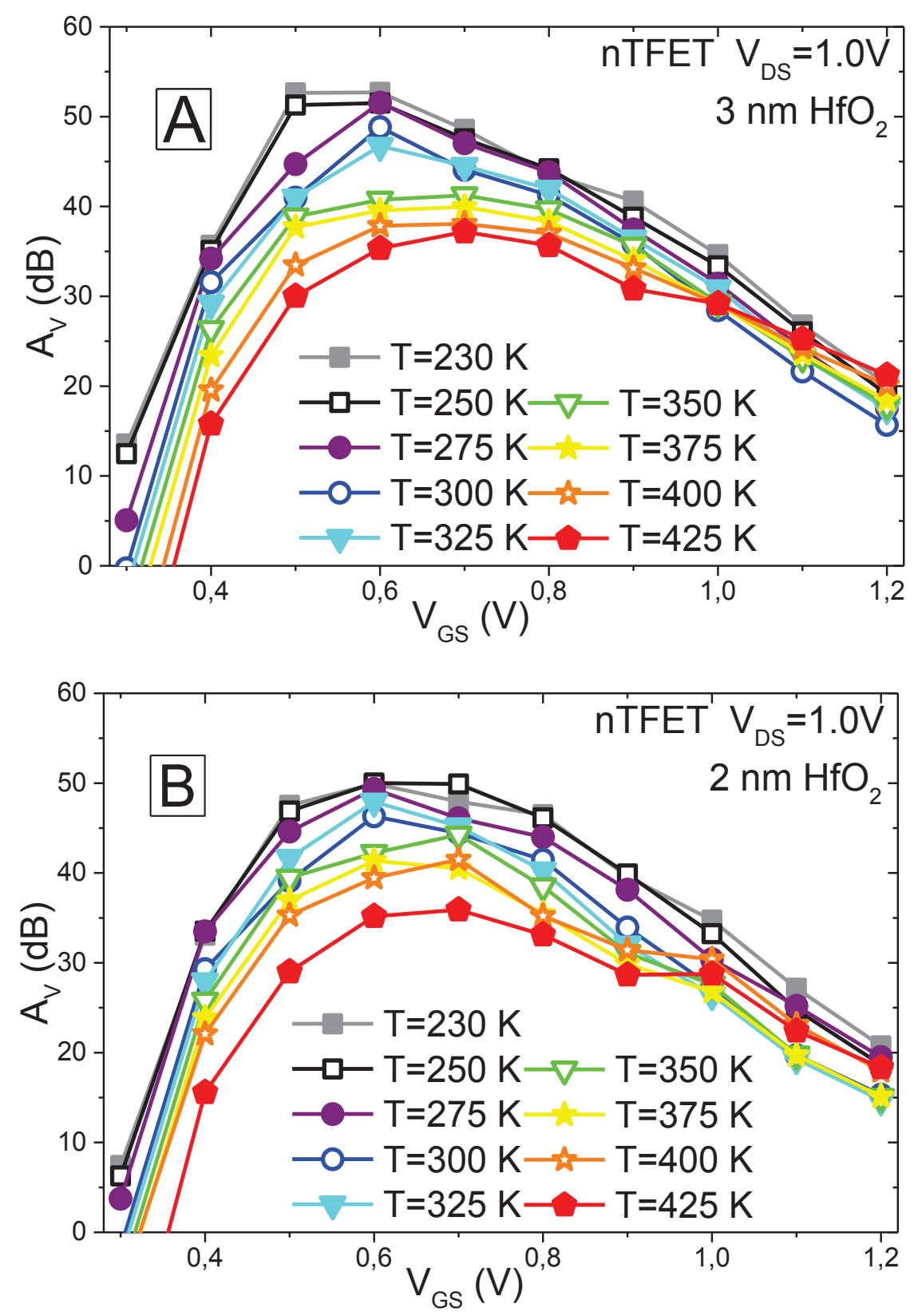

Fonte: Autor. 


\subsubsection{Comparação de TFETs com dopagem de fonte por fonte sólida e por fase gasosa}

Nesta seção é realizada uma análise comparativa entre ambos os processos utilizados para realizar a difusão de Zn na fonte. Esta comparação se baseia nos dispositivos de $\ln _{0,53} \mathrm{Ga}_{0,47} \mathrm{As}$ com os dielétricos de porta compostos por $3 \mathrm{~nm}$ de $\mathrm{HfO}_{2}$ em cima de $1 \mathrm{~nm}$ de $\mathrm{Al}_{2} \mathrm{O}_{3}$. Ambos os processos foram realizados com a mesma temperatura $\left(500^{\circ} \mathrm{C}\right)$ pelo mesmo tempo (60 segundos). Foi também comparada a lâmina de Ino,7 $\mathrm{Ga}_{0,3} \mathrm{As}$ com difusão por fonte sólida.

A figura Figura 4.68 apresenta IDS em função de $V_{G S}$ para os dispositivos de In $0,53 \mathrm{Ga0}, 47 \mathrm{As}$ com processos diferentes e o dispositivo de In $0,7 \mathrm{Ga}_{0,3} \mathrm{As}$ com difusão por fonte sólida. Utilizando como referência o dispositivo de $\ln _{0,53} \mathrm{Ga}_{0,47} \mathrm{As}$ com dopagem por fonte sólida é possível ver que tanto o dispositivo de In $0,7 \mathrm{Ga}_{0,3} \mathrm{As}$ quanto o dispositivo de In0,53Ga0,47As com difusão por fonte sólida apresentaram maiores IoN. lon é maior em $\ln _{0,7} \mathrm{Ga}_{0,3} \mathrm{As}$ devido a seu menor $\mathrm{E}_{\mathrm{G}}$ e maior concentração de dopagem na fonte devido à maior difusão de dopantes nesta liga (65), o que resulta em redução do comprimento de tunelamento. No dispositivo de $\ln _{0,53} \mathrm{Ga}_{0,47} \mathrm{As}$ com difusão por fase gasosa esse aumento é relacionado com a junção entre fonte e canal, a qual é mais abrupta, resultando em uma redução do comprimento de tunelamento.

Figura 4.68 - Corrente de dreno experimental normalizada em função da tensão na porta de nTFETs planares de $\ln _{x} \mathrm{Ga}_{1-x} \mathrm{As}$ com diferentes processos de difusão de $\mathrm{Zn}$ e porcentagens de In.

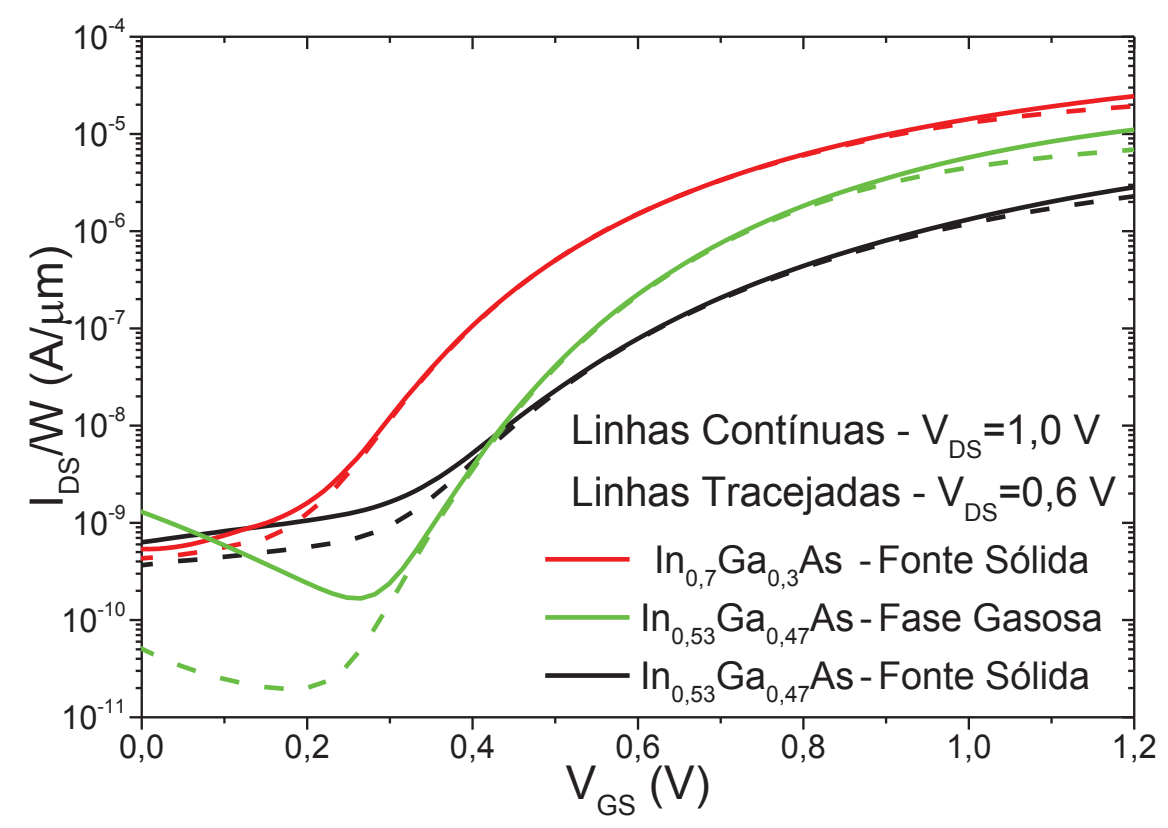

Fonte: Autor. 
A tensão mínima para que o BTBT seja o mecanismo de condução de corrente dominante também é diferente para estes dispositivos, onde o dispositivo de In ${ }_{0,7} \mathrm{Ga}_{0,3}$ As apresenta menor $V_{\text {ON }}$ do que os dispositivos de In no,53 $\mathrm{Ga}_{0,47} \mathrm{As}$. Também é notável que para os dispositivos de In $0,7 \mathrm{Ga}_{0,3} \mathrm{As}$ e de In $0,53 \mathrm{Ga} 0,47 \mathrm{As}$ com difusão por fase gasosa possuem menor SS, sendo este último capaz de atingir valores de SS menores que $60 \mathrm{mV} / \mathrm{dec}$.

Um aumento da transcondutância, apresentada na Figura 4.69, também pode ser notado, o qual é mais pronunciado no dispositivo de Ino,7 $\mathrm{Ga}_{0,3} \mathrm{As}$, devido a sua redução do comprimento de tunelamento e também redução de $V_{\mathrm{ON}}$, em vez de somente reduzir o comprimento de tunelamento para o dispositivo de $\ln _{0,53} \mathrm{Ga}_{0,47} \mathrm{As}$ com difusão por fase gasosa.

Figura 4.69 - Transcondutância em função da tensão na porta de nTFETs planares de InxGa1-XAs com diferentes processos de difusão de $\mathrm{Zn}$ e porcentagens de In.

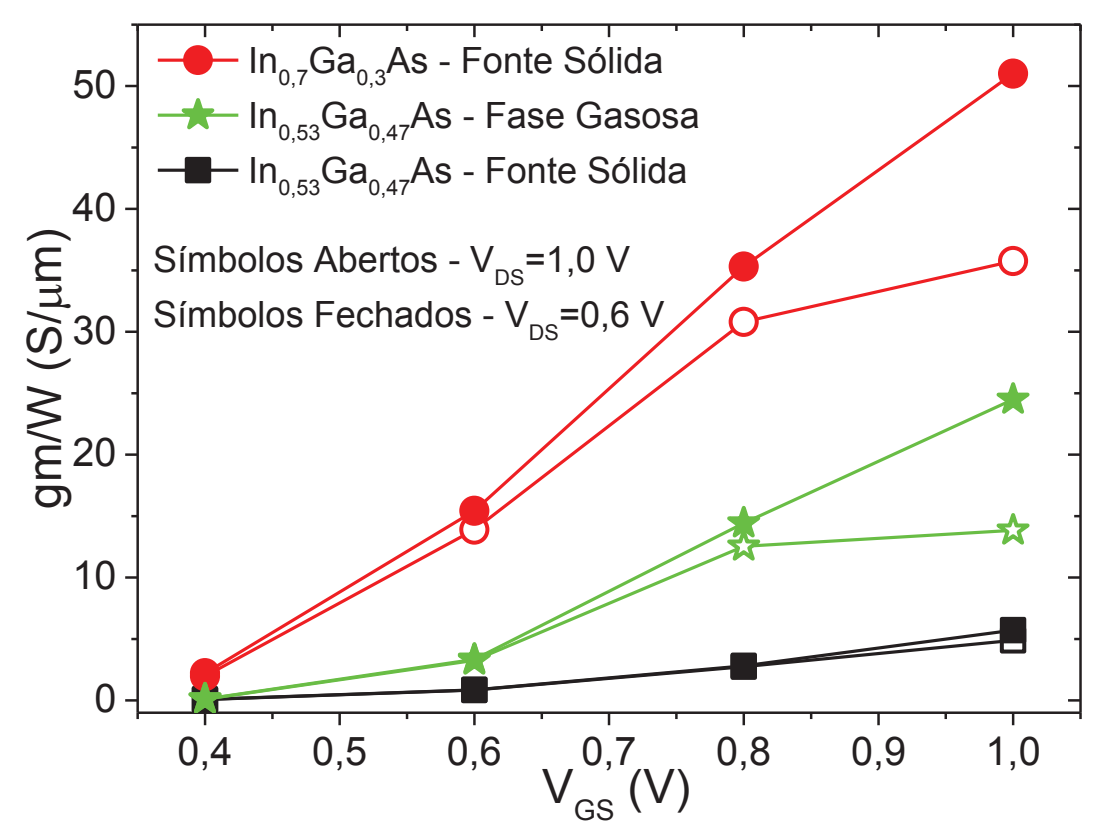

Fonte: Autor.

A Figura 4.69 também mostra que para baixos valores de $V_{G S}$, gm é quase independente de $V_{D S}$. Entretanto, quando $V_{G S}$ é aumentado, a janela efetiva de energia fica mais dependente de $V_{D S}$, o que faz com que gm aumente para altos $V_{D S}$. Este aumento de $V_{G S}$ também resulta em degradação de gD, como pode ser visto na Figura 4.70. Esta degradação é mais pronunciada no dispositivo de $\ln _{0,7} \mathrm{Ga}_{0,3} \mathrm{As}$, pois como ele possui menor $\mathrm{E}_{\mathrm{G}}$, sua janela de tunelamento é menor. Para maiores $\mathrm{V}_{\mathrm{GS}}$, 
quando $V_{D S}$ é aumentado, o dispositivo fica mais na região similar à saturação, reduzindo gD.

Figura 4.70 - Condutância de saída em função da tensão na porta de nTFETs planares de InxGa1-xAs com diferentes processos de difusão de Zn e porcentagens de In.

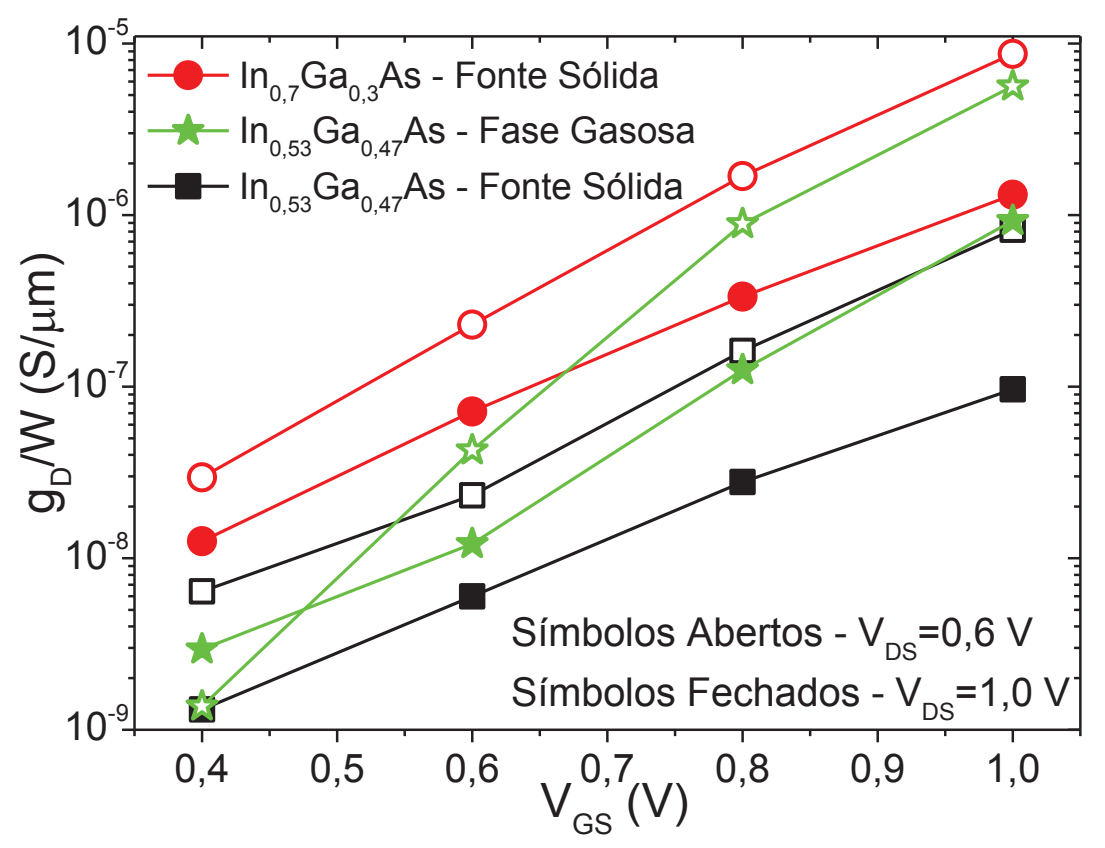

Fonte: Autor.

A Figura 4.71 apresenta a eficiência em função de IDs normalizada para os 3 dispositivos estudados.

Figura 4.71 - Eficiência do transistor em função da corrente de dreno de nTFETs planares de InxGa1-XAs com diferentes processos de difusão de $\mathrm{Zn}$ e porcentagens de In.

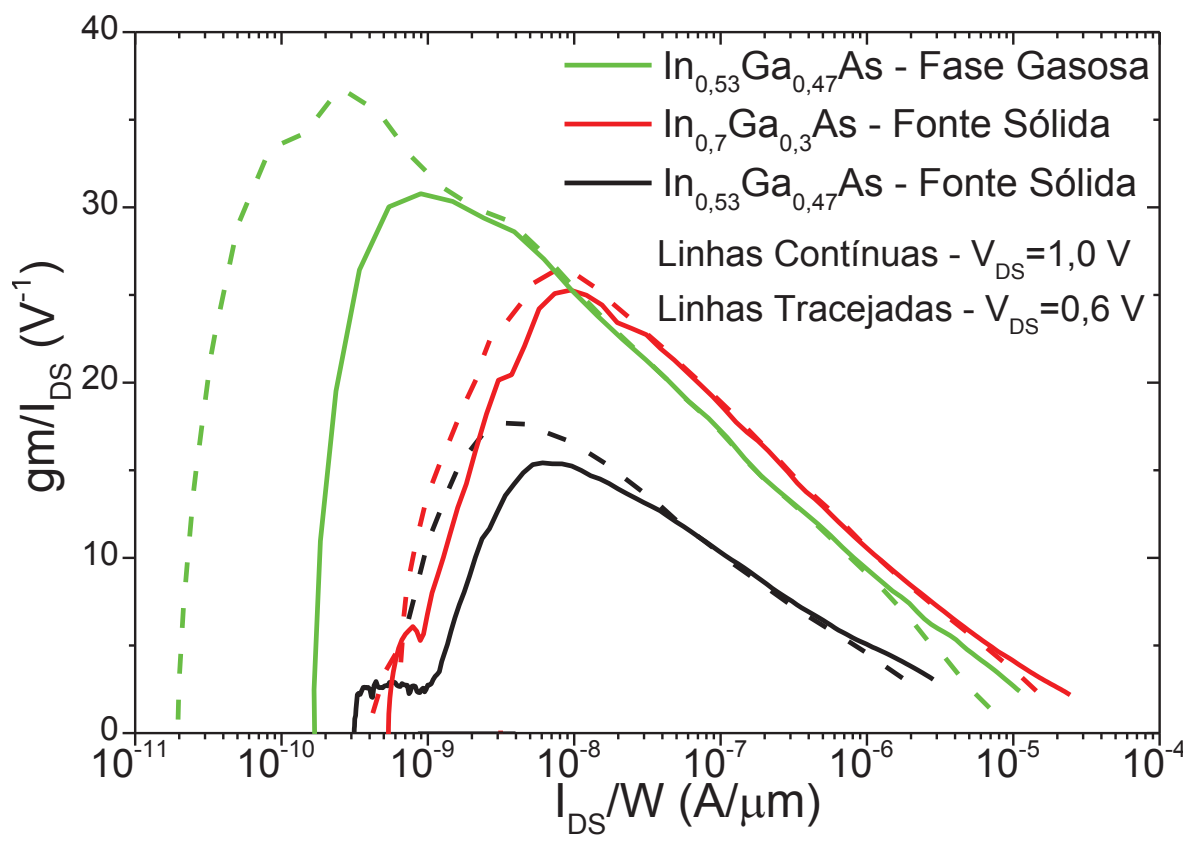

Fonte: Autor. 
Tanto o dispositivo de $\ln _{0,7} \mathrm{Ga}_{0,3}$ As quando o de $\ln _{0,53} \mathrm{Ga}_{0,47} \mathrm{As}$ com difusão por fase gasosa apresentaram alta $\mathrm{gm} / \mathrm{l}$ Ds para ambos regimes de condução de corrente. Em regime de alta condução, pode ser observado maior gm/los no dispositivo de Ino,7Ga0,3As devido ao seu maior gm. Entretanto, em baixa condução de corrente, o dispositivo de In $0,53 \mathrm{Ga0}, 47 \mathrm{As}$ com difusão por fase gasosa apresentou maior gm/lds, pois possui o melhor SS entre os dispositivos (56 mV/dec).

O ganho intrínseco de tensão, calculado pela razão entre gm e gD, é apresentado na Figura 4.72. Pode ser observado que para VDS maiores Av é maior, causado pela redução de gD porque os dispositivos operam mais na região similar à saturação, onde a influência de $V_{D S}$ é muito pequena. Entretanto, o aumento de $V_{G S}$ leva gD a aumentar, degradando $A v$. Comparando todos os dispositivos, é possível notar que dispositivo de $\ln _{0,53} \mathrm{Ga}_{0,47} \mathrm{As}$ com difusão por fase gasosa apresentou o

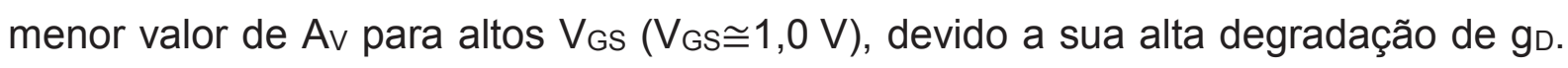
Porém, para baixos $V_{G S}\left(V_{G S \cong 0,6} \mathrm{~V}\right)$, ele possui um alto gm, maior que a degradação de gD, resultando em o maior valor de Av.

Figura 4.72 - Ganho intrínseco de tensão em função da tensão na porta de nTFETs planares de InxGa1-xAs com diferentes processos de difusão de $\mathrm{Zn}$ e porcentagens de In.

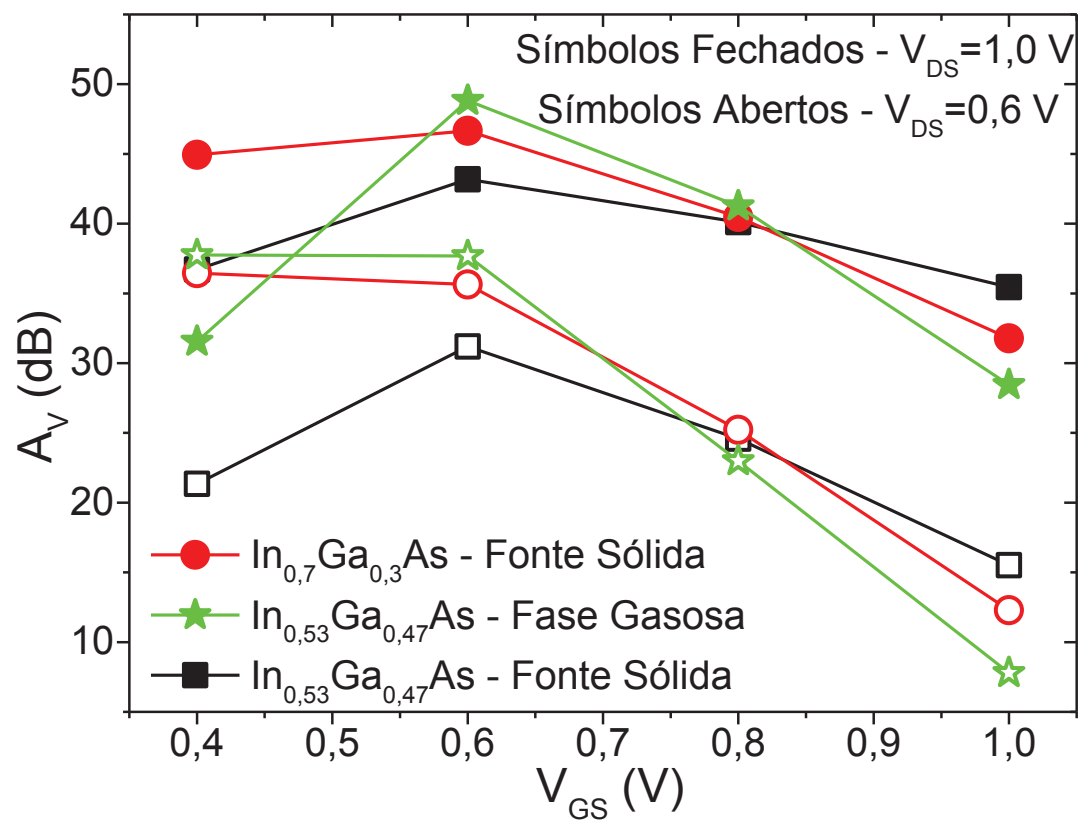

Fonte: Autor.

É importante também fazer a comparação entre estes dispositivos em diferentes temperaturas. A Figura 4.73 mostra a análise de gm (Figura 4.73(A)) e (Figura 4.73(B)) em função da temperatura. É possível ver Figura 4.73(A) que a 
redução da temperatura afeta mais gm para baixos $V_{G S}$ devido ao seu menor componente de BTBT. O dispositivo $\ln _{0,53} \mathrm{Ga}_{0,47} \mathrm{As}$ com difusão por fonte sólida apesentou a maior variação com a temperatura, devido à sua menor componente de BTBT. Na Figura 4.73(B) é possível ver que a variação de gD com a temperatura é maior que a variação de gm.

Figura 4.73 - Transcondutância (A) e condutância de saída (B) em função da temperatura de nTFETs planares de InxGa1-xAs com diferentes processos de difusão de Zn e porcentagens de In.
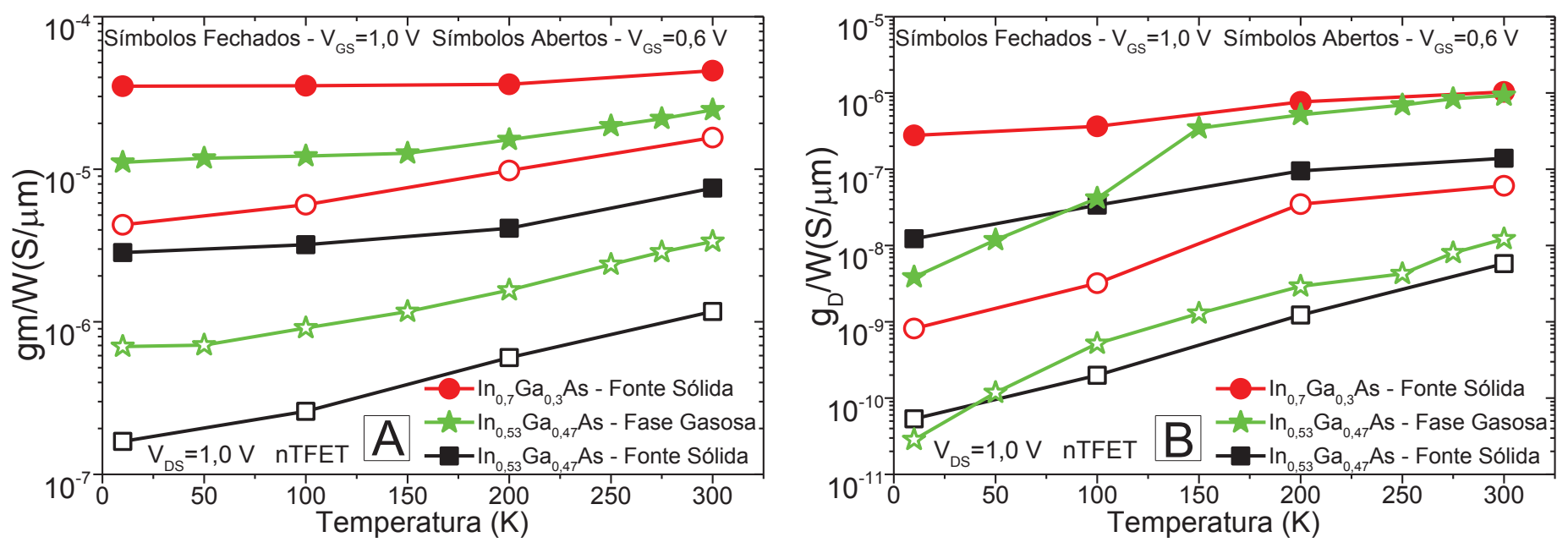

Fonte: Autor.

Similar a gm, em baixos valores de $V_{G S}$ há uma maior variação de Av (Figura 4.74) com a temperatura. O dispositivo $\ln _{0,53} \mathrm{Ga}_{0,47} \mathrm{As}$ com difusão por fase gasosa apresentou a maior redução de go a temperaturas muito baixas, influenciando fortemente $\mathrm{Av}$, fazendo com que Av atinja $90 \mathrm{~dB}$ com baixos $\mathrm{V}_{\mathrm{Gs}}$ a $10 \mathrm{~K}$.

Figura 4.74 - Ganho intrínseco de tensão em função da temperatura de nTFETs planares de InxGa1xAs com diferentes processos de difusão de Zn e porcentagens de In.

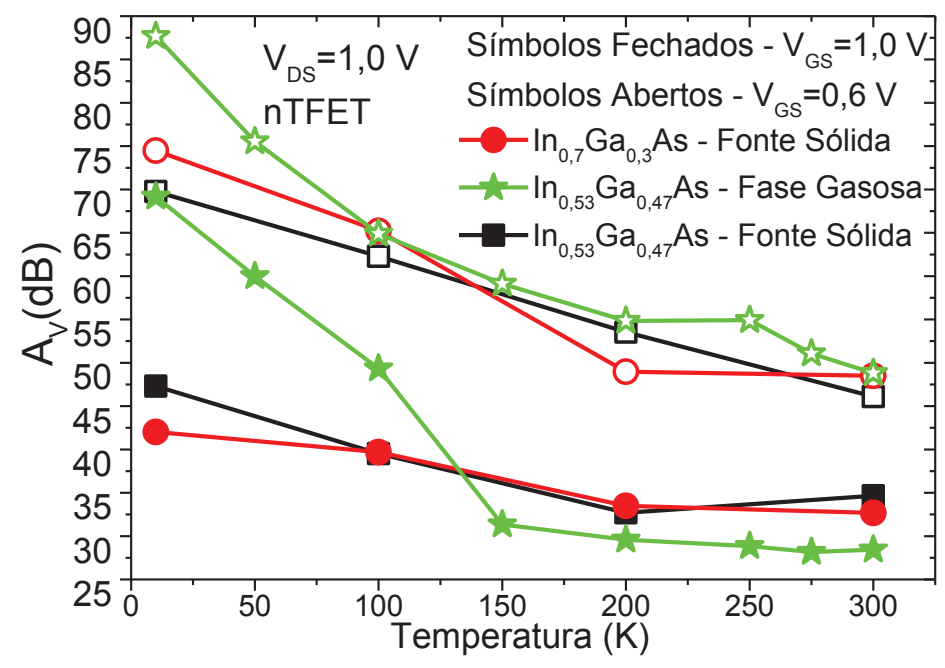

Fonte: Autor. 


\subsubsection{Conclusões parciais}

Neste capítulo foram estudados os efeitos do aumento da porcentagem de In na composição transistor, do uso de diferentes processos e temperaturas na difusão de Zn na fonte, da redução da espessura do dielétrico de porta e também do aumento da temperatura em dispositivos TFETs de InGaAs em estruturas planares, com leiaute em anel, com comprimento de canal de $5 \mu \mathrm{m}$ e largura de canal de $400 \mu \mathrm{m}$.

A Tabela 4-5 mostra resumidamente o efeito do aumento da porcentagem de In em transistores TFETs de InxGa1-XAs. Aumentando a concentração de In, a largura da banda proibida de energia reduz, obtemos menores comprimentos de tunelamento, ambos aumentando a componente BTBT e também reduzindo a tensão mínima para que BTBT seja o mecanismo de corrente dominante. Embora a transcondutância seja aumentada com o aumento da componente de BTBT, a condutância de saída também aumenta, principalmente para baixa polarização de porta. A competição de fatores gerada resulta em melhor ganho intrínseco de tensão para o dispositivo Ino,53Gaa,47As em baixa polarização de porta e em melhor ganho intrínseco de tensão para o dispositivo Ino,7Ga0,3As em altas polarizações de porta.

Tabela 4-5 - Tabela da influência da porcentagem de In em dispositivos InxGa1-XAs nos principais parâmetros estudados.

\begin{tabular}{|r|c|c|}
\hline & $\operatorname{In}_{0,53} \mathrm{Ga}_{0,47}$ & $\operatorname{In}_{0,7} \mathrm{Ga}_{0,3}$ \\
\hline IDS & Menor & Maior \\
\hline $\mathrm{V}_{\mathrm{ON}}$ & Maior & Menor \\
\hline $\mathrm{SS}$ & Maior & Menor \\
\hline $\mathrm{gm}$ & Menor & Maior \\
\hline $\mathrm{gD}$ & Menor & Maior \\
\hline $\mathrm{gm} / \mathrm{IDS}_{\mathrm{DS}}$ & Menor & Maior \\
\hline $\mathrm{V}_{\mathrm{EA}}$ & Menor & Maior \\
\hline $\mathrm{AV}_{\mathrm{V}}$ & Menor & Maior \\
\hline
\end{tabular}

De forma análoga ao aumento da porcentagem de In, usando temperaturas maiores de difusão de Zn na fonte, aumenta-se a concentração de dopantes na fonte, diminuindo o comprimento de tunelamento, ambos aumentando a componente BTBT, 
resultando em uma melhoria dos parâmetros destes dispositivos, conforme mostrado na Tabela 4-6.

Tabela 4-6 - Tabela da influência da temperatura da difusão de Zn na fonte em dispositivos $\ln _{0,53} \mathrm{Ga}_{0,47}$ As nos principais parâmetros estudados.

\begin{tabular}{|r|c|c|}
\hline & $500^{\circ} \mathrm{C}(1$ minuto $)$ & $520^{\circ} \mathrm{C}(1$ minuto $)$ \\
\hline IDS & Menor & Maior \\
\hline VoN & Maior & Menor \\
\hline $\mathrm{SS}$ & Maior & Menor \\
\hline $\mathrm{gm}$ & Menor & Maior \\
\hline $\mathrm{gD}$ & Menor & Maior \\
\hline $\mathrm{gm} / \mathrm{IDS}$ & Menor & Maior \\
\hline $\mathrm{V}_{\mathrm{EA}}$ & Menor & Maior \\
\hline $\mathrm{Av}$ & Menor & Maior \\
\hline
\end{tabular}

Comparando os diferentes processos de difusão de $\mathrm{Zn}$, como mostrado resumidamente na Tabela 4-7, o uso de difusão por fase gasosa resultou em uma junção mais abrupta, reduzindo o comprimento de tunelamento, aumentando a corrente de estado ligado destes dispositivos. Este processo também apresentou melhor inclinação de sublimiar, aumentando a eficiência do transistor em regime de baixa condução de corrente.

Tabela 4-7 - Tabela da influência de diferentes processos de difusão de Zn na fonte em dispositivos $\mathrm{In}_{0,53} \mathrm{Ga}_{0,47} \mathrm{As}$ nos principais parâmetros estudados.

\begin{tabular}{|r|c|c|}
\hline & Fonte sólida & Fonte gasosa \\
\hline IDS & Menor & Maior \\
\hline VoN & Maior & Menor \\
\hline SS & Maior & Menor \\
\hline gm & Menor & Maior \\
\hline gD & Menor & Maior \\
\hline gm/IDS & Menor & Maior \\
\hline$V_{E A}$ & Maior & Menor \\
\hline \multirow{2}{*}{ Av } & Baixo lDs: Menor & Baixo lDs: Maior \\
\cline { 2 - 3 } & Alto lDs: Maior & Alto lDs: Menor \\
\hline
\end{tabular}


$\mathrm{O}$ uso de fonte gasosa no dispositivo de $\operatorname{In}_{0,53} \mathrm{Ga}_{0,47} \mathrm{As}$ apresentou o menor ganho intrínseco de tensão para altas polarizações de porta, devido à alta degradação da condutância de saída. Entretanto, para baixas polarizações de porta, a transcondutância foi melhorada substancialmente, e sua condutância de saída não foi suficientemente degradada, resultando em maior valor de ganho intrínseco de tensão.

A análise do efeito ambipolar, através de simulações numéricas, mostrou que este efeito é muito acentuado para altas polarizações de dreno. $O$ efeito ambipolar degrada a inclinação de sublimiar e consequentemente a eficiência do transistor em regime de baixa condução de corrente.

O pico na curva do ganho intrínseco de tensão em função da tensão de porta, encontrado em todas as amostras, é relacionada com a polarização de porta onde o BTBT começa a ser o mecanismo de corrente dominante. Com polarizações próximas a esta, o aumento da transcondutância é máximo, começando a decair além desta polarização. Quando a taxa aumento da transcondutância passa a ser menor que a taxa de aumento da condutância de saída, a qual é mais constante, resulta em degradação do ganho intrínseco de tensão, reduzindo o seu valor para maiores polarizações de porta.

A redução da temperatura para valores menores que $100 \mathrm{~K}$ resulta em uma diminuição muito acentuada dos mecanismos de SRH e TAT, fazendo com que a corrente de estado desligado seja dominada pela corrente de porta. Como a corrente de porta é dominada pelo tunelamento direto, é pouco influenciada pela temperatura, resultando em uma corrente de estado desligado pouco influenciada pela temperatura.

A redução da temperatura causa degradação de gm, entretanto, a componente de BTBT é mais dominante, a qual é menos dependente da temperatura. A influência da temperatura na condutância de saída foi observada através de medidas experimentais e simulações numéricas. Com base nestes experimentos, foi provado que a redução da condutância de saída com a temperatura é relacionada com a redução da influência do dreno na taxa de geração de BTBT. A influência da temperatura é maior na condutância de saída do que na transcondutância, resultando em um aumento do ganho intrínseco de tensão em baixa temperatura. 
O pico na curva do ganho intrínseco de tensão em função da tensão de porta, o qual é relacionada com a polarização de porta onde o BTBT começa a ser o mecanismo de corrente dominante, é fortemente influenciado pela pela variação da temperatura. A variação da temperatura pode aumentar ou diminuir os mecanismos de TAT e SRH, causando uma mudança no mecanismo de corrente dominante, causando uma degradação do ponto de máximo e um deslocamento da curva para maiores valores de tensão de porta, em altas temperaturas e, analogamente, causando um aumento de seu pico e um deslocamento no sentido oposto em baixas temperaturas. 


\section{CONCLUSÕES E PROPOSTAS DE TRABALHOS FUTUROS}

\subsection{Conclusões}

Neste trabalho foram estudadas novas tecnologias para aumentar o desempenho de dispositivos nTFET. As soluções sugeridas para os problemas dos dispositivos TFET foram analisadas, focando em parâmetros digitais e analógicos, usando medidas experimentais e também simulações numéricas.

Usando dispositivos fabricados com InxGa1-xAs, utilizando leiaute em anel com comprimento de $5 \mu \mathrm{m}$ e largura de $400 \mu \mathrm{m}$, foi notável o aumento da corrente de dreno normalizada comparado aos dispositivos de canal de Si, como mostrada na Tabela 5-1. Este aumento é causado pela redução mais pronunciada da largura da banda proibida de energia nos dispositivos de $\ln _{\times} \mathrm{Ga}_{1-x A s}$, aumento muito a componente BTBT nestes dispositivos. Esse aumento da componente BTBT é responsável por reduzir a inclinação de sublimiar para valores próximos de $60 \mathrm{mV} / \mathrm{dec}$ (56 mV/dec), comparado aos $200 \mathrm{mV} / \mathrm{dec}$ apresentado pelos dispositivos de Si. Ao mesmo tempo que os dispositivos de InxGa1-xAs apresentaram uma melhoria dos parâmetros digitais, os dispositivos de Si apresentarem melhores características analógicas, porém os dispositivos com InxGa1-XAs ainda mostraram ótimos valores de ganho intrínseco de tensão, mesmo quando são usadas polarizações baixas, indicando que estes materiais são promissores em aplicações de baixa tensão e baixa potência.

Tabela 5-1 - Tabela comparativa entre os dispositivos de Si em estruturas de nanofios verticais e em dispositivos $\ln _{0,53} \mathrm{Ga}_{0,47}$ As em estruturas planares nos principais parâmetros estudados.

\begin{tabular}{|r|c|c|}
\hline & Si NW-TFETs & InGaAs TFETs \\
\hline IDS & Muito Menor & Muito Maior \\
\hline VoN & Muito Maior & Muito Menor \\
\hline SS & Muito Maior & Muito Menor \\
\hline gm & Menor & Maior \\
\hline gD & Menor & Maior \\
\hline $\mathrm{gm} / \mathrm{IDS}_{\mathrm{D}}$ & Menor & Maior \\
\hline $\mathrm{V}_{\mathrm{EA}}$ & Maior & Menor \\
\hline $\mathrm{A}_{\mathrm{V}}$ & Maior & Menor \\
\hline
\end{tabular}


A redução da espessura de $\mathrm{HfO}_{2}$ na composição de porta, de $3 \mathrm{~nm}$ para $2 \mathrm{~nm}$, resultou em uma melhoria, tanto no dispositivo de Si com fonte de Ge, quanto no dispositivo de $\ln _{0,53} \mathrm{Ga}_{0,47} \mathrm{As}$, conforme mostrado na Tabela 5-2. Esta melhoria é causada pelo melhor acoplamento eletrostático, aumentando a transcondutância e a inclinação de sublimiar, melhorando o ganho intrínseco de tensão tanto no regime de alta condução quanto no regime de baixa condução de corrente. No dispositivo de In $0,53 \mathrm{Ga}_{0,47} \mathrm{As}$, a redução da espessura de $\mathrm{HfO}_{2}$ é responsável por melhorar a inclinação de sublimiar, fazendo ela atingir $56 \mathrm{mV} / \mathrm{dec}$, apresentando o maior valor de eficiência em baixa condução de corrente neste estudo. A redução da espessura de $\mathrm{HfO}_{2}$ de $3 \mathrm{~nm}$ para $2 \mathrm{~nm}$ no dispositivo de In $0,53 \mathrm{Ga} 0,47$ As não foi suficiente para que a corrente de porta fosse aumentada a ponto de ser influente na composição das correntes.

Tabela 5-2 - Tabela da influência da redução da espessura do dielétrico em dispositivos de Si com fonte de $\mathrm{Ge}$ em estruturas de nanofios verticais e em dispositivos $\ln _{0,53} \mathrm{Ga}_{0,47} \mathrm{As}$ em estruturas planares nos principais parâmetros estudados.

\begin{tabular}{|r|c|c|}
\hline & $3 \mathrm{~nm}$ & $2 \mathrm{~nm}$ \\
\hline IDS & Menor & Maior \\
\hline VON $_{\text {SS }}$ & Maior & Menor \\
\hline $\mathrm{gm}$ & Maior & Menor \\
\hline $\mathrm{gD}$ & Menor & Maior \\
\hline $\mathrm{gm} / \mathrm{IDS}_{\mathrm{DS}}$ & Menor & Maior \\
\hline $\mathrm{V}_{\mathrm{EA}}$ & Menor & Maior \\
\hline $\mathrm{AV}_{\mathrm{V}}$ & Menor & Maior \\
\hline
\end{tabular}

Ao analisar as conclusões parciais obtidas nos dispositivos de $\mathrm{Si}$ em estruturas de nanofios, mostradas no capítulo 4.1.4, e nos dispositivos de InGaAs, mostradas no capítulo 4.2.4, pode-se chegar à conclusão de como obter possíveis dispositivos ideais para aplicações digitais, e de como obter possíveis dispositivos ideais para aplicações analógicas.

Comparando os dispositivos de InGaAs planares, tendo como referência o dispositivo de $\mathrm{In}_{0,53} \mathrm{Ga}_{0,47} \mathrm{As}$ com difusão de $\mathrm{Zn}$ na fonte realizada por fonte sólida à $500{ }^{\circ} \mathrm{C}$ e espessura de $\mathrm{HfO}_{2}$ de $3 \mathrm{~nm}$, poderiam ser obtidos dispositivos otimizados 
utilizando as diversas tecnologias estudadas anteriormente. Se um dispositivo de In ${ }_{0,7} \mathrm{Ga}_{0,3} \mathrm{As}$ for fabricado utilizando difusão de $\mathrm{Zn}$ na fonte por fase gasosa à $520^{\circ} \mathrm{C} \mathrm{e}$ espessura de $\mathrm{HfO}_{2}$ de $2 \mathrm{~nm}$, pode-se obter um dispositivo com características digitais muito melhores e também com características analógicas melhores, conforme podemos observar na Tabela 5-3. Ao fabricar um dispositivo de Ino,7Gao,3As com difusão de $\mathrm{Zn}$ na fonte realizada por fonte sólida à $520^{\circ} \mathrm{C}$ e espessura de $\mathrm{HfO}_{2}$ de $2 \mathrm{~nm}$ também poderá ser obtido um dispositivo otimizado, porém muito mais otimizado para as características analógicas à altos $V_{G S}$ (Tabela 5-3). Pode-se então concluir que para uma aplicação em processadores poderia ser utilizado um dispositivo otimizado com difusão de Zn por fase gasosa, e em uma aplicação de amplificadores ou chaves analógicas, poderia ser utilizado um dispositivo otimizado com difusão de Zn por fonte sólida.

Tabela 5-3 - Tabela dos parâmetros para dispositivos otimizados, tendo como referência um dispositivo com $\operatorname{In}_{0,53} \mathrm{Ga}_{0.47} \mathrm{As}$ com difusão de $\mathrm{Zn}$ na fonte realizada por fonte sólida à $500{ }^{\circ} \mathrm{C}$ e espessura de $\mathrm{HfO}_{2}$ de $3 \mathrm{~nm}$.

\begin{tabular}{|c|c|c|c|}
\hline & $\begin{array}{c}\text { In } 0,53 \mathrm{Ga}_{0,47} \mathrm{As} \\
\text { Fonte sólida a } 500^{\circ} \mathrm{C} \\
\mathrm{T}_{\mathrm{HFO}_{2}}=3 \mathrm{~nm}\end{array}$ & $\begin{array}{c}\text { In } 0,7 \mathrm{Ga}_{0,3} \mathrm{As} \\
\text { Fase gasosa a } 520^{\circ} \mathrm{C} \\
\mathrm{THFO}_{2}=2 \mathrm{~nm}\end{array}$ & $\begin{array}{c}\text { In } 0,7 \mathrm{Ga}_{0,3 \mathrm{As}} \\
\text { Fonte sólida a } 520^{\circ} \mathrm{C} \\
\mathrm{T}_{\mathrm{HFO}_{2}}=2 \mathrm{~nm}\end{array}$ \\
\hline IDS & Menor & Muito Maior & Maior \\
\hline VON & Maior & Muito Menor & Menor \\
\hline SS & Maior & Muito Menor & Menor \\
\hline gm & Menor & Muito Maior & Maior \\
\hline$g_{D}$ & Menor & Muito Maior & Maior \\
\hline $\mathrm{gm} / \mathrm{IDS}_{\mathrm{DS}}$ & Menor & Muito Maior & Maior \\
\hline$V_{E A}$ & Menor & Maior & Muito Maior \\
\hline \multirow{2}{*}{$A v$} & \multirow{2}{*}{ Menor } & Baixo VGs: Muito Maior & Baixo VGs: Maior \\
\hline & & Alto VGs: Maior & Alto VGs: Muito Maior \\
\hline
\end{tabular}

Se as estruturas de nanofios forem aplicadas em dispositivos de $\ln _{0,7} \mathrm{Ga}_{0,3} \mathrm{As}$, fabricados utilizando difusão de $\mathrm{Zn}$ na fonte por fase gasosa, para dispositivos que vão atuar em aplicações digitais, ou utilizando difusão de $Z n$ na fonte por fonte sólida, para dispositivos que vão atuar em aplicações analógicas, à $520^{\circ} \mathrm{C}$ por 1 minuto, ainda utilizando $2 \mathrm{~nm}$ de $\mathrm{HfO}_{2}$ na porta, pode-se esperar dispositivos muito melhores, tanto em características digitais, utilizando diâmetros menores de nanofios, quanto analógicas, utilizando diâmetros maiores. 


\subsection{Propostas de Trabalhos Futuros}

Como proposta de trabalho futuro, é interessante o estudo das características digitais e analógicas de dispositivos de $\ln \times \mathrm{Ga}_{1-\mathrm{X}} \mathrm{As}$, fabricados em estruturas de nanofios, unindo o conhecimento adquirido da redução dos diâmetros dos nanofios com o uso destes materiais. Esta proposta se torna ainda mais interessante se aplicados o aumento da concentração de In, aumento da temperatura de difusão de Zn por fase gasosa na fonte, e ainda utilizando menores espessuras de dielétricos de porta.

O estudo destes dispositivos em ambientes hostis pode ser complementado submetendo estes mesmos à radiação, com o intuito de melhor compreender seus efeitos em um ambiente susceptível à radiação, como por exemplo em aplicações aeroespaciais. 


\section{TRABALHOS GERADOS DURANTE O DOUTORADO}

\section{Publicações em revistas:}

BORDALLO, C.; MARTINO, J. A.; AGOPIAN, P. G. D.; ALIAN, A.; MOLS, Y.; ROOYACKERS, R.; VANDOOREN, A.; VERHULST, A. S.; SMETS, Q.; SIMOEN, E.; CLAEYS, C.; COLLAERT, N.. "The Influence of Oxide Thickness and Indium Amount on the Analog Parameters of InxGa1-xAs nTFETs", Transactions on Electron Devices, September 2017.

ALIAN, A.; MOLS, Y.; BORDALLO, C.; VERRECK, D.; VERHULST, A. S.; VANDOOREN, A.; ROOYACKERS, R.; AGOPIAN, P. G. D.; MARTINO, J. A.; THEAN, A.; LIN, D.; MOCUTA, D.; COLLAERT, N.. "InGaAs tunnel FET with subnanometer EOT and sub-60 mV/dec sub-threshold swing at room temperature", Applied Physics Letters, December 2016.

BORDALLO, C.; MARTINO, J. A.; AGOPIAN, P. G. D.; ALIAN, A.; MOLS, Y.; ROOYACKERS, R.; VANDOOREN, A.; VERHULST, A. S.; SMETS, Q.; SIMOEN, E.;CLAEYS, C.; COLLAERT, N.. "Analog parameters of solid source Zn diffusion In x Ga1-x As nTFETs down to $10 \mathrm{~K}$ ", Semiconductors Science and Technology, October 2016.

BORDALLO, C.; SIVIERI, V. B.; MARTINO, J. A.; AGOPIAN, P. G. D.; ROOYACKERS, R.; VANDOOREN, A.; SIMOEN, E.; THEAN, A.; CLAEYS, C. "Impact of the NW-TFET Diameter on the Efficiency and the Intrinsic Voltage Gain From a Conduction Regime Perspective", Transactions on Electron Devices, July 2016.

TEIXEIRA, F. F.; BORDALLO, C.; SILVEIRA, M. A. G.; MARTINO, J. A.; AGOPIAN, P. G. D.; SIMOEN, E.; CLAEYS, C. "Parasitic Conduction Response to X-ray Radiation in Unstrained and Strained Triple-Gate SOI MuGFETs", Journal of Integrated Circuits and Systems, 2014.

BORDALLO, C.; TEIXEIRA, F. F.; SILVEIRA, M. A. G.; MARTINO, J. A.; AGOPIAN, P. G. D.; SIMOEN, E.; CLAEYS, C. "Analog performance of standard and uniaxial strained triple-gate SOI FinFETs under x-ray radiation", Semiconductors Science and Technology, November 2014. 
Submissões em revistas que ainda não foram avaliadas:

BORDALLO, C.; MARTINO, J. A.; AGOPIAN, P. G. D.; ALIAN, A.; MOLS, Y.; ROOYACKERS, R.; VANDOOREN, A.; VERHULST, A. S.; MOCUTA, D.; LIN, D.; SIMOEN, E.; CLAEYS, C.; COLLAERT, N.. "The impact of the temperature on In ${ }_{0.53} \mathrm{Ga}_{0.47}$ As nTFETs", journal Nanoelectronic Devices, Submitted in November 2017.

CAPARROZ, L. F.; BORDALLO, C.; MARTINO, J. A.; SIMOEN, E.; CLAEYS, C.; AGOPIAN, P. G. D.. "Analysis of proton irradiated N- and P-Type strained FinfETs at low temperatures down to $100 \mathrm{~K}$ ", Solid State Electronics, Submitted in September 2017. 


\section{Publicações em congressos:}

BORDALLO, C.; MARTINO, J. A.; AGOPIAN, P. G. D.; ALIAN, A.; MOLS, Y.; ROOYACKERS, R.; VANDOOREN, A.; VERHULST, A. S.; SIMOEN, E.;CLAEYS, C.; COLLAERT, N.. "Impact of the $\mathrm{Zn}$ diffusion process at the source side of InxGa1-xAs nTFETs on the analog parameters down to $10 \mathrm{~K}$ ", In: IEEE SOI-3DSubthreshold Microelectronics Technology Unified Conference, S3S2017, San Francisco, USA, October 2017.

BORDAllO, C.; MARTINO, J. A.; AGOPIAN, P. G. D.; ALIAN, A.; MOLS, Y.; ROOYACKERS, R.; VANDOOREN, A.; VERHULST, A. S.; SIMOEN, E.;CLAEYS, C.; COLLAERT, N.. "Analysis of the transistor efficiency of Gas Phase Zn Diffusion In ${ }_{0.53} \mathrm{Ga}_{0.47}$ As nTFETs at different temperatures", In: Joint International EUROSOI Workshop and International Conference on Ultimate Integration on Silicon EUROSOI-ULIS 2017, Athens, April 2017.

CAPARROZ, J.; BORDALLO, C.; MARTINO, J. A.; SIMOEN, E.;CLAEYS, C.; AGOPIAN, P. G. D.. "Low temperature performance of proton irradiated strained SOI FinFET", In: Joint International EUROSOI Workshop and International Conference on Ultimate Integration on Silicon - EUROSOI-ULIS 2017, Athens, April 2017.

BORDAllo, C.; MARTINO, J. A.; AGOPIAN, P. G. D.; AliAN, A.; MOLS, Y.; ROOYACKERS, R.; VANDOOREN, A.; VERHULST, A. S.; SIMOEN, E.;CLAEYS, C.; COLLAERT, N.. "Analysis of different source materials on the drain current of nTFETs", In: Workshop on Semiconductors and Micro \& Nano Technology Seminatec 2017, São Paulo, April 2017.

BORDALLO, C.; MARTINO, J. A.; AGOPIAN, P. G. D.; ALIAN, A.; MOLS, Y.; ROOYACKERS, R.; VANDOOREN, A.; VERHULST, A. S.; SIMOEN, E.;CLAEYS, C.; COLLAERT, N.; THEAN, A.. "Impact of InxGa1-x composition and source $Z \mathbf{Z n}$ diffusion temperature on intrinsic voltage gain in InGaAs TFETs", In: IEEE SOI3D-Subthreshold Microelectronics Technology Unified Conference, S3S2016, San Francisco, USA, October 2016.

NASCIMENTO, V.; AGOPIAN, P. G. D.; ALMEIDA L. M.; BORDALLO, C.; SIMOEN, E.; CLAEYS, C.; MARTINO, J. A.. "Influence of Proton Radiation and Strain on nFinFET Zero Temperature Coefficient". In: 31st Symposium on Integrated Circuits and Systems Design, 2016, SBMicro2016, Belo Horizonte, Brasil, August 2016. 
BORDALLO, C.; MARTINO, J. A.; AGOPIAN, P. G. D.; ROOYACKERS, R.; VANDOOREN, A; THEAN, A.; SIMOEN, E.; THEAN, A.; CLAEYS, C.. "Influence of the Ge amount at source on transistor efficiency of vertical gate all around TFET for different conduction regimes". In: Joint International EUROSOI Workshop and International Conference on Ultimate Integration on Silicon - EUROSOI-ULIS 2016, Vienna, January 2016.

BORDALLO, C.; MARTINO, J. A.; AGOPIAN, P. G. D.; ROOYACKERS, R.; VANDOOREN, A; THEAN, A.; SIMOEN, E.; CLAEYS, C.. "Analysis of analog parameters in NW-TFETs with $\mathrm{Si}$ and SiGe source composition at high temperatures". In: 30th Symposium on Integrated Circuits and Systems Design, 2015, SBMicro2015, Salvador, Brasil, September 2015.

SIVIERI, V. B.; BORDALLO, C.; AGOPIAN, P. G. D.; MARTINO, J. A.; ROOYACKERS, R.; VANDOOREN, A; SIMOEN, E.; THEAN, A.; CLAEYS, C.. "Vertical Nanowire TFET Diameter Influence on Intrinsic Voltage Gain for Different Inversion Conditions". In: Proceedings of ECS Meeting, 2015, ECS 2015, Illinois, Chicago, May 2015.

BORDALLO, C.; SIVIERI, V. B.; MARTINO, J. A.; AGOPIAN, P. G. D.; ROOYACKERS, R.; VANDOOREN, A; SIMOEN, E.; THEAN, A.; CLAEYS, C.. "Impact of the diameter of vertical nanowire-tunnel FETs with Si and SiGe source composition on analog parameters". In: Joint International EUROSOI Workshop and International Conference on Ultimate Integration on Silicon - EUROSOI-ULIS 2015, Bologna, January 2015.

BORDALLO, C.; MARTINO, J. A.; AGOPIAN, P. G. D.; SIMOEN, E.; CLAEYS, C.. "The effect of stress and proton radiation on the ION/IOFF ratio of nMuGFETs". In: 29th Symposium on Integrated Circuits and Systems Design, 2014, SBMicro2014, Aracaju, Brasil, August 2014.

BORDALlO, C.; TEIXEIRA, F. F.; SILVEIRA, M. A. G.; MARTINO, J. A.; AGOPIAN, P. G. D.; SIMOEN, E.; CLAEYS, C.. "The effect of X-Ray Radiation on DIBL for Standard and Strained Triple-Gate SOI MuGFETs". In: Ninth International Caribbean Conference on DEVICES, CIRCUITS and SYSTEMS - ICCDCS 2014, Playa del Carmen, Mexico, April 2014. 


\section{REFERÊNCIAS}

(1) MOORE, G. E.; Cramming more components onto integrated circuits, Electronics Magazine, n. 4, 1965.

(2) MOORE, G. E. Progress in Digital Integrated Electronics. International Electron Devices Meeting, v. 21, p. 11-13, 1975.

(3) GARGINI, P. A. How to Successfully Overcome Inflection Points, or Long Live Moore's Law. I.E.E.E. Computing in Science \& Engineering, v. 19, n.2, p. 51-62, 2017.

(4) IZUMI, K. Proceedings of the Fourth International Symposium on Silicon-OnInsulator Technology and Advices, Vol. 90-6, p.3, 1990.

(5) COLINGE, J. P. Thin-film SOI technology: the solution to many submicron CMOS problems. IEDM, p. 817, 1989.

(6) COLINGE, J.P.; Silicon-On-Insulator Technology: Materials to VLSI. 3rd Ed. Massachusetts: Kluwer Academic Publishers, 2004.

(7) KATO, K.; WADA, T. and TANIGUCHI, T. Analysis of Kink Characteristics in Silicon-on-Insulator MOSFET's Using Two-Carrier Modeling. I.E.E.E. Transactions on Electron Devices, v. 32, p. 458-462, 1985.

(8) CLAEYS, C.; LEONELLI, D.; ROOYACKERS, R.; VANDOOREN, A.; VERHULST, A.; HEYNS, M.; GROESENEKEN, G.; DE GENDT, S.; Fabrication and characterization of $\mathrm{Si}$ and hetero-junction tunnel field effect transistors, G-COE PICE International Symposium, Tóquio, 2009.

(9) REDDICK W. M.; AMARATUNGA G. A. J.;. Silicon surface tunnel transistor. Appl. Phys. Lett., vol. 67, n.4, p. 494-496, 1995.

(10) KNOCH, J.; MANTL S.; APPENZELLER, J.; Impact of the dimensionality on the performance of tunneling FETs: Bulk versus onedimensional devices. Solid State Electron, vol. 51, n. 4, pp. 572-578, 2007. 
(11) SEABAUGH, A.; ZHANG, Q.; Low-voltage tunnel transistors for beyond CMOS logic, Proceedings of the IEEE, vol. 28, n. 12, p. 2095-2110, 2010.

(12) FISCHER W., Field Induced Tunnel Diode, IBM Technical Disclosure Bulletin, 1973.

(13) S. O. KOSWATTA, S. J. KOESTER E W. HAENSCH, 1D Broken-gap Tunnel Transistor with MOSFET-like On-currents and Sub-60mV/dec Subthreshold Swing, Proc. Int. Electron Devices Meeting, pp. 37.5.1-37.5.4, 2009.

(14) A. S. VERHULST, B. SORÉE, D. LEONELLI, W. G. VANDENBERGHE E G. GROESENEKEN; Modeling the single-gate, double-gate, and gate-all-around tunnel field-effect transistor, Journal of Applied Physics, vol. 107, p. 024518, 2010..

(15) S. SASAKI, K. TATENO, G. ZHANG, H. SUOMINEN, Y. HARADA, S. SAITO, A. FUJIWARA, T. SOGAWA E K. MURAKI; Encapsulated gate-all-around InAs nanowire field-effect transistors, Applied Physics Letters, vol. 103, p. 213502, 2013.

(16) Y. MORITA, T. MORI, S. MIGITA, W. MIZUBAYASHI, A. TANABE, K. FUKUDA, T. MATSUKAWA, K. ENDO, S. O'UCHI, Y. X. LIU, M. MASAHARA E H. OTA; Performance limit of parallel electric field tunnel FET and improvement by modified gate and channel configurations, Proceedings of the European Solid-State Device Research Conference (ESSDERC), pp. 45-48, 2013.

(17) J. KNOCH E J. APPENZELLER; Modeling of High-Performance p-Type III-V Heterojunction Tunnel FETs, IEEE ELECTRON DEVICE LETTERS, vol. 31, pp. 305$307,2010$.

(18) L. Wang, E. Yu, Y. Taur e P. Asbeck.; Design of Tunneling Field-Effect Transistors Based on Staggered Heterojunctions for Ultralow-Power Applications, IEEE ELECTRON DEVICE LETTERS, vol. 31, pp. 431-433, 2010.

(19) Y. YOON, D. E. NIKONOV E S. SALAHUDDIN; Scaling Study of Graphene Transistors, Proc. IEEE International Conference on Nanotechnology, pp. 1568$1571,2011$. 
(20) M. H. Lee, Y.-T. Wei, J.-C. Lin, C.-W. Chen, W.-H. Tu e M. Tang, Ferroelectric gate tunnel field-effect transistors with low-power steep turn-on, AIP Advances, vol. 4, p. 107117, 2014.

(21) VERHULST, A. S.; VANDENBERGHE W. G.; MAEX, K.; GROESENEKEN, G.; Tunnel field-effect transistor without gate-drain overlap, Applied Physics Letters, 91, issue 5, 2007.

(22) B. G. STREETMAN E S. K. BANERJEE; Solid State Electronic Devices, PHI Learning Private Limited, 2009.

(23) HALL, R.N.; Electron-hole recombination in Germanium, Physical Review, vol. 87, p. 387, 1952.

(24) SHRODER, D. K.; Semiconductor Material and Devices Caracterization, New York, John Wiley \& Sons.

(25) A. G. Chynoweth, W. L. Feldmann e R. A. Logan, Excess Tunnel Current in Silicon Esaki Junctions, Physical Review, vol. 121, pp. 684-694, 1961.

(26) Silvaco Atlas 2014 User's Manual.

(27) KANE, E. O.; Theory of Tunneling, Journal of Applied Physics, vol. 32, n. 1, p. 83-91, 1961.

(28) COLINGE, J. P.; COLINGE, C.A; Physics of Semiconductor Devices. Massachusetts (EUA): Kluwer Academic Publishers, 2002.

(29) HURKX, G. A. M.; KLAASSEN, D. B. M.; KNUVERS, M. P. G.; A New Recombination Model for Device Simulation Including Tunneling, IEEE Transactions on Electron Devices, vol. 39, n. 2, p. 331-338, 1992.

(30) A. Ortiz-Conde, F. J. García-Sánchez, J. Muci, A. Sucre-González, J. A. Martino, P. G. D. Agopian e C. Claeys; Threshold voltage extraction in Tunnel FETs, SolidState Electronics, vol. 93, pp. 49-55, 2014. 
(31) A. ORTIZ-CONDE, F. J. G. SÁNCHEZ, J. J. LIOU, A. CERDEIRA, M. ESTRADA E Y. YUE; A review of recent MOSFET threshold voltage extraction methods, Microelectronics Reliability, vol. 42, pp. 583-596, 2002.

(32) G. ENEMAN, M. WIOT, A. BRUGĖRE, O. SICART, I. CASAIN, S. SONDE et al, Impact of donor concentration, electric field, and temperature effects on the leakage current in germanium $\mathrm{p} \pm \mathrm{n}$ junctions, IEEE Transaction on Electron Devices, 55 (9) (2008), pp. 2287-2294

(33) A. VANDOOREN, D. LEONELLI, R. ROOYACKERS, A. HIKAVYY, K. DVRIENDT, M. DEMAND, R. LOO, G. GROESENEKEN E C. HUYGHEBAERT, Analysis of trapassisted tunneling in vertical Si homo-junction and SiGe hetero-junction Tunnel-FETs, Solid-State Electronics, vol. 83, pp. 50-55, 2013.

(34) Q. ZHANG, W. ZHAO E A. SEABAUGH, Low-Subthreshold-Swing Tunnel Transistors," IEEE Electron Device Letters, vol. 27, pp. 297-300, 2006.

(35) J.-P. COLINGE, Silicon-on-insulator Technology: Materials to VLSI, Springer, 2004.

(36) A. CHAKRABORTY E A. SARKAR., Investigation of analog/RF performance of staggered heterojunctions based nanowire tunneling field-effect transistors, Superlattices and Microstructures, vol. 80, pp. 125-135, 2015.

(37) AGARWAL, T.; SOREE, B.; RADU, I.; RAGHAVAN, P.; FIORI, G.; HEYNS, M.; DEHAENE, W. "Material Selection and Device Design Guidelines for Two-Dimensional Materials Based TFETs. Proceedings of 47th European Solid-State Device Research Conference (ESSDERC), p. 54-57, 2017.

(38) SUBRAMANIAN, V.; PARVAIS, B.; BORREMANS, J.; MERCHA, A.; LINTEN, D.; WAMBACQ, P.; LOO, J. ; DEHAN, M. ; COLLAERT, N. ; KUBICEK, S. ; LANDER, R. J. P. ; HOOKER, J. C. ; CUBAYNES, F. N.; DONNAY, S.; JURCZAK, M.; GROESENEKEN, G.; SANSEN, W.; DECOUTERE, S. Device and circuit-level analog performance trade-offs: a comparative study of planar bulk FETs versus FinFETs. Techinical Digest of IEDM, 851, 2005. 
(39) ALMEIDA, L. M.; MARTINO, J. A.; SIMOEN, E.; CLAEYS, C. Improved Analytical Model for ZTC Bias Point for Strained Tri-gates FinFETs. ECS Transactions, v. 31, n. 1, p. 385-392, 2010.

(40) LEE J. S.; SEO J. H.; CHO, S.; LEE, J. H.; KANG, S. W.; BAE, J. H.; CHO, E. S.; KANG, I. M. Simulation study on effect of drain underlap in gate-all around tunneling field-effect transistors. Current Applied Physics, v. 13, n. 6, p. 1143-1149, 2013.

(41) RUIZ, F. J. G.; TIENDA-LUNA, I. M.; GODOY, A.; DONETTI, L.; GÁMIZ, F. Equivalent oxide thickness of trigate SOI MOSFETs with high-K insulators. IEEE Transactions on Electron Devices, v. 56, n. 11, p. 2711-2719, 2009.

(42) BENDER, H. Physical characterization of high-k gate stacks deposited on Hf-last surfaces. Proceedings of the International Workshop on Gate Insulator, p. 86-92, 2001.

(43) PEACOCK, P. W.; ROBERTSON, J. Band offsets and Schottky barriers heights of high dielectric constant oxide. Journal of Applied Physics, v. 92, n. 8, p. 47124721, 2002.

(44) LEE, S. I. Recent progress in high-k dielectric films for ULSIs. Proceedings of the International Conference on Solid State Devices and Materials SSDM, p. 8, 2001.

(45) LEE, B. H. Ultrathin hafnium oxide with low leakage and excellent reliability for alternative gate dielectric application. IEEE Internation Electron Devices Meeting IEDM, p. 133-136, 1999.

(46) COPEL, M.; BRIBELYUK, M.; GUSEV, E. Structure and stability of ultrathin zirconium oxide layers on Si(001). Applied Physics Letters, v. 76, n. 4, p. 436, 2000.

(47) COLINGE, J.P.; FinFETs and Other Multi-Gate Transistors. 1st Ed. New York: Springers, 2008.

(48) COLINGE, J. P.; Greer, J. C. Nanowire Transistors: Physics of Devices and Materials in One Dimension. 1st Ed. Cambridge University Press, 2016.

(49) F. S. NEVES, M. D. V. MARTINO, P. G. D. AGOPIAN, J. A. MARTINO, R. ROOYACKERS, D. LEONELLI, C. CLAEYS, Temperature Influence on Nanowire 
Tunnel Field Effect Transistors, 27th Symposium on Integrated Circuits and Systems Design, 2012, SBMicro2012, 2012.

(50) A. MALLIK, A. CHATTOPADHYAY; Tunnel Field-Effect Transistors for Analog/Mixed-Signal System-on-Chip Applications, IEEE Transactions on Electron Devices, vol. 59, Issue 4, pp. 888-894, April 2012.

(51) CANALI, C. et al; Electron and Hole Drift Velocity Measurements in Silicon and Their Empirical Relation to Electric Field and Temperature, IEEE Transactions on Electron Devices, vol. ED-22, n. 11, p. 1045-1047, 1975.

(52) J. W. SLOTBOOM; The pn-product in silicon, Solid-State Electronics, vol. 20, pp. 279-283, 1977.

(53) S. Takagi; M.-S. Kim; M. Noguchi; K. Nishi; and M. Takenaka;“Tunneling FET device technologies using III-V and Ge materials," in Proc. Symp. Energy Efficient Electron. Syst. (E3S), October 2015.

(54) M. Noguchi et al., "High I on/I of $f$ and low subthreshold slope planar type InGaAs tunnel field effect transistors with Zn-diffused source junctions," J. Appl. Phys., vol. 118, no. 4, p. 045712, 2015.

(55) A. Alian et al., "Record performance InGaAs homo-junction TFET with superior SS reliability over MOSFET," in IEDM Tech. Dig., Dec. 2015, pp. 823-826.

(56) A. Alian et al., "InGaAs tunnel FET with sub-nanometer EOT and sub- $60 \mathrm{mV} / \mathrm{dec}$ sub-threshold swing at room temperature,” Appl. Phys. Lett., vol. 109, p. 243502, Dec. 2016.

(57) Synopsys, Sentaurus Device L-2016.03 User's Manual

(58) Q. SMETS, et al; InGaAs tunnel diodes for calibration of semi-classical and quantum mechanical band-to-band tunneling models, J. Appl. Phys., Vol. 115, pp. 184503, 2014.

(59) R. ROOYACKERS, A. VANDOOREN, A. S. VERHULST, A. WALKE, K. DEVRIENDT, S. LOCOROTONDO, M. DEMAND, G. BRYCE, R. LOO, A. HIKAVYY, T. VANDEWEYER, C. HUYGHeBAert, N. COllaert, A. THEAN; A New 
Complementary Hetero-Junction Vertical Tunnel-FET Integration Scheme," IEEE International Electron Devices Meeting (IEDM), pp. 4.2.1-4.2.4, 2013.

(60) A. VANDOOREN, D. LEONELLI, R. ROOYACKERS, A. HIKAVYY, K. DEVRIENDT, M. DEMAND, R. LOO, G. GROESENEKEN, C. HUYGHEBAERT. Analysis of trap-assisted tunneling in vertical Si homo-junction and SiGe heterojunction Tunnel-FETs, Solid-State Electronics, Vol. 83, pp. 50-55, May 2013.

(61) M. D. V. MARTINO, F. S. NEVES, P. G. D. AGOPIAN; J. A. MARTINO, A. VANDOOREN, R. ROOYACKERS, E. SIMOEN, A. THEAN, C. CLAEYS; Transport mechanism influence on Vertical Nanowire-TFET analog performance as a function of temperature, EuroSOI, Janeiro 2014.

(62) BORDALLO, C. C. M. ; SIVIERI, V. B. ; MARTINO, J. A. ; AGOPIAN, P. G. D. ; ROOYACKERS, R. ; VANDOOREN, A ; SIMOEN, E. ; THEAN, A. ; CLAEYS, C; Impact of the diameter of vertical nanowire-tunnel FETs with Si and SiGe source composition on analog parameters, Eurosol, Janeiro 2015.

(63) R. ROOYACKERS, A. VANDOOREN, A. S. VERHULST, A. WALKE, K. DEVRIENDT, S. LOCOROTONDO, M. DEMAND, G. BRYCE, R. LOO, A. HIKAVYY, T. VANDEWEYER; C. HUYGHEBAERT; N. COLLAERT; A. THEAN; A new complementary hetero-junction vertical Tunnel-FET integration scheme, IEEE International Electron Devices Meeting (IEDM), December 2013.

(64) R. E. Nahory, M. A. Pollack, W. D. Johnson, and R. L. Barns, "Band gap versus composition and demonstration of Vegard's law for $\ln _{1-x}$ Gax Asy $P_{1-Y}$ lattice matched to InP," Appl. Phys. Lett., vol. 33, no. 7, pp. 659-661, Oct. 1978.

(65) YAMAMOTO, Y.; et al., "Zn Diffusion in InxGa1-xAs with ZnAs2 Source," Japanese J. Appl. Phys., vol. 19, no. 1, pp. 121-128, 1980.

(66) AGOPIAN, P. G. D.; MARTINO, J. A.; SIMOEN, E.; CLAEYS, C. "Study of linear kink effect in PD SOI nMOSFETs" Microeletron. J., vol. 38, pp. 114-119, 2007.

(67) CHAO, K.; CHEN, M. "Fowler-nordheim limited band-to-band tunneling (FNBB) for p-MOSFET gate current in a floating bulk condition" Solid-State Electronics, Vol. 38, pp. 135-137, 1995. 
(68) LENZLINGER, M.; SNOW, E. "Fowler-Nordheim Tunneling into thermally grown $\mathrm{SiO}_{2}$ " J. Appl. Phys., vol. 40, pp. 278-283, 1969. 